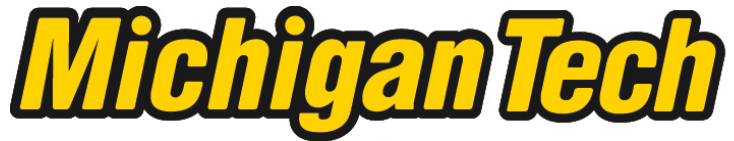 \\ Michigan Technological University Create the Future Digital Commons @ Michigan Tech
}

\section{Topographic and meteorological influences on spatial scaling of heavy convective rainfall in mountainous regions}

Antonio Rubert Godoy

Michigan Technological University

Follow this and additional works at: https://digitalcommons.mtu.edu/etds

Part of the Civil and Environmental Engineering Commons

Copyright 2003 Antonio Rubert Godoy

\section{Recommended Citation}

Godoy, Antonio Rubert, "Topographic and meteorological influences on spatial scaling of heavy convective rainfall in mountainous regions", Master's Thesis, Michigan Technological University, 2003.

https://doi.org/10.37099/mtu.dc.etds/238

Follow this and additional works at: https://digitalcommons.mtu.edu/etds

3 Part of the Civil and Environmental Engineering Commons 


\title{
Topographic and Meteorological Influences on Spatial Scaling of Heavy Convective Rainfall in Mountainous Regions
}

\author{
By \\ Antonio Rubert Godoy \\ A THESIS \\ Submitted in partial fulfillment of the requirements \\ for the degree of \\ MASTER OF SCIENCE IN ENVIRONMENTAL ENGINEERING \\ MICHIGAN TECHNOLOGICAL UNIVERSITY
}

2003 
This thesis, "Topographic and Meteorological Influences on Spatial Scaling of Heavy Convective Rainfall in Mountainous Regions," is hereby approved in partial fulfillment of the requirements for the degree of MASTER OF SCIENCE IN ENVIRONMENTAL ENGINEERING.

Department of Civil and Environmental Engineering

Dr. Deborah K. Nykanen, Thesis Advisor

$\overline{\text { Dr. C. Robert Baillod, Chair, Department of Civil and Environmental Engineering }}$

Date 


\section{Abstract}

Characterizing the spatial scaling and dynamics of convective precipitation in mountainous terrain and the development of downscaling methods to transfer precipitation fields from one scale to another is the overall motivation for this research. Substantial progress has been made on characterizing the space-time organization of midwestern convective systems and tropical rainfall, which has led to the development of statistical/dynamical downscaling models. Space-time analysis and downscaling of orographic precipitation has received less attention due to the complexities of topographic influences. This study uses multiscale statistical analysis to investigate the spatial scaling of organized thunderstorms that produce heavy rainfall and flooding in mountainous regions. Focus is placed on the eastern and western slopes of the Appalachian region and the Front Range of the Rocky Mountains. Parameter estimates are analyzed over time and attention is given to linking changes in the multiscale parameters with meteorological forcings and orographic influences on the rainfall. Influences of geographic regions and predominant orographic controls on trends in multiscale properties of precipitation are investigated. Spatial resolutions from $1 \mathrm{~km}$ to $50 \mathrm{~km}$ are considered. This range of spatial scales is needed to bridge typical scale gaps between distributed hydrologic models and numerical weather prediction (NWP) forecasts and attempts to address the open research problem of scaling organized thunderstorms and convection in mountainous terrain down to $1-4 \mathrm{~km}$ scales. 


\section{Acknowledgements}

I would like to thank Dr. Deborah Nykanen, my advisor, for being patient throughout my learning process, as well as helping me out with my uncountable questions and complains. I would also like to thank Dr. James A. Smith and Dr. Mary L. Baeck from Princeton University for providing the data used in this study and their valuable input to complete this work. Also, thanks to Dr. Daniel Harris for his colaboration with the multiscaling analysis. Thank to my committee-Drs. David Watkins, Alex Mayer, and William Cantrell - for their advise in this thesis.

I would also like to thank Mohammed Mahmoud for helping me out during the process of writing this thesis. I am very grateful to my friends in Houghton for keeping me busy outside the office.

Finally, thanks to my family and Maria Val for their great support and encouragement to complete this work. 


\section{Contents}

Abstract iii

Acknowledgments $\quad$ iv

List of Figures $\quad$ ix

List of Tables $\quad$ xvii

$\begin{array}{lll}1 & \text { Introduction } & 1\end{array}$

1.1 Motivation . . . . . . . . . . . . . . . . . . . . . . . 1

1.2 Multiscale Statistical Analysis of Orographic Precipitation. . . . . . . 5

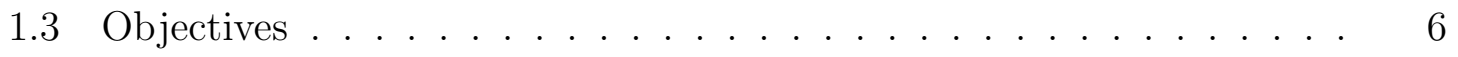

2 Case Studies and Data $\quad 8$

2.1 Overview of Case Studies . . . . . . . . . . . . . . . . . . . . . . 8

2.1 .1 Terminology . . . . . . . . . . . . . . . . . . . . 9

2.1 .2 Appalachian Mountains . . . . . . . . . . . . . . . 11

$2.1 .3 \quad$ The Front Range of the Rocky Mountains . . . . . . . . . 15

2.1.4 Similarities and Differences in Key Meteorological Features. . 20

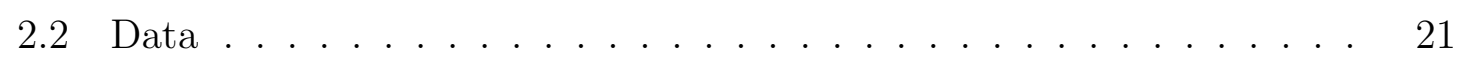

2.2 .1 Radar Data . . . . . . . . . . . . . . . . . . . . . . . 21

$2.2 .2 \quad$ Digital Elevation Data $\ldots \ldots \ldots \ldots \ldots$ 
$2.2 .3 \quad$ Individual Rawinsonde Soundings Data . . . . . . . . . . . 28

2.2.4 Sounding Station Parameters and Indices: Definition and Interpretation. . . . . . . . . . . . . . . 32

$\begin{array}{lll}3 & \text { Multiscale Statistical Analysis } & 35\end{array}$

3.1 Overview . . . . . . . . . . . . . . . . . . . . . . . . . 35

$3.2 \quad$ Spatial Fourier Spectral Analysis $\ldots \ldots \ldots$. . . . . . . . . . . 41

3.3 Structure Function Analysis $\ldots \ldots \ldots$. . . . . . . . . . . . . . . . 44

3.4 Moment-Scale Analysis . . . . . . . . . . . . . . . . . . . . 47

$\begin{array}{lll}4 & \text { Meteorology } & 52\end{array}$

4.1 Overview of Storm Environments $\ldots \ldots \ldots$

$4.1 .1 \quad$ Appalachian Mountains $\ldots \ldots \ldots \ldots$

4.1 .2 The Front Range of the Rocky Mountains . . . . . . . . . 55

4.2 Comparison to Storm Environment of Other Orographic Events _. . 59

4.3 Sounding and Stability Indices Results and Discussion. . . . . . . . 61

4.3 .1 Sounding Location and Chronology . . . . . . . . . . . . . . 61

4.3 .2 Sounding Results . . . . . . . . . . . . . . . . . . . 63

\begin{tabular}{|lll}
5 & Multiscaling Results and Discussion & 72
\end{tabular}

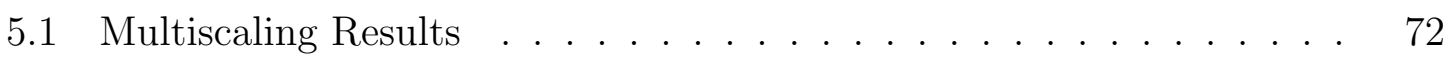

$5.1 .1 \quad$ Rapidan River Basin Storm of June 27, 1995 . . . . . . . . . 74

5.1 .2 Redbank Creek Storm of July 18-19, $1996 \ldots$. . . . . . . . 81

5.1 .3 Buffalo Creek Storm of July 12-13, 1996 . . . . . . . . . 86

$5.1 .4 \quad$ Fort Collins Storm of July 28-29, $1997 \ldots \ldots$

$5.1 .5 \quad$ Loveland Pass Storm of July 28-29, 1999 . . . . . . . . . . . 94

5.2 Summary of Results $\ldots \ldots \ldots \ldots$

5.3 Multiscale Behavior and Meteorological Indices _. . . . . . . . . 102

5.4 Comparison to Multiscale Properties of Previous Studies . . . . . . . 104 
6 Conclusions and Future Research 110

6.1 Conclusions . . . . . . . . . . . . . . . . . . . . . . . . . 110

6.2 Future Research . . . . . . . . . . . . . . . . . . . . . . . . . . . 112

\begin{tabular}{ll}
\hline References & 114
\end{tabular}

\begin{tabular}{|ll}
\hline A Atmospheric Sounding Indices & 118
\end{tabular}

A.1 Skew T, $\log \mathrm{P}$ diagram . . . . . . . . . . . . . . . . . 118

A.2 Sounding Station Parameters and Indices: Definition and Interpretation 120

A.2.1 LI (Lifted Index) . . . . . . . . . . . . . . . . . . . 120

A.2.2 SWEAT Index (Severe Weather Threat Index) . . . . . . . . 121

A.2.3 KINX Index . . . . . . . . . . . . . . . . . . . . . . 122

A.2.4 TOTL (Total Totals Index) $\ldots \ldots \ldots \ldots$

A.2.5 LFCT (Level of Free Convection) . . . . . . . . . . . . 124

A.2.6 LCL (Lifted Condensation Level) . . . . . . . . . . . . 125

A.2.7 CAPE (Convective Available Potential Energy) . . . . . . . 125

A.2.8 CINS(Convective Inhibition) . . . . . . . . . . . . 127

\begin{tabular}{|lll} 
A.2.9 & BRCH (Bulk Richardson number)
\end{tabular}$\ldots \ldots \ldots \ldots$

A.2.10 PWAT (Precipitable Water) … . . . . . . . . . . 130

\begin{tabular}{lll}
\hline B Atmospheric Sounding Plots 1 & 131
\end{tabular}

B.1 Rapidan River basin and southern Virginia Storm of June 27, 1995 . 131

\begin{tabular}{lll}
\hline C & Atmospheric Sounding Plots 2 & 138
\end{tabular}

C.1 Redbank Creek Storm of July 18-19, 1996 . . . . . . . . . . . . . 138

\begin{tabular}{|ll}
\hline D Atmospheric Sounding Plots 3 & 145
\end{tabular}

D.1 Buffalo Creek Storm of July 12-13, $1996 \ldots \ldots$ 
\begin{tabular}{lll}
\hline E & Atmospheric Sounding Plots 4 & 152
\end{tabular}

E.1 Fort Collins Storm of July 28-29, $1997 \ldots \ldots$

\begin{tabular}{|lll}
\hline F & Atmospheric Sounding Plots 5 & 159
\end{tabular}

F.1 Loveland Pass Storm of July 28-29, 1999 . . . . . . . . . . . . . . . 159 


\section{List of Figures}

1.1 Representation of a sample scheme for transferring of scales of a precipitation field from a NWP model to a Hydrologic model through a downscaling procedure ................. 2

$2.1 \quad$ Location of the five storms analyzed in this study . . . . . . . . . . 9

$2.2 \quad$ Windward-side vs Leeward-side events . . . . . . . . . . . . . . . . 10

2.3 Rapidan River Storm of June 27,1995: DEM + surface rainfall centroid. 12

2.4 Tracks of the Redbank Creek Storm of July 18-19, 1996 by surface rainfall centroid locations and the Pittsburgh (PIT) sounding station. They are portrayed over the underlying topography depicted by the Digital Elevation Model. . . . . . . . . . . . . . . . . . . . . . . 14

2.5 Buffalo Creek Storm of July 12-13, 1996: DEM + surface rainfall centroid. . . . . . . . . . . . . . . 16

2.6 Fort Collins Storm of July 28-29, 1997: DEM + surface rainfall centroid. 18

2.7 Tracks of the Loveland Pass Storm of July 28-29, 1999 by surface rainfall centroid locations and the Fort Carson (FCS) and Denver (DNR) sounding stations. They are portrayed over the underlying topography depicted by the Digital Elevation Model. . . . . . . . . 19

$2.8 \quad$ Rainfall sequence for the Redbank Creek storm of July 18-19, 1996. 24

$2.9 \quad$ Digital elevation Model data. World map from USGS webpage where data for the DEM representation was retrieved . . . . . . . . . . . . 29 
$2.10 \quad$ (a) Rawinsonde balloon launch and (b) flight (From Shemya Air Force Base webpage $) \ldots \ldots \ldots \ldots$. . . . . . . . . 30

$3.1 \quad$ (a) Energy transfer from large eddie to small eddie. (b) Energy trans-

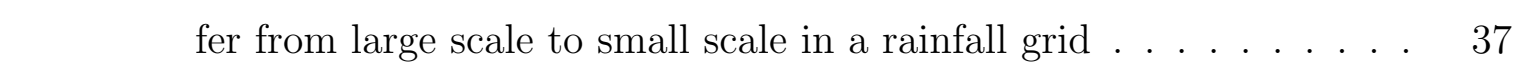

$3.2 \quad$ 2-D Cascade Model applied for a rainfall field $\ldots \ldots \ldots$

$3.3 \quad$ Fourier power spectra for the Fort Collins storms of 28-29 July, 1997.43

$3.4 \quad$ First-order $(q=1)$ generalized structure function for the Fort Collins

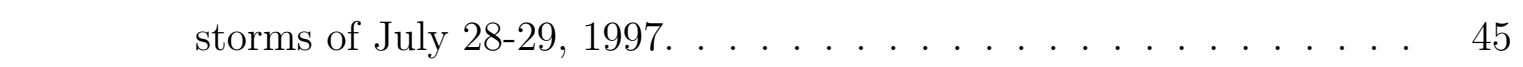

$3.5 \quad$ Moment scaling for the Fort Collins storms of 28-29 July, 1997 for the fractionally differentiated 2-D rainfall fields for $\mathrm{q}$ (moment) value

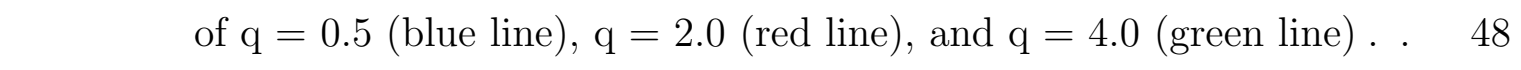

$\begin{array}{lll}3.6 & \mathrm{~K}(\mathrm{q}) \text { curve for the Fort Collins storms of 28-29 July, 1997. } \ldots . .50\end{array}$

$4.1 \quad$ SWEAT, KINX, and TOTL indices for the Rapidan River basin of \begin{tabular}{|c|c|}
\hline June 27, 1995 storms and the Redbank Creek of July 18-19 storms. 65 & 65
\end{tabular}

4.2 Lifted, Convective Available Potential Energy (CAPE), and Convective Inhibition (CINS) indices for the Rapidan River basin storm of June 27, 1995, the Redbank Creek storm of July 18-19, 1996, the Buffalo Creek storm of July 12-13, 1996, the Fort Collins storm of July 28-29, 1997, and the Loveland Pass storm of July 28-29, 1999. . 67 4.3 Lifted Condensation Level (LCLP) and Bulk Richardson Number (BRCH) indices for the Rapidan River basin storm of June 27, 1995, the Redbank Creek storm of July 18-19, 1996, the Buffalo Creek storm of July 12-13, 1996, the Fort Collins storm of July 28-29, 1997, and the Loveland Pass storm of July 28-29, 1999. . . . . . . . . . 70 
$4.4 \quad$ Precipitable Water (PWAT) for the Rapidan River basin storm of June 27, 1995, the Redbank Creek storm of July 18-19,1996, the Buffalo Creek storm of July 12-13, 1996, the Fort Collins storm of July 28-29, 1997, and the Loveland Pass storm of July 28-29, 1999. $\quad 71$

$5.1 \quad$ Multiscale statistical parameters $\beta$ and $H$ for the Rapidan River basin

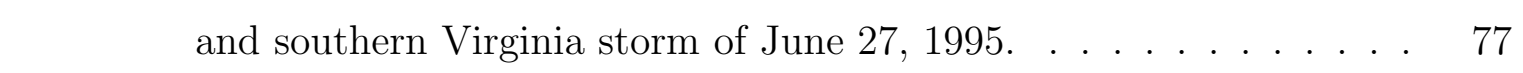

$5.2 \quad$ Multiscale statistical parameters $C_{1}$ and $\alpha$ for the Rapidan River

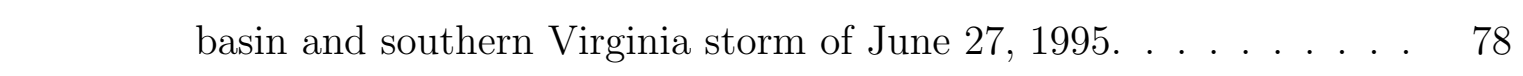

$5.3 \quad$ Topographic elevation of the surface rainfall centroid for the 27 June 1995 Rapidan River basin and southern Virginia storm of 27 June $1995 . \ldots \ldots \ldots \ldots \ldots$

5.4 Correlation of $C_{1}$ to topographic ELEV for the Rapidan River basin and southern Virginia storm of 27 June 1995. . . . . . . . . . 80

$5.5 \quad$ Multiscale statistical parameters $H$ and $\alpha$ for the Redbank Creek storm of July $18-19,1996 . \ldots \ldots \ldots$

$5.6 \quad$ Intermittency parameter and topographic elevation for the Redbank

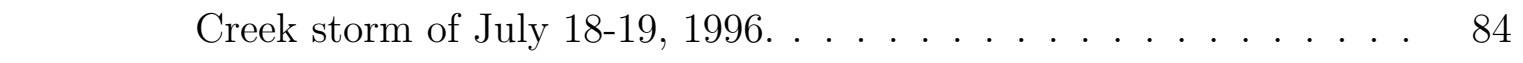

5.7 Correlation of $C_{1}$ to topographic ELEV for the Redbank Creek storm

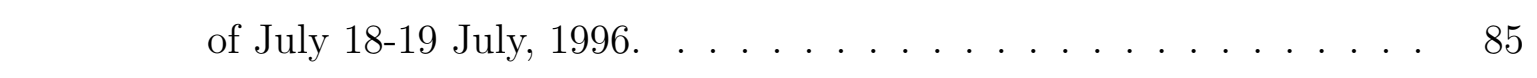

$5.8 \quad$ [Multiscale statistical parameters $H$ and $\alpha$ for the Buffalo Creek \begin{tabular}{|r}
\hline storm of July $12-13,1996$. \\
\hline
\end{tabular}

5.9 Intermittency parameter and topographic elevation for the Buffalo

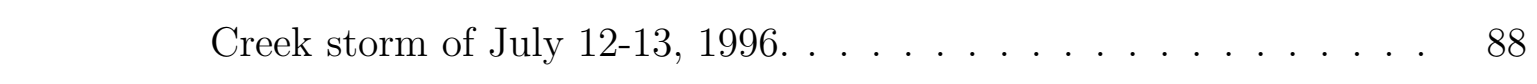

5.10 Correlation of $C_{1}$ to topographic ELEV for the Buffalo Creek storm

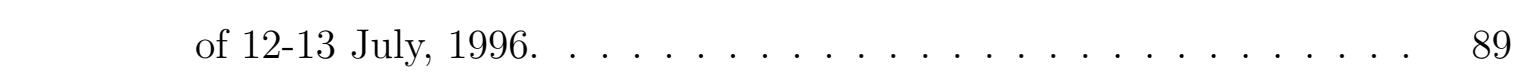

$5.11 \quad$ Multiscale statistical parameters $H$ and $\alpha$ for the Fort Collins storm of July $28-29,1997 . \ldots \ldots \ldots$. . . . . . . . . . . . 91 
5.12 Intermittency parameter and topographic elevation for the Fort Collins storm of July 28-29, 1997.

5.13 Correlation of $C_{1}$ to topographic ELEV for the Fort Collins storm of 28-29 July, 1997. . . . . . . . . . . . . . . . . . . . . . . . . 93

5.14 Multiscale statistical parameters $H$ and $\alpha$ for the Loveland Pass storm of July 28-29, 1999.

5.15 Intermittency parameter and topographic elevation for the Loveland Pass storm of July 28-29, 1999. . . . . . . . . . . . . . . . . . . . . 96

5.16 Correlation of $C_{1}$ to topographic ELEV for the Loveland Pass storm of July $28-29,1999$.

5.17 Correlation of $C_{1}$ to topographic ELEV for (a) all Rocky Mountain cases and (b) all leeward-side case studies. . . . . . . . . . . . . . 100

5.18 Correlation of $C_{1}$ to topographic elevation for all case studies . . . . 101

5.19 Intermittency parameter and topographic elevation for the storm of November 5-9, 1994 in the Southern Alps of New Zealand. . . . . . 106

A.1 (a) Representation of the Skew T, Log P diagram for a sample sounding and (b) Representation of the Skew T, Log P diagram for the Redbank Creek Storm at 1200 UTC 18 July, 1996 . . . . . . . . . . 119

A.2 Representation of the Skew T, Log P diagram for a sample sounding showing the shaded area of positive energy, also known as CAPE . . 126

A.3 Representation of the Skew T, Log P diagram for a sample sounding showing the shaded area of positive energy known as CINS . . . . . 128

B.1 Sterling, VA, temperature, dewpoint tmeperature, and wind sounding of the Rapidan River basin and southern Virginia storms for 0000 UTC on June 26, 1995. Listed are several stability indices . . . . . 132 
B.2 Sterling, VA, temperature, dewpoint tmeperature, and wind sounding of the Rapidan River basin and southern Virginia storms for 1200 UTC on June 26, 1995. Listed are several stability indices . . . . . 133

B.3 Sterling, VA, temperature, dewpoint tmeperature, and wind sounding of the Rapidan River basin and southern Virginia storms for 0000 UTC on June 27, 1995. Listed are several stability indices . . . . . 134

B.4 Sterling, VA, temperature, dewpoint tmeperature, and wind sounding of the Rapidan River basin and southern Virginia storms for 1200 UTC on June 27, 1995. Listed are several stability indices . . . . . 135

B.5 Sterling, VA, temperature, dewpoint tmeperature, and wind sounding of the Rapidan River basin and southern Virginia storms for 0000 UTC on June 28, 1995. Listed are several stability indices . . . . . 136

B.6 Sterling, VA, temperature, dewpoint tmeperature, and wind sounding of the Rapidan River basin and southern Virginia storms for 1200 UTC on June 28, 1995. Listed are several stability indices . . . . . 137

C.1 Pittsburgh, PA, temperature, dewpoint tmeperature, and wind sounding of the Redbank Creek storms for 1200 UTC on July 17, 1996. Listed are several stability indices . . . . . . . . . . . . . . . . . . 139

C.2 Pittsburgh, PA, temperature, dewpoint tmeperature, and wind sounding of the Redbank Creek storms for 0000 UTC on July 18, 1996. Listed are several stability indices . . . . . . . . . . . . . . . . . . . 140

C.3 Pittsburgh, PA, temperature, dewpoint tmeperature, and wind sounding of the Redbank Creek storms for 1200 UTC on July 18, 1996. Listed are several stability indices . . . . . . . . . . . . . . . . . 141

C.4 Pittsburgh, PA, temperature, dewpoint tmeperature, and wind sounding of the Redbank Creek storms for 0000 UTC on July 19, 1996. Listed are several stability indices . . . . . . . . . . . . . . . . . . 142 
C.5 Pittsburgh, PA, temperature, dewpoint tmeperature, and wind sounding of the Redbank Creek storms for 1200 UTC on July 19, 1996. Listed are several stability indices . . . . . . . . . . . . . . . . 143

C.6 Pittsburgh, PA, temperature, dewpoint tmeperature, and wind sounding of the Redbank Creek storms for 0000 UTC on July 20, 1996. Listed are several stability indices . . . . . . . . . . . . . . . . . . . 144

D.1 Denver, CO, temperature, dewpoint tmeperature, and wind sounding of the Buffalo Creek storms for 1200 UTC on July 11, 1996. Listed are several stability indices . . . . . . . . . . . . . . . 146

D.2 Denver, CO, temperature, dewpoint tmeperature, and wind sounding of the Buffalo Creek storms for 0000 UTC on July 12, 1996. Listed are several stability indices . . . . . . . . . . . . . . . . . 147

D.3 Denver, CO, temperature, dewpoint tmeperature, and wind sounding \begin{tabular}{|c|}
\hline of the Buffalo Creek storms for 1200 UTC on July 12, 1996. Listed \\
\hline
\end{tabular} are several stability indices . . . . . . . . . . . . . . . . . . . . 148

D.4 Denver, CO, temperature, dewpoint tmeperature, and wind sounding of the Buffalo Creek storms for 0000 UTC on July 13, 1996. Listed are several stability indices . . . . . . . . . . . . . . . . . . 149

D.5 Denver, CO, temperature, dewpoint tmeperature, and wind sounding of the Buffalo Creek storms for 1200 UTC on July 13, 1996. Listed are several stability indices . . . . . . . . . . . . . . 150

D.6 Denver, CO, temperature, dewpoint tmeperature, and wind sounding \begin{tabular}{|c|}
\hline of the Buffalo Creek storms for 0000 UTC on July 14, 1996. Listed \\
\hline
\end{tabular} are several stability indices . . . . . . . . . . . . . . . . 151

E.1 Denver, CO, temperature, dewpoint tmeperature, and wind sounding \begin{tabular}{|c|}
\hline of the Fort Collins storms for 1200 UTC on July 27, 1997. Listed are \\
\hline
\end{tabular} several stability indices . . . . . . . . . . . . . . . . 153 
E.2 Denver, CO, temperature, dewpoint tmeperature, and wind sounding of the Fort Collins storms for 0000 UTC on July 28, 1997. Listed are several stability indices . . . . . . . . . . . . . . . . . . . . 154

E.3 Denver, CO, temperature, dewpoint tmeperature, and wind sounding of the Fort Collins storms for 1200 UTC on July 28, 1997. Listed are several stability indices . . . . . . . . . . . . . . . . . . 155

E.4 Denver, CO, temperature, dewpoint tmeperature, and wind sounding of the Fort Collins storms for 0000 UTC on July 29, 1997. Listed are several stability indices . . . . . . . . . . . . . . . 156

E.5 Denver, CO, temperature, dewpoint tmeperature, and wind sounding of the Fort Collins storms for 1200 UTC on July 29, 1997. Listed are

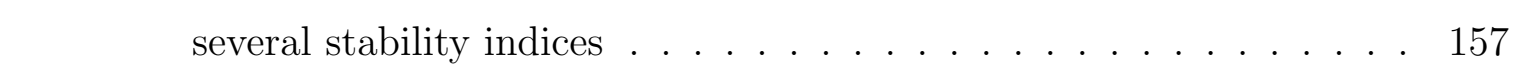

E.6 Denver, CO, temperature, dewpoint tmeperature, and wind sounding \begin{tabular}{|c|}
\hline of the Fort Collins storms for 0000 UTC on July 30, 1997. Listed are \\
\hline
\end{tabular} several stability indices . . . . . . . . . . . . . . . . . 158

F.1 Denver, CO, temperature, dewpoint tmeperature, and wind sounding of the Loveland Pass storms for 1200 UTC on July 27, 1999. Listed are several stability indices . . . . . . . . . . . . . . . . 160

F.2 Denver, CO, temperature, dewpoint tmeperature, and wind sounding of the Loveland Pass storms for 0000 UTC on July 28, 1999. Listed are several stability indices . . . . . . . . . . . . . . . . . . 161

F.3 Denver, CO, temperature, dewpoint tmeperature, and wind sounding \begin{tabular}{|c|}
\hline of the Loveland Pass storms for 0000 UTC on July 28, 1999. Listed \\
\hline
\end{tabular}

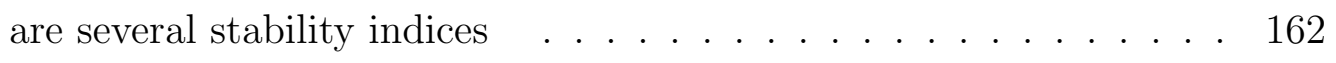

F.4 Denver, CO, temperature, dewpoint tmeperature, and wind sounding of the Loveland Pass storms for 1200 UTC on July 29, 1999. Listed are several stability indices . . . . . . . . . . . . . 163 
F.5 Denver, CO, temperature, dewpoint tmeperature, and wind sounding of the Loveland Pass storms for 0000 UTC on July 30, 1999. Listed are several stability indices ................. 164 


\section{List of Tables}

2.1 Effective reolution of radar rainfall data . . . . . . . . . . . . . . . . . 22

2.2 Summary of WSR-88D radars . . . . . . . . . . . . . . . . 23

2.3 Multiplicative bias (B) corrections used for the various case studies . 26

2.4 Summary of the possible sounding stations used throughout this study 32

2.5 Summary of Sounding Indices used throughout this study . . . . . . . 34

5.1 Summary of the correlation between $C_{1}$ vs. toporgaphic elevation for each of the case studies . . . . . . . . . . . . . . . . . . . . . . . . . . 98

5.2 Summary of the range on the multiscaling parameters $H, C_{1}$, and $\alpha$ for each of the cases, including $\mid$ Harris et al. $\mid\left[1996 \mid\right.$ and $\mid$ Purdy et al. $\_$_ [2001|case study . . . . . . . . . . . . . . . . . 108

A.1 Summary of atmospheric stability as a function of Li index value. . . 121

A.2 Summary of atmospheric stability as a function of SWEAT index value 122

A.3 Summary of probability of thunderstorms as a function of K index value 123

A.4 A more general summary of probability of thunderstorms as a function of $\mathrm{K}$ index value . . . . . . . . . . . . . . . . . . . . . . . . . . . . . . 123

A.5 Summary of probability of thunderstorms as a function of TOTL index value . . . . . . . . . . . . . . . . . . . . . . . . . . . . . . 124

A.6 Summary of convective potential as a function of LFCT value . . . . 125

\begin{tabular}{lll}
\hline A.7 & Summary of atmospheric stability as a function of CAPE index value 127
\end{tabular} 
A.8 Summary of atmospheric stability as a function of CINS index value . 129

A.9 Summary of probability of thunderstorms as a function of BRCH index value . . . . . . . . . . . . . . . . . . . . 129 


\section{Chapter 1}

\section{Introduction}

The primary goal of this study is to investigate the spatial organization of several orographic rainfall events using multiscale statistical analysis. In this chapter, the first section provides an introduction to the importance of upscaling and downscaling schemes for precipitation, followed by a description of previous studies on multiscaling of orographic precipitation fields. The last section of this chapter describes the scientific objectives of this study.

\subsection{Motivation}

Hydrologic forecasting deals with the assimilation and analysis of hydrometeorological data. This information is used in hydrologic modeling and prediction procedures to obtain forecasts of the various components of the hydrologic cycle, especially the streamflow conditions in streams and rivers. Precipitation is one of the key hydrometeorological variables used as input in hydrologic predictions. When considering mountainous regions, the spatial and temporal distribution of precipitation is strongly influenced by the local orography. The use of numerical weather prediction (NWP) models to provide input of spatial rainfall patterns for distributed hydrologic models has gained popularity over the past decade for studying the hydrologic response of 


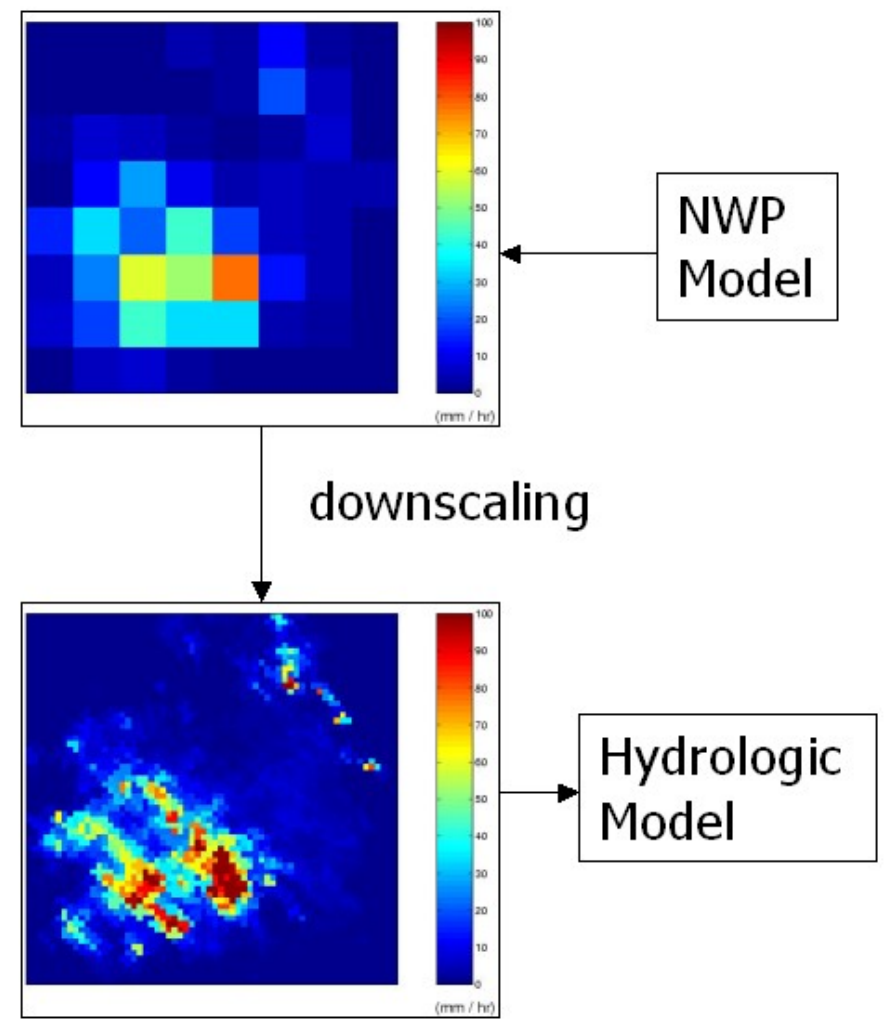

Figure 1.1 Representation of a sample scheme for transferring of scales for a precipitation field from a NWP model to a Hydrologic model through a downscaling procedure.

alpine catchments.

Difficulties. The scale differences between atmospheric models (coarser resolution) and local hydrological models (finer resolution) have been an issue in obtaining accurate hydrologic predictions in moderate to extreme topography. Regional-scale atmospheric models commonly use parameterization schemes at grid scales larger than $10 \mathrm{~km}$. When long-range routine simulations at resolutions as high as $1-4 \mathrm{~km}$ are considered, current constraints on computing power arise. On the other hand, if observed precipitation is used as input rainfall in hydrologic models, scale issues also arise due to the space-time resolutions of the observations. This is due to resolutions being too coarse (satellite) or too fine (gauge) for the requirements of the hydrologic model. 
Scaling Techniques. An attractive way to overcome these scale issues is provided by upscaling and downscaling techniques, which are used to transfer the precipitation field from one scale to another (see Figure 1.1 for visualization). To this end, it is first required to characterize the space-time organization and structure of the precipitation field. These characterization techniques are intended to incorporate the degree of scale variability of rainfall and to describe quantitatively the changes in rainfall nature. They incorporate certain properties from which the field can be described. Characterization techniques usually take the form of a simple power law, and can be portrayed by a few parameters as well as being the driving force of analysis methods that employ a scaling or multiscaling framework (e.g., Lovejoy and Schertzer 1995a and de Lima and Grasman 1999]). The characterization of the space-time organization of mid-western convective systems and tropical rainfall was studied by Kumar and Foufoula-Georgiou 1993a, Kumar and Foufoula-Georgiou [1993b, and Harris et al. 2001. They used this base to develop statistical/dynamical models of precipitation downscaling. To provide practical applications of the scaling parameters, the interplay between them and the meteorology of the process governing the rainfall field are needed. It was in this context that Perica and Foufoula-Georgiou [1996 linked the scaling parameters to the Convective Available Potential Energy ( $C A P E)$ of the prestorm environment for midwestern convective storms. The findings of these links can be used in a precipitation downscaling scheme in order to couple hydrologic and atmospheric models (see Nykanen et al. 2001). On the other hand, there has been a lack of attention in regards to precipitation in mountainous regions. This is in partly due to the complexities of the topographic influences of these areas. Consequently, downscaling of convective precipitation in mountainous terrain at small scales (1 - 10 $\mathrm{km}$ ) still remains an open problem.

Downscaling schemes. Downscaling schemes provide a method to obtain sub-grid temporal and spatial scale details of precipitation by applying statistical techniques. 
These statistical techniques preserve the statistical features of the spatial and temporal variability of the field as a function of scale and are typically based on methods such as regression (linear or non-linear), stochastic process, nonlinear dynamics, artificial neural networks (ANN), and multiplicative random cascade models, among others. ANN were studied by Kuligowski and Barros 1998 for short-term precipitation forecasting with radiosonde and numerical weather prediction variables as predictors. They found that ANN had potential as a downscaling technique and it was reported to perform better in moderate to heavy precipitation events than other currently used regression methods. Yet this was not the case in light to moderate precipitation events. In addition, a downscaling methodology based on the principles of fractal interpolation was developed by Bindlish and Barros 2000 to study the disaggregation of precipitation fields from atmospheric models to hydrologic models. They used the spatial properties of the terrain and space-time variability of wind fields to disaggregate the precipitation fields generated by an atmospheric model.

Cascade models. Multiplicative random cascade models have the ability of reproducing the scale invariance features, higher-order, and multi-point statistics observed in rainfall such as long range correlations, intermittency and extreme fluctuations (see Davis et al. 1994, Lovejoy and Schertzer 1995a, Lovejoy and Schertzer 1995b, Harris et al. [1996, Harris 1998, and de Lima and Grasman 1999, among others). In this study, the statistical framework used on the multiscale characterization of the precipitation field is cascade based, and offers a parsimonious parameterization that allows the posterior used for the purposes of stochastically downscaling precipitation fields. 


\subsection{Multiscale Statistical Analysis of Orographic Precipitation.}

Only a few previous studies have explored the multiscale properties of orographic precipitation in mountainous terrain. Harris et al. [1996 and Purdy et al. 2001] were the first studies to explore these properties. They focused on one-dimensional (1-D) temporal variability of rainfall by using high density networks of high temporal resolution rain gauges along transects in the Southern Alps of New Zealand. This event was described as a system moving warm, moist air eastwards from the Tasman sea towards the main divide of the Southern Alps. Harris et al. 1996 found that rainfall time series became less intermittent and less organized as topographic elevation increased along the transect. In addition, Purdy et al. 2001 focused on the meteorological processes that involved the event to explain the multiscaling results. They reported that convective precipitation yielded different multiscaling parameter values compared to stratiform or mixed (stratiform/convective) precipitation.

Nykanen and Harris 2003 used multiscale statistical analysis to characterize the organization and structure of a convective orographic rainfall event that produced flash flooding in the Blue Ridge Mountains of Virginia. They applied it to twodimensional (2-D) spatial variability of rainfall by using radar data. Parameter estimates were analyzed over time and focus was placed on relating rainfall multiscaling parameters to orographic influences. Nykanen and Harris 2003 found that intermittency increased with increasing topographic elevation, which contradicted the trend found by Harris et al. [1996 and Purdy et al. 2001]. The contradicting trends can be explained by the contrasting storm environments of the two events. These results verified the importance of considering meteorological influences on the multiscale properties of orographic precipitation.

This study builds on the work of Harris et al. [1996], Purdy et al. 2001], and Nykanen and Harris 2003 by using multiscale statistical analysis to further char- 
acterize the spatial organization and structure of four convective orographic rainfall events that occurred in the Appalachian Mountains and the Front Range of the Rocky Mountains. An effort is made in order to investigate the meteorological environment in addition to the topographic influences of the multiscale parameters. The multiscale analysis has been applied to 2-D spatial rainfall pattern, and parameters were estimated over time as in Nykanen and Harris 2003.

It is important to point out that this research is exploratory work. There is a theoretical link through physics to expect topography to influence storm environment which in turn will influence organization and behavior of rainfall. Therefore, we expect to see linkages between multiscale statistical properties of orographic precipitaion with both topographic and meteorological influences. This exploratory research is needed to begin to understand and quantify the interplay between topographic and meteorological forcings on the trends in multiscale behavior of rainfall, which leads to the objectives of this research.

\section{$1.3 \quad$ Objectives}

The purpose of this study is to analyze the spatial organization and multiscale properties of various convective rainfall events in mountainous terrain. To this end, meteorological environments, geographic location, and a range of spatial scales of interest to hydrometeorological forecasting are considered. The following are the objectives of this work:

- Determine and quantify whether spatial scaling exists as a common feature in orographic precipitation.

- Link topographic influences to multiscale statistical properties of orographic precipitation. 
- Explore potential linkages between multiscale statistical parameters and meteorological variables for practical applications of multiscaling statistics.

This study is enclosed in a field of research with the goal of improving atmospheric and hydrologic predictions in forecasts through the use of new space-based observations, data assimilation, and modeling. 


\section{Chapter 2}

\section{Case Studies and Data}

The previous chapter provided some background as well as motivation that has led to the development of this research. In this study, orographic precipitation events in various geographical regions are considered. Focus is placed on two main areas including the Front Range of the Rocky Mountains and the Appalachian Mountains. This chapter presents an overview of the five events that will be discussed throughout this research, including four events analyzed here and one event studied by Nykanen and Harris [2003]. The overview indicates time, location, similarities and differences among cases in key meteorological features along with some information regarding the consequences of those storms. In addition, the data used in this study is summarized in this chapter.

\subsection{Overview of Case Studies}

Five orographic events that are characteristic of organized thunderstorms and convection that produce heavy rainfall and catastrophic flooding in complex terrain are presented. The eastern and western slopes of the Appalachian Mountains and eastern slope of the Front Range of the Rocky Mountains are the locations where those events occurred. Figure 2.1 shows the location of the five events. A Digital Elevation Model 


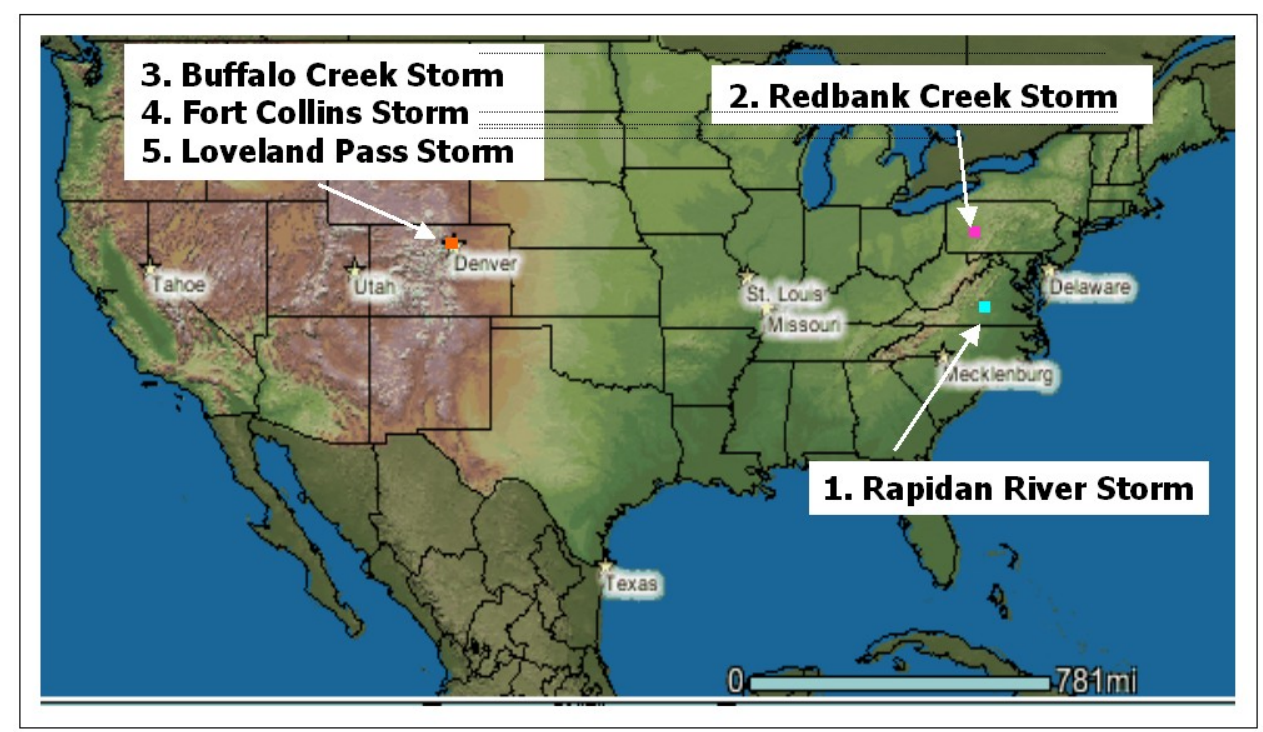

Figure 2.1 Location of the five storms analyzed in this study.

(hereinafter DEM) is used to represent the underlying topography for each event. Furthermore, a track of the storms is depicted using surface rainfall centroids that show the path followed by the storms and is overlapped with the DEM to facilitate visualization of storm movement relative to topography.

\subsubsection{Terminology}

Prior to giving an overview of all the storms, it is helpful to first supply some insight in specific terminology that is used throughout this section.

Windward-side vs. Leeward-side events. The terms windward and leeward refer to the direction of the winds in regards to a mountain range and the side where a storm would occur on this mountain range. Four of the cases analyzed in this study were leeward-side events, so that the prevailing winds aloft were in the opposite direction of the upslope low-level winds. There is also one case (Redbank Creek Storm 


\section{Windward vs Leeward}

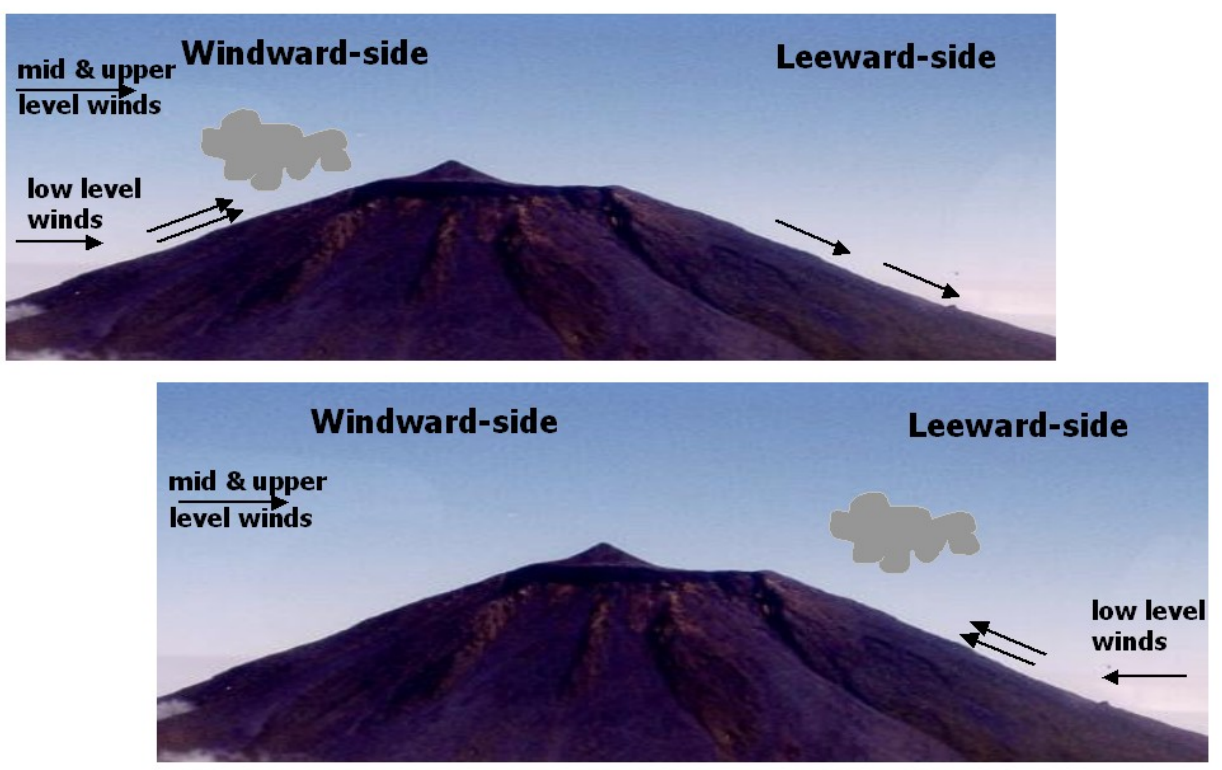

Figure 2.2 Windward-side vs Leeward-side events.

of July 18-19, 1996) that is characterized as a windward-side event, meaning that the prevailing upper level winds were the same direction as the upslope low-level winds. Figure 2.2 shows examples of both leeward-side (bottom panel) and winward-side (top panel) events, depicting the direction of the winds for each case.

Surface Rainfall Centroid. From rainfall data, surface rainfall centroids are computed to keep track of the storms. In essence, surface rainfall centroids are a sequence of weighted centroids of rainfall. They are calculated by the centroid or center of gravity of the rainfall field (i.e., matrix) finding its centroid across columns and its centroid across rows. This matrix is composed with $1 \mathrm{~km}$ by $1 \mathrm{~km}$ gridded rainfall radar data that represents the rainfall field for a specific time. 
Digital Elevation Model (DEM). A digital elevation model (DEM) is a digital file consisting of terrain elevations for ground positions at regularly spaced horizontal intervals. The DEM may be used in the generation of three-dimensional graphics displaying terrain slope, aspect (direction of slope), and terrain profiles between selected points.

\subsubsection{Appalachian Mountains}

Two events that occurred in the Appalachian Mountains are analyzed in this study. An overview on the background and different aspects of the storms is provided in this section.

1) Rapidan River Basin Storm of June 27, 1995. The Rapidan River Basin and Southern Virginia storm of June 27, 1995 was analyzed by Nykanen and Harris [2003]. This event is presented in this study in order to facilitate comparison with the other events considered here. The Rapidan River storm is a perfect example of storms with pronounced influence of topography, which is a common feature in many events that occur in the central Appalachians [Smith et al. , 1995]. There is rich literature available in regards to the meteorological conditions and the orographic forcings that involved the storm motion and evolution (e.g. Smith et al. [1995, Pontrelli et al. [1999], and Landel et al. [1999]).

Radar estimates underlined that this storm produced peak rainfall accumulations exceeding $600 \mathrm{~mm}$ in a 6-hr period during the morning and early afternoon (0500-0900 UTC) of June 27, 1995. A peak flood discharge of $3000 \mathrm{~m}^{3} / \mathrm{s}$ resulted on the Rapidan River, which placed this event on the envelope curve of flood discharge for the United States, east of the Mississippi River (see Smith et al. 1995]). Moreover, the return period for a flood event of these characteristics is close to 500 years along portions of the Rapidan River in Madison County. As a consequence of these storms, there was a total of 200 million dollars in damages (Virginia Department of Emergency Services 


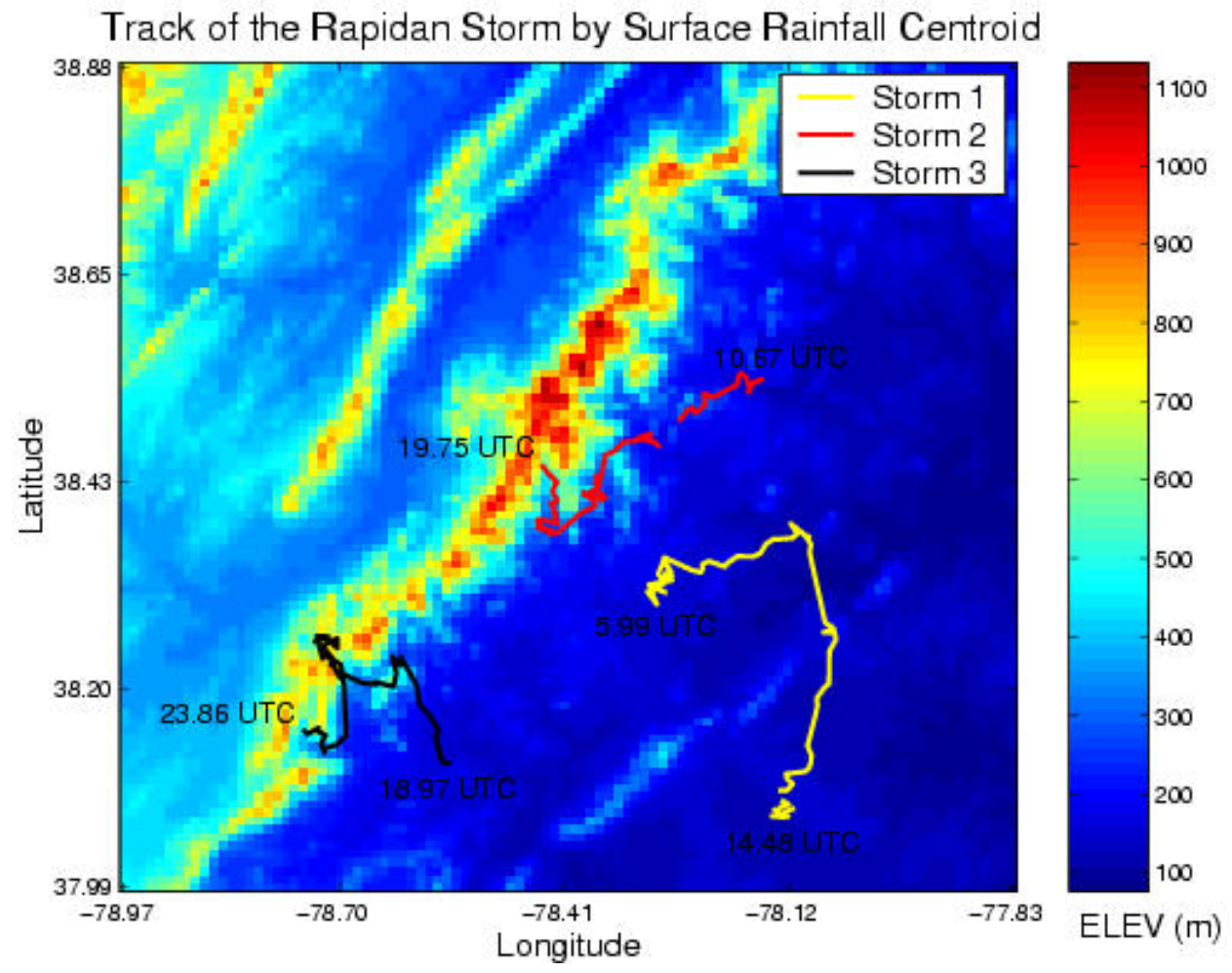

Figure 2.3 Tracks of the Rapidan River basin and southern Virginia storms of June 27, 1995 by surface rainfall centroid location. The underlying topography of the region is plotted using a Digital Elevation Model. Times shown corresponds to the beginning and end of the storm tracks using WSR-88D Sterling, Virginia, data of June 27, 1995 (From Nykanen and Harris [2003]). 
1998).

The event was divided into three systems (later referred to as Storms 1, 2, and 3). Storms 1 and 2 are also called the Piedmont and Rapidan storms, respectively. Storm 1 was described as mixed rainfall (stratiform/convective), while Storm 2 and 3 where both convective rainfall, although Storm 3 was more unstable. These three systems are shown in Figure 2.3 obtained from Nykanen and Harris 2003 where the surface rainfall centroid of the three storms are depicted and overlapped on the DEM of the region. This area was covered by the Sterling, Virginia WSR-88D, which was the radar used to obtain the rainfall data. A more detailed explanation about the radar data is given in Section 2.2.1.

2) Redbank Creek Storm of July 18-19, 1996. The Redbank Creek storm took place on the western slope of the Appalachian Mountains in Western Pennsylvania. This event produced disastrous flash flooding across six counties of Western Pennsylvania, causing one fatality and 225 million dollars in damage. The worst damage (100 million dollars) was concentrated in Jefferson County, primarily in the towns of Punxsutawney, Summerville, and Brookville. Record river flooding resulted from the widespread flash flooding and some places received more than $230 \mathrm{~mm}$ of rainfall in less than $12 \mathrm{hr}$. Due to a previous flood in 1936, a flood wall was built through Punxsutawney. However, water overflowed the flood wall on July 19, 1996 for the first time since its construction. As a result, most of the town was inundated with water and consequently suffered considerable flood damage.

In this study, the Redbank Creek storm was divided into four systems, as shown in Figure 2.4. The tracks of the four storms are represented by their surface rainfall centroids and are overlaid on the underlying topography of the area. Also, the sounding station located inside this region is plotted. It can be observed that the storms traveled eastward towards the Appalachians Mountains, thus they were moving into higher topography as they evolved. S3 was the system that dominated the whole 
Track of the Redbank Creek Storm by Surface Rainfall Centroid

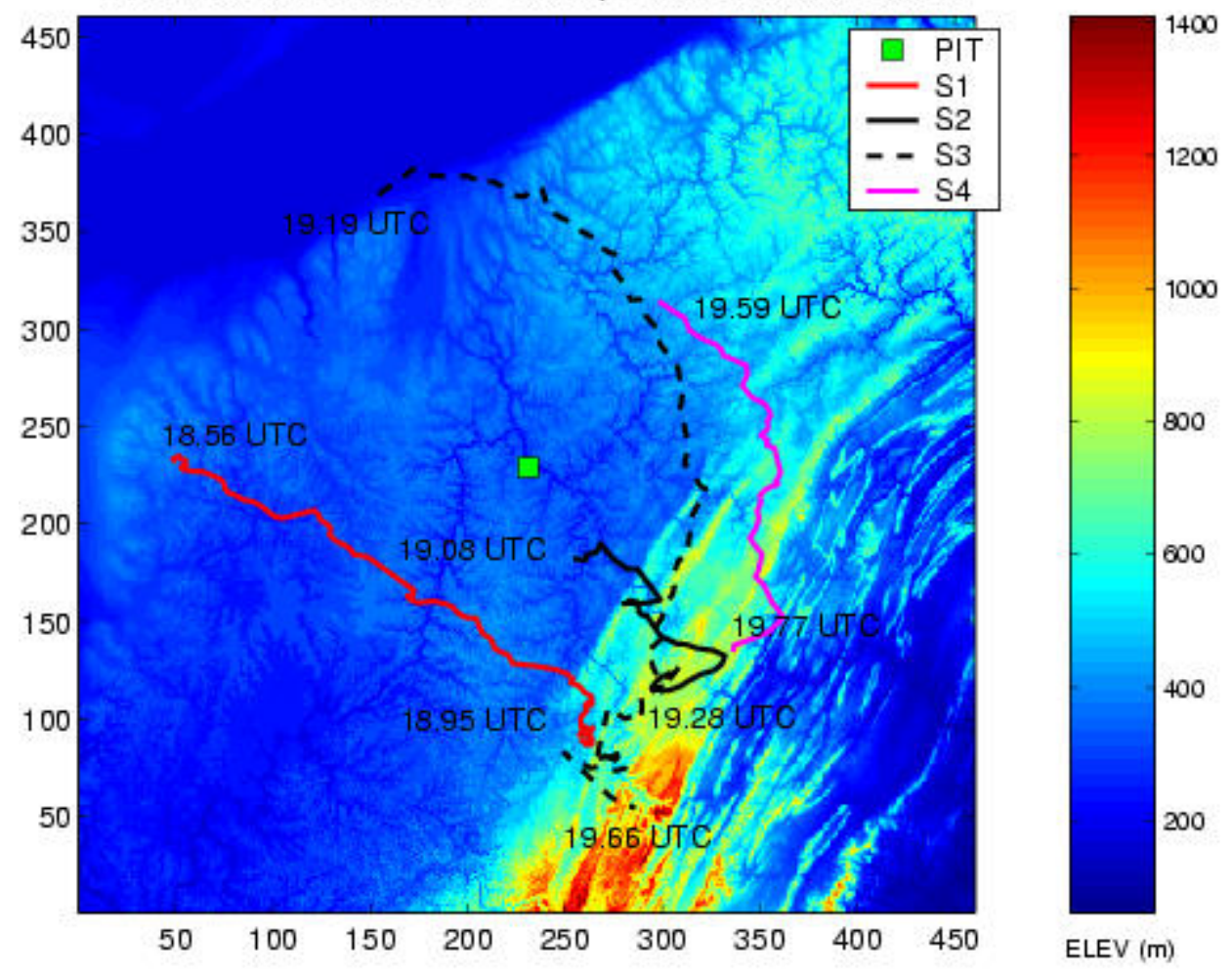

Figure 2.4 Tracks of the Redbank Creek Storm of July 18-19, 1996 by surface rainfall centroid locations and the Pittsburgh (PIT) sounding station. They are portrayed over the underlying topography depicted by the Digital Elevation Model (DEM). Times shown corresponds to the beginning and end of the storm tracks using WSR-88D Pittsburgh, Pennsylvania, data of July 18-19, 1996. 
event, producing the most widespread flash flooding.

\subsubsection{The Front Range of the Rocky Mountains}

Many extreme rainfall events have occurred in Colorado during the last century. Documentation through 1997 reported that there have been seven storms with at least $10 \mathrm{in}$. of rainfall falling within $24 \mathrm{hr}$ periods. The eastern slope near the base of the Rocky Mountains has been the location of those storms. The orography of the region is one of the main sources of influence on the enhancement of these catastrophic events.

There are some patterns of distribution for these events throughout the year and most of them ranged between mid-April and mid-October. The storms ranging from May and early June are considered spring storms. The three events described in this study are considered summer storms as they all occurred in July. The summer storms are often highly convective systems, usually small in areal extent, and have occurred in the eastern foothills of the Rocky Mountains.

3) Buffalo Creek Storm of July 12-13, 1996. A flash flood occurred in the eastern slope of the Rocky Mountains across the Buffalo and Spring Creek watersheds

at approximately $45 \mathrm{~km}$ to the south of Denver, Colorado on the night of July 12 , 1996. The storm produced modest total rainfall accumulations. However, it resulted in record flash flooding due to a recent wildfire in May 1996, which lowered the infiltration capacity and erosion threshold of the watershed. Furthermore, the storm motion was coincident with the flood wave propagation. Precipitation accumulations exceeded $80 \mathrm{~mm}$ in a 1-hr period over both watersheds. Two lives were lost as a direct result of the flooding.

Figure 2.5 shows the topography of the region and five concurrent storm systems that were tracked using $128 \mathrm{~km}$ by $128 \mathrm{~km}$ moving windows to compute the surface rainfall centroid of each storm. The storms moved eastward into lower topography as 


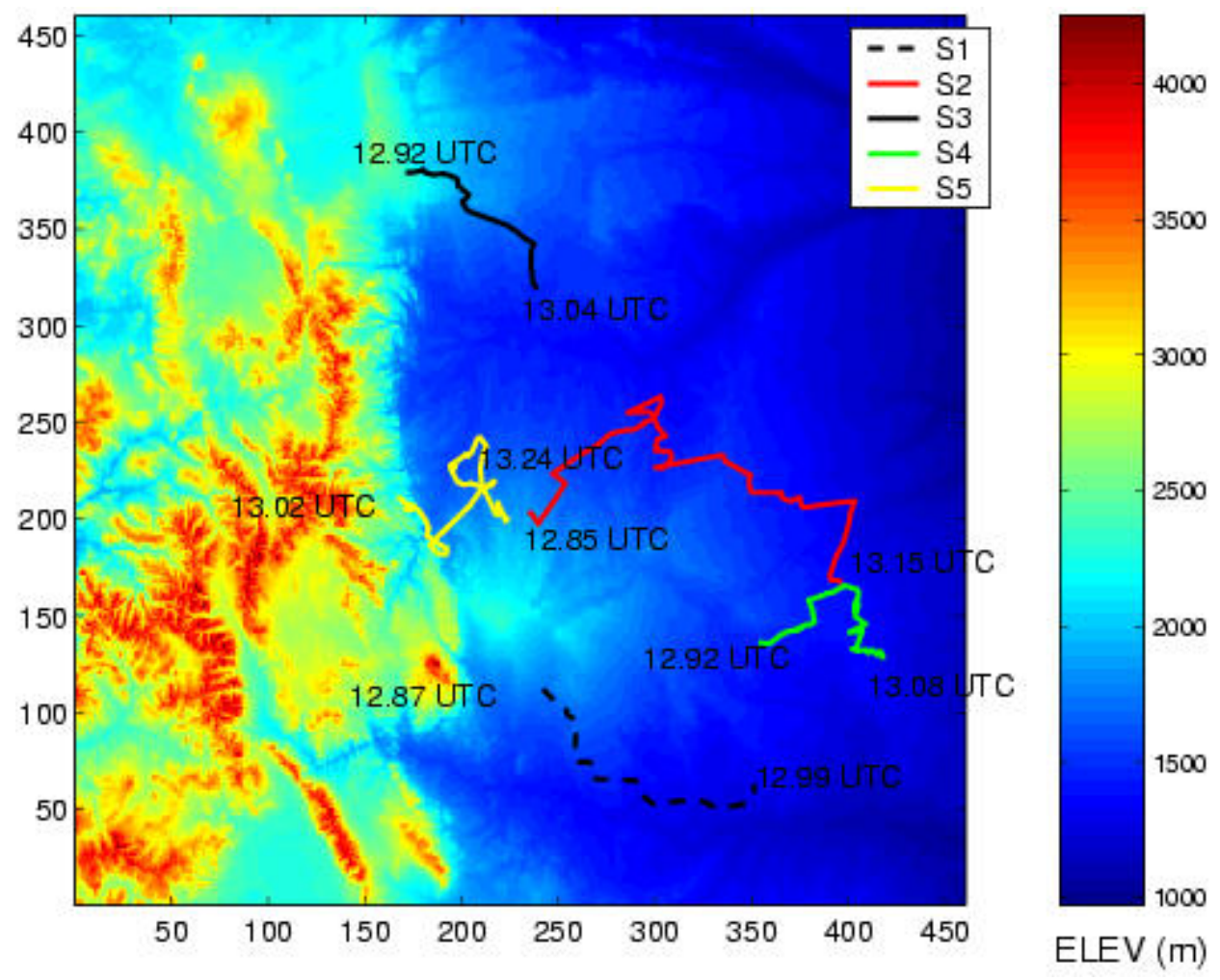

Figure 2.5 Tracks of the Buffalo Creek storm of July 12-13, 1996 by surface rainfall centroid location. The underlying topography of the region is plotted using a Digital Elevation Model. Times shown corresponds to the beginning and end of the storm tracks using WSR-88D Denver, Colorado, data of July 12-13, 1996. 
they evolved. S2 corresponds to the storm that produced the July 13 Buffalo Creek flood.

Landel et al. [1999] indicated that the main significance of the Buffalo Creek storm corresponded to the magnitude of the flooding at spatial scales of $0.1-10 \mathrm{~km}^{2}$. They pointed out that at this spatial scale the principal controlling factor in flood response is the rainfall rate variability at $1-15$ min time scale.

4) Fort Collins Storm of July 28-29, 1997. The Fort Collins Storm of July 28-29, 1997 is one of the largest events ever documented over a developed urban area in Colorado. It occurred in the eastern slope of the Front Range of the Rocky Mountains near Fort Collins, Colorado. Maximum accumulations exceeded $254 \mathrm{~mm}$ over a 6 -hr period in the western part of the city. Rainfall amounts recorded by a wide variety of instruments revealed that this event exceeded the Fort Collins 100-yr 6-hr and 24-hr rainfall amounts as indicated by the National Oceanic and Atmospheric Administration (NOAA). The storm produced record flash flooding that caused five deaths and 200 million dollars in damage. A more detailed explanation can be found in Petersen et al. 1999 and Landel et al. 1999

These catastrophic systems passed within the Cheyenne WSR-88D radar, which is used here in the multiscale statistical analysis. Radar data from the Cheyenne WSR-88D and rain gage observations revealed a peak storm total rainfall of $300 \mathrm{~mm}$ in western Fort Collins over the Spring Creek catchment.

Figure 2.6 illustrates the event that was divided into two systems, the July 28 and the July 29 storms. On July 28, the storm moved westward towards the Rocky Mountains. It then reversed direction and moved east, remaining quasi-stationary on the foothills of the northern Colorado Front Range. The July 29 system went across the High Plains southeast of Fort Collins and traveled steadily to the northeast, moving away from the Front Range into lower topography. The July 29 storm produced the devastating Fort Collins flood. 


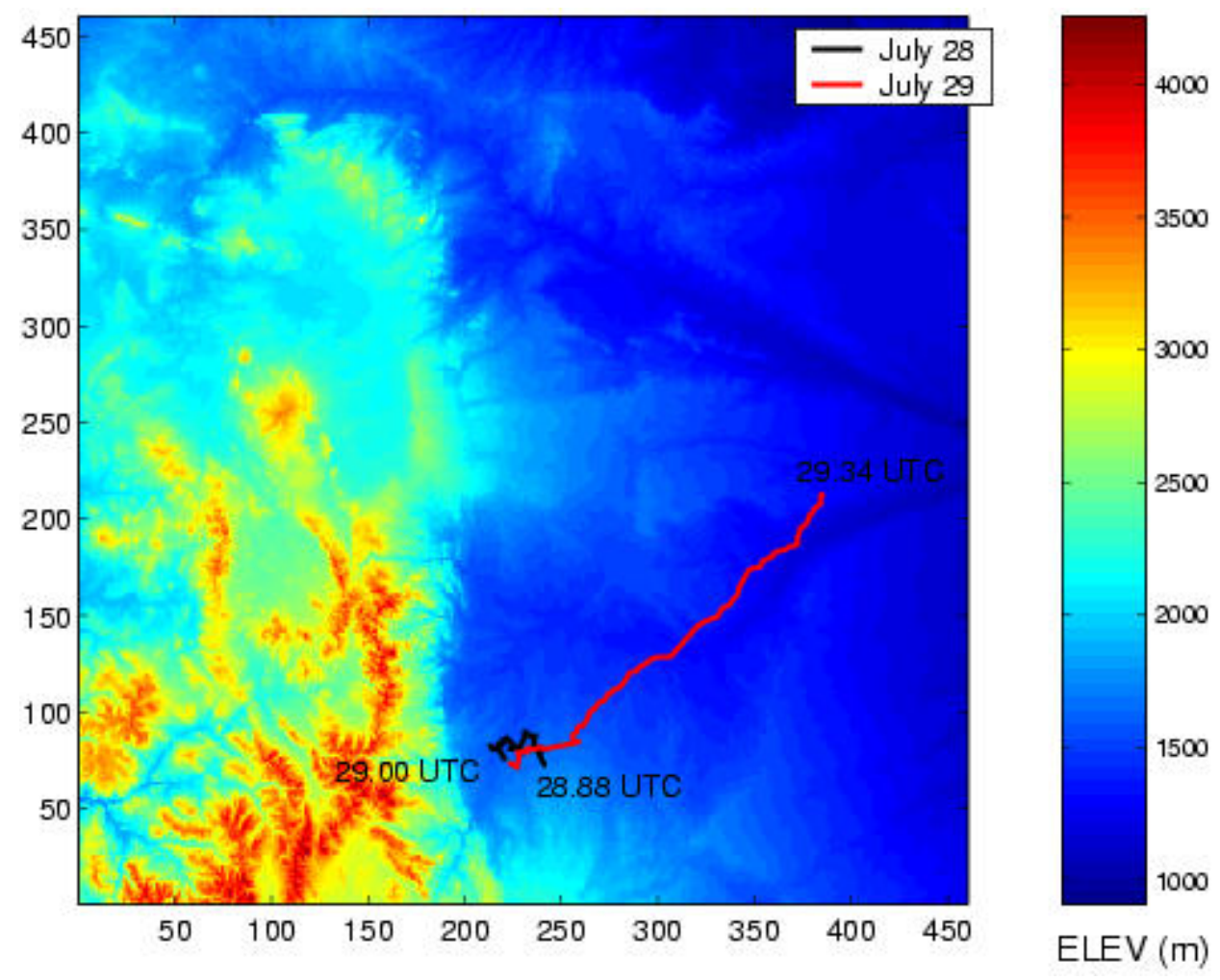

Figure 2.6 Tracks of the Fort Collins Storm of July 28-29, 1997 by surface rainfall centroid location. The underlying topography of the region is plotted using a Digital Elevation Model. Times shown corresponds to the beginning and end of the storm tracks using WSR-88D Cheyenne, Wyoming, data of July 28-29, 1997. 


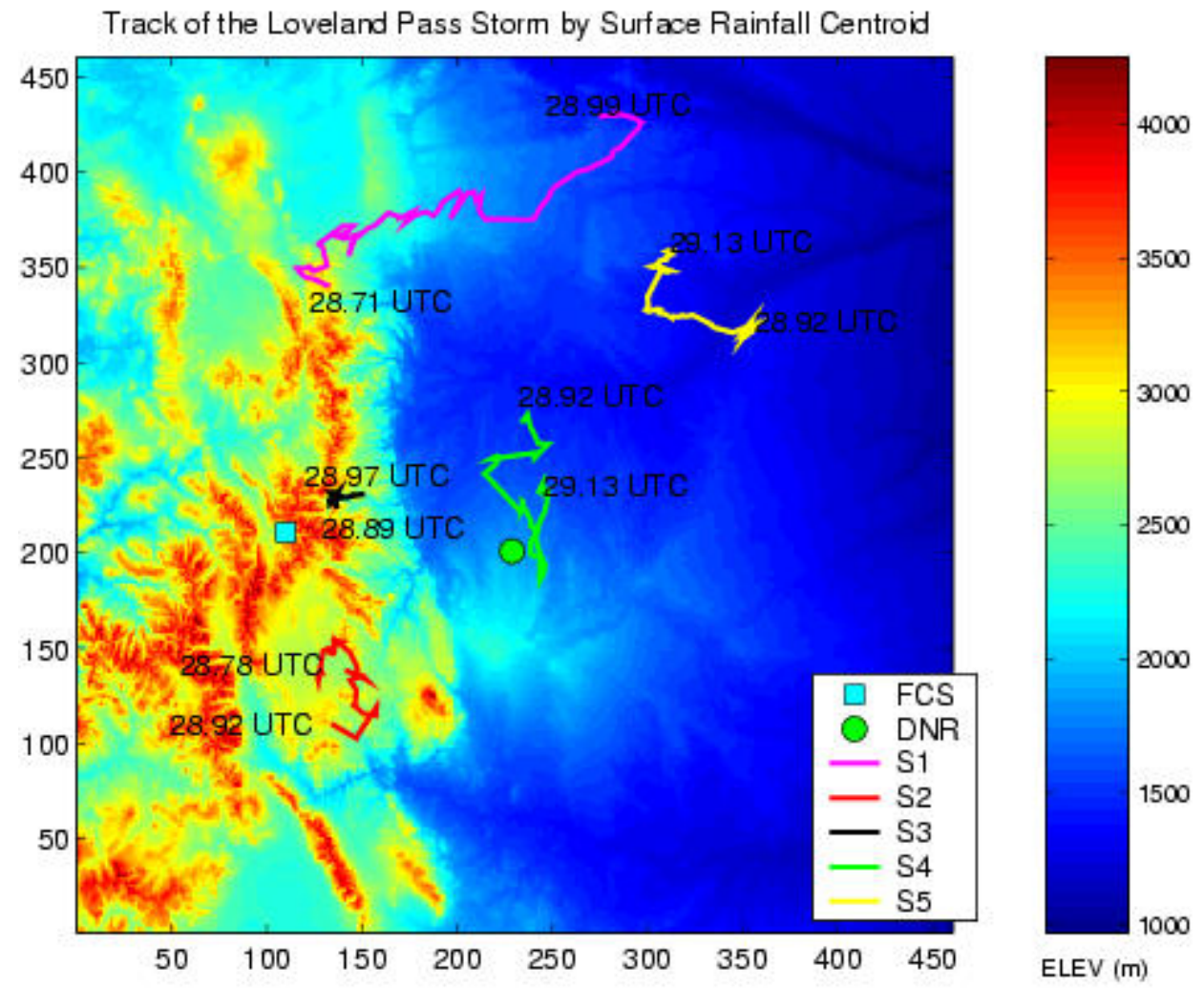

Figure 2.7 Tracks of the Loveland Pass Storm of July 28-29, 1999 by surface rainfall centroid locations and the Fort Carson (FCS) and Denver (DNR) sounding stations. They are portrayed over the underlying topography depicted by the Digital Elevation Model. Times shown correspond to the beginning and end of the storm tracks using WSR-88D Denver, Colorado, data of July 28-29, 1999.

5) Loveland Pass Storm of July 28-29, 1999. The Loveland Pass Storm of July 28-29, 1999 occurred in the eastern slope of the Front Range of the Rocky Mountains near Denver, Colorado. This storm was enclosed in a period of prolonged flow of monsoonal moisture which lasted from about July 26 - August 2, 1999. There are some indications that the storm produced an excess of $3 \mathrm{in}$. of rain. As a result of the rainfall, the storms generated debris flows in about 20 channels during the July 28 storm along Interstate 70 (I-70) between Georgetown and the Eisenhower Tunnel in central Colorado. The Interstate was closed for approximately $24 \mathrm{hr}$. (see http://landslides.usgs.gov/i70/ USGS webpage for more information) 
The event was divided into five systems as shown in Figure 2.7. The underlying image corresponds to the DEM of the region where the storms took place. Also, the sounding stations of the region used to obtain the atmospheric soundings are depicted. On July 28, storm S1 moved eastward away from the Rocky Mountains, while S2 and S3 appeared to be mostly stationary and remained centered over complex terrain.

\subsubsection{Similarities and Differences in Key Meteorological Fea- tures.}

The events analyzed in this study show similarities and differences in key meteorological features. A detailed explanation of the meteorological environment is provided in Chapter 4 of this thesis, where information from sounding data and literature has been taken into account to highlight a deeper knowledge of the storms' environment. However, providing a summary of the main similarities and differences in key meteorological characteristics between all storms would help in further explanations and is therefore provided here:

Similarities in Key Meteorological Features. There are certain characteristics that were a common feature in all storms. These similarities in key meteorological features are:

1. Pronounced influence of orography,

2. Convective rainfall events that produced catastrophic flooding,

3. High humidity in the atmospheric profile,

4. Dominance of warm rainfall processes. 
Differences in Key Meteorological Features. At the same time, these events also showed differences between each other. These differences in key meteorological features are:

1. Appalachian Mountains cases were characterized by the storm centroid moving into higher topography as the storm evolved,

2. For Rocky Mountains cases, storm centroids moved into lower topography,

3. Cases 1, 3, 4, and 5 are all charcterized as being leeward-side events,

4. Case 2 is a windward-side event.

\subsection{Data}

This study uses variety of data sets to analyze the five storms. The spatial and temporal evolution of the rainfall produced by the storms is provided by radar. This data is used as input in the multiscale statistical analysis. Individual rawinsonde soundings from several stations along with a rich literature are used to analyze the storm environments. This section presents a brief description of the data as well as the specific radar and sounding stations used throughout this study. It also discusses some of the limitations associated with each of these data sources.

\subsubsection{Radar Data}

The precipitation field is estimated from the Weather Surveillance Radar-1988 Doppler network (hereinafter WSR-88 Radar) which comprises approximately 160 sites throughout the United States and select overseas locations. The WSR-88D estimates rainfall from a three-dimensional volume scan reflectivity field (level II radar reflectivity). The WSR-88D estimates radar reflectivity using a polar coordinate system with resolution of approximately $1^{\circ}$ in azimuth by $1 \mathrm{~km}$ in range. The radar samples a volume 
of the atmosphere that increases with distance. Both the $1^{\circ}$ azimuth and increasing elevation of the radar beam with distance from the radar contribute to larger volume being sampled at farther distances from the radar. The polar coordinate radar data is converted to rectangular coordinate data with approximately 1-km x 1-km grids using nearest neighbor mapping. Due to the $1^{\circ}$ azimuth, the effective resolution of the data is higher than $1-\mathrm{km} \times 1-\mathrm{km}$ as the distance from the center of the radar increases. For ranges where the effective resolution is greater than 1-km x 1-km, the same polar coordinate data value is mapped into multiple grids. The change in effective resolution with distance from the radar is shown in Table 2.1. This effective resolution limitation is important to keep in mind distances far from the radar location.

Table 2.1 Effective reolution of radar rainfall data.

\begin{tabular}{cc}
\hline Range $(\mathrm{km})$ & Effective Resolution $(\mathrm{km})$ \\
\hline $0 \sim 57$ & 1 \\
$57 \sim 114$ & 2 \\
$114 \sim 171$ & 3 \\
$171 \sim 229$ & 4 \\
\hline
\end{tabular}

A power law equation is used to compute radar rainfall estimates from radar reflectivity $(Z)$ observations. The equation has the form,

$$
R=B a Z^{b}
$$

where $R$ is the rainfall rate $(\mathrm{mm} / \mathrm{hr}$ ), B is the multiplicative bias, (see Landel et al. [1999] and Smith et al. [1996]), $a$ and $b$ are the default WSR-88D Z-R parameters with values of $a=0.017$ and $b=0.714$ for convective rainfall, and $Z$ is the radar reflectivity. This equation is usually expressed in its inverse form as $Z=300 R^{1.14}$ for standard convective rainfall.

One WSR-88 radar is used to obtain the rainfall data for each storm in this study. The area of coverage of the selected radars encircled the whole spatial and temporal 
distribution of the storms. A description of the main features of the radars used in this study is shown in Table 2.2. As an example of the display of the radar data used to generate the rainfall sequence, a plot of two different time periods is shown in Figure 2.8. These rainfall sequences portrayed a squall line that moved southeast during the Redbank Creek Storm of July 18-19, 1996.

Table 2.2 Summaryof WSR-88D radars used to obtain the rainfall data.

\begin{tabular}{ccccccc}
\hline \multirow{2}{*}{ Storm } & $\begin{array}{c}\text { NEXRAD } \\
\text { Station Name }\end{array}$ & $\begin{array}{c}\text { International } \\
\text { Call Sign }\end{array}$ & Elevation & $\begin{array}{c}\text { Antenna } \\
\text { Height }\end{array}$ & Latitude & Longitude \\
\hline \multirow{2}{*}{ Rapidan River } & Sterling (VA) & KLWX & $82.9 \mathrm{~m}$ & $25 \mathrm{~m}$ & $38^{\circ} 58^{\prime} 31^{\prime \prime} \mathrm{N}$ & $077^{\circ} 28^{\prime} 40^{\prime} \mathrm{W}$ \\
Rebank Creek & Pittsburgh (PA) & KPBZ & $361.3 \mathrm{~m}$ & $20 \mathrm{~m}$ & $40^{\circ} 31^{\prime} 54^{\prime \prime} \mathrm{N}$ & $080^{\circ} 13^{\prime} 05^{\prime \prime} \mathrm{W}$ \\
Buffalo Creek & Denver (CO) & KFTG & $1675.9 \mathrm{~m}$ & $30 \mathrm{~m}$ & $39^{\circ} 47^{\prime} 12^{\prime \prime} \mathrm{N}$ & $104^{\circ} 32^{\prime} 45^{\prime \prime} \mathrm{W}$ \\
Fort Collins & Cheyenne (WY) & KFTG & $1868.3 \mathrm{~m}$ & $15 \mathrm{~m}$ & $4^{\circ} 09^{\prime} 07^{\prime \prime} \mathrm{N}$ & $104^{\circ} 48^{\prime} 22^{\prime \prime} \mathrm{W}$ \\
Loveland Pass & Denver (CO) & KCYS & $1675.9 \mathrm{~m}$ & $30 \mathrm{~m}$ & $39^{\circ} 47^{\prime} 12^{\prime \prime} \mathrm{N}$ & $104^{\circ} 32^{\prime} 45^{\prime \prime} \mathrm{W}$ \\
& & & & & & \\
\hline
\end{tabular}


(a)

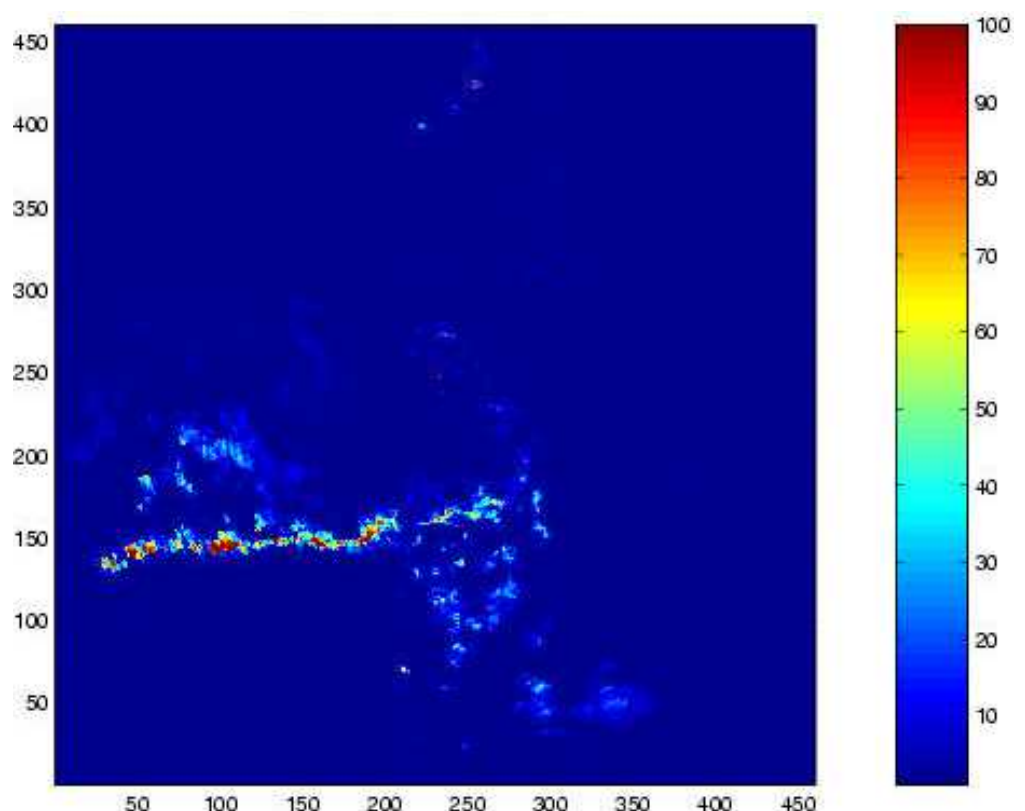

(b)

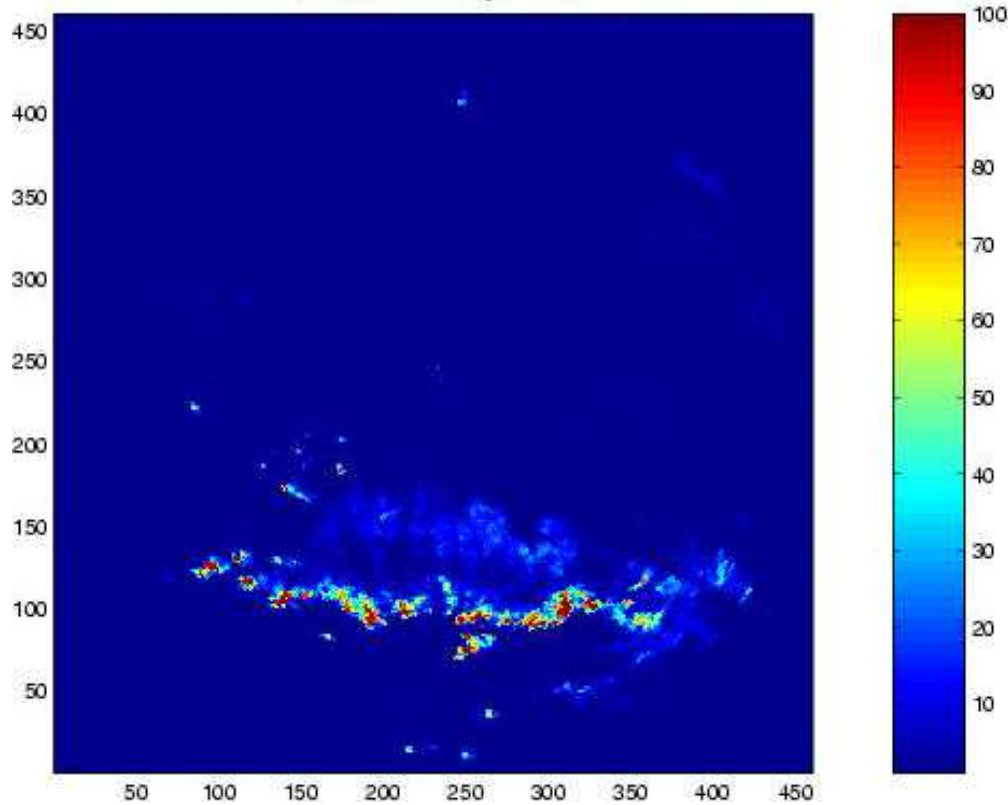

Figure 2.8 Rainfall sequence for the Redbank Creek storm of July 18-19, 1996. The rainfall sequence shows a squall line that moved southeast (a) 1734 UTC July 18, (b) 1949 UTC July 18. The scale bar represents rainfall in $\mathrm{mm} / \mathrm{hr}$. 
Radar Limitations. There have been different studies reporting either underestimation or overestimation of rainfall by the WSR-88D rainfall algorithm (see Smith et al. 1995 and Fulton 1999), especially in extreme rainfall events. The aim of the WSR-88D algorithm is to transform reflectivity factor measurements into rainfall accumulations and incorporate rain gauge data to improve the radar estimates. The rain gauge data is used to assess the overall under or overestimation of the radar for each storm. The multiplicative bias correction factor $B$ attempts to account for these radar estimation problems by adjusting the magnitude of the rainfall throughout the field. A detailed description of the operational WSR-88D rainfall estimation algorithm is presented in Fulton et al. 1998.

Different factors may be the cause of the underestimation of rainfall. Caracena et al. 1979 reported that radar underestimates rainfall for storms that produce extreme rainfall and are dominated by warm rain processes, since the highest reflectivity values occur in the lowest portion of the cloud. For example, an underestimation by a factor of 2 compared to the rain gauge accumulations was estimated for the total rainfall of the Fort Collins Storm Ogden et al. 2000. The distinctive cloud microphysics of extreme storms, the vertical structure of the storm, abnormal propagation of the radar beam, and radar calibration error were indicated as the main responsible features of the underestimation. A detailed study of radar-rainfall estimation errors for the Fort Collins storm can be found in Petersen et al. 1999]. Furthermore, there are other studies involving the performance of the WSR-88D rainfall estimates that involve the storms that are analyzed in this study. Baeck and Smith 1998 focused on assessing the utility of weather radar in the investigation of extreme rainfall storms. For this purpose, they analyzed 4 different storms, including the Rapidan River Storm. Multiplicative bias factors used to account for radar underestimation in the events studied here are presented below.

Other sources of error that may affect the radar data are ones that concern artifacts used to measure the reflectivity. Krajewski et al. 1996] and Harris et al. 1997. studied 
radar processing artifacts. These studies are addressed in more detail below. In this study, radar data noise (electrical, digital quantization, and sampling noise) tend to be averaged by applying a threshold of $1 \mathrm{~mm}$ to the rainfall estimated. This means that values with rainfall less than $1 \mathrm{~mm}$ will not be considered as rainfall.

Multiplicative Bias (B) Correction . Rainfall data was obtained from James A. Smith and Mary Lynn Baeck at Princeton University. They provided the multiplicative bias $(B)$ correction for four of the storms, but did not computed a bias correction for the Loveland Pass storm. A default $B$ value of 1.00 was used for this storm since there was no other information available regarding its bias correction parameter. A list of the $B$ values used for the various case studies is shown in Table 2.3.

\begin{tabular}{lc}
$\begin{array}{l}\text { Table } 2.3 \text { Multiplicative bias (B) cor- } \\
\text { rections used for the various case } \\
\text { studies. }\end{array}$ \\
\hline Storm & Multiplicative bias (B) \\
\hline Rapidan River & 2.70 \\
Redbank Creek & 2.00 \\
Buffalo Creek & 1.73 \\
Fort Collins & 1.90 \\
Loveland Pass & 1.00 \\
\hline
\end{tabular}

Effects of Radar Inaccuracies on Multiscaling Analysis The different multiplicative bias $(B)$ corrections provided by James A. Smith and Mary Lynn Baeck (see Table 2.3) are applied in order to provide realistic values in visualization of the rainfall fields. However, the value of $B$ has no bearing on the results of the multiscaling analysis since $B$ is a multiplicative constant and the analysis is based on using power law filters. 
On the other hand, radar data is subject to artifacts from which rainfall rate estimation is obtained. Radar measures reflectivity $(Z)$, which is approximately proportional to the electromagnetic energy scattered by rain drops in the direction of the radar antenna. Estimation of the radar rainfall reflectivity involves several steps in which radar sensor and the methods used for processing radar observations have significant effects on inferred statistics of rainfall. Krajewski et al. 1996 considered some of the quantitative effects of radar on several statistics computed from radar rainfall estimates. To this end, certain statistical parameters from radar rainfall estimates were compared using two different algorithms, a simple and a complex algorithm. They found that the effect of the radar rainfall estimation algorithm may be significant, and a much higher difference between algorithms was obtained from minute to hourly to daily accumulation fields. Krajewski et al. 1996 also suggested that a way to provide some insight into the difference of the statistics computed from different algorithms is through the statistical analysis of simulated rainfall fields. Further investigation is needed in regards to the accuracy of the inferred statistics.

Please note that some multiscaling terminology will need to be used in this paragraph. The term $\beta$ is the power spectral exponent, $K(q)$ is known as the moment scaling function, and $q$ refers to the moment. The reader is referred to Chapter 3 where a detailed explanation of the multiscaling analysis is provided. In addition, Harris et al. 1997] studied the effects of noise and instrumental artifacts of the electronic rain gauges used for the analysis of the Southern Alps of New Zealand Storm of November 5-9, 1994 on the multiscaling analysis results. Emphasis was placed on quantization noise, electrical noise, and gradient transformations. It was found that $K(q)$ and $\beta$ were robust to the digital quantization effect although visible changes were obtained in $K(q)$ for very small $q$ values. Electrical noise affected a larger range of $q$ in $K(q)$ in comparison to quantization. However, $K(q)$ and $\beta$ were also very robust to small amounts of noise. In contrast, gradient transformation, which is the second step carried out in the multiscaling analysis, did show strong additive noises 
at smaller amounts of noise and quantization. Harris et al. 1997 also compared the multiscaling analysis results obtained from two different sources measuring the same rainfall event: a high resolution rain gauge and radar. More intermittent fields were reported from radar data than gauge data. These results indicated that in order to arrive at any general conclusions, the significance of taking into account differing measurement techniques before comparing results from different instruments should be considered. Further investigation is needed to better quantify the effects of radar inaccuracies on multiscaling statistics.

\subsubsection{Digital Elevation Data}

Data to represent the topography of the locations of interest was retrieved from United States Geological Survey (USGS) webpage and is free, downloadable data available from http://edcdaac.usgs.gov/gtopo30/gtopo30.html. GTOPO30 is a global digital elevation model (DEM) with a horizontal grid spacing of 30 arc seconds (approximately $1 \mathrm{~km}$ ). GTOPO30 was derived from several raster and vector sources of topographic information. This model is divided into tiles which can be selected from Figure 2.9. Detailed information on the characteristics of GTOPO30 can be found on the USGS webpage, which includes the data distribution format, the data sources, production methods, accuracy, and hints for users.

\subsubsection{Individual Rawinsonde Soundings Data}

Individual rawinsonde soundings are used to depict the storm environment of the events studied. The terms balloon sounding, sounding, and rawinsonde are used interchangeably in the following paragraphs. They are believed to well represent the relation between static stability and the occurrence of measurable precipitation (see Peppler and Lamb 1989] for references). The atmospheric sounding data used in this study was acquired from the Department of Atmospheric Science at the University 


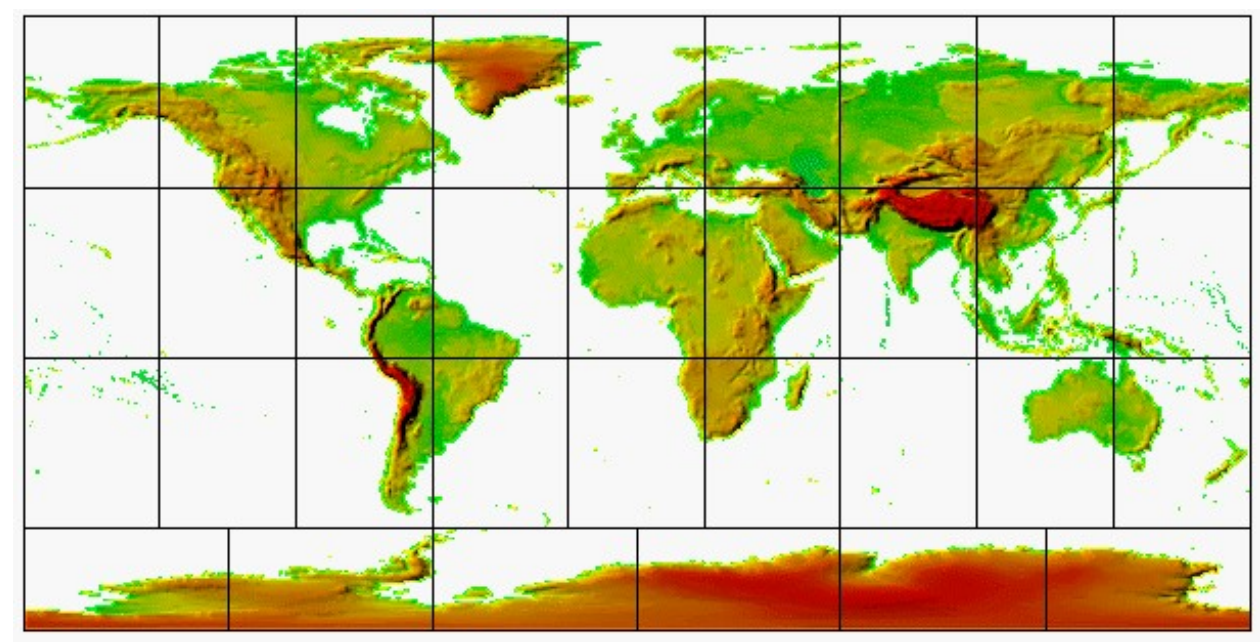

Figure 2.9 Digital elevation Model data. World map from USGS webpage where data for the DEM representation was retrieved.

of Wyoming $(D A S U W)$ webpage (see Appendices B - F).

A rawinsonde is an instrument carried into the upper atmosphere by a balloon (see Figure 2.10). Rawinsondes carry temperature, pressure and relative humidity sensors and they report up to six variables: pressure, geopotential height, temperature, dewpoint depression, wind direction and wind speed. Measurements are used in weather forecasting, and are of increasing interest to those studying climate change.

A rawinsonde provides information to plot the vertical distribution of the temperature, dewpoint, wind speed, and wind direction of the atmosphere from where it was launched. Therefore, an atmospheric sounding may also be defined as a "picture" of the atmosphere at a certain location and time. This information allows the estimation of convective indices, which may explain specific features of the analyzed atmosphere. The rawinsonde data used for this study were individual, twice-daily (0000 and 1200 UTC) soundings made at U.S. stations. Further information on those stations appear later in this section. 
(a)

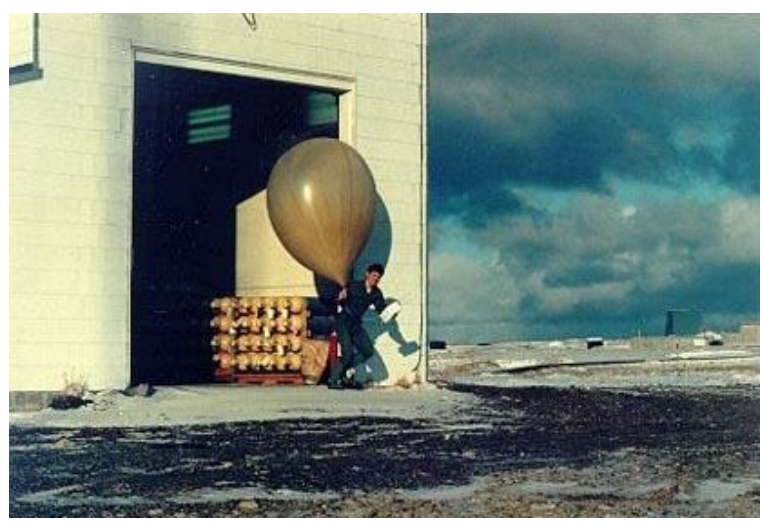

(b)

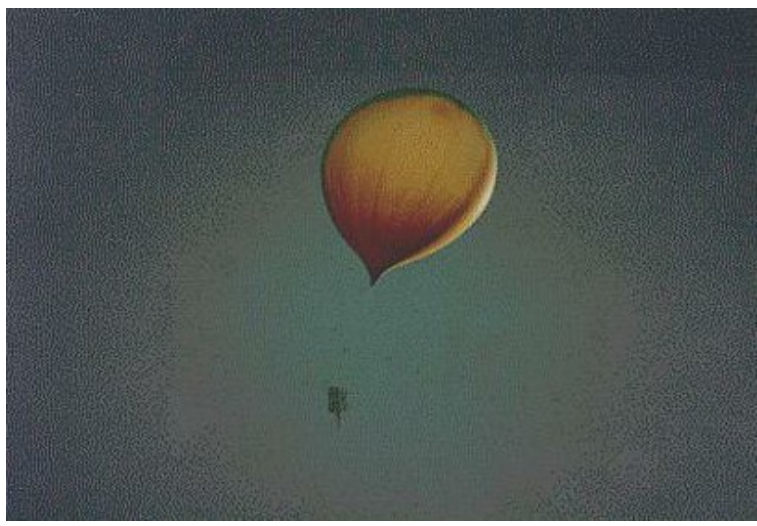

Figure 2.10 (a) Rawinsonde balloon launch and (b) flight (From Shemya Air Force Base webpage). 
Sounding Limitations. When launching a rawinsonde balloon to obtain the sounding data, specific conditions may affect the information collected. The strength of the winds aloft are a factor that influence the movement of the balloon through the atmosphere, so with strong winds the information may not be representative because the balloon is blown far away from the site of the launch. Also, one could consider that the data reported from a sounding is subject to the limitation inherent on the instruments and artifacts used to measure the different parameters. Furthermore, a sounding is the representation of the atmosphere for a certain location and time. The spatial extent of a storm may cover a large area, so that in order to better depict the storm environment of the entire system several sounding stations located near or in the area of interest may be taken into account. The combination of various soundings may then improve the representation of the storm environment. It is worthy to mention that the location of the sounding stations should be over the effective area of the storm. A station location far away from the storm will not provide any valuable information.

Sounding location. In order to better understand how well the sounding may represent the storm environment, it is important to indicate where the different soundings are located. A sounding represents a fixed point in space for a certain time, while the storm is passing by or close to their locations. Thus, the spatial and temporal evolution of the events depicted by the surface rainfall centroid can be used along with the literature on the meteorological features to better interpret the stability indices. More than one sounding station may be used for the representation of one storm, although this was not possible to do in this study due to the large separation distance of the surrounding stations with the location of the storms. A list with the sounding stations used for this study, as well as the possible surrounding stations, is detailed in Table 2.4. Only the stations marked with an asterisk $\left(^{*}\right)$ were not considered because they were located too far from the storm or did not report data for specific time 
period.

Table 2.4 Summary of the possible sounding stations. $\left(^{*}\right)$ indicates the station that was used in this study.

\begin{tabular}{ccccc}
\hline Station & Station & & & \\
Name & Initials & Elevation & Latitude & Longitude \\
\hline Sterling, Wash Dulles (VA) $\left(^{*}\right)$ & IAD & $0085 \mathrm{~m}$ & 38.98 & -77.47 \\
Pittsburgh, Moon Township (PA) $\left(^{*}\right)$ & PIT & $0360 \mathrm{~m}$ & 40.53 & -80.23 \\
Phillips AFB, Aberdeen (MD) & APG & $0005 \mathrm{~m}$ & 39.47 & -76.07 \\
Wilmington (OH) & ILN & $0317 \mathrm{~m}$ & 39.42 & -83.82 \\
Buffalo, Grtr Arpt (NY) & BUF & $0218 \mathrm{~m}$ & 42.93 & -78.73 \\
Denver, Stapleton Arpt (CO) $(*)$ & DNR & $1611 \mathrm{~m}$ & 39.77 & -104.88 \\
Fort Carson, Army(CO) & FCS & $1788 \mathrm{~m}$ & 38.70 & -104.77 \\
& & & & \\
\hline
\end{tabular}

\subsubsection{Sounding Station Parameters and Indices: Definition and Interpretation.}

Atmospheric soundings indices are used to study the characteristics of the storms. Convective indices are used in this study, which means that only the parameters derived from the data contained in a single rawinsonde ascent are applied. Not all the existing indices reported in the literature to estimate tropospheric stability are used. However, an effort was made to include the most significant indices based on previous studies (see Peppler and Lamb [1989], Pontrelli et al. [1999], and Landel] et al. 1999) and on the basis of their traditional use. Table 2.5 shows and explains the indices used in this work to analyze the storm environment of the various case studies.

These parameters describe the stability of the atmosphere and/or indicate the likelihood of convection of the storm environment. Several factors may lead to an increase in the instability of the atmosphere such as cold air aloft, warm air at lower levels, and an abundance of moisture. Moreover, the combination of these factors with the turning of the winds with height may influence the severity of thunderstorms. All these variables are intended to be included in the stability indices depicting the storm 
environment. To this end, temperature, dew point temperature, winds, and pressure at different levels are considered. This data is obtained by the atmospheric sounding and provides the information needed to estimate the stability indices. The reader is refer to Appendix A for a more detail explanation in regards to each of the stability indices used throughout this research.

In addition, this work focuses on storms that occur in mountainous regions. In these storms, the orography of the region may affect the interpretation of commom indices because orography can provide energy to produce thunderstorms and break the inversion cap. In mountainous regions, lifting of the air mass is more influenced by mechanical processes than heating processes, which also affects the estimation of the different stability indices. Systematic local or regional effects (e.g., orographic) may be significant in one region and may not be in another (non-orographic region). Thus, stability indices should be more of an experimental or investigative tool than a routine one, unless wide correlation studies selected an index as being significant for the extended general application and critical values of the index were determined for various weather conditions. 
Table 2.5 Summary of Sounding Indices used in this study.

\begin{tabular}{|c|c|c|}
\hline Indice & Type & Interpretation \\
\hline $\begin{array}{c}\text { LI } \\
\text { (Lifted Index) }\end{array}$ & Stability & $\begin{array}{l}\text { Positive values } \\
\text { reflect stable conditons } \\
\text { Negative values } \\
\text { reflect unstable condition }\end{array}$ \\
\hline $\begin{array}{c}\text { SWEAT } \\
\text { (Severe Weather Threat Index) }\end{array}$ & $\begin{array}{l}\text { Potential for } \\
\text { severe weather }\end{array}$ & $\begin{array}{c}\text { Higher values } \\
\text { reflect greater } \\
\text { potential for severe weather }\end{array}$ \\
\hline KINX index & $\begin{array}{l}\text { Probability } \\
\text { of thunderstorms }\end{array}$ & $\begin{array}{l}\text { Higher values reflect } \\
\text { greater probability of thunderstorms }\end{array}$ \\
\hline TOTL (Total Totals index) & $\begin{array}{l}\text { Probability } \\
\text { of thunderstorms }\end{array}$ & $\begin{array}{l}\text { Higher values reflect } \\
\text { greater probability of thunderstorms }\end{array}$ \\
\hline $\begin{array}{c}\text { LFCT } \\
\text { (Level of Free Convection) }\end{array}$ & $\begin{array}{l}\text { Convective } \\
\text { Potential }\end{array}$ & $\begin{array}{l}\text { Higher pressure values } \\
\text { (lower height) reflect } \\
\text { greater potential of convection }\end{array}$ \\
\hline $\begin{array}{c}\text { LCL } \\
\text { (Lifted Condensation Level) }\end{array}$ & $\begin{array}{l}\text { Height at which } \\
\text { clouds form }\end{array}$ & $\begin{array}{l}\text { Higher pressure } \\
\text { means lower height }\end{array}$ \\
\hline $\begin{array}{c}\text { CAPE } \\
\text { (Convective Avaliable } \\
\text { Potential Energy) }\end{array}$ & Stability & $\begin{array}{l}\text { Higher values reflect } \\
\text { greater unstable atmosphere }\end{array}$ \\
\hline $\begin{array}{c}\text { CINS } \\
\text { (Convective Inhibition) }\end{array}$ & Stability & $\begin{array}{c}\text { Low and high values } \\
\text { indicate no thunderstorms } \\
\text { development likely } \\
\text { Middle values indicate } \\
\text { thunderstorm can form }\end{array}$ \\
\hline $\begin{array}{c}\text { BRCH } \\
\text { (Bulk Richardson number) }\end{array}$ & $\begin{array}{l}\text { Probability } \\
\text { of thunderstorms }\end{array}$ & $\begin{array}{l}\text { Higher values reflect } \\
\text { greater probability } \\
\text { of thunderstorms }\end{array}$ \\
\hline $\begin{array}{c}\text { PWAT } \\
\text { (Precipitable Water) }\end{array}$ & $\begin{array}{l}\text { amount of } \\
\text { water vapor }\end{array}$ & $\begin{array}{l}\text { Higher values reflect } \\
\text { greater potential for heavy rain }\end{array}$ \\
\hline
\end{tabular}




\section{Chapter 3}

\section{Multiscale Statistical Analysis}

The main objective of this chapter is to explain the method used in this study, to introduce the reader to multiscaling terminology, and give an overview of the different steps taken throughout the analysis. These steps include the spatial Fourier spectral analysis for scaling fields, the structure function analysis, and the scaling moment analysis.

\subsection{Overview}

In the last fifteen years, multiscale statistical analysis methods have been used extensively to study diverse types of geophysical processes. Basically, this analysis characterizes the multifractal properties of a field by several different types of scaling exponents. Before proceeding with the multiscale analysis, it is beneficial to first provide some insight in the specific terminology and concepts involving this statistical analysis in order to better understand further steps.

Fractals, Multifractals and Multiscaling. The term fractal itself emerged with the work of Benoit Mandelbrot in the 1960s and 1970s [Mandelbrot, 1974], and its definition is far from being trivial, depending on a formal description of dimension. The 
information from several chapters of an advanced analysis book would be necessary in order to define the notion of dimension. This notion is not unique and for a given set has various definitions that may lead to different numerical results. When these results differ, the set is called fractal. In the words of Benoit Mandelbrot "a fractal is by definition a set for which the Hausdorff-Besicovitch dimension strictly exceeds the topological dimension". This subject itself would require an entire chapter and is beyond the scope of this study. A brief overview is given below, although more detail can be found in Mandelbrot [1974], Mandelbrot [1977], and Turcotte 1997.

This idea of fractal was proposed as a way to deal with problems of scale in the real world. Fractals can be thought of as objects or patterns that are characterized by having non-integer dimensions (fractional dimension), self-similarity, and scale invariance. The topological dimension $(D)$ of a point is, as one would expect, zero, a line would have a $D=1$, a plane would have a $D=2$, and so on. However, when considering a set of disconnected lines, like a string of morse code or a jagged, convoluted line tracing a rough coastline, they are not just a series of points $(D=$ $0)$, but neither does it make a continuous line $(D=1)$. Therefore, the coastline or landscape mosaic challenge the limitations of one dimensional characterization, although they do not fully fill the higher dimension space in which they are embedded. More detailed explanation can be found in Turcotte [1997, where some examples of objects with fractal dimension are presented (e.g. the Koch curve, the Cantor set, or the Sierpinski triangle). On the other hand, the idea of self-similarity means that if we shrink or enlarge a fractal pattern, its appearance should remain unchanged. A correlate of the inherent self-similarity of fractals is the idea of scale-dependence. The classic illustrative concept here is a coast line, considered as a fractal. This coastline is scale-dependent, which means that its length will depend on the length of the ruler one would use to measure it.

Multifractals are mathematical generalizations of fractals and can be considered as measures (distributions) displaying a spectrum of fractal dimensions rather than 
(a)

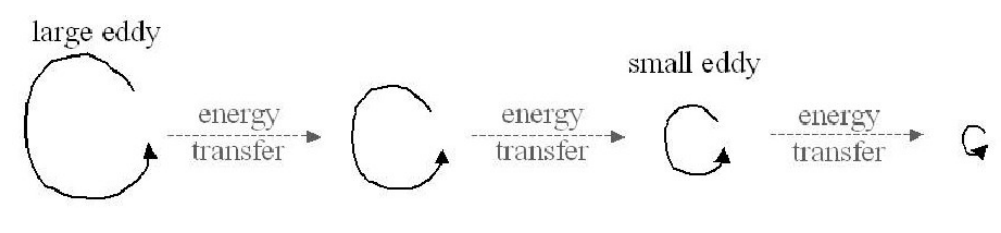

(b)

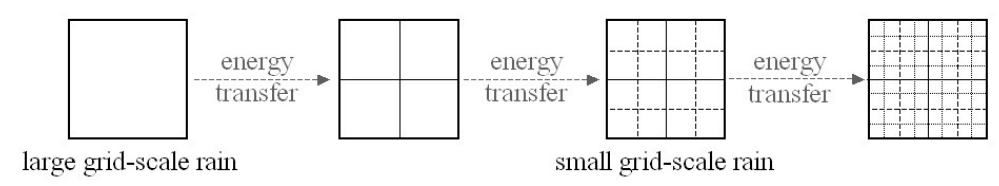

Figure 3.1 (a) Energy transfer from large eddie to small eddie. (b) Energy transfer from large scale to small scale in a rainfall grid.

being point sets. The simplest way to create a multifractal is by a multiplicative cascade. This theory relied on the basic idea that the energy is redistributed from larger to smaller scales via a splitting mechanism involving random multiplicative factors known as cascade generators as shown in Figure 3.1 (a). The scaling structure nature of these types of models has extended its applications to a wide variety of natural phenomena including rainfall. These cascade models are particularly useful in reproducing the higher-order and multi-point statistics of observed rainfall. Figure 3.1 (b) shows the energy transfer from a large to a small grid-scale for a rainfall field.

Both frameworks, multifractal and multiscaling, are theoretically related (see Hasley et al. [1986]), yet they show differences with regards to analysis techniques. Multifractal and multiscaling terms are often used interchangeably, however a multifractal description refers to a hierarchy of generalized dimensions or codimensions of singularities, while multiscaling involves more specifically the scaling of statistical moments and this formalism can be related to the multifractal description. Multiscaling analysis is used in this work and the reader is referred to Harris 1998 for an overview of a historical perspective on multiscaling descriptors. An insight on the mathematical framework of multiscaling statistics can be found in e.g., Schertzer and Lovejoy 1987 and Gupta and Waymire 1993. 
Self-similar Cascades and Reasons for Adopting this Framework. After the introduction of multifractal formalism, multiplicative cascade models are found inside the theory of random cascades. This theory has been applied in numerous research studies involving the hypothesis of scale invariance to understand the structure of spatial rainfall. Both continuous and discrete forms of the random cascade theory can be used for this purpose, yet in this study a discrete multiplicative cascade form is assumed for the spatial rainfall fields. A more detailed explanation of the differences between continuous and discrete, as well as the theory of discrete random cascades can be found in Over and Gupta 1996. The principal reason to adopt this framework is its ability to characterize inhomogeneity ("intermittency") at different scales and to preserve the spatial structure of the cascades. Furthermore, this framework allows the description of the multiscale structure of a field by three parameters, with which the variability of the field can be represented over a wide range of scales. Those three statistical parameters are linked to physical characteristics observed in a wide range of geophysical phenomena (e.g. rainfall) such as long-range correlations, smoothness, intermittency, and extreme fluctuation (spikiness). Therefore, due to their simplicity of construction and rich statistical properties, and their ability to reproduce the variability of observed rainfall, cascades are practical procedures for downscaling purposes.

The parameter quantifying the smoothness establishes the degree of spatial integration to transform an unsmoothed cascade to a smoother field depicting the same statistical structure of the observed rainfall. The other two statistical parameters characterize the multiplicative cascade one would use in a downscaling procedure. These parameters describe the distributions of the random multiplicative weights used in a cascade construction process. The process involving the estimation of the parameters, as well as their interpretation, is explained in more detail throughout this chapter.

One-kilometer horizontal gridded rainfall data from WSR-88D radars is used in 
this study to provide 2-D spatial rainfall fields. Those fields are seen as smoothed or spatially averaged self-similar multiplicative cascades. Cascades in 2-D are simple constructs whereby one takes a unit area of the rainfall field, divides the area into four quarters of equal rainfall, and multiplies each of the four quarters of rainfall values by a random multiplicative weight. Subsequently, each quarter is further divided in four quarters and the rainfall is multiplied again by random weights, and so on. Figure 3.2 shows the process described above for a rainfall field. The randomly chosen weights (e.g. $w_{i}$ and $w_{j}$ ) are independently and identically distributed (iid) random variables from a specified distribution. The log-stable model used to generate $w_{i}$ and $w_{j}$ has weights distributed as,

$$
W=e^{-\sigma S_{\alpha}-c \sigma^{\alpha}}
$$

where $S_{\alpha}=S_{\alpha}(1,1,0)$ is a stable variable (Samorodnitsky and Taqqu [1994) and $c=$ $-(\cos (\pi * \alpha / 2))^{-1}$. The variable parameters, $\alpha$ and $\sigma$, are the shape and scale parameters of the distribution, respectively. They are constrained to $0<\alpha \leq 2$ and $\sigma>0$. If $\alpha=2$, it corresponds to a Gaussian distribution.

Analysis Framework. The analysis framework of this study focuses on multiscale characterization of 2-D rainfall fields. As a premise, a field may exhibit multiscaling when its Fourier power spectrum has the power-law form,

$$
P(k) \sim k^{-\beta}
$$

over a finite range of scales. This fact indicates the presence of scaling or scaleinvariance. Moreover, a field (e.g. a rainfall field) is said to exhibit multiscaling if its $\mathrm{q}^{\text {th }}$ order moment of its fractionally differentiated field $\varphi_{r}$ at scale $\mathrm{r}$ behaves as,

$$
\left\langle\left|\varphi_{r}(x, y)\right|^{q}\right\rangle=r^{-K(q)}
$$

where $\langle\ldots\rangle$ denotes the average over all pixels of scale $r$ in an image. This equation gives the multiscale moments of any field $\varphi_{r}$ computed for a range of averaging scales 


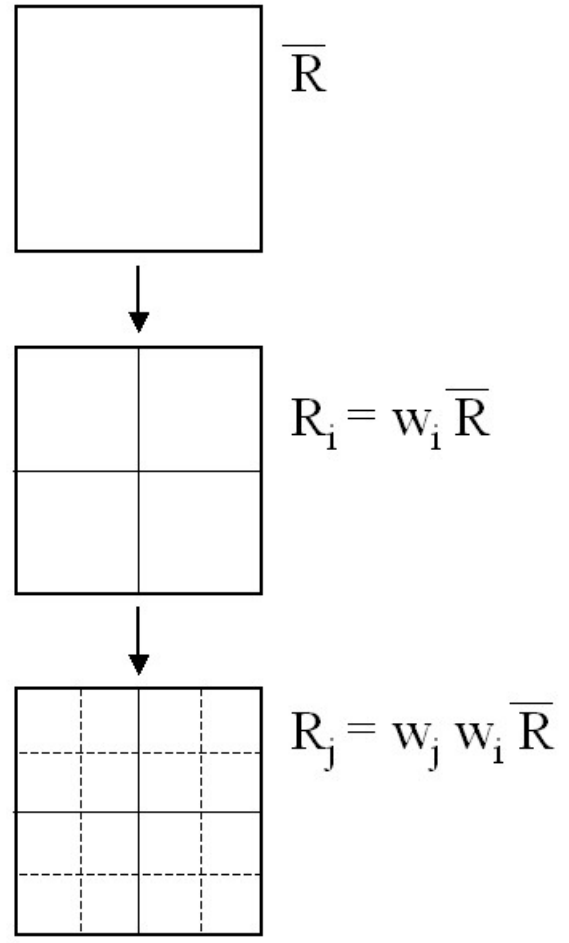

Figure 3.2 2-D Cascade Model applied for a rainfall field. 
$r$ (higher $r$ implies coarser scale), and provides information about the intermittency of the field. There are references involving the analysis methods used in this work which focus mainly on parameter estimation and analysis results such as Davis et al. [1994, Harris et al. 1996, 1997, 2001], and Nykanen and Harris 2003], among others.

\subsection{Spatial Fourier Spectral Analysis}

As a first step in the scaling analysis for the characterization of a field, a Fourier spectral analysis is carried out. This analysis allows the study of the variability of any field over a wide range of scales. A scaling behavior of the power spectrum means that no scale is characteristic of this field, therefore as mentioned above, a multiscaling field must obey a power law form over a certain range of scales as shown in equation 3.2 .

Procedure. The power spectrum for a 2-D field is computed using a 2-D fast Fourier transform (FFT) (e.g., Press et al. [1992]). In essence, this algorithm performs the FFT of the original 2-D field $R(x, y)$ to obtain the Fourier transform $\tilde{R}\left(k_{x}, k_{y}\right)$, which is then multiplied by its complex conjugate. The result is the 2-D power spectrum $P\left(k_{x}, k_{y}\right)$, where $k_{x}$ and $k_{y}$ are the wavenumber components. In dimensions higher than one, $P$ is averaged over all angles about the wavenumbers $k_{x}=k_{y}=0$ in order to facilitate visualization and evaluation. This process yields $P(k)$, also known as the isotropic power spectrum with $k=\sqrt{{k_{x}}^{2}+k_{y}^{2}}$. The concept of the isotropic power spectrum means that the angular averaging about any $k$ direction integrates anisotropy, which facilitates graphical visualization.

To verify the presence of scaling, a log-log linear relationship over a finite range of scales is portrayed in the Fourier power spectra. The power spectral exponent, $\beta$, is the slope of the log-log linear regression over a scaling range (e.g. $2 \mathrm{~km}$ to $\sim 20$ $\mathrm{km}$ ) as shown in Figure 3.3 . This range was determined visually and was intended to 
range approximately between the scale of interest for downscaling puposes.

Interpretation. The spectral slope, $\beta$, is an indicator of the organization of the precipitation fields (see Davis et al. [1996], Harris et al. [1996] for more details). A steeper spectral slope with a high $\beta$ indicates a more rapid decrease in the energy fluctuations at smaller scales (high wavenumbers) or a more organized field. This means that the field has a more correlated structure (e.g., Harris et al. [1996] and Nykanen and Harris 2003). In this case, the contribution to the signal from lowfrequency components is more significant when compared to the contribution from the high-frequency components. On the other hand, a low $\beta$ or low spectral slope has more energy in fluctuations at small scales with a predominant contribution to the signal from high-frequency components. A low $\beta$ indicates a less organized field. An extreme case with a low $\beta$ would be a random uncorrelated (i.e., white noise) field which is unsmooth, disorganized, and has a value of $\beta=0$ enclosing equal distribution of energy fluctuations at all scales. Furthermore, it is known that the power spectral exponent, $\beta$, can be linked to certain rainfall characteristics. High $\beta$ would express the existence of individual rain cells and would be linked to convective rainfall. By contrast, lower $\beta$ would show less organization within the scaling range and would be representative of stratiform rainfall. Further explanations can be found in Harris [1998 and Purdy et al. 2001.

The value of $\beta$ is needed for the next steps of the multiscaling analysis. This value will establish whether or not it is necessary for meaningful multiscale analysis to apply a power law filter or a structure function analysis as described below. It is known that self-similar cascades can not yield fields with $\beta$ greater than the embedding dimension of the field Menabde et al., 1997. Rainfall fields usually have values of $\beta>D$. This is confirmed here where for a $D=2, \beta$ was found to be greater than 2 for all the storms analyzed. In those cases, the field does not exhibit scaling moments and must be seen as a smoothed self-similar cascade. Hence, it is required to study 

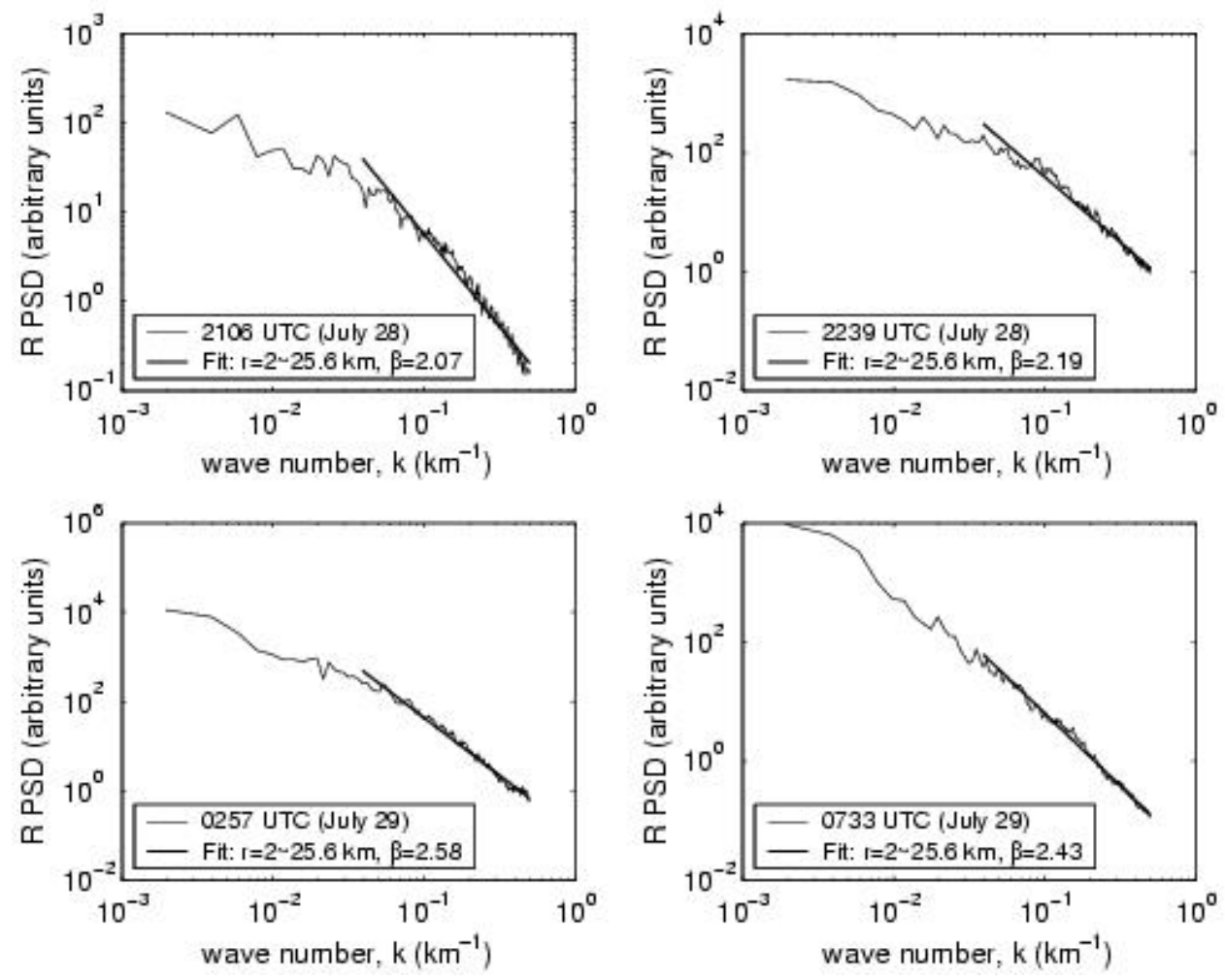

Figure 3.3 Fourier power spectra for the Fort Collins storms of July 28-29, 1997 at 2106 UTC and 2239 UTC during July 28, and 0257 UTC and 0733 UTC during July 29. The scaling range used to compute $\beta$ was $2 \sim 25.6 \mathrm{~km}$ for all storms except for the Rapidan River case (R PSD means Rainfall Power Spectra for a 2D radar image). 
a related field with $\beta<D$ in order for the field to be multiscaling. The method used to obtain a field that preserves the scaling nature of the power spectrum is known as the structure function analysis. This analysis is performed by differentiating the field (with respect to different lags in space) and analyzing these absolute gradients to eliminate the smoothing of the self-similar cascade. A structure function analysis has been applied in this study since the application of a power law filter would require a more intricate process. There are several studies showing evidence of scaling power spectra for rainfall fields in both space and time, and the reader is referred to Harris et al. [1996], Lovejoy and Schertzer 1995a, Menabde et al. [1997], and de Lima and Grasman 1999 for further explanations.

\subsection{Structure Function Analysis}

Once the value of the power spectral exponent is obtained, the next step in the multiscale analysis is the structure function analysis, which yields the parameter that determines the degree of fractional differentiation needed in the field. This analysis is correspondent to fractional differentiation. In essence, it is similar to the technique used to remove the non-stationarity $(\beta>1)$ in a field to obtain a stationary field $(\beta<1)$ in a time series. Structure function analysis is performed when the value of $\beta>2$ (since $D=2$ ), which is the case in this study. If $\beta \leq 2$, one would not carry out this step since the field can be seen as an unsmoothed or pure multiplicative cascade. This analysis computes absolute fluctuations of the field to obtain the parameter $H$, known as the Hurst exponent. $H$ is used to fractionally differentiate the rainfall field for multiscaling analysis.

Procedure. The first step to carry out in this analysis is the calculation of the generalized structure function. In this study, focus is placed on the first-order $(q=1)$ generalized structure function, where different values of $q$ would emphasize extreme 

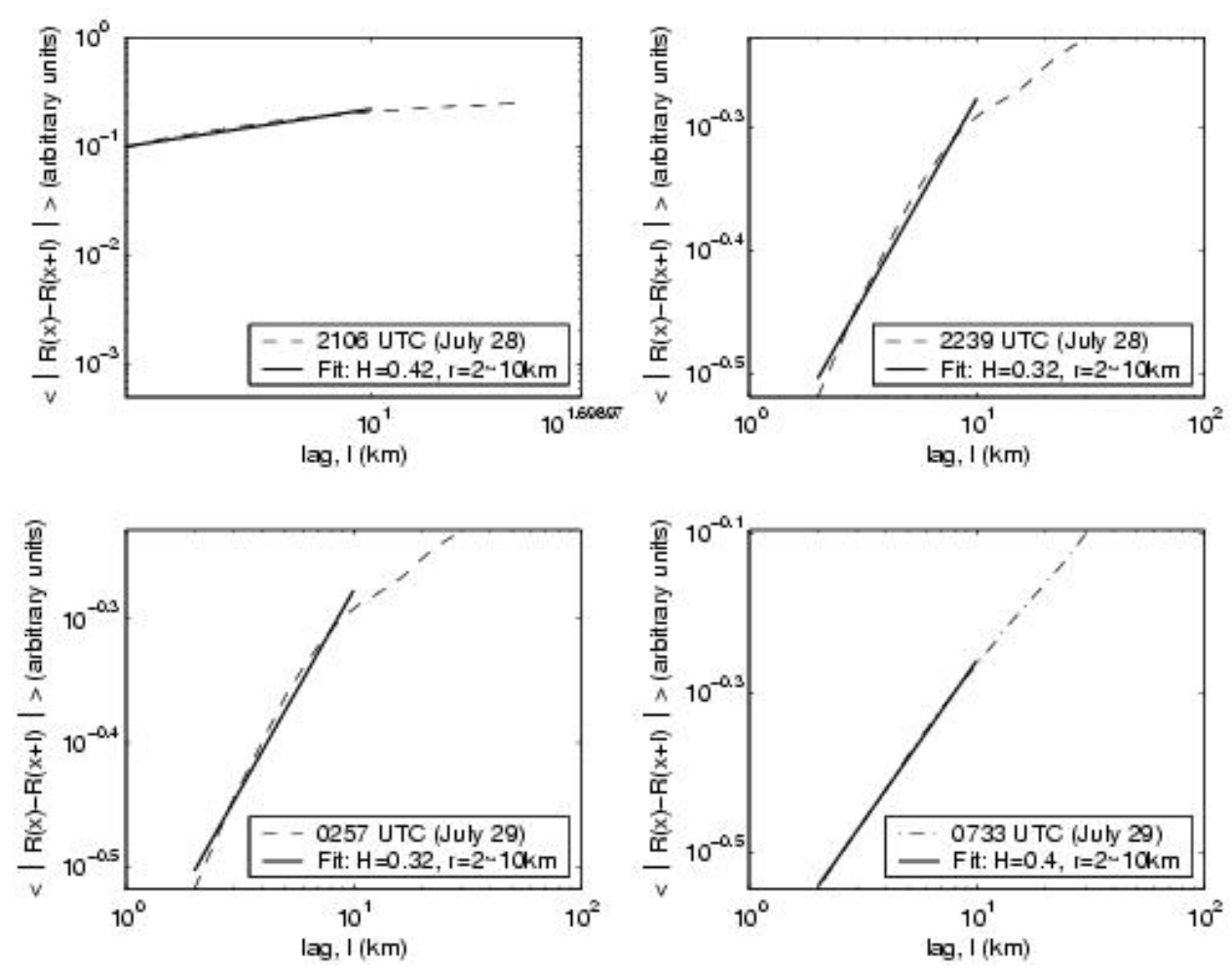

Figure 3.4 First-order $(q=1)$ generalized structure function for the Fort Collins storms of 28-29 July, 1997 at 2106 UTC and 2239 UTC during July 28, and 0257 UTC and 0733 UTC during July 29. The scaling range used to compute $H$ was $2 \sim 10 \mathrm{~km}$ for all storms except for the Rapidan River case.

(high $q$ ) or small $(0<q<1)$ fluctuations (a more detailed explanation can be found in Harris et al. [2001]). The first-order $(q=1)$ generalized structure function is defined as,

$$
S_{l}\left(l_{x}, l_{y}\right)=<\left|R\left(x+l_{x}, y+l_{y}\right)-R(x, y)\right|>
$$

where $\mathrm{R}$ is the field to be analyzed, $<\ldots>$ indicates the average over the nonzero pixels in the data obtained from the radar image, and $x$ and $y$ are the spatial coordinates that denote the directions of the lags $l_{x}$ and $l_{y}$, respectively. The isotropic structure function is computed by averaging $S_{l}\left(l_{x}, l_{y}\right)$ over all angles $l_{x}=l_{y}=0$, and the lag $l=\sqrt{l_{x}^{2}+l_{y}^{2}}$.

The second step refers to the method used to compute the $H$ value in order to 
test for scaling. A log-log linear regression is performed to do so, and scaling exists when the generalized structure function obeys the power law form,

$$
S_{l}(l) \sim l^{H}
$$

where $H$ is found in Figure 3.4 by a log-log liner regression over a finite scaling range (e.g. 2 to $\sim 10 \mathrm{~km})$.

Interpretation. The Hurst exponent, $H$, is also (like $\beta$ ) an indicator of the organization of the precipitation field. Higher $H$ values indicate a more organized field for which $H$ points out the degree of fractional differentiation of the field. In order to better understand the process that accounts for the structure function analysis, one may apply equation 3.5 for different fields where as a general rule $S_{l}(l)$ increases with $l$. This relationship is an indicator of the correlation structure of the field, thus for a random uncorrelated (i.e., white noise) field which is unsmooth and disorganized, one would see that an increasing lag has little effect on $S_{l}(l)$. This field would not exhibit scaling in the first-order $(q=1)$ generalized structure function. In case a field shows that the increments of $S_{l}(l)$ are proportional to the increments in the lag, points which are close to each other are likely to be similar in magnitude, yet the larger the lag the bigger the difference. This type of field would follow equation 3.5, and exhibit scaling in the first-order $(q=1)$ generalized structure function. The slopes in Figure 3.4 would be steeper (higher $H$ ) indicating a more correlated or organized field.

Once $H$ is obtained, one can apply this parameter to fractionally differentiate the original field. This would allow the computation of the cascade parameters in the moment-scale analysis in the next section. However, in a downscaling procedure, $H$ would be used as the parameter indicating the degree of smoothing (fractional integration) of the field. Schertzer and Lovejoy 1987] and Davis et al. [1996 pointed out that both fractional differentiation and integration are most easily carried out 
in Fourier space. Therefore, if $\tilde{R}(k)$ is the Fourier transform of the (real valued) generic field, R, then the inverse Fourier transform of $\tilde{R}(k)|k|^{H}, H>0$, corresponds to fractional differentiation, while the inverse Fourier transform of $\tilde{R}(k)|k|^{-H}, H>0$ corresponds to fractional integration.

\subsection{Moment-Scale Analysis}

Moment-scale analysis is the final step in the multiscale statistical analysis and yields the remaining two parameters characterizing the field. This analysis is carried out by computing standard statistical moments of the fractionally differentiated field for multiple scales. As mentioned above, it provides the cascade parameters that one would apply for a downscaling scheme.

Procedure. The fractionally differentiated field is referred to as $\varphi$ in order to distinguish it from the original rainfall field, $R$,

$$
\varphi(x) \sim \delta^{H} R(x) / \delta x^{H}
$$

The multiscale moments of any field $\varphi$ are computed for a range of averaging scales, $r$ (higher $r$ implies coarser scale),

$$
M_{q}(r)=<\left|\varphi_{r}(x, y)\right|^{q}>
$$

where $\varphi_{r}$ represents fractionally differentiated field values at scale $r, q$ is the order of the moment, and $\langle\ldots\rangle$ denotes the average over all the pixels of scale $r$ in an image. This procedure is performed for certain moments (e.g., $q=0.5$ or $q=4$ ) starting with the image from the original field (highest) resolution. The field is then degraded by successive spatial averaging of nearest neighbors which increases the scale by a factor of two at each step. Scaling moments are estimated by a log-log linear regression over a finite range of scales as shown in Figure 3.5. The scaling moments follow the power 

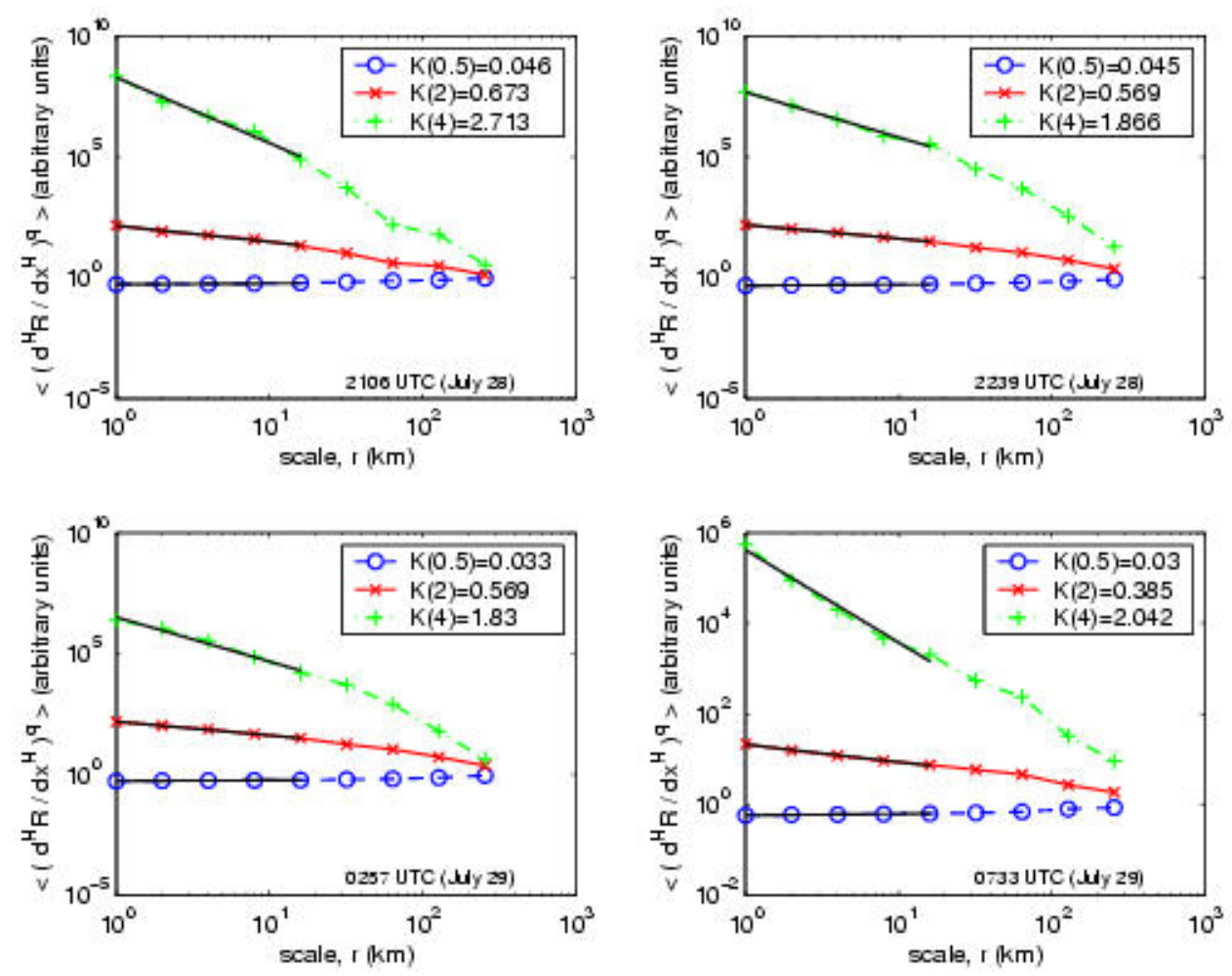

Figure 3.5 Moment scaling for the Fort Collins storms of July 28-29, 1997 for the fractionally differentiated 2-D rainfall fields for $q$ (moment) value of $q=0.5$ (blue line), $q=2.0$ (red line), and $q=4.0$ (green line) at 2106 UTC and 2239 UTC during July 28, and 0257 UTC and 0733 UTC during July 29.

law form,

$$
M_{q}(r) \sim r^{K(q)}
$$

where $K(q)$ is the moment scaling exponent function and corresponds to the slope of the log-log linear regression for each computed moment in Figure 3.5. If no existence of scaling was present, one would not consider the field multiscaling. It is important to note that just values of $q$ ranging from $q=0$ to $q=3 \sim 4$ are considered, since there is an upper limit value for $q$ above which $K(q)$ becomes linear Harris et al. [1996]). In Figure 3.6 the entire $K(q)$ curve is depicted for this range of moments $(0 \leq q \leq 3)$. $K(0)=0$ since the zeroth moment for a scale series is the sum of a binary sequence, implying that all values are nonzero. Simultaneously, $K(1)=0$ due 
to the fact that the unconditional mean of the entire field is scale independent.

Theoretically, the entire $K(q)$ curve is necessary to completely characterize the moment scaling properties of the field. In principal, $K(q)$ is an unknown function that involves an infinite number of parameters. However, one would require a closed form for $K(q)$ in order to fully parameterize the field. Different analytical forms of the function $K(q)$ can be found in Gupta and Waymire 1993, where a description of selfsimilar cascades and the theory of branching processes are provided. The self-similar model is defined by the distribution of the weights (see Figure 3.2 and related text). In this study, the cascade model adopted has log-stable distributed weights yielding what is also referred to as universal multifractals (e.g., Pecknold et al. 1993, Lovejoy and Schertzer 1995a, and Lovejoy and Schertzer 1995b]). A detailed explanation on stable distributions and their derivation can be found in Samorodnitsky and Taqqu [1994. The log-stable cascade generates a $K(q)$ function given by

$$
K(q)=C_{1}\left(q^{\alpha}-q\right) /(\alpha-1)
$$

where $0<\alpha \leq 2$ and $\alpha \neq 1, q \geq 0$.

$C_{1}$ is a fundamental characteristic of the $K(q)$ curve. Its derivative at $q=1$, $K^{\prime}(1)=C_{1}$, is known as the codimension of the mean fluctuations Lovejoy and Schertzer, 1990. $\alpha$ is the Levy index or shape parameter, and as mentioned above, a value of $\alpha=2$ corresponds to a log-normal cascade or Gaussian distribution. A log-stable cascade is used here which allows $0<\alpha \leq 2$. Both parameters $C_{1}$ and $\alpha$ are estimated by a nonlinear regression fitting to equation 3.9 .

Interpretation. In order to facilitate the evaluation of the results of the momentscale analysis, one may consider two different types of fields. A significant organized field would present peaks which are not so localized. In this case, a degradation of the resolution of the field would not have an excessive effect on those intense values (peaks) since they are surrounded by other values with similar magnitude. Consequently, Figure 3.5 would show less steep slopes. In contrast, a field characterized by 

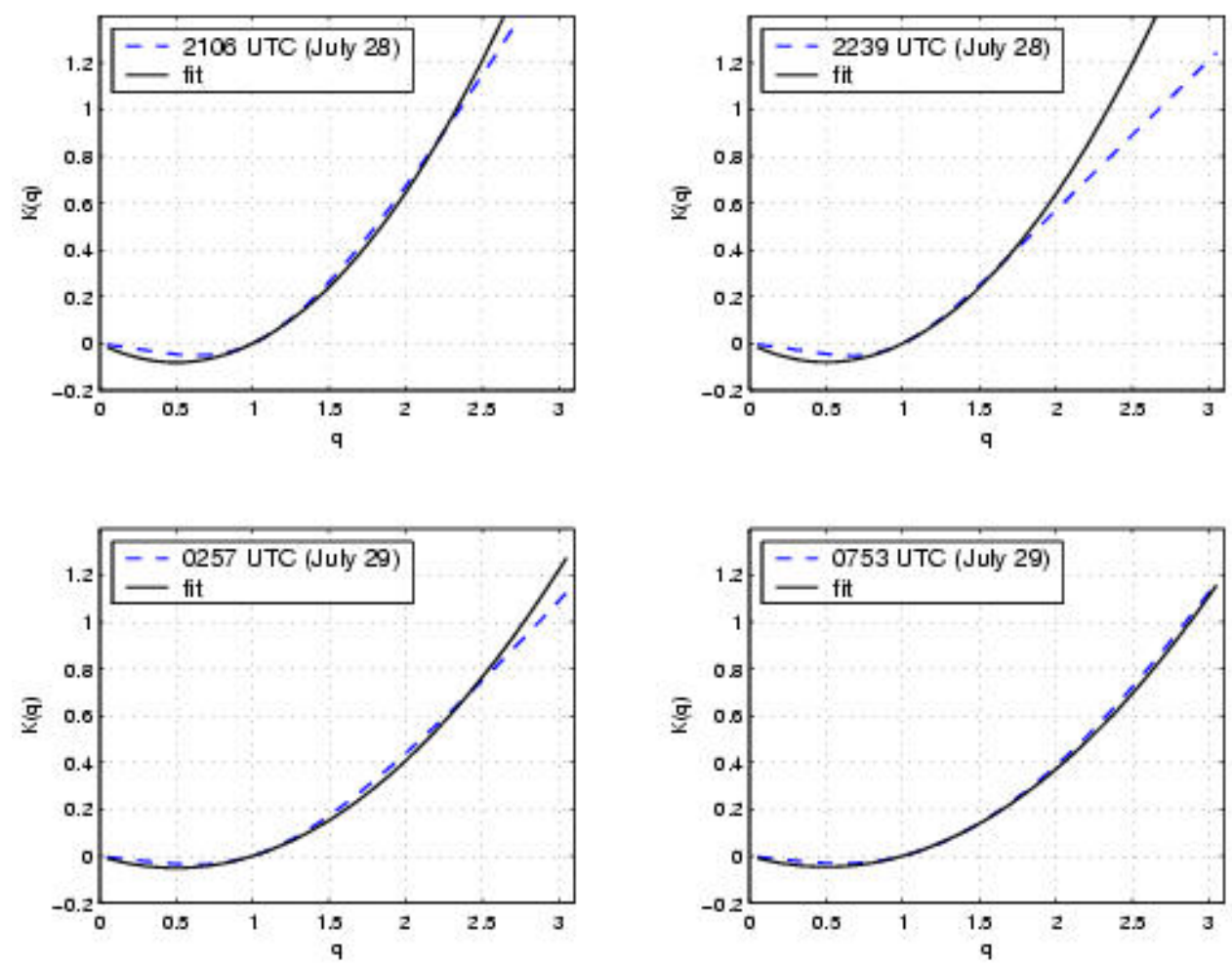

Figure 3.6 K(q) curve for the Fort Collins storms of July 28-29, 1997. The parameter $C_{1}$ values are estimated as $0.36,0.32,0.20$, and 0.19 for 2106 UTC, 2239 UTC, 0257 UTC, and 0753 UTC, respectively. The $\alpha$ parameter values are estimated as 2 for 2106 UTC, 2239 UTC, 0257 UTC, and 0753 UTC.

being highly intermittent and "spiky" would have isolated peaks and jagged gradients. When degrading the field, the high values associated with the spikes are averaged with lower surrounding values. For moments where $q>1$, the averaging would lead to negative slopes, as is shown in Figure 3.5 for values of $q=2.0$ and $q=4.0$.

The physical interpretation of the analysis can be studied through the parameters $C_{1}$ and $\alpha$. The parameter $C_{1}$ has become accepted for its interpretation as an intermittency parameter. $C_{1}$ has been applied in the literature in a wide range of geophysical phenomena (e.g. Davis et al. [1994], Lovejoy and Schertzer [1995a]). Hence, the moment-scale analysis provides information about the intermittency of a field, although it is important to point out that intermittency does not refer to the 
condition of rain/no-rain. Essentially, intermittency $\left(C_{1}\right)$ refers to the varying degree of sparseness or inhomogeneity of different intensity levels which means that higher intensity levels are more intermittent (sparse) than the lower intensities. Therefore, $C_{1}$ increases as the intermittency of the field increases.

Alternatively, $\alpha$ is related to the extreme fluctuations (spikiness) of the field. An increase in $\alpha$ corresponds to a narrower tail of the distributions, so that extreme fluctuations are infrequent and show up as spikes (see Figure 2.9 in Harris 1998 for further explanation and visualization). Thus, raising the value of $\alpha$ makes the field more "spiky".

The results obtained in the multiscale statistical analysis are shown and discussed throughout this thesis for five convective storms with strong orographic influence. Focus is placed on exploring the potential relationship between $C_{1}$ and the underlying topography where the storms took placed and meteorology of the storms. 


\section{Chapter 4}

\section{Meteorology}

The previous chapter highlighted the methods used in this study to compute the statistical parameters that describe the spatial variability of five storms in orographic terrain. It also presented the procedures used to analyze these storms in order to determine the dominant patterns throughout the evolution of the case studies. A brief outline of sounding plots and the definition of the different indices was provided in Chapter 2. This chapter will present an overview of the storm environments and several weather parameters and indices as a result of atmospheric soundings. A meteorological study from a quantitative point of view is performed using these indices.

\subsection{Overview of Storm Environments}

Five storms have been analyzed in this study with focus placed on two regions of the United States, the Appalachian Mountains and the Front Range of the Rocky Mountains. A brief summary on the background of the storms was provided in Chapter 2. This section gives an overview of the storm environments with focus on the main features that triggered the systems. 


\subsubsection{Appalachian Mountains}

Two systems were analyzed in the Appalachian Mountains. The meteorological forcing that triggered these systems are presented based on previous studies.

1) Rapidan River Basin Storm of June 27, 1995. Nykanen and Harris 2003 summarized the key meteorological features of the Rapidan River storms that are relevant for this study. An overview based on their report is provided in this section.

The prestorm environment at 0000 UTC June 27 was described by a high-pressure system positioned over New England and a low-pressure system over the east-central states. An easterly flow was supplying cool, moist air from the Atlantic into the east slopes of the Appalachians. A cold front was pushed by the synoptic high-pressure system into northeastern Virginia by 0600 UTC June 27. This produced a convective system called the Piedmont storm or Storm 1 (see Figure 2.3 in Chapter 2 for storm track visualization of the various storms). This system was characterized by Pontrelli et al. [1999] as prefrontal and initiated around 0700 UTC in the prefrontal air in Madison and Orange counties, just east of the Blue Ridge. Storm 1 advanced steadily with the cold front to the south and west reaching Madison County around 1000 UTC where it produced the first flash flood warnings. Once Storm 1 was surpassed by the front, the convection moved southward and then Storm 1 started dissipating and finally disappeared. This first system was the largest in areal extent of the three events, although it did not produce the greatest flooding due to a relatively fast storm motion $(\sim 21 \mathrm{~km} / \mathrm{h})$ compared to the second system $(\sim 3 \mathrm{~km} / \mathrm{h})$.

The Rapidan storm (as referred to in the literature) or Storm 2, was the second convective system that triggered and formed around 1200 UTC northeast of Madison County. This system was characterized by a significant slow storm motion that helped to produce a large flash flood. Sounding data from Pontrelli et al. [1999] revealed that the atmosphere was conditionally unstable with a near-saturated atmospheric column of around $6 \mathrm{~km}$ above ground level. The wind pattern was dominated by 
constant low-level easterlies, that advected maritime air into the northern region, southerly mid-level winds, that explained the low storm motion, and westerly upper level winds. The Blue Ridge Mountains lifted the moist easterlies due to the upward orography, enhancing the convection. All these factors enabled the Rapidan Storm or Storm 2 to produce heavy rainfall for approximately 6 hours into the Rapidan River Basin. Then, around 1800 UTC the storm decayed when it approached the crest of the Blue Ridge.

In addition, a low-echo centroid was determined for the Rapidan Storm (Storm 2) by Smith et al. [1995], Pontrelli et al. [1999], and Landel et al. [1999]. This meant that the highest reflectivity values were located in the warm portion of the cloud below the $0{ }^{\circ} \mathrm{C}$ level (which was located at approximately $4 \mathrm{~km}$ ) and reflected the dominance of warm rainfall processes. The presence of low-echo centroid structure is characteristic of storms with high precipitation efficiencies. An example is the $90 \%$ precipitation efficiency computed by Smith et al. 1995] for Storm 2. In all those three references it was noted that low-echo centroid structures reflected the importance of warm rainfall processes as a main feature to consider in catastrophic orographic precipitation. Furthermore, Storm 2 had some similarities with the Fort Collins storm (also considered in this study). Both of them showed the presence of low-echo centroids as well as the development and evolution of another storm in the vicinity.

After the Madison storm ended at approximately 1900 UTC, the cold front moved to the south of the North Carolina-Virginia border and drifted into the Blue Ridge in Southern Virginia. The environment was revealed to be less stable along the front than northern Virginia. The combination of frontal convergence and orographic lift generated convection, which formed a third system, here referred to as Storm 3. This system was centered over the mountains of the Blue Ridge of southern Virginia, remaining quasi-stationary and causing extreme rainfall and flooding in the morning of June 28, 1995. 
2) Redbank Creek Storm of July 18-19, 1996. On July 18-19, 1996 several storms contributed to the Redbank Creek flash flood event. Different factors combined to develop these systems (see Davis 2000 for more information). Fast atmospheric flow, a very moist atmosphere with high relative humidity, a deep warm coalescence layer, and significant wind shear were the main features that triggered this event. Furthermore, a characteristic of significant wind shear is its contribution to the development of super-cell storms. The parallel orientation of the west-northwest winds aloft and a warm frontal boundary across southwest Pennsylvania incited the development of a number of organized convective storm clusters (see Figure 2.4). Due to this atmospheric flow, thunderstorms formed over Crawford county and moved southeast to western Clearfield County. In southwest Pennsylvania, the passage of a warm frontal boundary worked to focus and retain the storms.

Although most flash floods are associated with small net motion, this case evidenced a rapid cell movement. Thus, flash flooding was produced over a large area due to the rapid movement of the storms at speeds of $20-25 \mathrm{~m} / \mathrm{s}$. The combination of several high speed storms over the same area resulted in widespread flash flooding.

\subsubsection{The Front Range of the Rocky Mountains}

An overview of the storm environments at the Front Range of the Rocky Mountains is presented. Focus is placed on the meteorological features associated with the storms that originated catastrophic flash flooding.

3) Buffalo Creek Storm of July 12-13, 1996. On July 12, 1996 a weak front moved from the northeast into Colorado. This made the wind turn to upslope easterlies in the Eastern Plains. Convection triggered along the north-south line over the higher elevations of Colorado was associated with a dissipating line moving southeastward from eastern Oklahoma and Texas. The convection moved towards the east into the Plains, becoming more organized. At approximately 1700 UTC thunderstorms 
developed over central Colorado producing heavy rainfall.

At around 0000 UTC on July 13, upslope east-southeasterly surface winds in eastern Colorado started advecting moist air along the Front Range of the Rockies, producing high surface dewpoints. In addition, a weak stationary front was draped northwest-to-southeast across the region, and an upper-level ridge over the West Coast created mid- and upper-level west-northwesterly winds. This upper-air flow combined with a jet approaching the Rockies from Canada resulting in an atmospheric environment convectively unstable, where the boundary layer moisture increased and deepened. It is believed that ageostrophic circulations in the exit region of the jet were responsible for large-scale vertical motion over Colorado.

Around 0100 UTC July 13 the Buffalo Creek storms formed near the crest of a southeast to northwest oriented ridge with a peak elevation of $3700 \mathrm{~m}$. The storm moved into lower topography heading eastward at high speed ( $35 \mathrm{~km} / \mathrm{h}$ ). Around 0200 UTC it slowed down $(10 \mathrm{~km} / \mathrm{h})$ due to an interaction between the storm and an outflow boundary, which was created by multiple convective storms that moved from northwest to southeast. This slower motion of the event combined with a rapid shift northward in the storm direction caused the most intense rainfall over Buffalo Creek, which corresponds to S2 in Figure 2.5. After 0330 UTC the storm started dissipating as a consequence of crossing a ridge perpendicular to its course. Five other convective rainfall events were reported in the vicinity of the Buffalo Creek watershed during this period and produced precipitation of comparable magnitude to that of the Buffalo Creek Storm.

Therefore, the combination of a possible upper-air flow supported from a jet stream approaching the Rockies from Canada, high pressure surface dewpoints, lowlevel upslope flow, and a weak stationary front triggered convection over the Front Range of the Colorado Rockies. Furthermore, it is also worthy to mention the importance of a wildfire that occurred two months earlier, which enhanced the flooding in the region. A detailed explanation about the meteorological conditions that char- 
acterized the Buffalo Creek storms can be found in Landel et al. 1999, Chen et al. 2001, and Warner et al. 1999.

4) Fort Collins Storm of July 28-29, 1997. The Fort Collins Storm of July 2829, 1997 basically formed when the high humidity associated with the easterly winds produced surface upslope flow. This meant that relatively little lifting was necessary to raise boundary air to its Level of Free Convection (LFC) by the ridges of the Front Range of the Rockies. Not only are the foothills of the Rockies responsible for the triggering of the storm, but also the combination of other factors such as outflow boundaries nearby the storms, latent and sensible heating gradients, and pressure perturbations may have played an important role in the development of these storms.

During the last days of July 1997, the presence of a ridge with an axis that extended from the Mississippi Delta to the Pacific Northwest indicated the existence of an expansive high pressure over west-central United States. At 1100 UTC on 28 of July 1997, the development of moist low-level upslope flow and weak upper-level winds resulted in a special weather statement for heavy rainfall and flash flooding in and along the foothills of the northern Colorado Rockies by the National Weather Service (NWS). Moderate to heavy rain fell along the foothills west and northwest of Fort Collins until 2000 UTC July 28. In the evening of that day, heavy rainfall redeveloped over central and northern foothills west and northwest of Fort Collins and two convective systems moved over Fort Collins producing heavy rain.

The two main systems that produced the heaviest rainfall and catastrophic flooding developed as a consequence of atypically moist atmospheric conditions. These conditions were caused by an extraordinary strong flow of monsoonal moisture, which was reported preceding the Fort Collins Storm of July 28-29, 1997 in Colorado. In northeastern and southeastern Wyoming, anticyclonic flow from a deep layer of cool and very moist Canadian air mass produced low-level northeasterly to southeasterly winds over the High Plains. The slow-moving cool front that led the Canadian air 
mass was blocked against the face of the Rockies in Colorado and Wyoming around 0000 UTC July 29, 1997. Furthermore, a cyclone was apparent in the surrounding area of Denver, so that this fact along with the convergence appears to be the main factor in the initiation of a bow echo in the Denver area around 0000 UTC July 29. On the other hand, light to moderate mid- and upper-level southern and southwesterly winds fed a deep layer of moisture into Colorado along the spine of the southern Rocky Mountains.

The bow echo moved onto the plains and was coincident with the passage of a long-lived convective feature over the Denver area. Thus, from 0000-0300 UTC July 29 there was a notable distinction between the convection to the south of Fort Collins and that over Fort Collins. The convection located on the south was associated to the High Plains storm and moved with the bow echo to the northeast. On the other hand, the convection over Fort Collins was related to the Fort Collins Storm and was characterized by stationary convection. A detailed description on the mesoscale meteorology of the storm is given by Petersen et al. [1999.

The Fort Collins storm moved northeast from 0100-0200 UTC July 29 and then remained stationary with small net storm motion. However, there were significant changes in the storm structure that increased the convective intensity. In contrast, the High Plains storm moved across the High Plains and went northeast into lower topography at an average speed of $15 \mathrm{~km} / \mathrm{h}$. It then disappeared around 0600 UTC July 29 (see Landel et al. 1999). The storm track maps are shown in Figure 2.6 of Chapter 2.

An important feature that characterized the Fort Collins Storm was the presence of a LEC structure as in the Rapidan Storm, involving warm rain processes. Other similarities were common to the Fort Collins storm and the Rapidan storm such as similar vertical storm structures due to a comparable vertical humidity profile, partial distribution of storm total rainfall, and the existence of another storm that showed contrasts in storm motion and structure. In these cases, the High Plains storm was 
paired with the Fort Collins storm and the Piedmont storm was paired with the Rapidan storm.

5) Loveland Pass Storm of July 28-29, 1999. There is lack of information regarding the meteorological environment of the Loveland Pass Storm. A description of the storm environment has not been published as of yet for this case. However, sounding data has been reported and an explanation based on this data is given in section 4.3 .

\subsection{Comparison to Storm Environment of Other Orographic Events}

It was mentioned in the introduction that this study builds on the work by Harris et al. [1996], Purdy et al. 2001, and Nykanen and Harris 2003]. The same multiscaling statistical analysis framework has been adopted to analyze all cases. A comparison of the storm environment between these cases and previous studies is presented in this section. The Rapidan River basin and southern Virginia storm of June 27, 1995 has been considered in this study and a detailed description of the storm and multiscaling results is provided based on the work by Nykanen and Harris 2003. The similarities and differences in meteorological conditions are considered for all the events to better understand the resemblance and disparity in the multiscaling results between the various events.

Southern Alps of New Zealand Storm of 5-9 November 1994. The storm environment of this event was described by Purdy et al. 2001. The storm occurred on the west side of the Southern Alps of New Zealand and was characterized as a windward-side event. The storm was triggered by a moist, low-level upslope flow and showed a change in the stability of the atmosphere between prefrontal conditional 
instability and postfrontal unstable air mass. This variation in the atmosphere resulted in marked differences in the rainfall time series from the low-lands to the alpine region.

Similarities and Differences in Meteorological Features. There are two significant characteristics that are worthy to mention in regards to the meteorology of the Southern Alps event and the cases considered in this study. The Southern Alps as well as the Redbank Creek event were windward-side orographic precipitation events, which means that little directional shear was present at high and low level winds as both were mainly westerly. However, the other four events were characterized as leeward-side and exhibited wind shear between low (easterly) and high (westerly) level winds.

Furthermore, another feature of the Southern Alps event was the presence of a bright band as indicated by the vertically point radar data. This is characteristic of cold rain processes aloft, while the five cases considered here indicated dominance of warm rain precipitation processes aloft as shown by the presence of low echo centroid (LEC) structure (see ?, Pontrelli et al. 1999, and Petersen et al. 1999]).

In the Southern Alps event, it was also reported that upslope westerly winds advected convective components from the lowlands into the foothills. However, these components were not propagated to the alpine region. Purdy et al. 2001 used a Regional Atmospheric Modeling System (RAMS) in which they found that regions of descending flow aloft existed just upwind of the main divide. Based on these findings, it was suggested that the descent of saturated air was the source of a suppression mechanism that stabilized the alpine air impeding the propagation of the convective elements into that region. This mechanism was discussed to be the origin of stratiform rainfall near the main divide and directly related to the decrease in intermittency and extreme fluctuations with increasing topographic elevation. The findings of Purdy et al. 2001 showed increasing intermittency with increasing topographic elevation. 
As will be shown in Chapter 5, this trend is in a contrary nature to the events studied by Nykanen and Harris 2003 and the other case studies presented here.

\subsection{Sounding and Stability Indices Results and Dis- cussion}

These events were the result of a series of rain systems that occurred for over more than a 24-h period. It was intended to consider a range of time that was representative of the whole event for each storm in order to capture the main characteristics of the prestorm, storm, and poststorm environment. However, data availability posed some limitations on this anlysis. Sounding plots as well as stability indices results are shown and discussed in this section.

\subsubsection{Sounding Location and Chronology}

A detailed description of the period considered for each storm is provided. All radiosonde data and corresponding indices were obtained from Department of Atmospheric Science at University of Wyoming $(D A S U W)$ webpage (see references). The representations of the sounding plots along with a list of the values of the different indices considered can be found in Appendices B - F. Plots of surface rainfall centroid, DEM, and sounding stations were shown in Chapter 2 (see from Figure 2.3 - Figure 2.7 in order to facilitate visualization and better understanding of how sounding results may be related to the movement of the storm passing through the sounding location.

Appalachian Mountains. No plot is shown for the Rapidan River storm since the location of the sounding station is placed on the upper right corner out of the DEM region considered. This is due to the fact that the area of the square representing the 
topography of the region is $100 \times 100 \mathrm{~km}^{2}$ and the sounding location is not included in this region. However, the Redbank Creek storm is enclosed in a representation of a $460 \times 460 \mathrm{~km}^{2}$ area and the sounding station used to obtain the data is placed inside that region. A plot with the Redbank Creek storm, DEM and the stations close to that area is portrayed in Figure 2.4 .

1. Rapidan River Storm of June 27, 1995: sounding data is taken from 0000 UTC 26 Jul to 1200 UTC 28 Jul (every 12 hours, which means 6 sounding measurements)

2. Redbank Creek Storm of July 18-19,1996: sounding data is taken from 1200 UTC 17 Jul to 0000 UTC 20 Jul (every 12 hours, which means 6 sounding measurements)

Front Range of the Rocky Mountains. All three storms that occurred in the Front Range of the Rocky Mountains are located near the same sounding stations. For these cases, two stations could have been used to analyze the storms. However, it seemed that no balloon was launched during the period of interest for these cases from the Fort Carson (FCS) station and no observations were available. Thus, the sounding data was provided from the Denver station (DNR). Figure 2.7 shows the location of the station with the underlying topography for the Loveland Pass storm over the $460 \times 460 \mathrm{~km}^{2}$ spatial extension.

3. Buffalo Creek Storm of July 12-13, 1996: sounding data is taken from 1200 UTC 11 Jul to 0000 UTC 14 Jul (every 12 hours, which means 6 sounding measurements)

4. Fort Collins Storm of July 28-29, 1997: sounding data is taken from 1200 UTC 27 Jul to 0000 UTC 30 Jul (every 12 hours, which means 6 sounding measurements) 
5. Loveland Pass Storm of July 28-29, 1999: sounding data is taken from 1200 UTC 27 Jul to 0000 UTC 30 Jul (every 12 hours, which means 5 sounding measurements, since no data was available at 1200 UTC July 28)

\subsubsection{Sounding Results}

As was mentioned above, sounding plots and stability indices were acquired in $D A$ $S U W$ webpage (see references). One station was used to obtain the data for each storm. The temporal evolution of the stability indices is shown for a period of time that was intended to encompass the duration of the storms. Hence, an effort was made to represent the prestorm, storm, and poststorm environments of the various events. The results are summarized by groups, since several storm parameters were only computed for some of the events and not for all of them. The results obtained from the soundings are not only representative of the changes in the storm structure over time, but also the movement of the systems in regards to the sounding location. It is important to remember that as the storm moves farther from the sounding station, the interpretation of the sounding indices becomes only weakly related to the storm environment.

SWEAT index, KINX index, and TOTL index. These indices were only available for the Rapidan River storms and the Redbank Creek storms. They measure the potential for severe weather, and instability in the atmosphere. Figure 4.1 shows the values obtained for the Rapidan River storms and the Redbank Creek storms. The SWEAT index appears to be steady during the Rapidan River storms with values ranging between $189^{\circ} \mathrm{C}$ to $216^{\circ} \mathrm{C}$, indicating an environment with an unlikely risk of severe thunderstorms unless strong lifting such as orographic forcing is present (see Table A.2 from Appendix A). In contrast, the SWEAT index did increase significantly during the Redbank Creek storms and varied from $100{ }^{\circ} \mathrm{C}$ to $350{ }^{\circ} \mathrm{C}$, the higher values are related to potential for severe thunderstorms even without orographic lift- 
ing. This increase in the value is coincident with the development of Storm 2 and the proximity of Storm 3 and 4, which were located near the sounding station. In addition, the same trends as in the SWEAT index were found for the KINX and TOTL indices during both storms. The $K I N X$ values were high in magnitude indicating approximately 80 - $90 \%$ probability of thunderstorms with heavy rain. However, the TOTL values ranged between 44 to 47 for the Rapidan River storm, indicating favorable conditions for the development of thunderstorms if the inversion were broken, while the Redbank Creek storm showed lower values. It is worthy to note that while SWEAT was higher during the Redbank Creek storms, the TOTL index presented higher values for the Rapidan River storms.

All three parameters did show different trends over time between both storms. Rapidan River storms indices remained very stable during the whole period, while the indices found for the Redbank Creek storms were representative of the movement of Storms 2 and 3 approaching the sounding station. The results found were not significantly high and only the KINX index values were related to a quick burst of heavy rain.

LI, CAPE, and CINS indices. The results of these indices were obtained for all case studies. The time series of these indices are shown in Figure 4.2. The Lifted index values varied from approximately -4.0 to 4.0 for all events. The Rocky Mountains cases have similar trends over time, while the Rapidan River case depicts an increase in the value that is associated to movement of the storm away (southwest) of the sounding location. However, Pontrelli et al. [1999] reported a value of -4.1 for the lifted index in a sounding located south at Greensboro, North Carolina at 1200 UTC June 27 that corresponds to $t=1.5$ day in the graph. In addition, the Redbank Creek storms did show a decreasing trend in the $L I$ until $\mathrm{t}=2.0$ day, but yielded higher values than the other storms during most of the period considered. This is consistent with the movement of the various systems to the sounding station (see Figure 2.4), 
(a)
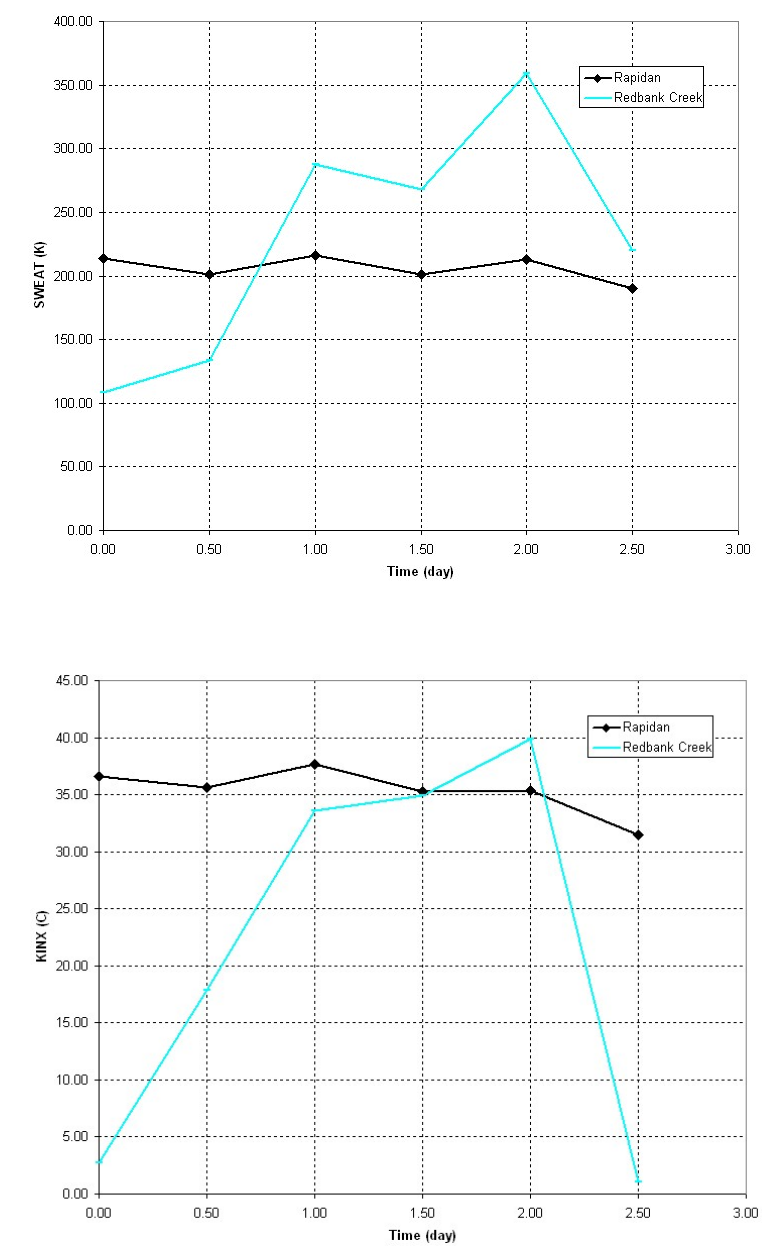

(b)

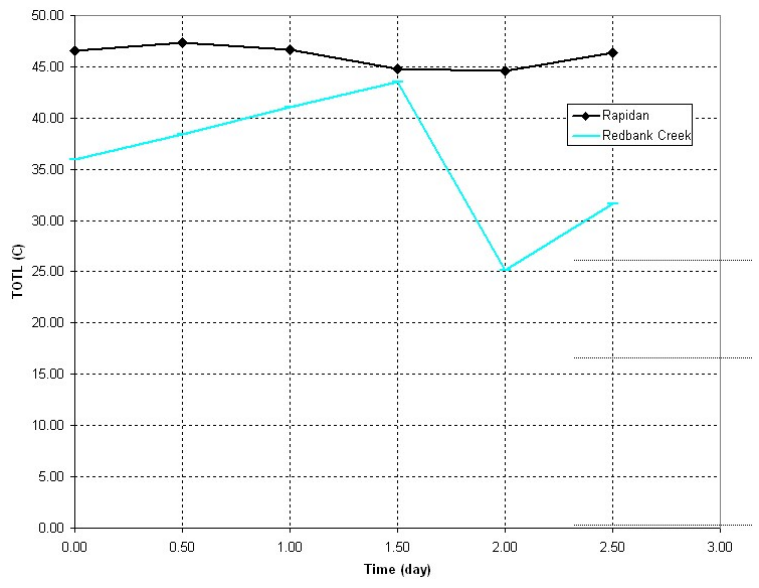

(c)

Figure 4.1 SWEAT, KINX, and TOTL indices for the Rapidan River basin storm of June 27, 1995 (black line) and the Redbank Creek of July 18-19 storm (cyan line): (a) SWEAT index, (b) KINX index, and (c) TOTL index. 
which increased the instability of the atmosphere. In general, negative values were predominant during the storm environment (from day 0.50 to 2.00), although the magnitude of the order of -2.0 to -3.0 is relatively small compared to other events (see Pontrelli et al. [1999]), which indicates a slightly unstable troposphere as was mentioned in Chapter 2 (see Table A.1 from Appendix A).

The bigger the CAPE and CINS indices, the more vigorous the convection and the probable thunderstorm development. However, in the case of orographic forced events, $C A P E$ and $C I N S$ may be less meaningful as the orographic lifting provides additional energy to the storm. Significant decrease in the $C A P E$ value from $\sim 2000.0$ $\mathrm{J} / \mathrm{kg}$ to $0.0 \mathrm{~J} / \mathrm{kg}$ was found during the Rapidan River storms. A value of $\sim 2000.0$ $\mathrm{J} / \mathrm{kg}$ in the prestorm environment indicates a moderatively unstable atmosphere. Also, the Loveland Pass storm did show a decreasing trend, but with smaller values in the prestorm environment. However, the Fort Collins storms presented an increase in the $C A P E$ during the poststorm environment, which signified the presence of another possible front coming in. The Buffalo Creek storms presented a jagged line with the highest values during the storm environment. Again, the Redbank Creek storms had a maximum value of $\mathrm{CAPE} \sim 2000.0 \mathrm{~J} / \mathrm{kg}$ at $\mathrm{t}=2.0$ day. In summary, the values observed for $C A P E$ were very similar in magnitude and relatively small, which indicated a marginally unstable atmosphere for all cases as indicated in Table A.7 and points to the importance of orographic forcing in these events to trigger thunderstorm development.

The CINS index values varied approximately from $0.0 \mathrm{~J} / \mathrm{kg}$ to $-80.0 \mathrm{~J} / \mathrm{kg}$ during the Rapidan River storms, Fort Collins storms, and Loveland Pass storms, with the exception of the last values of the Loveland Pass storms for which a value of -191.0 $\mathrm{J} / \mathrm{kg}$ was found and could be associated to another front. Values ranging between $-50.0 \mathrm{~J} / \mathrm{kg}$ to $-150.0 \mathrm{~J} / \mathrm{kg}$ were obtained during most of the time for the Fort Collins storms and Loveland Pass storms. These values may be related to the possible formation of favorable strong lines of thunderstorms. However, the Rapidan River storm 
(a)

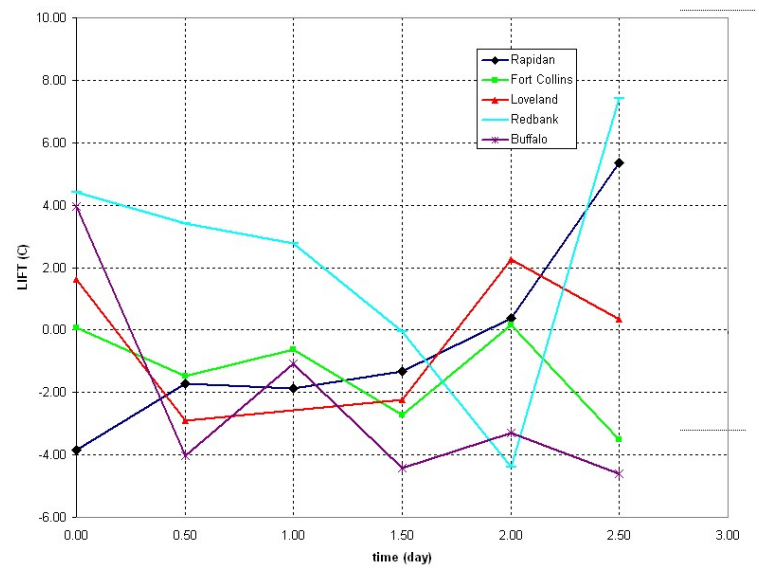

(b)

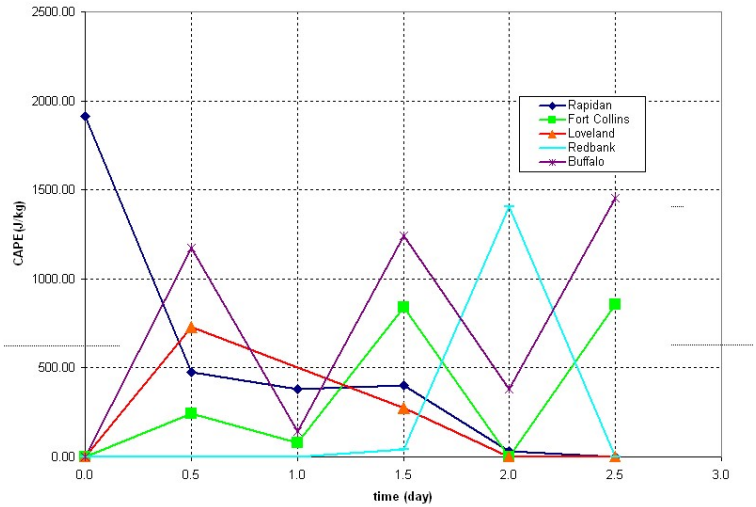

(c)

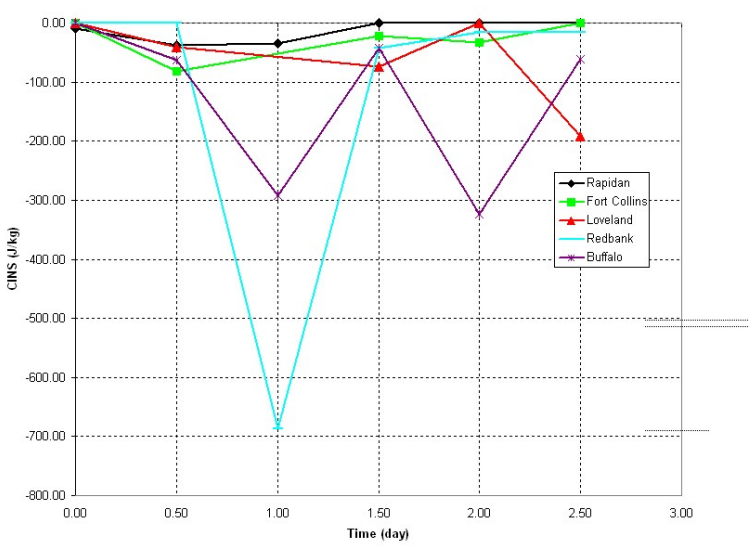

Figure 4.2 Lifted, Convective Available Potential Energy (CAPE), and Convective Inhibition (CINS) indices for the Rapidan River basin of June 27, 1995 storms (black line), the Redbank Creek storm of July 18-19, 1996 (cyan line), the Buffalo Creek storm of July 12-13 (purple line), 1996, the Fort Collins storms of July 28-29, 1997 (green line), and the Loveland Pass storms of July 28-29, 1999 (red line): (a) Lifted index, (b) CAPE index, and (c) CINS index. 
did have a very small CINS after day 1.5 (1200 UTC June 27), which is consistent with the storm's moving pattern to the southwest. In addition, the Redbank Creek storms and Buffalo Creek storms portrayed significant higher negative values than the other events. CINS values below - 200.0 J/kg were reported. This meant that a strong cap was present and no thunderstorm development was likely (see Table A.8 for reference) without orographic uplift.

\section{Level of Free Convection (LFCT), Lifted Condensation Level (LCLP), and} Bulk Richardson Number (BRCH). These three parameters are shown in Figure 4.3 for all case studies. They are indicators of convective storm environments as mentioned in Chapter 2 (see Table 2.5). The small dewpoint depressions for the various events produced low $L F C T$ and $L C L P$. This indicated that very little lifting was needed to initiate convection and conditions were prime for orographic lifting to produce thunderstorms. The $L F C T$ and $L C L P$ indices remained quite constant during the whole period. However, the Rapidan River storms showed unusual lower $L F C T$ values indicating the vertically higher $L F C T$. Only the Redbank Creek storms presented a significant increase during the storm development. Furthermore, similar LFCT values were found for the Redbank Creek compared to the Rockies case studies. In regards to $L C L P$, lower values were obtained for the Rocky Mountains cases than the Appalachian Mountains cases due to the higher elevations of the region in the Rockies case studies. It is important to note that higher pressure means closer to the surface (i.e., lower height).

The $B R C H$ index values signified the presence of multi-cell storms for the Rapidan River storms, Fort Collins storms, and Loveland Pass storms. The Fort Collins storm peak value of 235 appeared to be related to the storm's proximity to the sounding station (see Figure 2.6). At the same time, the Rapidan River storm showed high values of $B R C H$ that were decreasing as the storm moved away from the sounding. Lower values were found for the Loveland Pass storm in regards to the multi-cell 
character of the $B R C H$ results than the other two storms. On the other hand, $B R C H$ stability index reported considerably different magnitudes during the Redbank Creek and the Buffalo Creek storms in comparison to the other three cases in which similar trends and values over time were observed. Values of $B R C H$ below 50.0 were obtained for these two cases, indicating a moderate chance of thunderstorms with super-cell nature (see Table A.9 from Appendix A). 
(a)

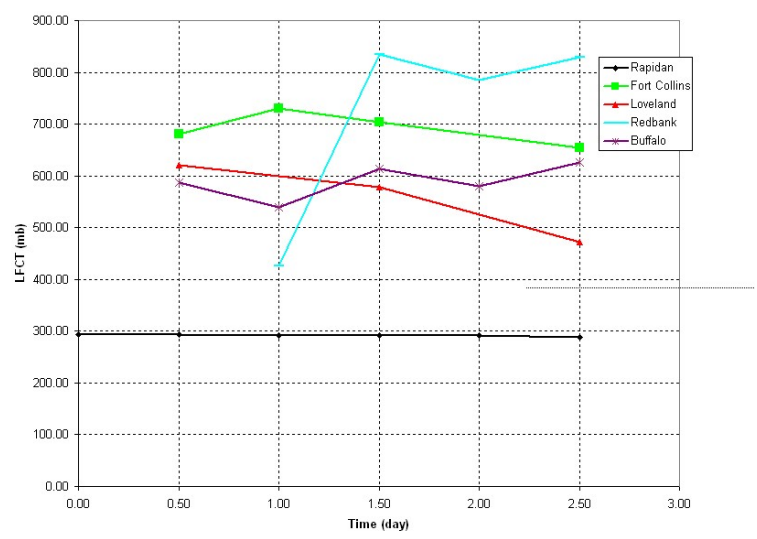

(b)

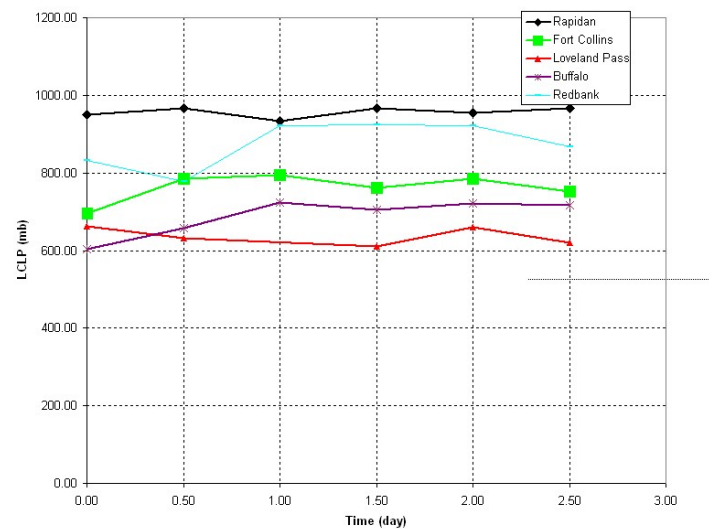

(c)

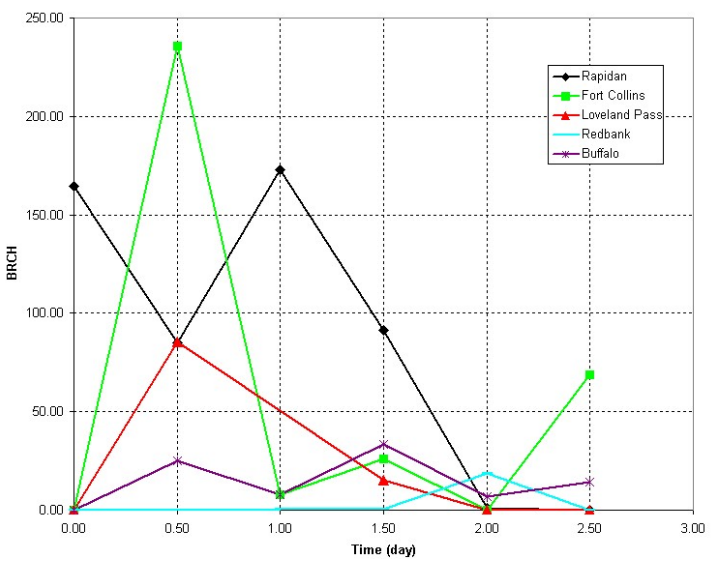

Figure 4.3 Level of Free Convection (LFCT), Lifted Condensation Level (LCLP), and Bulk Richardson Number (BRCH) indices for the Rapidan River basin of June 27, 1995 storms (black line), the Redbank Creek storm of July 18-19, 1996 (cyan line), the Buffalo Creek storm of July 12-13, 1996 (purple line), the Fort Collins storms of July 28-29, 1997 (green line), and the Loveland Pass storms of July 28-29, 1999 (red line): (a) LFCT index, (b) LCLP index, (c) BRCH index. 


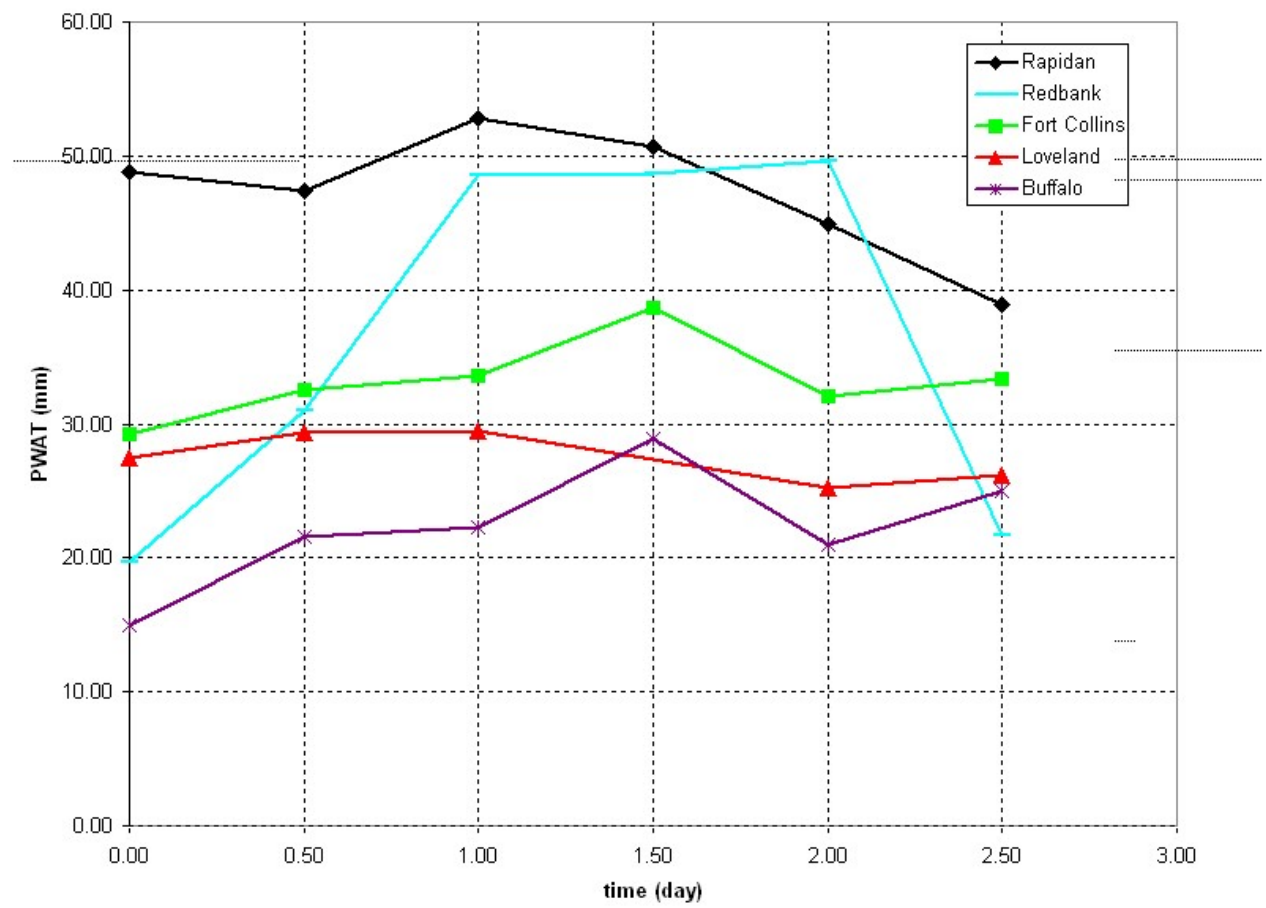

Figure 4.4 Precipitable Water (PWAT) for the Rapidan River basin of June 27, 1995 storms (black line), the Redbank Creek storm of July 18-19,1996 (cyan line), the Buffalo Creek storm of July 12-13, 1996 (purple line), the Fort Collin storm of July 28-29 (green line), 1997, and the Loveland Pass storm of July 28-29, 1999 (red line)..

Precipitable water (PWAT). This index was obtained for all storms. As was mentioned in Chapter 2 (see Appendix A for more information), the total precipitable water is a measure of the water vapor contained in a vertical column from the surface to the top of the atmosphere. The $P W A T$ found for these events indicated high humidity in the atmosphere with values ranging from $20 \mathrm{~mm}$ to $50 \mathrm{~mm}$. Figure 4.4 depicts the temporal evolution of the $P W A T$ index. The values remained very steady and only the Redbank Creek storm appear to have an increasing trend from the prestorm to the storm environment that diminishes during the poststorm environment. Higher values of the PWAT were found for the Appalachian Mountains cases $(\sim 50 \mathrm{~mm})$ than the Rocky Mountains cases $(\sim 30 \mathrm{~mm})$, with the Buffalo Creek storm showing the lowest values. 


\section{Chapter 5}

\section{Multiscaling Results and Discussion}

Chapter 3 emphasized the 2-D multiscale statistical analysis that is used to characterized the spatial organization patterns of the various case studies. The multiscale parameters have been analyzed over time and their properties for each case are presented in this chapter. Attention is given to linking multiscale statistical parameters to topographic influences on the rainfall in order to find a generalized behavior comparing the results for all cases. The next section presents and interprets some preliminary results that may link the interplay of the stability indices and the multiscaling parameters. The last section provides a comparison with the results found for orographic rainfall in the Southern Alps of New Zealand by Harris et al. [1996. and Purdy et al. 2001.

\subsection{Multiscaling Results}

In order to facilitate the discussion of the results, the manner in which the results are presented and discussed is outlined in this section. The presentation will begin with the multiscale parameters that are linked to the scale dependent variability of 
rainfall, spatial organization, intermittency, and extreme fluctuations. The multiscale parameters $\beta, H, C_{1}$, and $\alpha$ were computed for each case using the WSR-88D derived 1-km horizontally gridded rainfall. The areas upon which the multiscale parameters were evaluated depended on the extent of the storm considered. However, no less than a $100 \times 100 \mathrm{~km}^{2}$ area was used for all storms, as well as more than 400 rainy pixels within this area were required for meaningful statistical results. These parameters are shown in a time series plot that was created by calculating the 2-D multiscale analysis for a sequence of 6-min interval rainfall patterns throughout the entire duration of the storms. In these cases, the statistical parameters were plotted employing a 18-min moving average, so that each parameter value was averaged with that from the previous and following rainfall fields, 6-min earlier and 6-min later, respectively. This is performed in order to smooth the representation and provide a better visualization. In addition, the topographic elevation associated with the surface rainfall centroids for each storm is plotted versus time. The correlation between the topographic elevation of the storms associated with the surface rainfall centroid and the intermittency parameter $C_{1}$ is presented.

Multiscale Parameters Overview. In the first step of the multiscale statistical analysis, $\beta$ is determined from the Fourier power spectra over a finite range of scales in which log-log linear relationships occur. Then, $H$ is obtained as the log-log linear slope over a finite range of scales from the first-order generalized structure function as explained in Chapter 3. The last step is the computation of the $K(q)$ or moment scale exponent function using the first five points of the q-order moment scaling. The multiscale parameters $C_{1}$ and $\alpha$ were estimated by nonlinear regression to the $K(q)$ curves. $K(q)$ was fitted using values of $q \leq 3$, since the higher moments $(q \geq 4)$ are dominated by a very small portion of the data corresponding to the single largest value in the field. When $q$ values range between 0 and 1 , the $K(q)$ curve is very sensitive to low level noise and discretization in the data. A more detailed explanation can be 
found in Harris et al. [1997] in regards to the outcome of small and large values on fitting the $K(q)$ curve.

\subsubsection{Rapidan River Basin Storm of June 27, 1995}

Nykanen and Harris 2003 computed the multiscale parameters for the Rapidan River basin and southern Virginia storms of June 27 over a 100 x $100 \mathrm{~km}^{2}$ area. The storm tracks of the various systems were shown in Figure 2.3 (Chapter 2). The findings of Nykanen and Harris 2003 are repeated here to facilitate comparison with other case studies. The scaling range used to compute $\beta$ varied somewhat between storms, so that the entire range of observable scale was employed during Storm 1. Nykanen and Harris [2003] reported that the scaling range during Storm 2 was 1 to $\sim 64 \mathrm{~km}$ until 1630 UTC and 1 to $\sim 42 \mathrm{~km}$ later, and during Storm 3 the scaling range was reduced from 1 to $\sim 21 \mathrm{~km}$. The finite range of scales used to calculate $H$ from the first-order generalized function was 1 to $20 \mathrm{~km}$ for all three storms.

The $\beta$ parameter indicates organization of the rain field structure. A physical interpretation of the $\beta$ parameter is provided in Purdy et al. [2001], where high $\beta$ values are linked to the existence of individual rain cells and low $\beta$ values would refer to the existence of stratiform rainfall. The time series for the multiscaling parameters $\beta$ and $H$ are depicted in Figure 5.1. It can be observed that the rainfall fields are moderately organized for Storm 1 and 2, although Storm 2 contained higher $\beta$ values which indicated a more organized field. The increment in the $\beta$ value from Storm 1 to 2 can be explained with the changes in the storm environment. Storm 1 was described as a convective system that moved with the cold front and had high net storm motion and large area of coverage. Storm 2 had small net storm motion that was controlled by the growth of new storm cells instead of wind direction. The repeated formation

and growth of individual storm cells resulted in a higher value of $\beta$ for Storm 2. On the other hand, Storm 3 showed lower values and a decreasing trend, indicating a less 
organized rainfall field. The findings obtained for $\beta$ are confirmed by the multiscaling parameter $H$ results as shown in Figure 5.1 (b), where higher values were found during Storm 2. It is important to note that $H$ is less noisy than $\beta$, since $H$ is a first-order measure and $\beta$ is a second-order measure. Therefore, $H$ represents more clearly the trends of the storms than $\beta$ and will be used for the rest of the cases in order to explain the level of field organization.

The intermittency parameter $C_{1}$ and shape parameter $\alpha$ are portrayed in Figure 5.2, where Storms 2 and 3 showed higher values or higher intermittency compared to Storm 1. Purdy et al. 2001 described the physical interpretation of the lower values of $C_{1}$ being associated with widespread, stratiform rainfall and higher values with more organized, convective rainfall. The results of $C_{1}$ found by Nykanen and Harris 2003 are consistent with the interpretation reported by Purdy et al. 2001, since the lower values of $C_{1}$ obtained during Storm 1 revealed a widespread rainfall, and the higher values of Storm 2 and 3 indicated more focus of these storms on intermittent convective elements. The shape parameter or $\alpha$ is related to the extreme fluctuations of the field. $\alpha$ was of limited use due to its exceedingly sensitive nature, and being highly variable for all three storms. However, in Figure 5.2 it depicted higher peak values in $\alpha$ during Storms 2 and 3 .

The temporal evolution of the multiscale parameters and its relation with the orographic influences on the rainfall is one of the main objectives of this study. For this purpose, surface rainfall centroids were estimated separately during Storms 1, 2, and 3 and were used to track the storms during its lifetime. Topographic elevations are associated to the surface rainfall centroids from the underlying topography which is derived from 1-km DEM data. The changes in topographic elevation over time for all three storms can be seen in Figure 5.3 .

The trends over time between the intermittency parameter $C_{1}$ and the topographic elevation of the surface rainfall centroids for all three storms were similar. The correlation between $C_{1}$ and orography is shown in Figure 5.4, where a correlation coefficient 
of 0.67 was obtained. This result provides evidence of orographic influence on the spatial organization of these rainfall events and thus indicates that ELEV has potential as a predictor of $C_{1}$. 
(a)
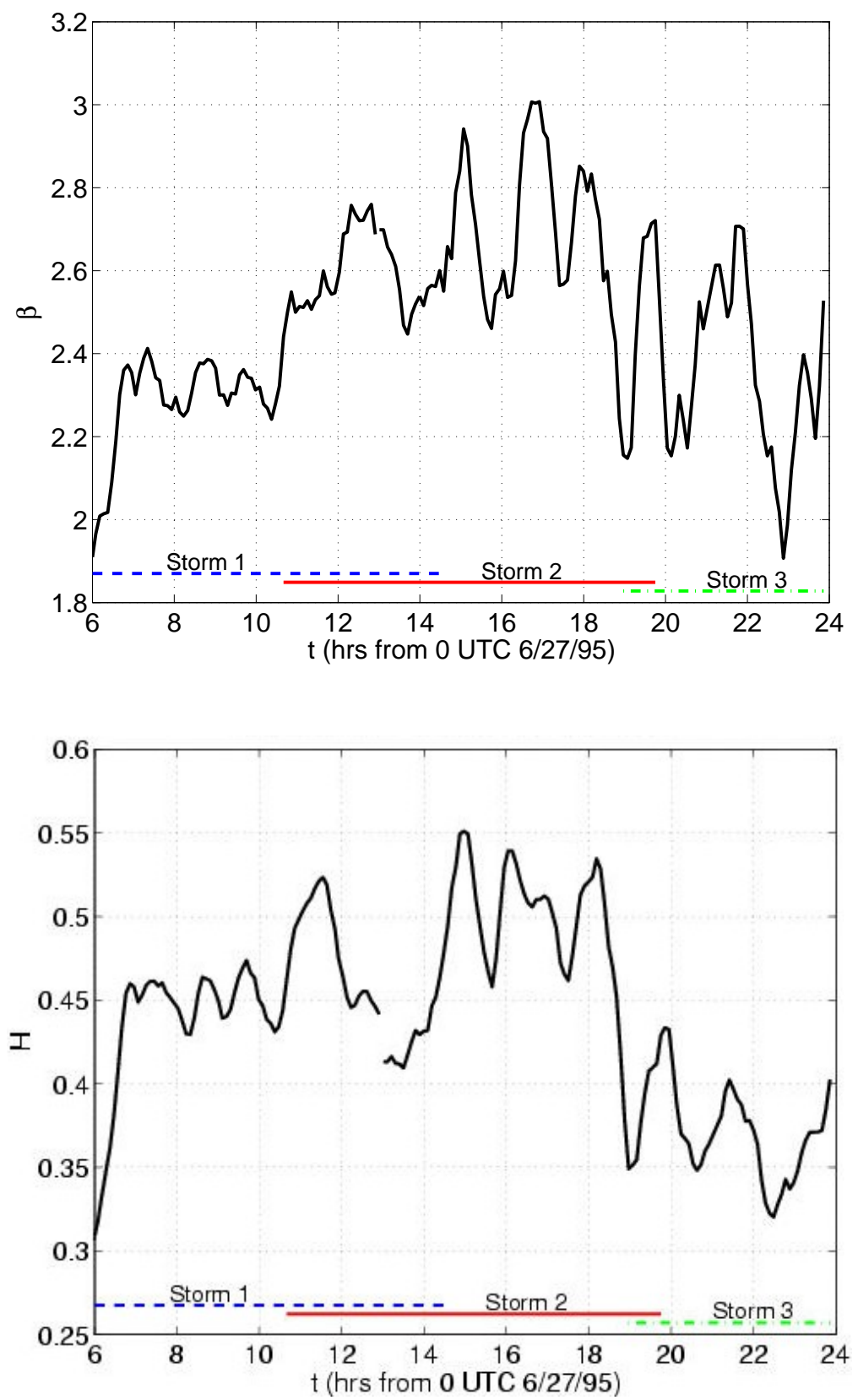

Figure 5.1 Multiscale statistical parameters $\beta$ and $H$ for the Rapidan River basin and southern Virginia storm of June 27, 1995. The parameters have been plotted as 18 -min moving average, so that each value was averaged with that from the previous and following rainfall fields, 6 min later and 6 min earlier, respectively. (a) power expectral exponent $\beta$ and (b) Hurst exponent $H$ (From Nykanen and Harris [2003]). 
(a)
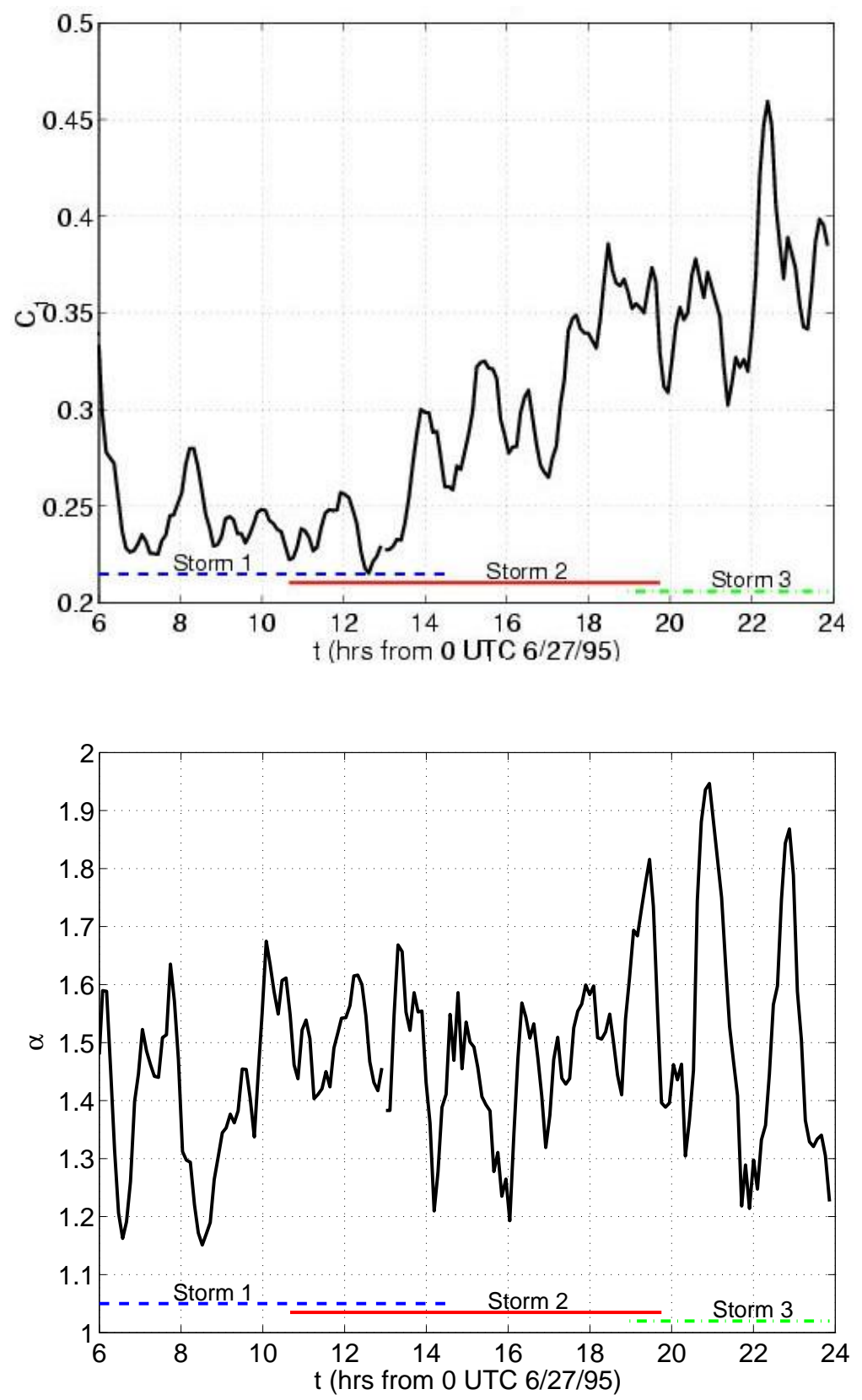

(b)

Figure 5.2 Multiscale statistical parameters $C_{1}$ and $\alpha$ for the Rapidan River basin and southern Virginia storm of June 27, 1995. The parameters have been plotted as 18-min moving average, so that each value was averaged with that from the previous and following rainfall fields, $6 \mathrm{~min}$ later and 6 min earlier, respectively. (a) intermittency parameter $C_{1}$ and (b) shape parameter $\alpha$ (From Nykanen and Harris [2003]). 


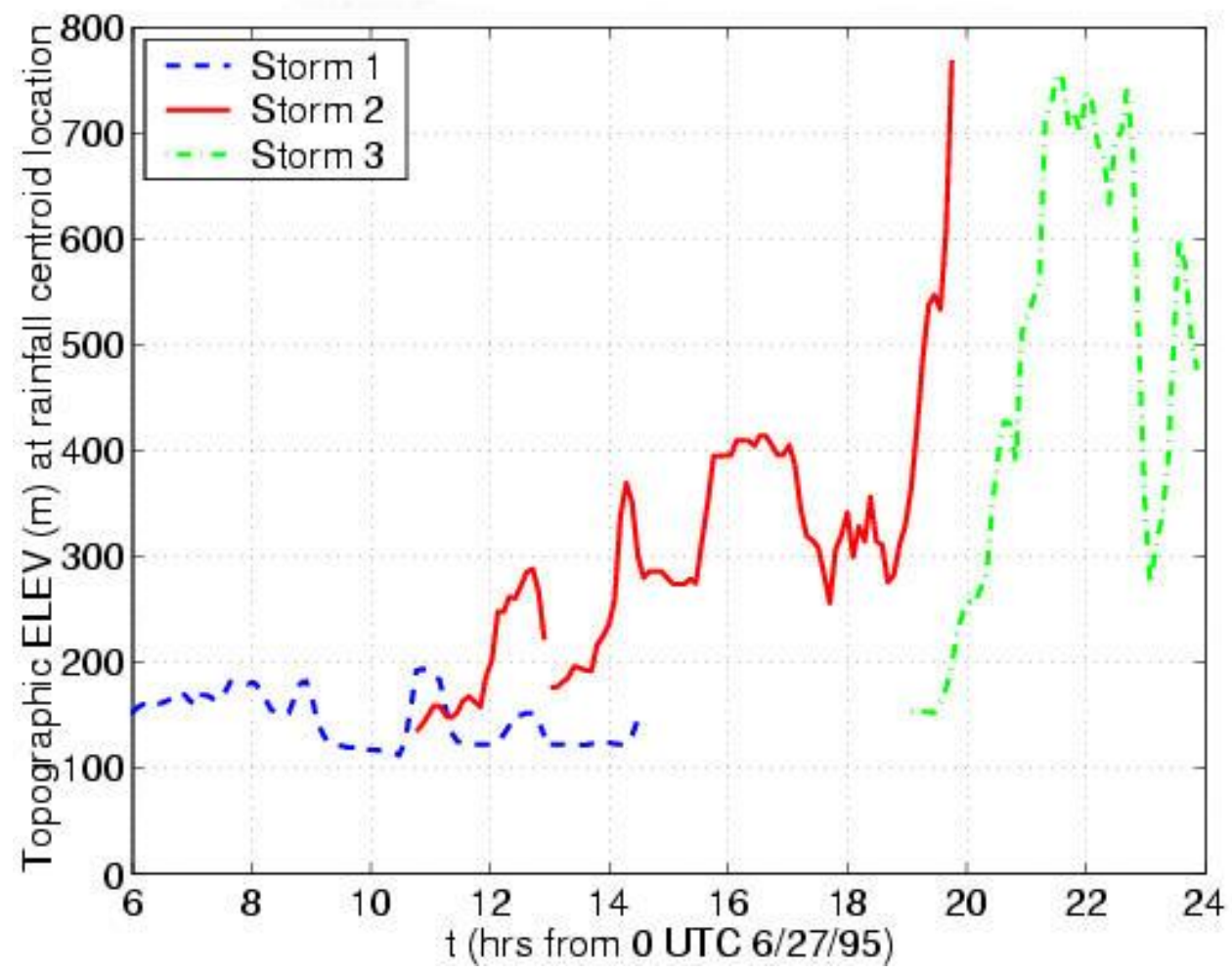

Figure 5.3 Topographic elevation of the surface rainfall centroid for the Rapidan River basin and southern Virginia storm of 27 June 1995. The topographic elevation associated to rainfall centroid location has been plotted as 18-min moving average, so that each elevation was averaged with that from the previous and following rainfall fields, 6 min later and 6 min earlier, respectively (From Nykanen and Harris 2003]). 


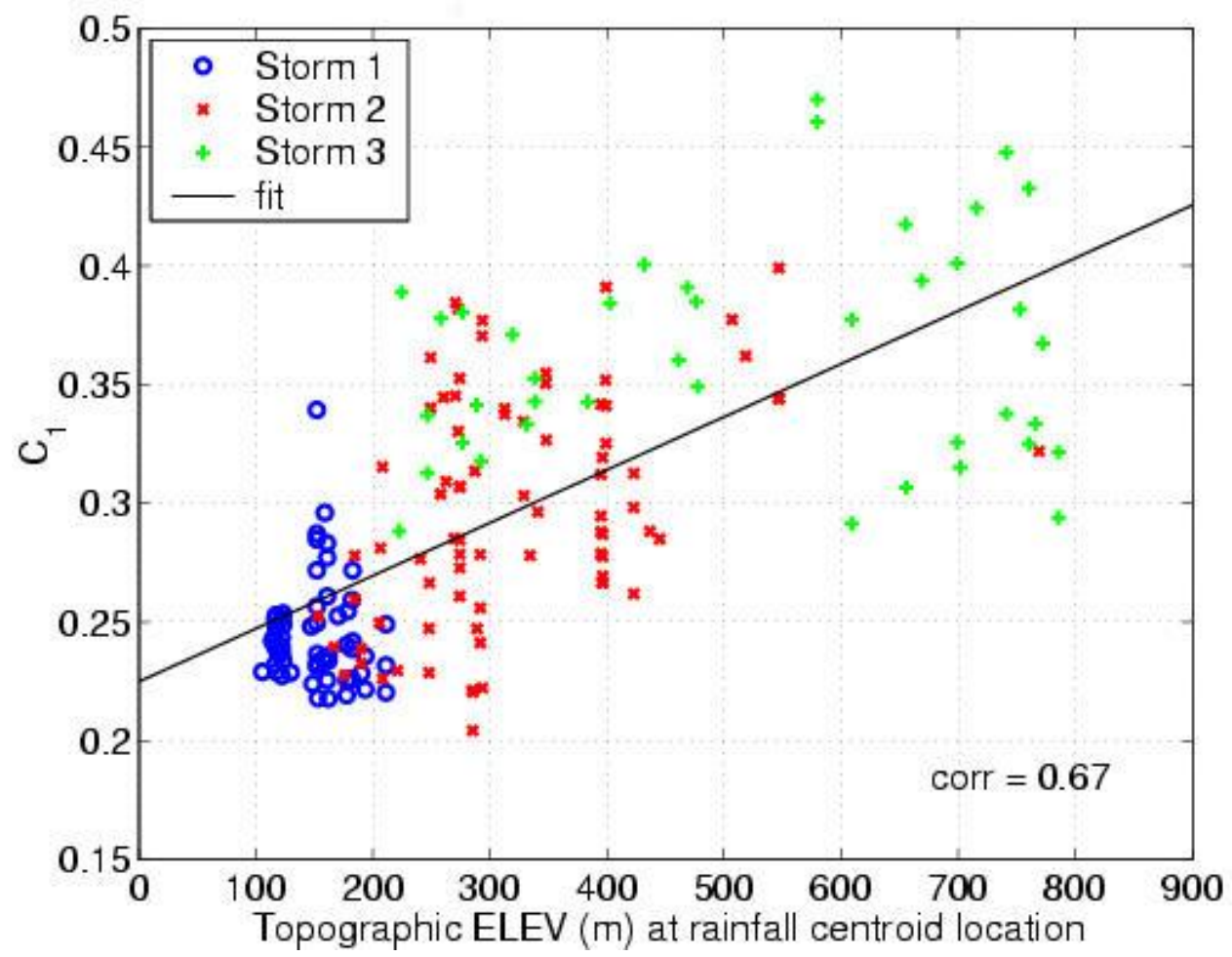

Figure 5.4 Correlation of $C_{1}$ to topographic ELEV for the Rapidan River basin and southern Virginia storm of 27 June 1995. The actual values for the $C_{1}$ and topographic ELEV pairs have been plotted and used in computing the correlation rather than the 18-min moving average values (From Nykanen and Harris [2003]). 


\subsubsection{Redbank Creek Storm of July 18-19, 1996}

The Redbank Creek storm occurred in the western slope of the Appalachian mountains on July 18-19, 1996 and is the only windward case considered. The multiscaling parameters for this case were computed using moving windows that were intended to encompass the entire spatial extent of each system. The scaling range used to compute $\beta$ for this case was 2 to $\sim 25 \mathrm{~km}$. In order to calculate $H$ the scaling range used was 2 to $\sim 10 \mathrm{~km}$. The same procedure used to compute the multiscaling parameters and scaling range in determining $\beta$ and $H$ was performed for the Rocky Mountain case studies considered below. In all four cases, these scaling ranges were selected visually and they were specified in regards to how representative the fit was in obtaining a meaningful value. An example was shown throughout Chapter 3 for both parameters $\beta$ and $H$ in Figures 3.3 and 3.4 for the Fort Collins storms of July 28-29, 1997 at 1915 UTC and 2239 UTC during July 28, and 0257 UTC and 0733 UTC during July 29.

The multiscale statistical parameters $H$ and $\alpha$ are shown in Figure 5.5. The temporal evolution of the organization parameter $H$ indicated that the rainfall fields of the various systems had different trends. Storm 1 and 3 were found to have decreasing trends, while Storm 2 and 4 had increasing trends. Storms 1 and 3 were the systems that produced the heaviest and most widespread rainfall of the whole event. The fall in the $H$ value during Storm 1 could be caused by the transition from a few convective systems initiating the storm to a multitude of widespread convective cells. Afterwards, the storm moved as a squall line south-eastward into higher topography, and the rainfall field became more organized. The smaller and decreasing trend in the organization of Storm 3 could be associated to the character of the storm, which behaved as a large organized series of convective storm clusters that moved rapidly $(25-30 \mathrm{~km} / \mathrm{h})$ into higher topography. On the other hand, Storms 2 and 4 were smaller in magnitude and area. Both storms showed an increment in the 
organization as they evolved. However, Storm 4, that was characterized as a squall line, was found to yield higher values indicating a more organized rainfall field. The shape parameter $\alpha$ did show higher values during Storms 1 and 3, where $\alpha$ was close to 2 during the whole period. These results indicate that more extreme fluctuations were present in these storms compared to the lower values obtained for Storms 2 and 4 .

The results obtained for the intermittency parameter $C_{1}$ are consistent with the physical interpretations provided by Purdy et al. [2001]. Figure 5.6 (a) shows the temporal evolution of $C_{1}$. Lower values were found for Storms 1 and 3 indicating the widespread nature of the rainfall, where both illustrated increasing intermittency at higher topographic elevations. However, Storm 3 showed a slight decrease in the intermittency during its initial stages of development. The growth of individual rain cells during Storm 2 could explain the higher intermittency observed, which increases as the storm moved into higher topography. In contrast, Storm 4 showed a pronounced reduction of the intermittency as the storm developed and passed over a ridge. Furthermore, the topographic elevation of the surface rainfall centroids is shown in Figure 5.6 (b). It can be seen that in general all storms moved into higher topography, although a more drastic change in elevation is observed during Storms 2 and 3 .

The correlation between the multiscale parameter $C_{1}$ and the topographic elevation of the rainfall centroids is depicted and measured in Figure 5.7, where a correlation value of 0.43 was found. The trends in $C_{1}$ and elevation were comparable over time but with weaker correlation than was found in the Rapidan River storm case. 
(a)
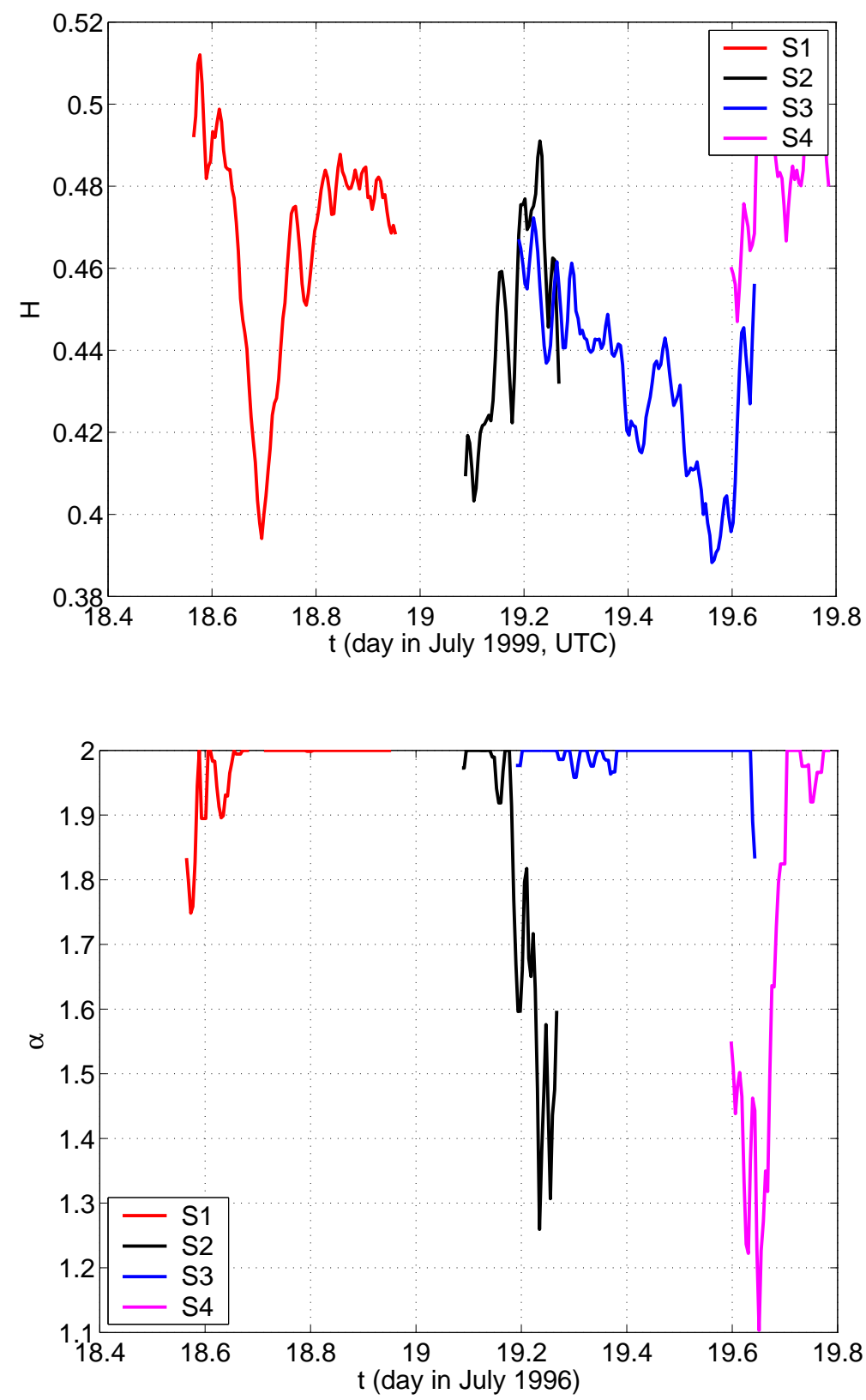

(b)

Figure 5.5 Multiscale statistical parameters $H$ and $\alpha$ for the Redbank Creek storm of July $18-19,1996$. The parameters have been plotted as 18-min moving average, so that each value was averaged with that from the previous and following rainfall fields, 6 min later and 6 min earlier, respectively. (a) Hurst exponent $H$ and (b) the shape parameter $\alpha$. 
(a)
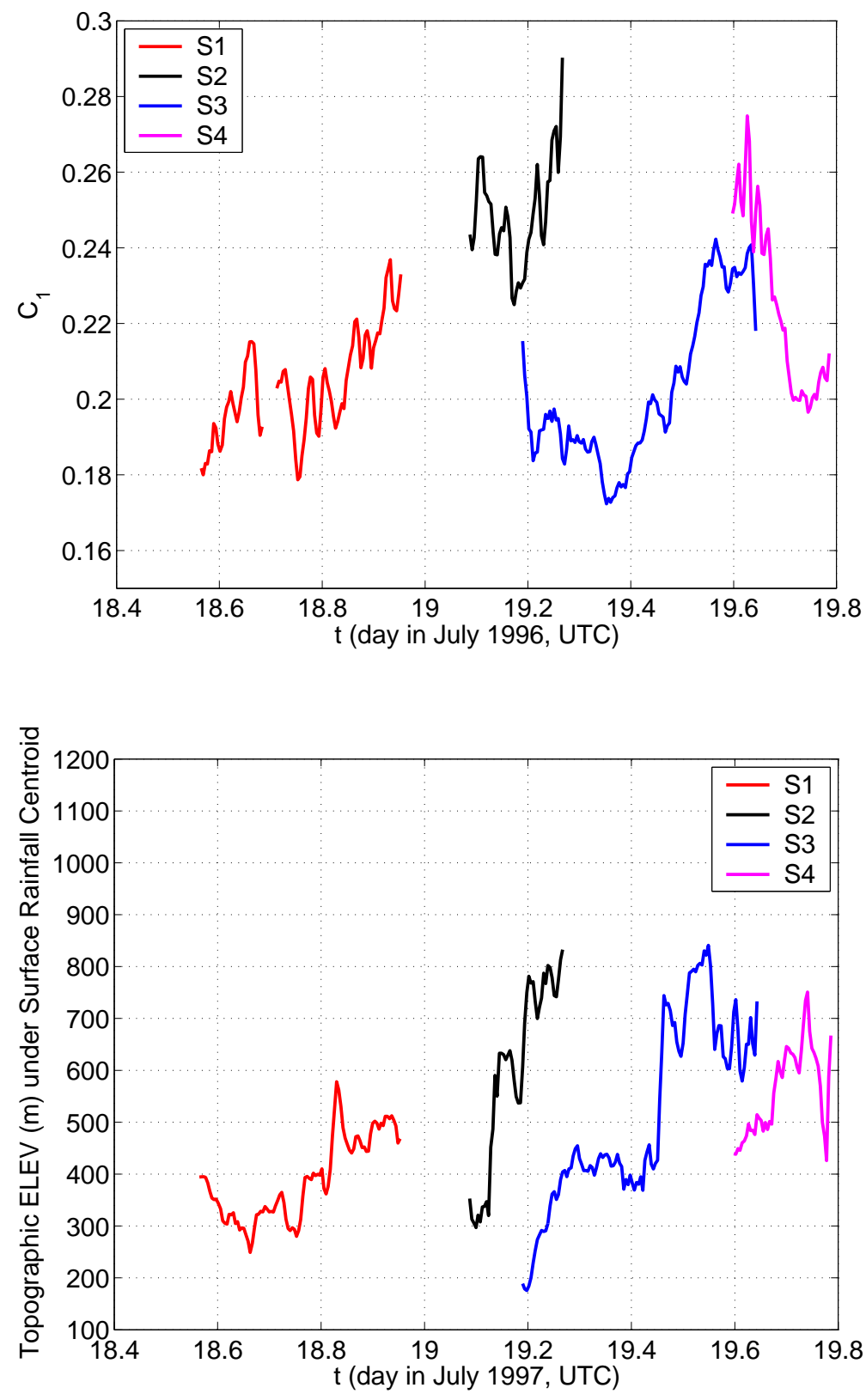

(b)

t (day in July 1997, UTC)

Figure 5.6 Intermittency parameter and topographic elevation for the Redbank Creek storm of July 18-19, 1996. The parameters have been plotted as 18-min moving average, so that each value was averaged with that from the previous and following rainfall fields, 6 min later and $6 \mathrm{~min}$ earlier, respectively. (a) intermittency parameter $C_{1}$ and (b) topographic elevation of the surface rainfall centroid. 


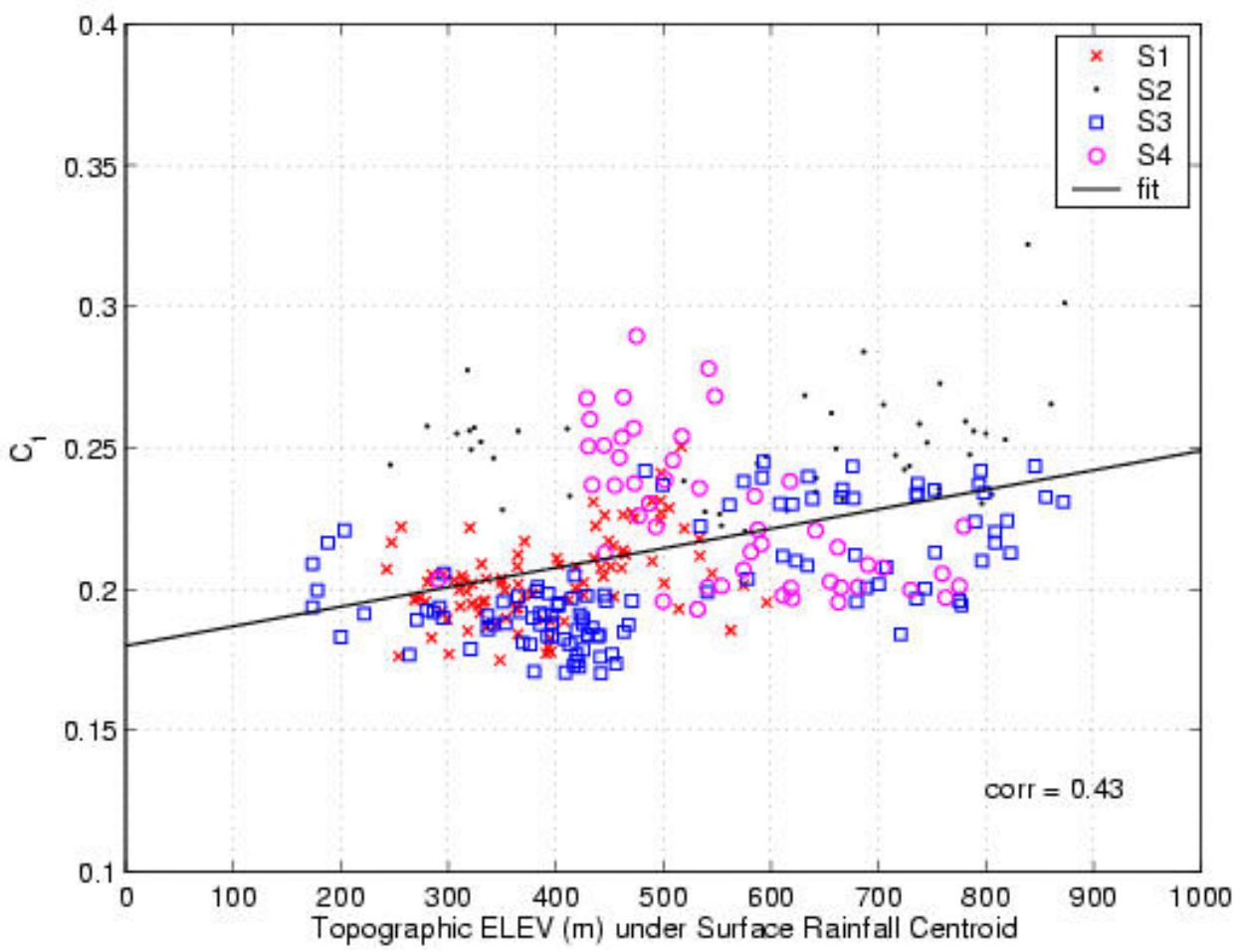

Figure 5.7 Correlation of $C_{1}$ to topographic ELEV for the Redbank Creek storm of July 18-19 July, 1996. The actual values for $C_{1}$ and topographic ELEV pairs have been plotted and used in computing the correlation rather than the 18-min moving average values. 


\subsubsection{Buffalo Creek Storm of July 12-13, 1996}

The multiscale parameters and surface rainfall centroids for the Buffalo Creek storms of July 12-13, 1996 were computed using 128 x $128 \mathrm{~km}^{2}$ moving windows. In Chapter 2 was portrayed the storm track map of the various systems that formed the event (see Figure 2.5).

The temporal evolution of the multiscale parameters $H$ and $\alpha$ is provided in Figure 5.8, Storm 1 showed an increasing trend in the $H$ value as the storm evolved. This storm was described as a convective system that moved over the plains to the east and became more organized (see Warner et al. [1999]). Storms 2, 3, 4, and 5 were formed by multiple convective systems associated to an outbreak. The heaviest rainfall and flooding was produced by Storm 2, which had lower organization at the beginning, corresponding with a period of high net storm motion. The increase in $H$ is coincident with the slower motion of the event due to an interaction with an outflow boundary. The lower $H$ values during Storm 5 along with the presence of a decreasing trend indicates that the storm environment was less organized. The values of the shape parameter $\alpha$ were significantly low. Values varied from 0.9 to 1.4 and were found to be highly variable for all five systems.

The intermittency parameter $C_{1}$ and the topographic elevation of the rainfall centroids are depicted in Figure 5.9 for all five storms. A decreasing trend in $C_{1}$ during Storms 1, 2, and 3 can be observed. The low $C_{1}$ values mean that rainfall usually fluctuates by small amounts, so that the rainfall is relatively steady. Lower $C_{1}$ are associated with widespread background rainfall features (e.g., embedded convection, mixed stratiform/convective, or stratiform rainfall) (see Purdy et al. [2001] and Nykanen and Harris [2003]). Storm 4 was found to yield lower $C_{1}$ values, yet they remained quite similar over time and no trend was evident. On the other hand, the quasi-stationary movement, unstable air, and strong convection triggered by a drastic enhancement of the elevation during Storm 5 would be a sign of its higher 
(a)
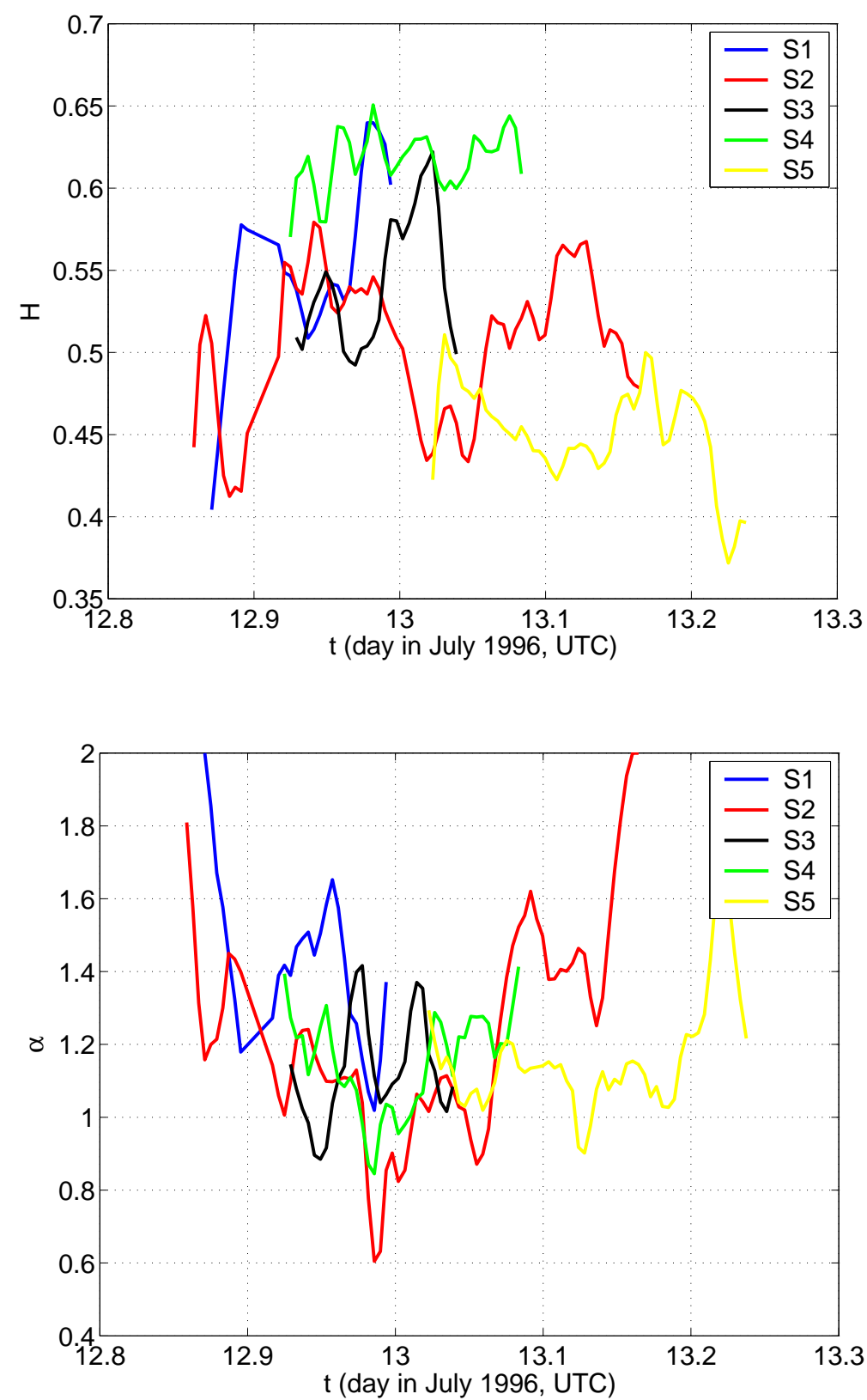

(b)

Figure 5.8 [Multiscale statistical parameters $H$ and $\alpha$ for the Buffalo Creek storm of July $12-13,1996$. The parameters have been plotted as 18 -min moving average, so that each value was averaged with that from the previous and following rainfall fields, $6 \mathrm{~min}$ later and $6 \mathrm{~min}$ earlier, respectively. (a) Hurst exponent $H$ and (b) the shape parameter $\alpha$. 
(a)
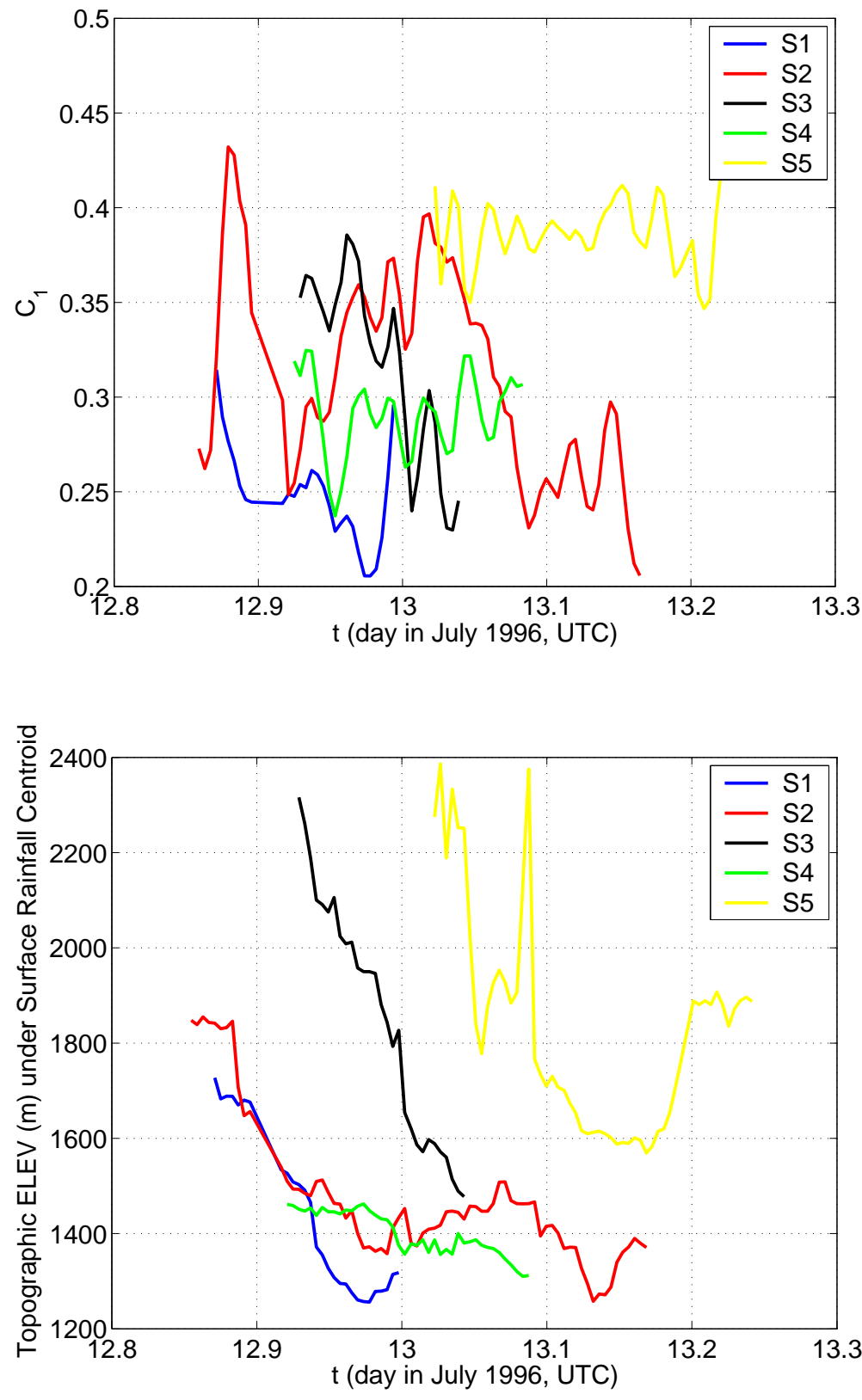

(b)

Figure 5.9 Intermittency parameter and topographic elevation for the Buffalo Creek storm of July 12-13, 1996. The parameters have been plotted as 18-min moving average, so that each value was averaged with that from the previous and following rainfall fields, 6 min later and 6 min earlier, respectively. (a) intermittency parameter $C_{1}$ and (b) topographic elevation of the surface rainfall centroid. 


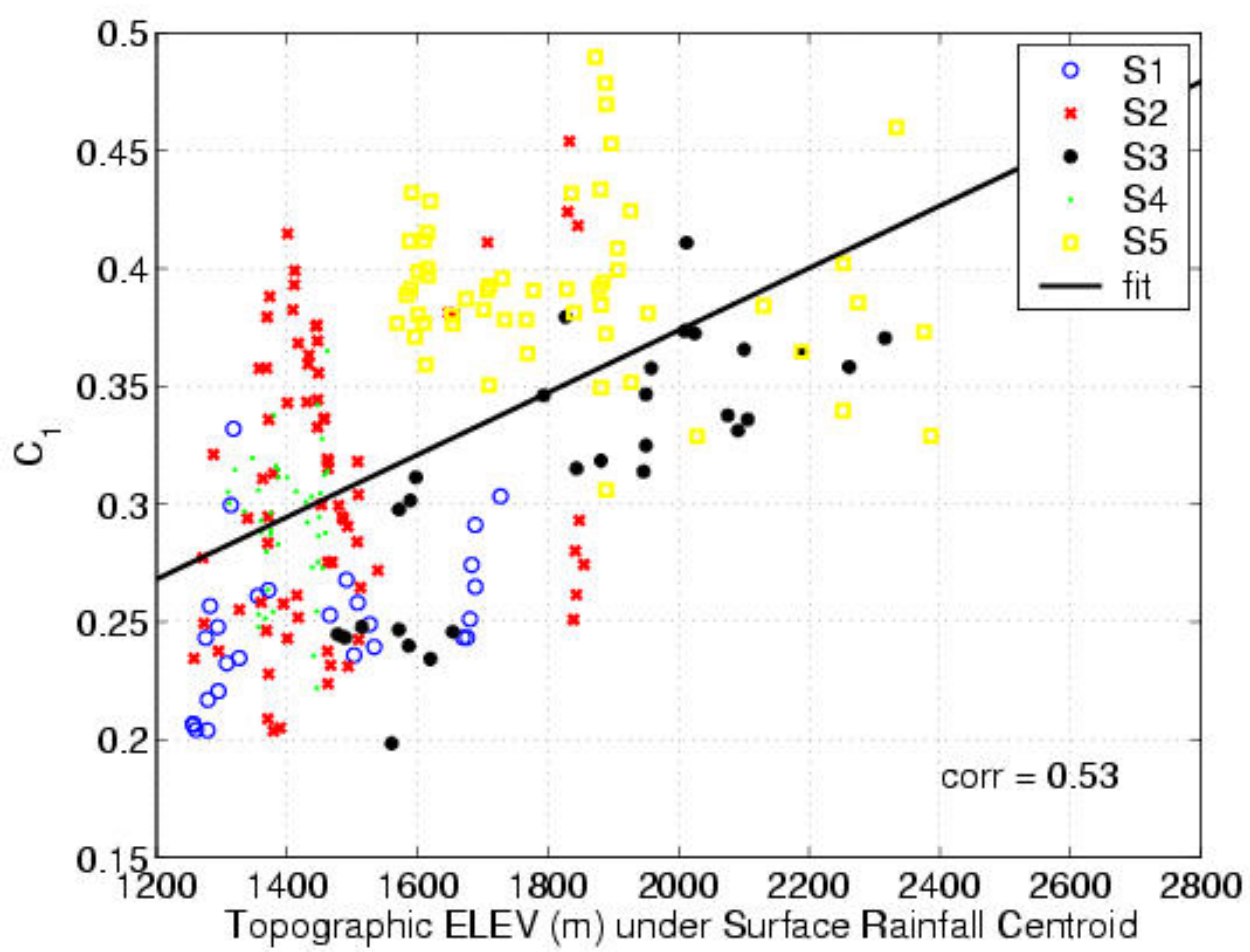

Figure 5.10 Correlation of $C_{1}$ to topographic ELEV for the Buffalo Creek storm of 12-13 July, 1996. The actual values for $C_{1}$ and topographic ELEV pairs have been plotted and used in computing the correlation rather than the 18-min moving average values..

intermittency on the rainfall field. The topographic elevation of the surface rainfall centroids of the various systems are shown in Figure 5.9 (b). Decreasing trends were observed for all five storms, with significantly higher drops during Storms 1, 3, and 5 compared to Storms 2 and 4.

Trends in $C_{1}$ and the topographic elevation of the rainfall centroids were similar over time and a correlation coefficient of 0.53 was shown in Figure 5.10 . This result corroborates with that found for the Rapidan River basin and southern Virginia storm of June 27, 1995 for which the meteorological features were more similar to the Buffalo Creek storm than to the Redbank Creek storm. 


\subsubsection{Fort Collins Storm of July 28-29, 1997}

The Fort Collins storms occurred on the eastern slope of the Rocky Mountains. As was mentioned before, moving windows were used to compute the surface rainfall centroids and the multiscaling parameters. In Chapter 2, the storm track maps of the two system were provided (see Figure 2.6).

The temporal evolution of the multiscale parameters $H$ and $\alpha$ are shown in Figure 5.11. The storm organization parameter $H$ was found to remain very stable during the whole event. Both storms appeared to be very organized with no apparent presence of any trend. However, slight higher $H$ values were observed during the July 29 event, indicating more organization compared to the July 28 event. On the other hand, the shape parameter $\alpha$ remained approximately equal to 2 over the whole duration of the event, except for the first and last stages of the July 29 storm, indicating the presence of smaller extreme fluctuations. High $\alpha$ values would be expected for convective rainfall and they would indicate the presence of extreme fluctuations in the rainfall field.

The intermittency parameter $C_{1}$ showed a significantly decreasing trend as the storm moved over lower topography. The $C_{1}$ and topographic elevation of the rainfall centroids are depicted in Figure 5.12. It was observed that the July 28 storm remained centered over complex terrain. This system was characterized by stationary convection having higher intermittency and clustering of peak rain rate values in the rainfall field than those found during the July 29 storm. In contrast, the convection of the July 29 storm was associated to a bow echo that moved into lower topography at high net storm motion. This system depicted a considerable decrease in the intermittency as the storm evolved. It can be observed from Figure 5.12 that trends in $C_{1}$ and topographic elevation were similar over time.

The correlation between $C_{1}$ and orography is shown in Figure 5.13. Two correlation coefficients were computed for this case. The dashed line corresponds to the 


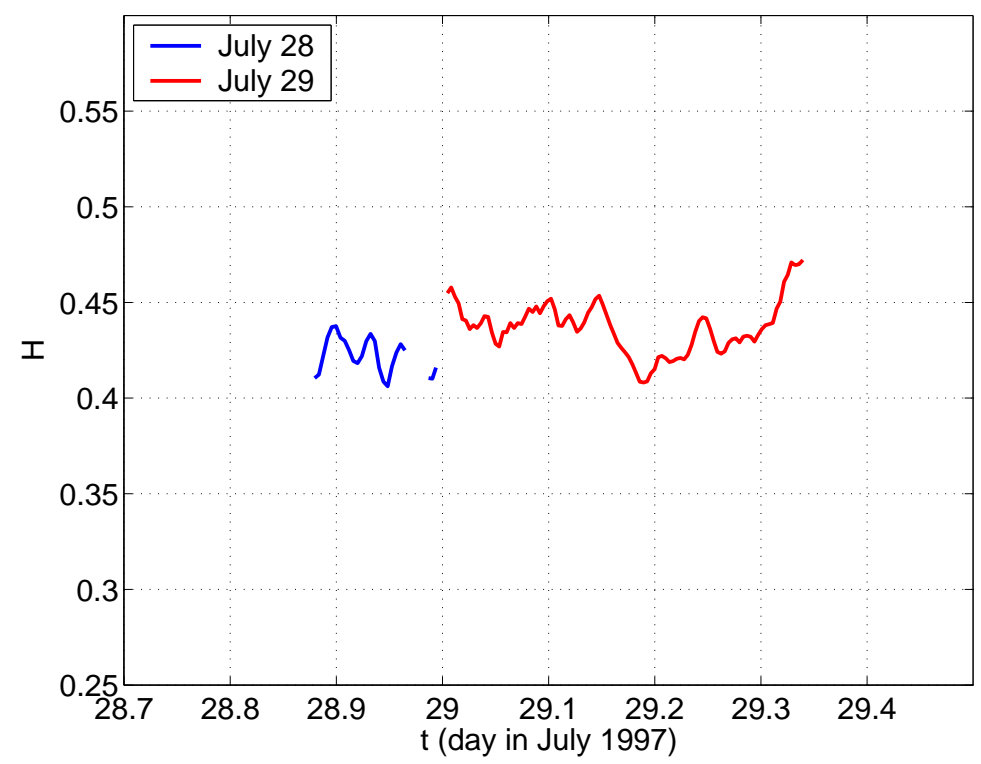

(a)

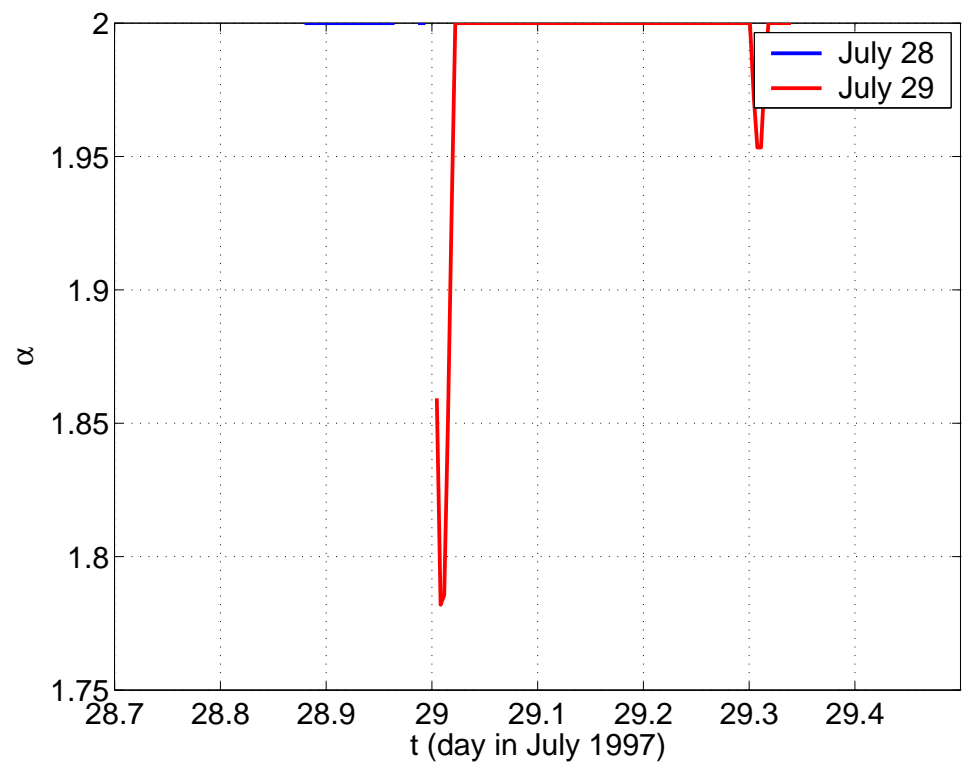

(b)

Figure 5.11 Multiscale statistical parameters $H$ and $\alpha$ for the Fort Collins storm of July 28-29, 1997. The parameters have been plotted as 18-min moving average, so that each value was averaged with that from the previous and following rainfall fields, 6 min later and 6 min earlier, respectively. (a) Hurst exponent $H$ and (b) the shape parameter $\alpha$. 
(a)

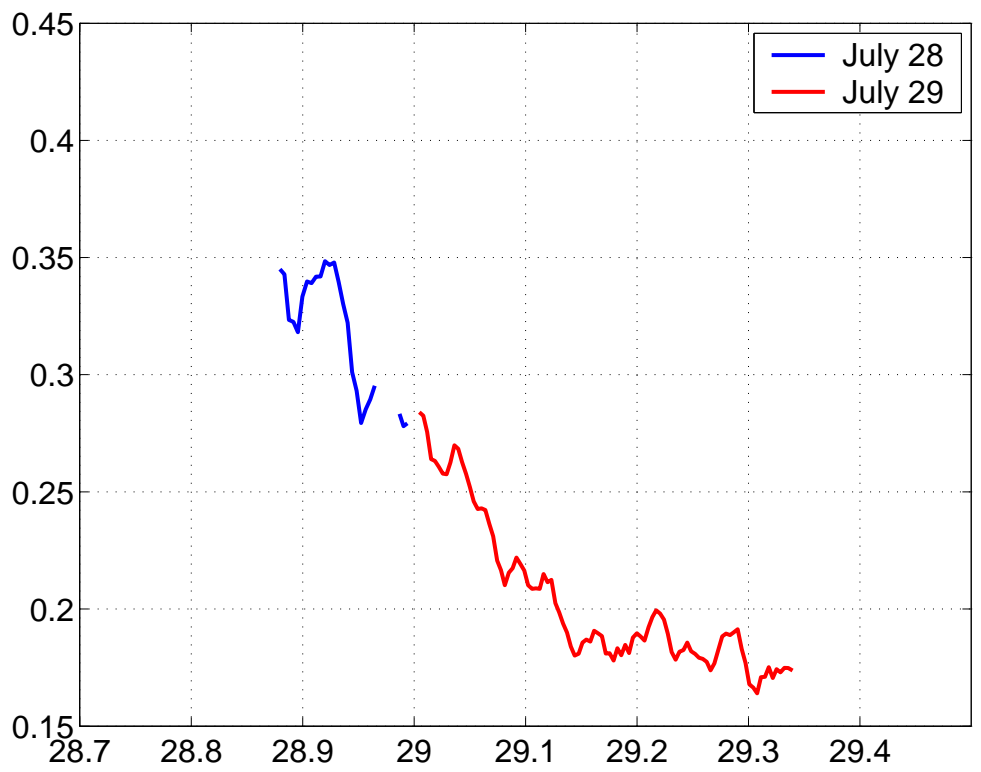

(b)

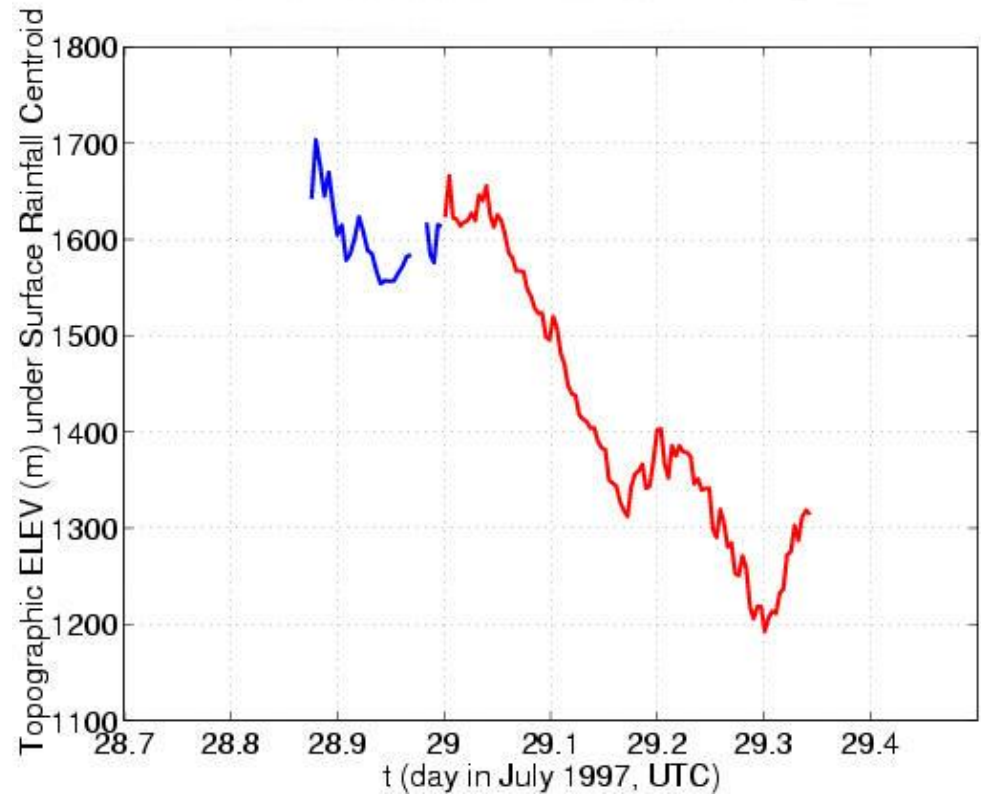

Figure 5.12 Intermittency parameter and topographic elevation for the Fort Collins storm of July 28-29, 1997. The parameters have been plotted as 18-min moving average, so that each value was averaged with that from the previous and following rainfall fields, 6 min later and 6 min earlier, respectively. (a) intermittency parameter $C_{1}$ and (b) topographic elevation of the surface rainfall centroid. 


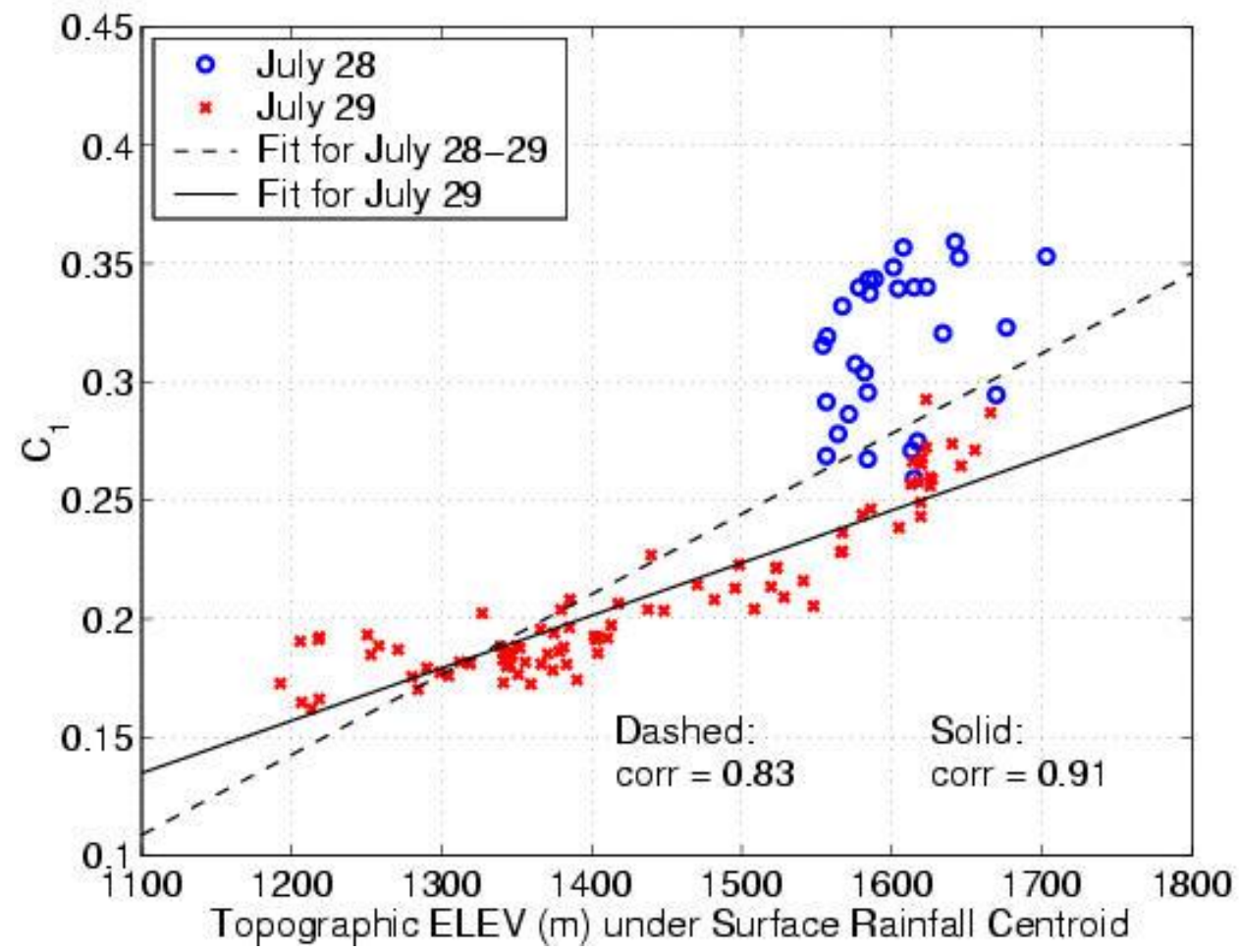

Figure 5.13 Correlation of $C_{1}$ to topographic ELEV for the Fort Collins storm of 28-29 July, 1997. The actual values for $C_{1}$ and topographic ELEV pairs have been plotted and used in computing the correlation rather than the 18 -min moving average values.

correlation coefficient that accounted for the whole event, where a correlation coefficient value of 0.83 was obtained. The solid line fit only considered the event that occurred during July 29. In this case, $C_{1}$ had a stronger correlation with elevation, and a correlation coefficient value of 0.91 was found. 


\subsubsection{Loveland Pass Storm of July 28-29, 1999}

The Loveland Pass storm of July 28-29, 1999 is the last event considered. The rainfall sequence of the storms indicated the presence of an organization and motion of multiple widespread storms over large spatial scales.

The results obtained for the organization parameter $H$ and $\alpha$ can be seen in Figure 5.14. Storms 1 and 2 had an increase in the organization of the storm as they developed. On the other hand, Storms 3, 4, and 5 appeared to be mostly steady over the whole period and no significant changes in the organization of the rainfall field were found. Figure 5.14 also verified the highly sensitive nature of the shape parameter $\alpha$. However, Storm 3 showed lower peaks in $\alpha$.

The temporal evolution of the intermittency parameter $C_{1}$ and the topographic elevation of the rainfall centroids are shown in Figure 5.15. The intermittency parameter $C_{1}$ pointed out decreasing trends for all five storms, which is consistent with the widespread character of the rainfall systems. The topographic elevation associated to the rainfall centroids of each storm reported a significant change in elevation during Storm 1, which moved eastward from the Rocky Mountains. However, the other four storms showed only slight changes in elevation. Storm 2 and 3 appeared to be mostly stationary and remained centered over complex terrain, while Storm 4 and 5 remained over lower terrain as shown in Figure 2.7 (Chapter 2).

Trends in $C_{1}$ and elevation were similar over time with Storm 1 having the strongest correlation. The temporal evolution of the intermittency parameter $C_{1}$ and the topographic elevation is combined in Figure 5.16 in order to quantify the correlation between them. A value of 0.62 for the correlation coefficient was found between $C_{1}$ and topographic elevation. These findings corroborate the results obtained for the rest of the case studies showing an increasing trend in $C_{1}$ with topographic elevation. 
(a)
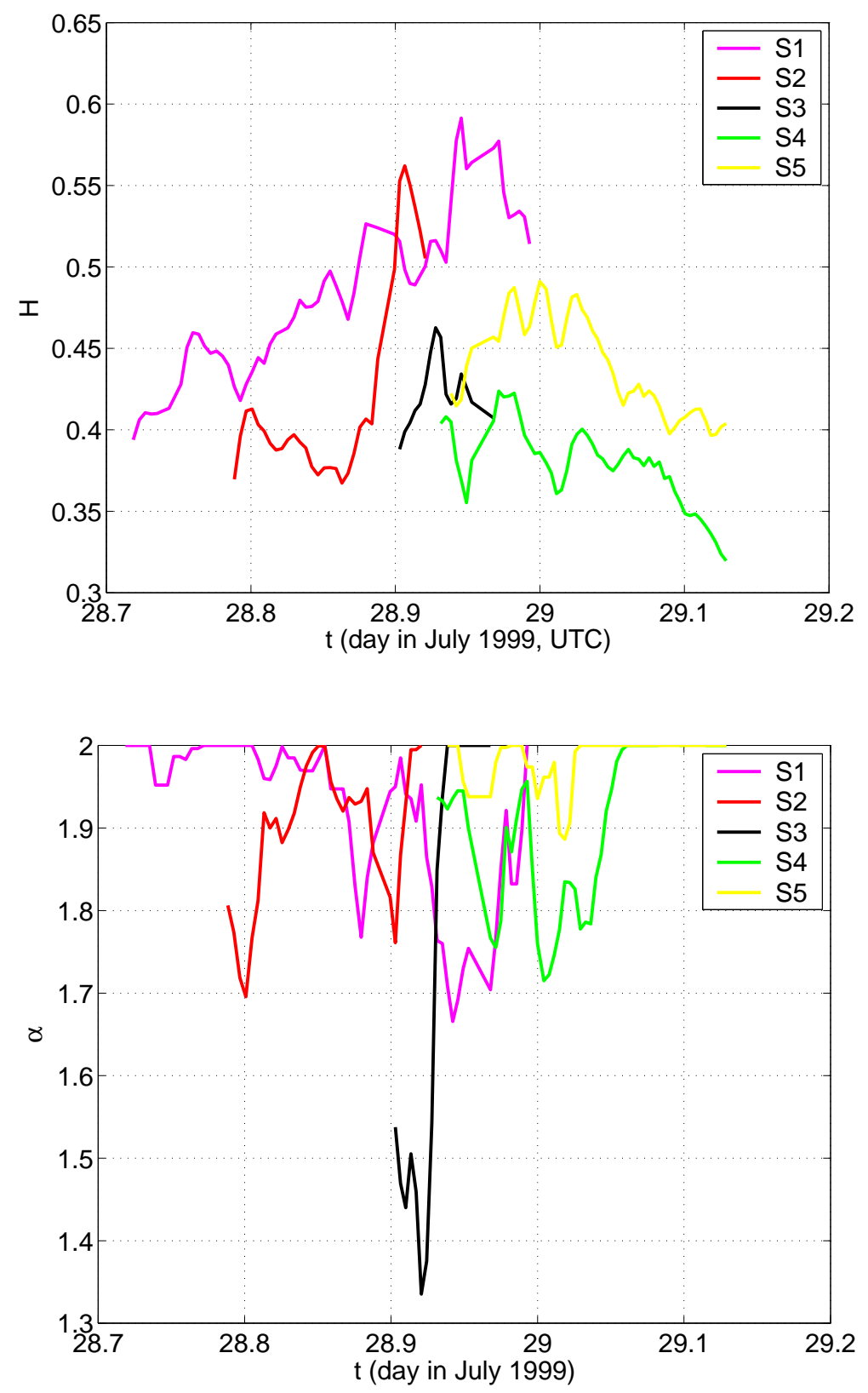

(b)

Figure 5.14 Multiscale statistical parameters $H$ and $\alpha$ for the Loveland Pass storm of July 28-29, 1999. The parameters have been plotted as 18-min moving average, so that each value was averaged with that from the previous and following rainfall fields, 6 min later and 6 min earlier, respectively. (a) Hurst exponent $H$ and (b) the shape parameter $\alpha$. 
(a)
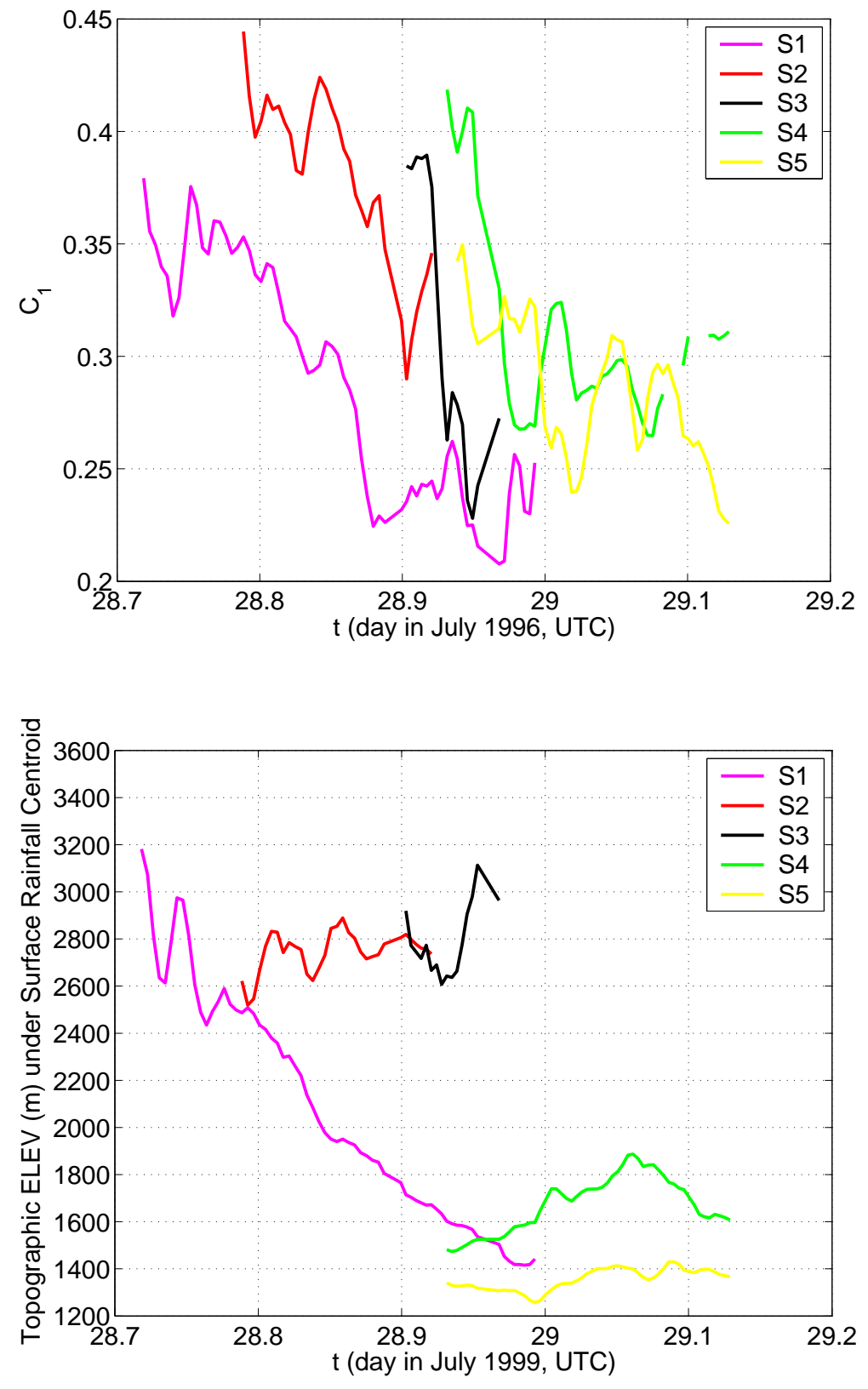

(b)

Figure 5.15 Intermittency parameter and topographic elevation for the Loveland Pass storm of July 28-29, 1999. The parameters have been plotted as 18-min moving average, so that each value was averaged with that from the previous and following rainfall fields, 6 min later and 6 min earlier, respectively. (a) intermittency parameter $C_{1}$ and (b) topographic elevation of the surface rainfall centroid. 


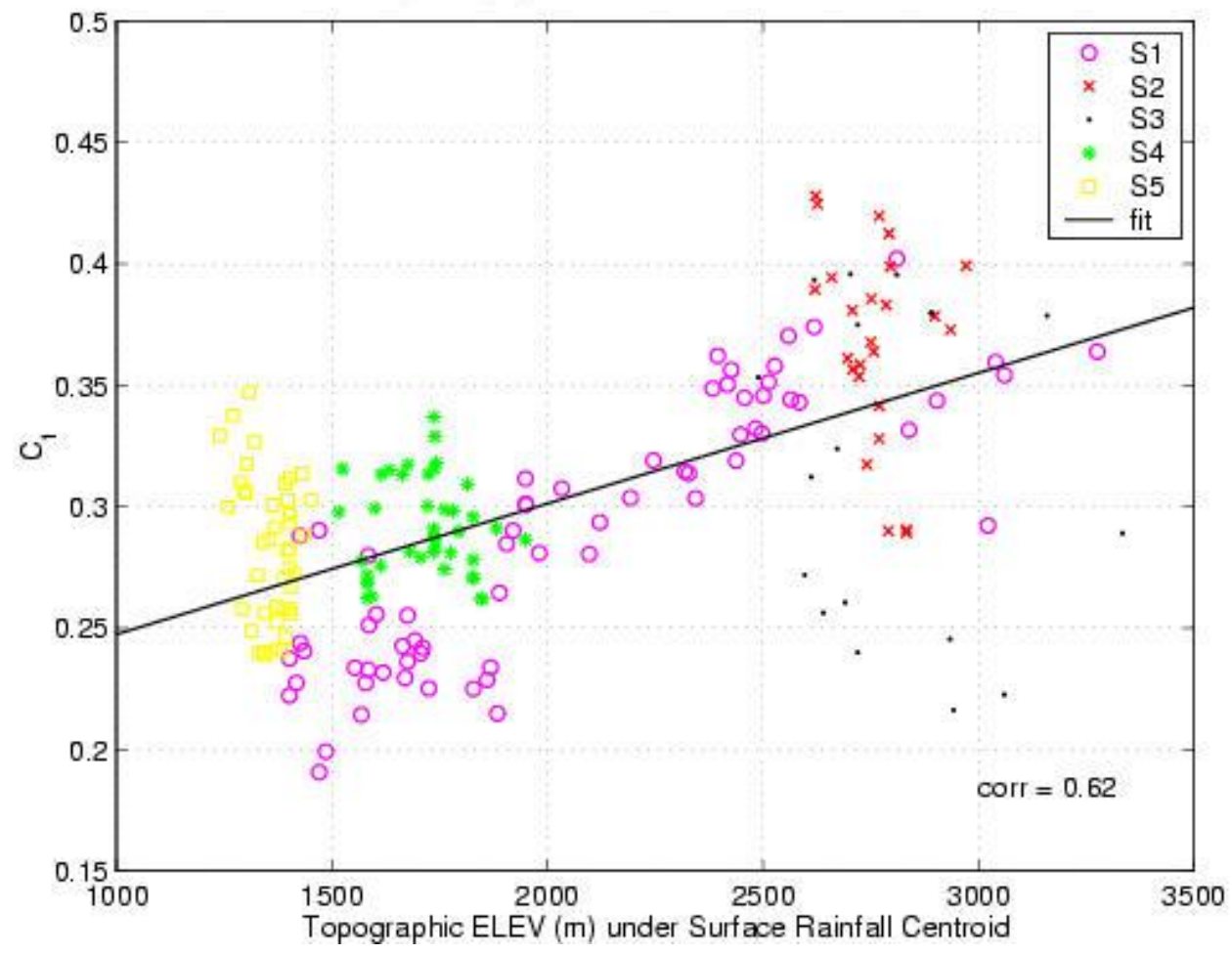

Figure 5.16 Correlation of $C_{1}$ to topographic ELEV for the Loveland Pass storm of July 28-29, 1999. The actual values $C_{1}$ and topographic ELEV pairs have been plotted and used in computing the correlation rather than the 18 -min moving average values. 


\subsection{Summary of Results}

A summary of the correlation between $C_{1}$ and the topographic elevation obtained for each case study, slope and y-intercept is presented in Table 5.1 (a value of the slope of 0.000223 means $0.223 / 1000$ - ft or that $C_{1}$ changes by 0.223 in $1000 \mathrm{ft}$ elevation change). In addition, a correlation between $C_{1}$ and the topographic elevation has been plotted for all Rocky Mountain case studies, all leeward-side events, and all case studies. In Figure 5.17 (b) and Figure 5.18, the topographic elevations were normalized by subtracting the baseline elevation for each case study (100 $\mathrm{m}$ for the Rapidan Storm and $1200 \mathrm{~m}$ for the Rocky Mountains storm). It can be seen that two correlation values were computed when considering all Rocky Mountains events. A correlation of 0.48 was found when all the events were considered compared to a correlation coefficient of 0.60 when the Loveland Pass Storm was not included. The same procedure was followed for the computation of the correlation coefficient for all leeward-side events. A correlation coefficient of 0.46 was found for all the events, while a correlation coefficient of 0.59 was obtained when the Loveland Pass Storm was not included. This was due to the flatter slope found for this case in comparison to the others (see Table 5.1.

\begin{tabular}{|c|c|c|c|}
\hline Storm & Correlation $\left(C_{1}\right.$ vs. ELEV $)$ & slope & $\mathrm{y}$-intercept \\
\hline Rapidan River & 0.67 & 0.000223 & 0.224871 \\
\hline Redbank Creek & 0.43 & 0.000069 & 0.179982 \\
\hline Buffalo Creek & 0.53 & 0.000132 & 0.109604 \\
\hline Fort Collins & 0.81 & 0.000339 & -0.264022 \\
\hline Loveland Pass & 0.62 & 0.000054 & 0.193462 \\
\hline
\end{tabular}

As shown in Figure 5.17, a generalized trend in $C_{1}$ and topographic elevation was 
found across all leeward-side cases, even though the Appalachian storm was moving into higher topography and the Front Range storms were moving into lower topography. Also, the windward-side event was found to have increasing $C_{1}$ with topographic elevation but had weaker correlation than the leeward-side events. A correlation coefficient value of 0.41 was found when considering all case studies as depicted in Figure 5.18. These results highlight that elevation appears to have potential as a predictor of $C_{1}$. Further research is needed to better understand why the Loveland Pass and Redbank Creek storms have flatter slopes. The explanation can most likely be found through a more complete comparison of storm environments amongst the different cases. This would require the availability of a more detail information in regards to the meteorology variables that characterize the storm environments of the various events. 
(a)
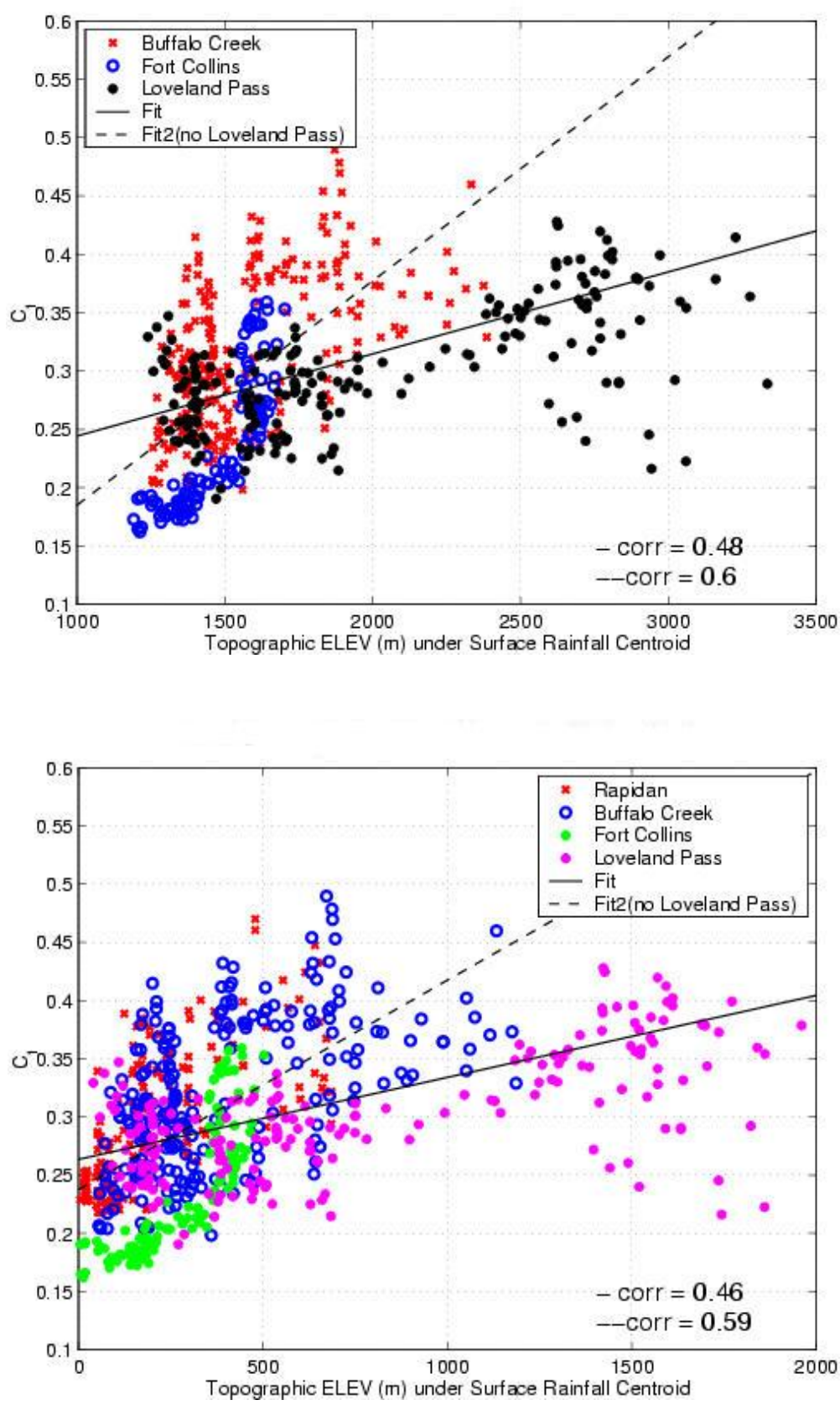

Figure 5.17 Correlation of $C_{1}$ to topographic elevation for (a) all Rocky Mountain cases and (b) all leeward-side case studies. The actual values for $C_{1}$ and topographic elevation pairs have been plotted and used in computing the correlation rather than the 18-min moving average values. The topographic elevations were normalized in (b) by subtracting the baseline elevation for each case study (100 m for the Rapidan Storm and $1200 \mathrm{~m}$ for the Rocky Mountains Storms). 


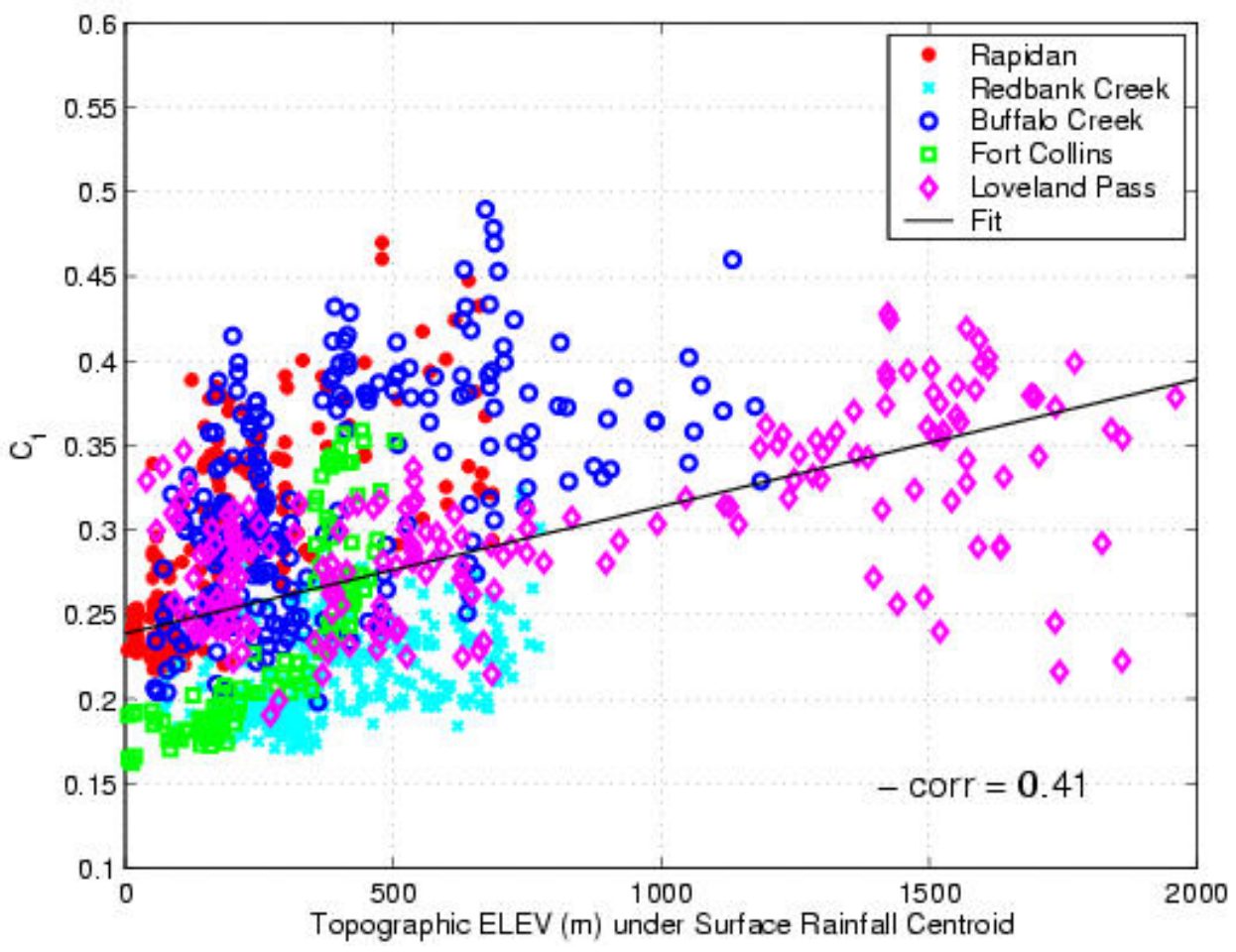

Figure 5.18 Correlation of $C_{1}$ to topographic elevation for all case studies. The actual values for $C_{1}$ and topographic elevation pairs have been plotted and used in computing the correlation rather than the 18-min moving average values. The topographic elevations were normalized in (b) by subtracting the baseline elevation for each case study (100 m for the Appalachian Mountains Storms and $1200 \mathrm{~m}$ for the Rocky Mountains Storms). 


\subsection{Multiscale Behavior and Meteorological Indices}

Several stability indices for the various case studies were presented and interpreted in Chapter 4. The preliminary findings obtained for these indices are intended to shed some light on the difference between the multiscale behavior of the events considered in this study. However, additional meteorological information for the case studies, such as numerical weather prediction model output, is needed to more completely address the linkages between multiscale parameters and storm environment.

\section{Severe Weather Threat Index (SWEAT) and Total Totals Index (TOTL).}

The $S W E A T$ index measures the potential for severe weather, whereas the TOTL index shows instability in the atmosphere as indicated in Appendix A (see Table A.2 and Table A.5 for reference). These two indices were only reported during Rapidan River storms and Redbank Creek storms (see Figure 4.1 (a) and (c) in Chapter 4). The differing values obtained during these two storms may be linked to the weaker correlation obtained during Redbank Creek storms. However, further results would be needed during the other case studies to better explore this potential relationship.

Lifted Index (LI) and Level of Free Convection (LFCT). The $L I$ is a stability parameter. Positive values indicate a stable atmosphere, while negative values are associated with a more unstable atmosphere as reported in Table A.1. During Redbank Creek storms significantly higher $L I$ index values were found as well as a different trend compared to the other cases (see Figure 4.2). This result pointed out a considerably more stable atmosphere during most of the period considered for this case. On the other hand, the level of free convection (LFCT) gives an idea of the potential of convection in the atmosphere. Table A.6 in Appendix A presented the range used to consider an atmosphere with weak to strong convective potential. For the Redbank Creek storms, LFCT was found to be greater (which means it was located at a lower height since higher pressure means lower height) than the rest of the events, 
indicating more potential for convection even without the presence of orographic lift. Moreover, the magnitude of the $L F C T$ values for this particular case were closer to the Rockies events than to the Appalachian event (Rapidan River storms). The contradicting findings obtained for these indices during the Redbank Creek storms may be related to the weaker correlation found between the intermittency parameter $C_{1}$ and topographic elevation.

Bulk Richardson Number (BRCH) and Convective Inhibition (CINS). As mentioned in Chapter 2, the $B R C H$ index is an indicator of convective storm environments, with higher values indicating a strong chance of convection. The CINS index provides information on the probability of a thunderstorm developing. Higher negative values indicate that the storm will be less likely to overcome the CINS. These two indices showed considerably different magnitudes during Redbank Creek storms and Buffalo Creek storms compared to the other three events in which similar trends and values over time were observed (see Figure 4.3 (c) and Figure 4.2 (c)). The $B R C H$ was significantly lower for these two case studies, indicating unlikely thunderstorm development (see Table A.9 in Appendix A). Also, higher negative CINS values were found during both storms, which is related to less probability of thunderstorm development (see Table A.8 in Appendix A). Again, these results lead to the hypothesis that the two parameters may be related to the lower correlation obtained between $C_{1}$ and topographic elevation during Redbank Creek storms and Buffalo Creek storms.

Lifting Condensation Level (LCLP) and Precipitable Water (PWAT). In Section 5.2, correlation coefficients were presented for all Rockies events and all leeward-side events with a value of 0.48 and 0.46 , respectively. Also, correlation coefficients were computed for all Rockies events and all leeward-side events, without considering the Loveland Pass storm. This fact resulted in an improvement in both 
correlation coefficient values, which yielded 0.60 and 0.59 , respectively. The reason in not considering Loveland Pass storms was due to its flatter slope (see Table 5.1) on the correlation between $C_{1}$ and topographic elevation. This may be in part due to its higher peak elevations and differences in trends of $C_{1}$ during most of the systems that formed the event. In Chapter 2 and Appendix A, LCLP was explained as the height at which clouds form, although the vertical extent of the cloud will depend on several factors such as temperature or moisture content. Loveland Pass storms did show the highest surface centroid elevations and LCLP was found to yield lower values (meaning higher height) than the other events (see Figure 4.3 (b)). In addition, the precipitable water index $P W A T$ reported lower values during this event than the other four storms (see Figure 4.4). These results may explain the flatter slope obtained between $C_{1}$ and topographic elevation during the Loveland Pass storms. however, future research is needed to better explore these potential relationships.

\subsection{Comparison to Multiscale Properties of Previ- ous Studies}

This section provides a comparison of the multiscaling results of previous studies Harris et al., 1996, Purdy et al., 2001, and Nykanen and Harris, 2003 and the results obtained in this work.

Harris et al. 1996] and Purdy et al. 2001] studied a storm that occurred November 5-9, 1994 in the Southern Alps of New Zealand. They found increasing scaling range and decreasing $C_{1}$ and $\beta$ with increasing topographic elevation from lowlands through the foothills and into the alpine region (see Figures 2 and 3c in Purdy et al. 2001), and both parameters were always positively correlated. In contrast, Nykanen and Harris 2003 found increasing trends in the multiscale parameters $C_{1}$ and $\beta$ (or $H$ ) with increasing topographic elevation, and decreasing trends in scaling range with 
increasing topographic elevation. They found positive correlation between $C_{1}$ and $H$ during Storms 1 and 2 which is consistent with the results of Purdy et al. 2001. However, during Storm 3 a decreasing $H$ was found with increasing $C_{1}$. The study presented in this thesis found increasing trends in the multiscale parameter $C_{1}$ with increasing topographic elevation as was found by Nykanen and Harris [2003]. For the systems moving into lower topography, increasing $H$ was found with decreasing $C_{1}$. Nevertheless, the Fort Collins storm did not show significant changes in the temporal evolution of $H$, yet $C_{1}$ decreased considerably with increasing elevation. Furthermore, the systems that remained over the same topographic elevation were found to yield decreasing $C_{1}$ with no significant variation or slightly decreasing $H$. On the other hand, the Redbank Creek storms moved into higher topography and a negative correlation between $C_{1}$ and $H$ was found during Storm 1 and 3, where decreasing $H$ was obtained with increasing $C_{1}$. However, Storm 2 did show a positive correlation between these two parameters.

This disagreement between studies demonstrates the importance of the interplay between meteorological forcings and topographic influences on the multi-scale properties of orographic rainfall. Contradicting trends between $C_{1}$ and $H$ in this study with those that were found in the Southern Alps events and Rapidan River storms can be explored by contrasting several key differences in the storm environment and meteorological conditions of the different locations and events as summarized in Chapter 2 and touched upon in Chapter 4.

The cases analyzed in this study were all leeward-side events, so that the prevailing winds aloft were southwesterly but the upslope low-level winds were easterly. However, the Redbank Creek storm was a windward-side event as the Southern Alps of New Zealand storms, meaning that the prevailing upper level winds were westerly and the upslope low-level winds were also westerly. Furthermore, the five events considered here were characterized by the dominance of warm rainfall processes. Whereas, the Southern Alps of New Zealand storm showed the presence of cold rain processes. 
The study of these cases provides the basis for a generality in $C_{1}$ and topographic elevation trends for leeward-side events. In addition, the weak correlation between $C_{1}$ and topographic elevation for the windward-side event (Case 2: Redbank Creek Storm) studied here does not provide enough evidence to support or deny potential differences in trends for leeward-side vs. windward-side orographic forcing.

The decrease in the intermittency $C_{1}$ and organization $\beta$ (or $H$ ) with increasing topographic elevation along the transect (see Figure 5.19) during the Southern Alps event can be explained through the processes associated to the rainfall. Purdy et al. 2001 reported that the system was dominated by cold rain and snow processes aloft in the alpine region, which combined with a supression mechanism produced the stabilization of the atmosphere upwind of the main divide. This aspect could have been the cause of preventing the propagation of convective cells from the lowlands to the alpine region. Furthermore, the presence of descending saturated air from the alpine region converging with the upslope lowland flow caused lateral spreading and mixed rainfall processes in the foothills, which would explain the trends found. These characteristics were not found during the events presented in this study, so no suppression mechanism or cold rain processes were observed. In contrast, they showed warm rainfall processes, and the propagation of convective elements were enhanced by upslope and upper-level winds, which forced the systems to moved towards or away from higher topographic elevations. Nykanen and Harris 2003 cited the absence of moist downdrafts as the primary key that verified the influence of the terrain in the storm motion during the Rapidan River case. Petersen et al. [1999] dicussed the presence of outflow boundaries during the Fort Collins storms, which played an important role in cell motion and distribution. In addition, the same role was associated with the presence of a weak stationary front forcing along with a jet stream (see Warner et al. [1999]) during the Buffalo Creek storms.

Difference in the magnitude of the intermittency parameter $C_{1}$ and organization $H$ were found between this study and the Southern Alps event. However, similar 
values were reported in the Rapidan River case. Table 5.2 summarizes the range reported on the multiscale parameters $\beta, H, C_{1}$, and $\alpha$ for the various case studies.

Table 5.2 Summary of the multiscaling paramters $H, C_{1}$, and $\alpha$ for each of the cases, including Harris et al. [1996] and Purdy et al. [2001] case study.

\begin{tabular}{cccc}
\hline Storm & $H$ & $C_{1}$ & $\alpha$ \\
\hline Southern Alps of New Zealand & & $0.04-0.28$ & \\
Rapidan River & $0.35-0.55$ & $0.23-0.45$ & $1.2-1.9$ \\
Redbank Creek & $0.39-0.51$ & $0.18-0.29$ & $1.2-2.0$ \\
Buffalo Creek & $0.40-0.63$ & $0.20-0.47$ & $0.7-1.9$ \\
Fort Collins & $0.40-0.47$ & $0.17-0.35$ & $1.8-2.0$ \\
Loveland Pass & $0.33-0.59$ & $0.21-0.44$ & $1.4-2.0$
\end{tabular}

Harris et al. 1996] found $C_{1}$ values that ranged between 0.192 to 0.04 from the lowlands to the main divide. The values found in this study for $C_{1}$ varied approximately from 0.17 to 0.45 . The lower $C_{1}$ values correponded to the windward-side event (Case 2: Redbank Creek Storm) which indicated a less intermittent field. In addition, $C_{1}$ increased with topographic elevation during all five events. The magnitudes of the values of the organization parameter $H$ values were found to be quite similar for the cases analyzed here and those obtained from Nykanen and Harris [2003]. $H$ varied from approximately 0.3 to 0.63 where the higher values were related to the Rocky Mountain case studies.

It is important to note that in previous studies by Harris et al. 1996] and Purdy et al. 2001 multiscale analysis was performed on 1-D temporal rainfall data (rain gages) and parameters were estimated along a transect during the Southern Alps event. On the other hand, this study was performed on 2-D spatial rainfall data (radar) and parameters were analyzed over time. As was mentioned by Nykanen and Harris 2003], only an assumption similar to that of "frozen turbulence" would 
allow a direct comparison of temporal and spatial statistics. This means that great prudence is required in order to compare actual parameter values between these studies. However, during this study focus was placed on the relative trends observed for the various parameters. Such comparison may be directly performed, since greater intermittency in a time series will typically correspond to greater intermittency in space. 


\section{Chapter 6}

\section{Conclusions and Future Research}

The purpose of this study was to investigate the spatial organization of several convective rainfall events that produced heavy rainfall and catastrophic flooding in mountainous regions using multiscale statistical analysis. The interplay of multiscale statistical parameters to meteorological processes for practical applications of multiscaling statistics was also investigated. This research was motivated by results obtained from previous studies such as Harris et al. [1996], Purdy et al. 2001, and Nykanen and Harris 2003], which indicated contradicting trends in the multiscaling parameter $C_{1}$ with the underlying topography in cases with contrasting storm environments. The results obtained in this study are summarized in the next section. Based on these findings, more work is recommended in order to develop a better understanding of the influence of meteorological forcings and topographic influences on the multiscale properties of orographic rainfall.

\subsection{Conclusions}

In this work, radar rainfall data and storm environments of five orographic precipitation events that were characteristic of organized thunderstorms and convection, and produced heavy rainfall and catastrophic flooding in complex terrain, were analyzed 
to better quantify the topographic influences on the multiscale properties of rainfall.

Scaling Range. Multiscaling behavior in the case studies was found in two dimensional (2-D) spatial patterns of orographic convective rainfall. The presence of scaling in orographic convective rainfall over a $2 \sim 20 \mathrm{~km}$ range was established. This is an essential step in the development of downscaling methods for orographic rainfall. Forecasts and satellite estimates of rainfall are examples of fields typically available at $\sim 20 \mathrm{~km}$ resolutions, whereas many hydrologic forecast models benefit from higher resolution estimates of rainfall $(\sim 4 \mathrm{~km})$.

Trends. The results obtained throughout this study showed generalized trends between the multiscale parameter $C_{1}$ and topographic elevation for the leeward-side events across case studies in the Appalachian Mountains and the Front Range of the Rocky Mountains. These findings lead to the hypothesis that the geographical regions of eastern versus western United States may not significantly alter trends. Furthermore, it is concluded that relative topographic change and storm environment may be the primary forcings in the multiscale properties $\left(C_{1}\right)$ of orographic convective rainfall. These results are important in the application of a downscaling procedure. The relationship between $C_{1}$ and topographic elevation would allow the estimation of the parameters used in a downscaling procedure when high resolution rainfall data is not available.

Storm Environment. This study indicates that storm environment plays a major role in determining the trends of orographic forcing on the multiscale properties of rainfall. As will be discussed in Section 6.2, the differences between leeward-side versus windward-side rainfall events and warm versus cold rainfall processes requires further investigation. In addition, the preliminary results of the atmospheric soundings for the case studies showed evidence of potential relationships between the stability indices obtained and the multiscale behavior of the various case studies. Differences 
between certain stability indices were associated with the weaker correlation related to the Redbank Creek storms as well as the lower correlation coefficient found during the Buffalo Creek storms. Also, some insight was provided through the discussion of the stability indices to understand the flatter slope found during the Loveland Pass storms. However, further investigation is required in regards to the meteorological forcings from a quantitative point of view due to the limited information of this study on the meteorological variables. This would help in the linking of the multiscale statistical parameters to the meteorological processes for practical applications of multiscaling statistics such as the development of downscaling schemes for orographic precipitation.

\subsection{Future Research}

Results presented in this study have provided a basis for the topographic influence on the multiscale properties of orographic precipitation events in mountainous terrain. This study has also shown that meteorological forcings play a major role in determining the trends of orographic forcing on the multiscale properties of rainfall. However, this research has provided only limited information on the meteorological variables of the storm environment of the various case studies, as well as a limited number of orographic precipitation events.

Orographic Rainfall Events. The analysis of additional windward-side and leewardside events in both Appalachian and Rocky Mountains would provide additional information needed to further corroborate the findings of this study.

Topographic Influences. In this study, topographic elevation was used as an initial assessment of orographic forcing. Further investigation should be focus on exploring potential relationships between multiscale parameters with slope and aspect 
of the regions considered.

Meteorological Influences. A next step would be to conduct the analysis of atmospheric soundings and meteorological variables forecasted with Numerical Weather Prediction (NWP) models and climate prediction models, as well as satellite data, which produces satellite derived soundings, meteorological indices, winds, precipitation rates, and surface skin temperatures. This would help to further investigate the meteorological forcings that generated these events. This supplemental meteorological information would supply additional insight into how meteorological forcings influence the magnitude and trends in multiscale parameters of orographic rainfall.

Non-orographic Storms. Future research should also include the analysis of precipitation events in non-orographic regions. The results obtained for these storms in regards to the links between multiscale behavior and meteorological differences would assist in verifying or denying the casualty of orographic versus meteorological forcings. 


\section{References}

AWS, The use of the Skew T, Log P diagram in analysis and forecasting, Air Weather Service, 1979.

Baeck, M. L., and J. A. Smith, Rainfall estimation by the WSR-88D for heavy rainfall events, Wea. For., 13(2), 416-436, 1998.

Bindlish, R., and A. P. Barros, Disaggregation of rainfall for one-way coupling of atmospheric and hydrological models in regions of complex terrain, Global and. Planetary. Change., 25, 11-132, 2000.

Caracena, F., R. A. Maddox, L. R. Hoxit, and C. F. Chapell, Meso-analysis of the Big Thompson storm, Mon. Weather Rev., 10\%, 1-17, 1979.

Chen, F., T. T. Warner, and K. Manning, Sensitivity of Orographic Moist Convection to Landscape Variability: A study of the Buffalo Creek, Colorado, Flash Flood Case of 1996, J. Atm. Sci., 58, 3204-3223, 2001.

DASUW, University of Wyoming Department of Atmospheric Science, Web address: http://weather.uwyo.edu/upperair/sounding.html.

Davis, A., A. Marshak, W. Wiscombe, and R. Cahalan, Multifractal characterizations of nonstationarity and intermittency in geophysical fields: observed, retrieved, or simulated, J. Geophys. Res., 99(D4), 8055-8072, 1994.

Davis, A., A. Marshak, W. wiscombe, and R. Cahalan, Multifractal characterizations of intermittency in nonstationary geophysical signals and fields: A model based perspective on ergodicity issues illustrated with cloud data, in Current Topics in Nonstationary analysis, edited by G. Trevino, J. Hardin, B. Douglas, and E. Andreas, pp. 97-158, World Scientific, 1996.

Davis, R. S., http://www.erh.noaa.gov/er/pit/redbank.htm from (National Weather Service), 2000.

de Lima, M. I. P., and J. Grasman, Multifratcal analysis of 15-min and daily rainfall from a semi-arid region in Portugal, J. Hydrology., 220, 1-11, 1999. 
Fulton, R. A., Sensitivity of WSR-88D rainfall estimates to the rain-rate threshold and rain gauge adjustment: A flash flood case study, Wea. For., 14(5), 604-624, 1999.

Fulton, R. A., T. O'Bannon, J. P. Breidenbach, D. J. Seo, and D. A. Miller, The WSR-88D rainfall algorithm, Wea. For., 13(2), 377-395, 1998.

Gupta, V., and E. Waymire, A statistical analysis of mesoscale rainfall as a random cascade, J. Appl. Met., 32, 251-267, 1993.

Harris, D., Multiscaling Properties of Rainfall: Methods and Interpretationphd dissertation, Ph.D. thesis, University of Auckland, New Zealand, 1998.

Harris, D., M. Menabde, A. Seed, and G. Austin, Multifractal characterization of rain fields with a strong orographic influence, J. Geophys. Res., 101(D21), 26,405-26,414, 1996.

Harris, D., A. Seed, M. Menabde, and G. Austin, Factors affecting multiscaling analysis of rainfall time series, J. Nonlinear Proc. Geophys., 4(3), 137-156, 1997.

Harris, D., E. Foufoula-Georgiou, K. K. Droegemeier, and J. J. Levit, Multi-scale statistical properties of a high-resolution precipitation forecast, J. Hydromet., 2(4), 406-418, 2001.

Hasley, T. C., M. H. Jensen, L. P. Kadanoff, I. Procaccia, and B. Shraiman, Fractal measures and their singularities: The characterization of strange sets, Phys. Rev., A(33), 1141-1151, 1986.

Knutsvig, R., http://people.aero.und.edu/ knutsvig/swx2.html.

Krajewski, W., E. N. Anagnostou, and G. J. Ciach, Effects of the radar observation process on inferred rainfall statistics, J. Geophys. Res., 101(D21), 26,493-26,502, 1996.

Kuligowski, R. J., and A. P. Barros, Experiments in short-term precipitation forecasting using artificial neural networks, Mon. Weather Rev., 126, 470-482, 1998.

Kumar, P., and E. Foufoula-Georgiou, A multicomponent decomposition of spatial rainfall fields, 1. segregation of large- and small-scale features using wavelet transforms, Water. Resour. Res., 29(8), 2515-2532, 1993a.

Kumar, P., and E. Foufoula-Georgiou, A multicomponent decomposition of spatial rainfall fields, 2. self-similarity in fluctuations, Water. Resour. Res., 29(8), 2533-2544, 1993b.

Landel, G., J. A. Smith, M. L. Baeck, and M. Steiner, Radar studies of heavy convective rainfall in mountainous terrain, J. Geophys. Res., 104(D24), 31,451-31,465, 1999.

Lovejoy, S., and D. Schertzer, Multifractals universality classes and satellite and radar measurements of cloud and rain fields, J. Geophys. Res., 95(D3), 2021-2034, 1990.

Lovejoy, S., and D. Schertzer, Multifractals and rain, in New Uncertainty Concepts in Hydrology and Hydrological Modeling, edited by A. W. Kundzewicz, pp. 61-103, Cambridge University Press, 1995a. 
Lovejoy, S., and D. Schertzer, How bright is the coast of Brittany?, in Fractals in Geoscience and Remote Sensing, edited by G. Wilkinson, I. Kanellopoulos, and J. Megier, pp. 102-151, Institute for Remote Sensing Application, Brussels, Belgium, 1995b.

Mandelbrot, B., Intermittent turbulence in self-similar cascades: Divergence of the high moments band dimension of the carrier, J. Fluid Mech., 62(2), 331-358, 1974.

Mandelbrot, B., The Fractal Geometry of nature, in The Fractal Geometry of nature, edited by W. H. Freeman and N. Y. Co., p. 468, 1977.

Menabde, M., D. Harris, A. Seed, G. Austin, and D. Stow, Multiscaling properties of rainfall and bounded random cascades, Water. Resour. Res., 33(12), 2823-2830, 1997.

Miller, B., http://www.weathertool.com/sounding.htm.

Nykanen, D. K., and D. Harris, Orographic influences on the multiscale statistical properties of precipitation, J. Geophys. Res., 108(D8), 8381, 2003.

Nykanen, D. K., E. Foufoula-georgiou, and W. M. Lapenta, Impact of small-scale rainfall variability on large-scale spatial organization of land-atmosphere fluxes, J. Appl. Met., 2(2), 105-121, 2001.

Ogden, F. L., H. o. Sharif, S. u. S. Senarath, J. A. Smith, M. L. Baeck, and j. R. Richardson, Hydrologic analysis of the Fort Collins, Colorado flash flood of 1997, J. Hydrology., 228, $82-100,2000$.

OSU, Ohio State University Atmospheric Sciences Program, Web address: http://twister.sbs.ohio-state.edu/.

Over, T. M., and V. K. Gupta, Stable NonGaussian Random Processes: Stochastic Models with Infinitive Variance, J. Geophys. Res., 101(D21), 26,319-26,331, 1996.

Pecknold, S., S. Lovejoy, D. Schertzer, C. Hooge, and F. Malouin, The simulation of universal multifractals, in Cellular Automata: Prospects in Astrophysical Applications, edited by J. M. Perdang and A. Lejeune, pp. 228-267, 1993.

Peppler, R. A., and P. J. Lamb, Tropospheric Static Stability and Central North American Growing Season Rainfall, Mon. Weather Rev., 117, 1156-1180, 1989.

Perica, S., and E. Foufoula-Georgiou, Linkage of scaling and thermodynamic parameters of rainfall: results from midlatitude mesoscale convective systems, J. Geophys. Res., 101(D3), 7431-7448, 1996.

Petersen, W. A., L. D. Carey, S. A. Rutledge, J. Knievel, N. J. Doesken, R. H. Johnson, T. B. Mckee, T. V. Haar, and J. F. Weaver, Mesoscale and Radar Observations of the Fort Collins Flash Flood of 28 July 1997, Bull. Amer. Meteor. Soc., 80, 191-216, 1999.

Pontrelli, M. D., G. Bryan, and J. M. Fritsch, The Madison County, Virginia, Flash flood of 27 June 1995, Wea. For., 14, 384-404, 1999. 
Press, W. H., S. A. Teukolsky, W. T. Vetterling, and B. P. Flannery, in Numerical Recipes in C: The Art of Scientific Computing, edited by 2nd edition, p. 994 pp., Cambridge University Press, 1992.

Purdy, J. C., D. Harris, G. L. Austin, A. W. Seed, and W. Gray, A case study of orographic rainfall processes incorporating multiscaling characterization techniques, J. Geophys. Res., 106(D8), 251-267, 2001.

Samorodnitsky, G., and M. S. Taqqu, in A space-time theory of mesoscale rainfall using random cascades, p. 632, Chapman and Hall, new York, 1994.

Schertzer, D., and S. Lovejoy, Physical modeling and analysis of rain and clouds by anisotropic scaling multiplicative processes, J. Geophys. Res., 92(D8), 9693-9714, 1987.

Shemya Air Force Base, A., http://www.truslow.com/shemya/rawinsonde.htm.

Smith, J. A., M. L. Baeck, M. Steiner, A. J. M. D. J. Seo, M. L. Baeck, and M. D. Hudlow, Catastrophic rainfall from an upslope thunderstorm in the central Appalachians: The Rapidan Storm of June 27, 1995, Water. Resour. Res., 32, 3099-3113, 1995.

Smith, J. A., D. J. Seo, M. L. Baeck, and M. D. Hudlow, An intercomparison study of NEXRAD precipitation estimates, Water. Resour. Res., 32(7), 2035-2045, 1996.

Turcotte, D. L., Fractals and Chaos in Geology and Geophysics, chap. 2, pp. 6-27, Cambridge University Press, 1997.

Warner, T. T., E. A. Brandes, J. Sun, D. Yates, and C. K. Mueller, Prediction of a Flash Flood in Complex Terrain. Part I: A Comparison of Rainfall Estimates From Radar, and Very Short Range Rainfall Simulations from A Dynamic Model and an Automated System, J. Appl. Met., 39, 797-814, 1999. 


\section{Appendix A}

\section{Atmospheric Sounding Indices}

\section{A.1 Skew T, Log P diagram}

There are several ways for plotting sounding data. Thermodynamic diagrams such as the Emagram, Tephigram, the Pseudo-Adiabatic diagram, and the Skew T, Log P diagram can be used for this purpose. All of them use the same physical relationship and show the same parameters in their graphs. The Skew T, Log P diagram was selected by American Weather Society (AWS) as the most convenient thermodynamic diagram for general use. AWS chose this diagram based on its easy way of using different meteorological procedures as well as by its convenient and useful representation of the different axis used in the graph. A more detailed explanation concerning the Skew T, Log $\mathrm{P}$ diagram can be found in $A W S[1979$.

Skew T, Log P diagram is a standard plot used by meteorologists to analyze data from a balloon sounding. A sample sounding is shown in Figure A.1 (a) for better visualization. The different axes used in the plot are indicated to distinguish them. In Figure A.1 (a) the pressure lines are plotted horizontally in gold. The concept of Skew $\mathrm{T}$ means that the temperature is not plotted vertically, but off to the right at a 45 degree angle. The temperature lines of the Skew $\mathrm{T}$ are in orange. The darker green lines are called dry adiabats. The light dotted purple lines are saturation adiabats. The dotted dark blue lines are lines of constant mixing ratio. The sounding is plotted as two lines of red and blue. The red line is the temperature profile and the blue line is the dewpoint temperature profile. The winds are plotted as wind barbs with the height on the right edge of the plot. The light green line is the temperature an air parcel would see as lifted dry-adiabatically until saturated and saturation-adiabatically thereafter. This process is performed through several steps. The first step is to determine the Lifting Condensation Level $(L C L)$, which corresponds to the height at which a parcel becomes saturated with water vapor when it is lifted dry-adiabatically. Then, from the $L C L$ a line is drawn upwards and parallel to 
(a)

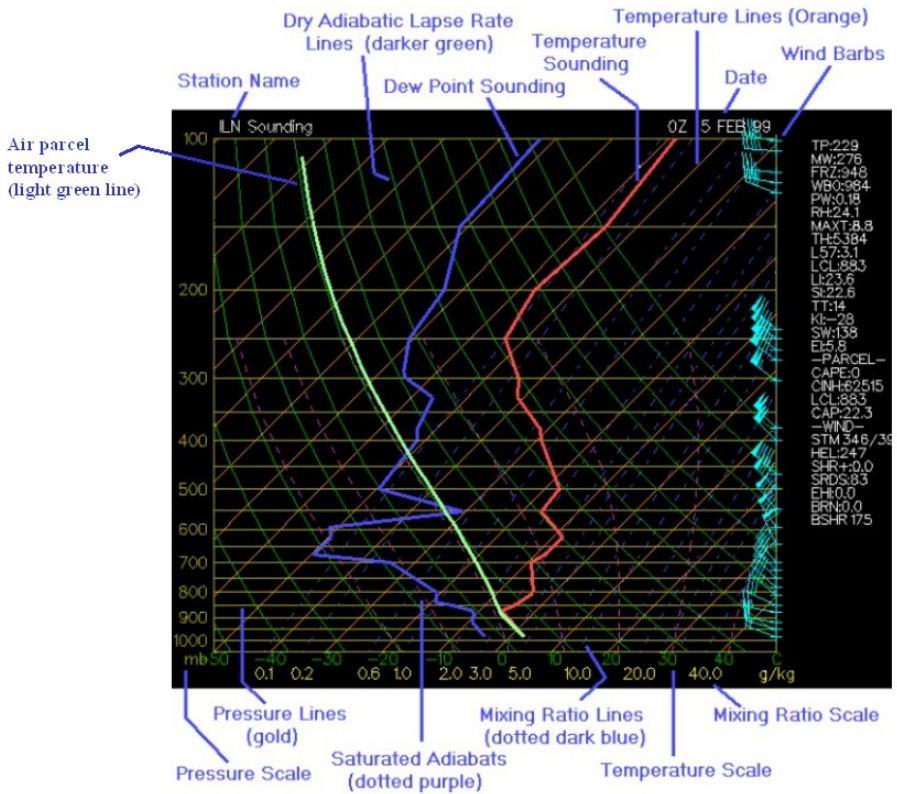

(b)

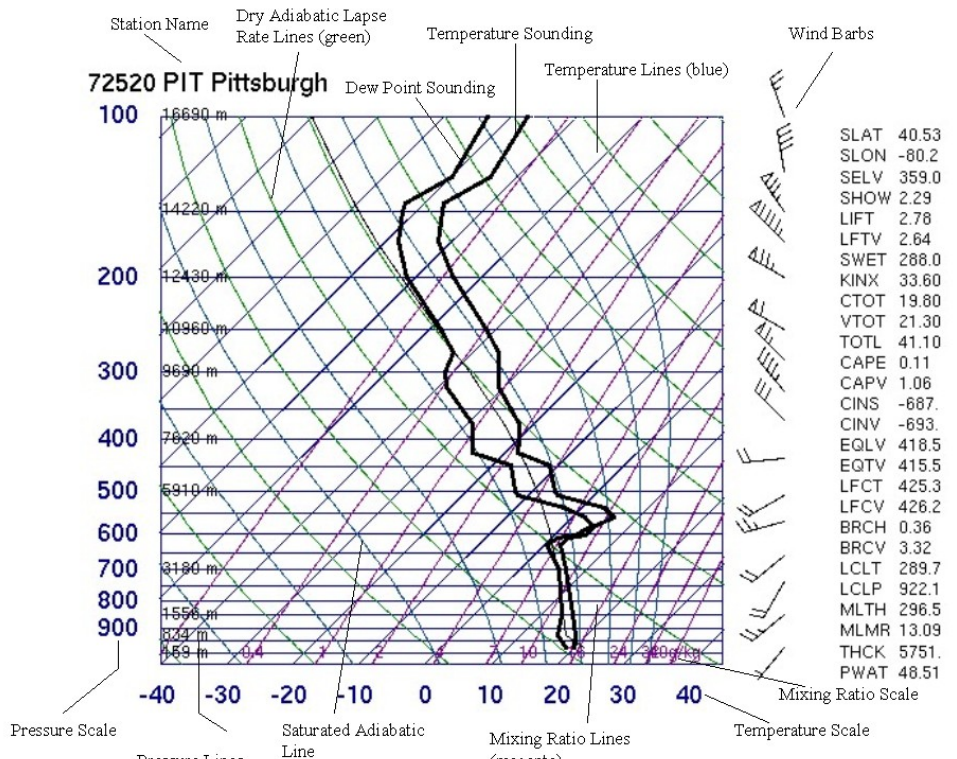

Figure A.1 (a) Representation of the Skew T, Log P diagram for a sample sounding (From the Ohio State University $|O S U|$ webpage) and (b) Representation of the Skew T, Log P diagram for the Redbank Creek storm at 1200 UTC 18 July, 1996 (From the $D A S U W$ webpage). 
the near saturation adiabat beyond the Equilibrium Level (EQVL.) This would also allow the computation of the Convective Available Potential Energy $(C A P E)$ and Convective Inhibition $(C I N S)$. These terms are explained later in this chapter. In addition, Figure A.1 (b) represents a sounding from the Redbank Creek Storm at 1200 UTC 18 July, 1996. As mentioned above, this sounding was obtained from the $D A S U W$ webpage.

\section{A.2 Sounding Station Parameters and Indices: Def- inition and Interpretation}

Atmospheric soundings indices are used to study the characteristics of the storms. Convective indices are used in this study, which means that only the parameters derived from the data contained in a single rawinsonde ascent are applied. Not all the existing indices reported in the literature to estimate tropospheric stability are used. However, an effort was made to include the most significant indices based on previous studies (see Peppler and Lamb [1989], Pontrelli et al. [1999], and Landel et al. [1999]) and on the basis of their traditional use. The following paragraphs show and explain the indices and ranges used to describe the stability of the atmosphere as well as the degree of potential thunderstorms. All parameter values considered in the tables were acquired at Knutsvig and Miller webpages (see References chapter).

\section{A.2.1 LI (Lifted Index)}

The lifted or $L I$ index is a stability parameter defined as the difference between the 500 $\mathrm{mb}$ temperature and the temperature (at $500 \mathrm{mb}$ ) of a parcel lifted from the surface dry adiabatically to the condensation level and then moist adiabatically to $500 \mathrm{mb}$. It incorporates moisture and lapse rate (static stability) into one number, which is less vulnerable to observations at individual pressure levels. $L I$ was originally intended to utilize average moisture and temperature properties within the planetary boundary layer (3000 feet deep). Positive values reflect stable conditions, while negative values reflect unstable conditions. $L I$ index can be computed using,

$$
L I=T_{e}(500 m b)-T_{p}(500 m b)
$$

where $L I$ is expressed in Celsius $\left({ }^{\circ} \mathrm{C}\right), T_{e}$ represents the $500 \mathrm{mb}$ environmental temperature and $T_{p}$ is the rising air parcel's $500 \mathrm{mb}$ temperature. These $L I$ values are based on lifted parcels using average lowest $100 \mathrm{mb}$ moisture and temperature values, although variations exist on how $L I$ values are calculated. Table A.1 shows the interpretation of $L I$ index for different values. 
Table A.1 Summary of atmospheric stability as a function of $\mathrm{LI}$ index value.

\begin{tabular}{cc}
\hline Li index & Stability \\
\hline & for $L I=1-3$ if strong lifting is present) \\
0 to -3 & Marginally unstable \\
-3 to -6 & Moderately unstable \\
-6 to -9 & Very unstable \\
$>-9$ & Extremely unstable \\
\hline
\end{tabular}

\section{A.2.2 SWEAT Index (Severe Weather Threat Index)}

The $S W E A T$ index measures the potential for severe weather by combining several parameters into one index. These parameters take into account thermal instability, low level moisture content, vertical wind shear and horizontal wind speeds. Therefore, both kinematic and thermodynamic information are intended to be incorporated into one index. The $S W E A T$ index should be used to assess severe weather potential and not ordinary thunderstorm potential. The main difference between this index and others is that the SWEAT index accounts for the wind velocities at lower and upper levels. Hence, if a thunderstorm develops, the factor determining whether or not the thunderstorm will sustain itself or dissipate is the wind. If there is no vertical wind shear, then the precipitation will fall into the updraft and the storm will fail to sustain itself. The life-cycle of this storm type is around one hour. On the other hand, if the winds are veering with height (turning clockwise with height) then the updraft and downdraft can be diverted from intersecting each other and a longer lifetime can be expected. Veering winds also often indicate warm air advection at lower levels which increases the instability. In the $S W E A T$ index, the $850 \mathrm{mb}$ and $500 \mathrm{mb}$ are the two levels where the winds are considered. The wind shear between these two levels is a main feature to be considered when forecasting severe weather. Thus, $S W E A T$ index is calculated as,

$$
S W E A T=12[T d(850 m b)]+20(T O T L-49)+2(f 8)+f 5+125(S+0.2)
$$

where TOTL represents the Total Totals index value (see explanation below), $f 8$ and $f 5$ represent the $850 \mathrm{mb}$ and $500 \mathrm{mb}$ wind speed in knots, respectively, and $\mathrm{S}=\sin (500 \mathrm{mb}$ minus $850 \mathrm{mb}$ wind direction), i.e., the sine of the angle between the 500 and $850 \mathrm{mb}$ wind directions (the shear term). Table A.2 shows the range of values for severe weather as a function of the $S W E A T$ index.

It is worthy to note that severe storms may also be possible for SWEAT values of 250 


\begin{tabular}{cc}
\multicolumn{2}{c}{ Table A.2 Summary of atmospheric stability as a function of SWEAT index value } \\
\hline SWEAT index & Potential for severe weather \\
\hline$<270$ & Unlikely \\
$270-300$ & Slight Risk \\
$300-400$ & Moderate Risk (Potential for severe Thunderstorms) \\
$400-600$ & Strong Risk (Potential for Tornados) \\
$601-800$ & High Risk \\
\hline
\end{tabular}

- 300 if strong lifting is present, which is the case in orographic events.

\section{A.2.3 KINX Index}

The $K I N X$ or $K$ index was composed for forecasting air mass thunderstorms, or thunderstorms with no dynamic triggering mechanism. This index is based on the $850 \mathrm{mb}$ to $500 \mathrm{mb}$ lapse rate plus $850 \mathrm{mb}$ dewpoint (larger values of this dewpoint indicate a low level moisture present and an increase in the chance of convection) minus the $700 \mathrm{mb}$ dewpoint depression for moisture input at mid levels (a small dewpoint depression points out a possibility for deep convection). Strong springtime thunderstorms often need dry air at mid-levels to cap the convection, which is enhanced by lower dew point depression at $700 \mathrm{mb}$. Conversely, summer air mass thunderstorms require a very moist atmosphere at mid-levels to prevent evaporation through entrainment. The equation used to compute the $K$ index is,

$$
K I N X=\left(T_{850}-T_{500}\right)+T_{d 850}-\left(T_{700}-T_{d 700}\right)
$$

where $\mathrm{T}$ and $\mathrm{T}_{d}$ are the temperatures and dewpoints, respectively in degree Celsius $\left({ }^{\circ} \mathrm{C}\right)$. The numbers 500, 700, and 850 refer to the level in mb. As a general rule, the higher the $K$ index value, the greater the potential for heavy rain. A guide for different $\mathrm{K}$ index values is shown in Table $\mathrm{A} .3$ and Table A.4. 


\begin{tabular}{|c|c|}
\hline $\mathrm{K}$ index & Probability of Thunderstorms \% \\
\hline$<15$ & 0 \\
\hline from 15 to 20 & 20 \\
\hline from 21 to 25 & 20 to 40 \\
\hline from 26 to 30 & 40 to 60 \\
\hline from 31 to 35 & 60 to 80 \\
\hline from 36 to 40 & 80 to 90 \\
\hline$>40$ & near 100 \\
\hline
\end{tabular}

Table A.4 A more general summary of probability of thunderstorms as a function of $\mathrm{K}$ index value.

\begin{tabular}{cc}
\hline K index & Probability of Thunderstorms \\
\hline$<30$ & Thunderstorms with heavy rain or severe weather possible \\
$>30$ & Better potential for thunderstorms with heavy rain \\
$>40$ & Best potential for thunderstorms with very heavy rain \\
\hline
\end{tabular}

\section{A.2.4 TOTL (Total Totals Index)}

The TOTL index shows instability in the atmosphere focusing on two components, the Cross Total $(C T)$ and the Vertical Total $(V T)$. The $C T$ is a measure of how buoyant the air parcel is due to moist air in the lower levels and takes into account the amount of moisture present. The $C T$ index is based on the difference between the $850 \mathrm{mb}$ dew point temperature and the $500 \mathrm{mb}$ temperature. The $V T$ is a measure of how buoyant the air parcel is due to warm air at lower levels, representing the static stability or the lapse rate between $850 \mathrm{mb}$ and $500 \mathrm{mb}$ temperature (thermal difference). The sum of the Cross and Vertical section totals is the Total Totals and is shown in equation A.4.

$$
T O T L=V T+C T
$$

where,

$$
C T=T d(850 m b)-T(500 m b)
$$




$$
V T=T(850 m b)-T(500 m b)
$$

$T$ is expressed in Celsius $\left({ }^{\circ} \mathrm{C}\right)$ at the indicated levels. The Total Totals index behaves like the $K$ index, so that an increase in the index corresponds to a greater likelihood of thunderstorms. As with all stability indices there are no magic threshold values, yet there is a general guide as shown in Table A.5.

Table A.5 Summary of probability of thunderstorms as a function of TOTL index value.

\begin{tabular}{cc}
\hline TOTL index & Probability of Thunderstorms \\
\hline$>44$ & possible thunderstorms, slight chance of severe (weak indicator) \\
$>50$ & chance of severe thunderstorms \\
$>55$ & strong chance of severe thunderstorms (strong indicator) \\
\hline
\end{tabular}

Some limitations can arise in the TOTL index due to large lapse rates producing large $T O T L$ values with little low level moisture, thus TOTL index is region specific.

\section{A.2.5 LFCT (Level of Free Convection)}

The Level of Free Convection or $L F C T$ is the level where the temperature of a parcel lifted from the surface, dry-adiabatically until saturated and then saturation-adiabatically. Thereafter becomes greater or warmer than the surrounding environment. When a parcel reaches this point, it means that it is free to continue rising without the need of any additional energy input from the environment, or in other words, is free to continue convecting. The $L F C T$ is located at the dividing level between the Convective Inhibition or CINS (negative) and the Convective Available Potential Energy or CAPE (positive) energy regions, and is a measure of the pressure (hPa) level at this dividing location. It is important to point out that some soundings may not have a $L F C T$. This may occur in situations with dry low-level conditions or warm upper level temperatures, mainly with sounding temperature inversions. Thus, the atmosphere is considered ultra-stable and there is no chance of convection.

A range of values of $L F C T$ (see Table A.6) are used as a guide to predict and indicate the chances of convection. Higher pressure (mb) means lower heights $(\mathrm{m})$ since pressure gets smaller as move higher vertically. 


Table A.6 Summary of convective po-
tential as a function of LFCT value.
\begin{tabular}{cc} 
Height of LFCT & Convective Potential \\
\hline $600 \mathrm{mb}-640 \mathrm{mb}$ & Weak \\
$640 \mathrm{mb}-745 \mathrm{mb}$ & Moderate \\
$745 \mathrm{mb}-850 \mathrm{mb}$ & Strong
\end{tabular}

\section{A.2.6 LCL (Lifted Condensation Level)}

When an unsaturated air parcel rises, it expands and cools. If this parcel has enough moisture, there is a certain altitude at which the air parcel cools to its dewpoint temperature and becomes saturated. The level at which this occurs is called the Lifted Condensation Level, or $L C L$. If the air parcel continues to rise, one would expect to see condensation with cloud forming, thus the cloud base would be at the $L C L$. The vertical extent of the cloud would be determined by several factors such as temperature or moisture content of the air above the $L C L$. The stability index $L C L$ is a good parameter for the estimation of the bases of cumulus clouds that form by convection. LCLP is the pressure $(\mathrm{mb})$ at the $L C L$, from an average of the lowest 500 meters.

\section{A.2.7 CAPE (Convective Available Potential Energy)}

In essence, $C A P E$ is the amount of energy $(\mathrm{J} / \mathrm{kg})$ that is available to a surface parcel which has reached its Level of Free Convection ( $L F C T)$. Figure A.2 shows a sample sounding where the shaded area represents $C A P E$. This is considered as the positive area and is defined by a parcel that can rise freely because it is in a layer where the adiabat it follows is warmer than the surrounding environment. This area between the adiabat and the sounding is proportional to the amount of kinetic energy the environment gains (positive energy) from the environment. Therefore, $C A P E$ is the area enclosed by the environmental temperature profile and the moist adiabat connecting the $L F C T$ to the Equilibrium Level $(E Q L V) . E Q L V$ is defined as the height where the temperature of a freely rising parcel of air again becomes equal to the surrounding air. An increase in the temperature difference between the warmer parcel and the environment corresponds to an increase in CAPE. Higher values of $C A P E$ tend to produce more vigorous convection due to an increase in the updraft acceleration. The equation used to compute $C A P E$ is,

$$
C A P E=G r a v i t y * \operatorname{Sump}\left(\operatorname{Del} z *\left(T_{p}-T_{e}\right) / T_{e}\right)
$$

where Sump is the sum over sounding layers from $L F C T$ to $E Q L V$ for which $\left(\mathrm{T}_{p}-\mathrm{T}_{e}\right)$ is greater than zero, Delz is the incremental depth, $\mathrm{T}_{p}$ is the temperature of a parcel from the 


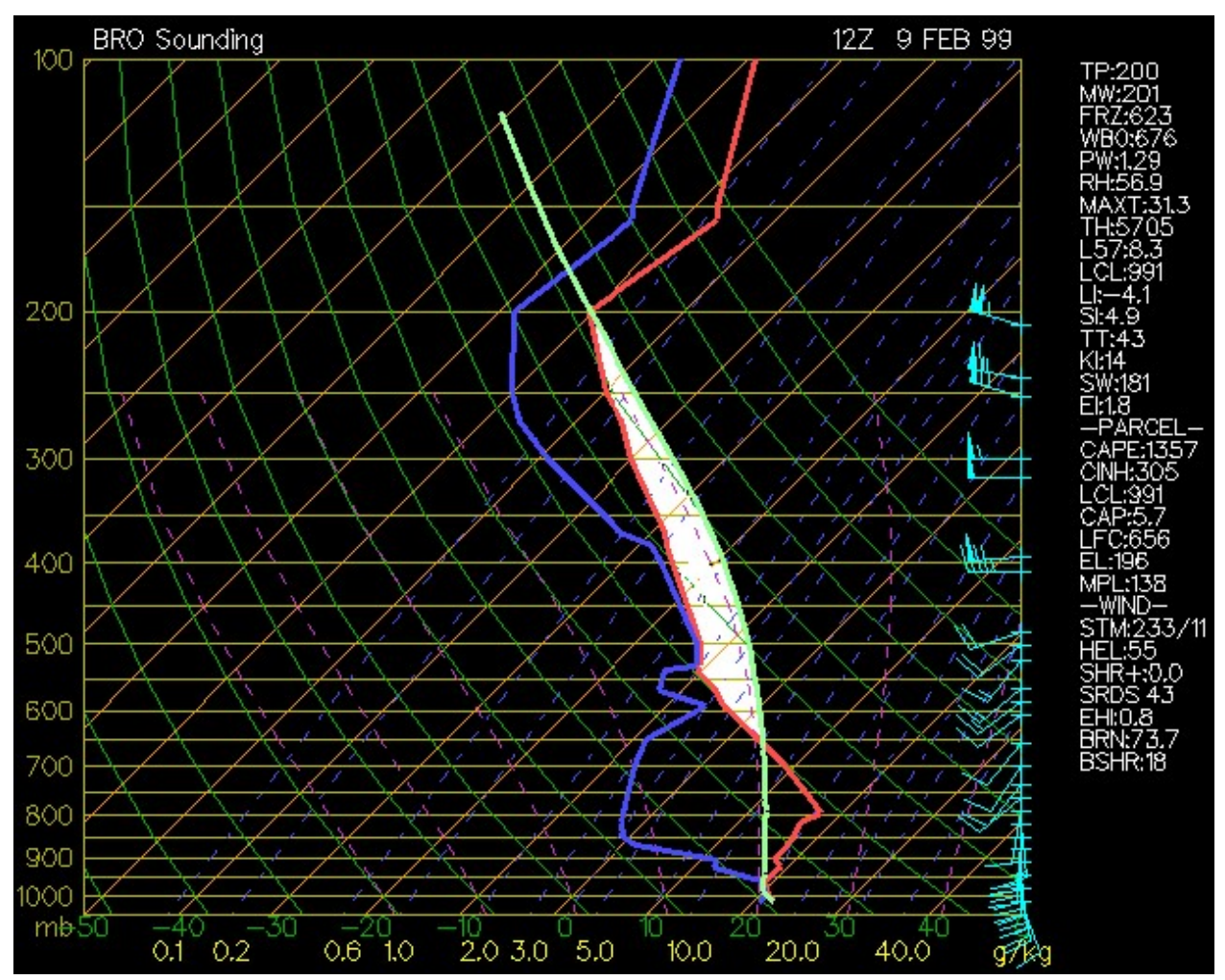

Figure A.2 Representation of the Skew T, Log P diagram for a sample sounding showing the shaded area of positive energy, also known as CAPE, where the parcel sounding (light green line) is warmer or farther to the right than the atmosphere sounding (red line) (From $O S U$ webpage).

lowest $500 \mathrm{~m}$ of the atmosphere, raised dry adiabatically to the $L C L$ and moist adiabatically thereafter, and $\mathrm{T}_{e}$ is the temperature of the environment. The values showed in Table A.7 are based on a parcel lifted with the average temperature and moisture of the lowest 100 mb layer (i.e., the boundary layer).

Furthermore, not only the value of $C A P E$ is important, but the shape of the positive area that determines this value is important too. Hence, two soundings may have the same $C A P E$ value and different convective characteristics, which is due to differences in the shape of the area between the $L F C T$ and $E Q L V$. A longer, narrower profile indicates the potential for slower updraft acceleration but it also indicates taller thunderstorms, which enhance high precipitation efficiency. In contrast, a shorter, fatter shape would indicate a more rapid vertical acceleration, thus potential development of updraft rotation within the storm would be important.

It is worthy to point out that sometimes areas with a large value of $C A P E$ do not have the presence of thunderstorms, while many areas with small $C A P E$ values receive thunderstorms on a daily basis. This absence of thunderstorms may be due to a lack of 


$\begin{aligned} & \text { Table A.7 Summary of atmospheric } \\ & \text { stability as a function of CAPE index } \\ & \text { value. }\end{aligned}$
$\begin{array}{cc}\text { CAPE index } & \text { Atmospheric Stability } \\ <0 & \text { Stable } \\ 0 \text { to } 1000 & \text { Marginally unstable } \\ 1000 \text { to } 2500 & \text { Moderatly unstable } \\ 2500 \text { to } 3500 & \text { Very unstable } \\ 3500 \text { to } 4000 & \text { Extremely unstable }\end{array}$

triggering mechanism, dry air in the low to middle troposphere or a shallow boundary layer. On the other hand, when thunderstorms are present but a low $C A P E$ value is obtained, strong large scale upward motions (e.g. mountains), elevated heat sources, or small-scale circulations (e.g. sea breezes) could be the cause.

Finally, although $C A P E$ depends on the parcel chosen and on whether the movement of this parcel is a result of heating or lifting, $C A P E$ involves an integration over a depth of the atmosphere and is not as sensitive to specific sounding details. Thus, $C A P E$ is usually a much better indicator of instability than indices relying on the difference between two arbitrarily chosen surfaces (or heights) such as the $L I$, TOTL or $K$ indices, among others.

\section{A.2.8 CINS(Convective Inhibition)}

This parameter can be defined as the amount of energy $(\mathrm{J} / \mathrm{kg})$ beyond the normal work of expansion needed to lift a parcel from the surface to the Level of Free Convection $(L F C)$, so that energy has to be provided in order to move a parcel either up or down. Orographic lifting is one of the mechanism that could supply the necessary energy. CINS is considered a measure of how unlikely thunderstorm development is, or in other words, the energy needed for thunderstorms to develop.

In Figure A.3 the shaded area corresponds to CINS, also called "negative" (energy) area. This area is enclosed between the temperature of the sounding on the right and the dry/saturated adiabats on the left (dry if below the Lifting Condensation Level $(L C L)$, wet if above the $L C L)$. CINS index was computed as,

$$
\text { CINS }=\text { Gravity } * \operatorname{Sump}\left(\operatorname{Del} z *\left(T_{p}-T_{e}\right) / T_{e}\right)
$$

which is the same equation used to compute $C A P E$ but with the difference being that the term $S u m p$ is the sum over sounding layers from $L F C$ to $E Q L V$ for which $\left(\mathrm{T}_{p}-\mathrm{T}_{e}\right)$ is less 


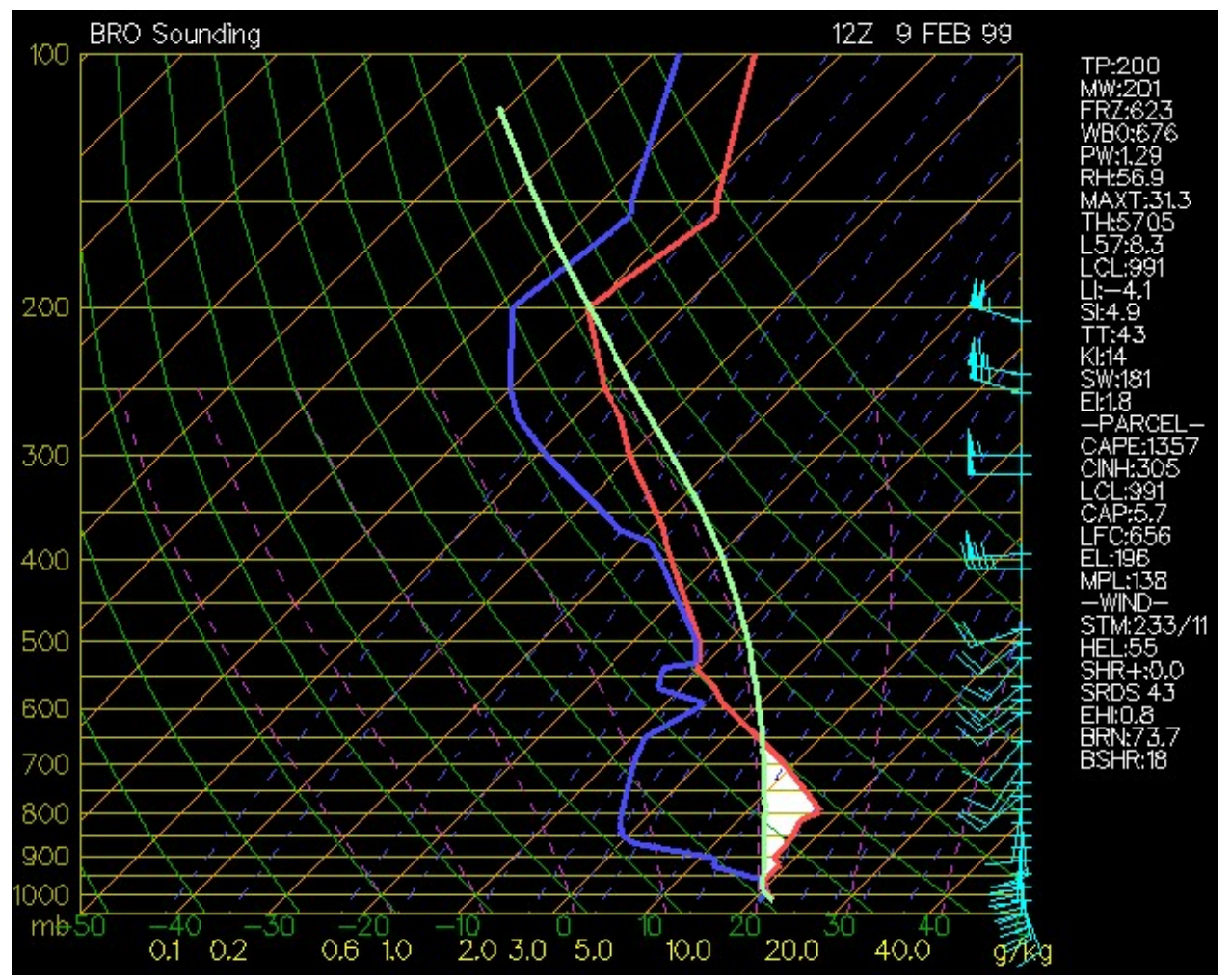

Figure A.3 Representation of the Skew T, Log P diagram for a sample sounding showing the shaded area of positive energy known as $C I N S$, where the parcel sounding (light green line) is colder or farther to the left than the atmosphere sounding (red line) (From $\mathrm{OSU}$ webpage). 
than zero. Favorable thunderstorm conditions would be present for $C I N S$ values that are neither too strong nor too weak, ranging between -50 to $-150 \mathrm{~J} / \mathrm{kg}$. Values to interpret the CINS range are shown in Table A.8.

Table A.8 Summary of atmospheric stability as a function of CINS index value.

\begin{tabular}{cc}
\hline CINS index & Atmospheric Stability \\
$<-15$ & fair weather (CINS overcome early) \\
-15 to -50 & a few strong thunderstorms can form (if CINS is overcome) \\
-50 to -150 & strong lines of thunderstorms can form (if $C I N S$ is overcome) \\
$>-200$ & strong cap, no thunderstorms development likely (CINS usually not overcome)
\end{tabular}

\section{A.2.9 BRCH (Bulk Richardson number)}

The $B R C H$ is an indicator of convective storm environments. This parameter incorporates buoyant energy $(C A P E)$ and the vertical shear of the horizontal wind, which are critical factors in order to determine storm development, evolution, and organization. Thus, BRCH is a measure of thunderstorm type and is computed using the following equation,

$$
B R C H=C A P E /\left(0.5 * U^{2}\right)
$$

where $U^{2}$ is the magnitude of shear $(\mathrm{u} 2-\mathrm{u} 1) *(\mathrm{v} 2-\mathrm{v} 1)$, with $\mathrm{u} 1$ and $\mathrm{v} 1$ being the average velocities $\mathrm{u}, \mathrm{v}$ in the lowest $500 \mathrm{~m}$, and $\mathrm{u} 2$ and $\mathrm{v} 2$ being the average $\mathrm{u}, \mathrm{v}$ in the lowest 6000 $\mathrm{m}$. $B R C H$ is a dimensionless number and the magnitude of the values are indicated in Table A.9.

Table A.9 Summary of probability of thunderstorms as a function of $\mathrm{BRCH}$ index value.

\begin{tabular}{cr}
\hline BRCH index & Probability of Thunderstorms \\
\hline $11-49$ & Thunderstorms unlikely \\
$\geq 50$ & Strong chance - multi cell type
\end{tabular}




\section{A.2.10 PWAT (Precipitable Water)}

Precipitable water or $P W A T$ is a measure of the amount of water vapor contained in a small vertical column extending from the surface to the top of the atmosphere, although the majority of the moisture is located within the lowest 10000 feet. As a rule of thumb, the higher the PWAT, the higher the potential for heavy rain due to thunderstorms if they were to develop. Furthermore, rainfall totals can actually exceed $P W A T$ values of the air in which the storm evolves, since moisture precedent from advection and convergence can provide additional input to the specific location. $P W A T$ values of $\sim 25 \mathrm{~mm}$ are common in the spring and summer east of the Front Range of the Rocky Mountains. When values exceed $50 \mathrm{~mm}$ in the summer, the atmosphere is characterized by having a very high moisture content, typical of a tropical air mass. 
Appendix B

Atmospheric Sounding Plots 1

B.1 Rapidan River basin and southern Virginia Storm of June 27, 1995 


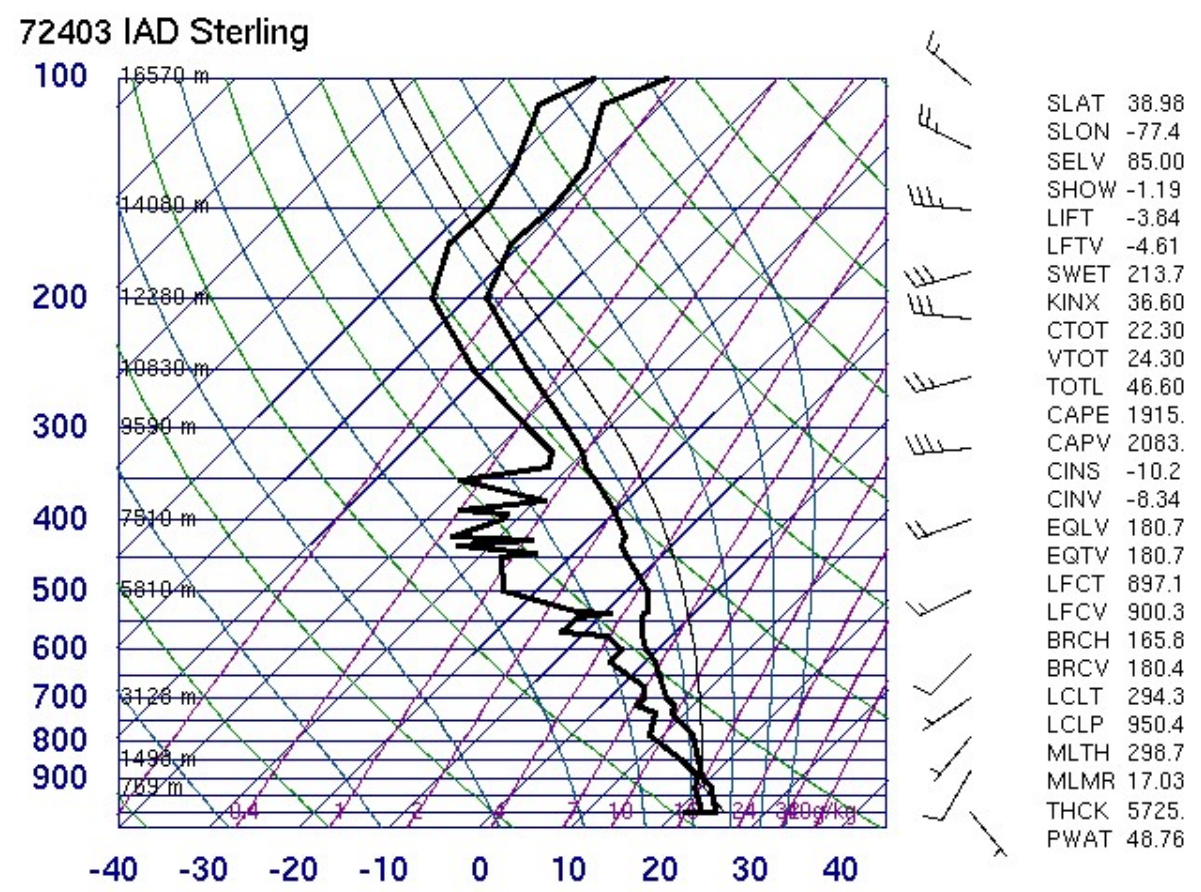

Figure B.1 Sterling, VA, temperature, dewpoint tmeperature, and wind sounding of the Rapidan River basin and southern Virginia storms for 0000 UTC on June 26, 1995. Listed are several stability indices. 


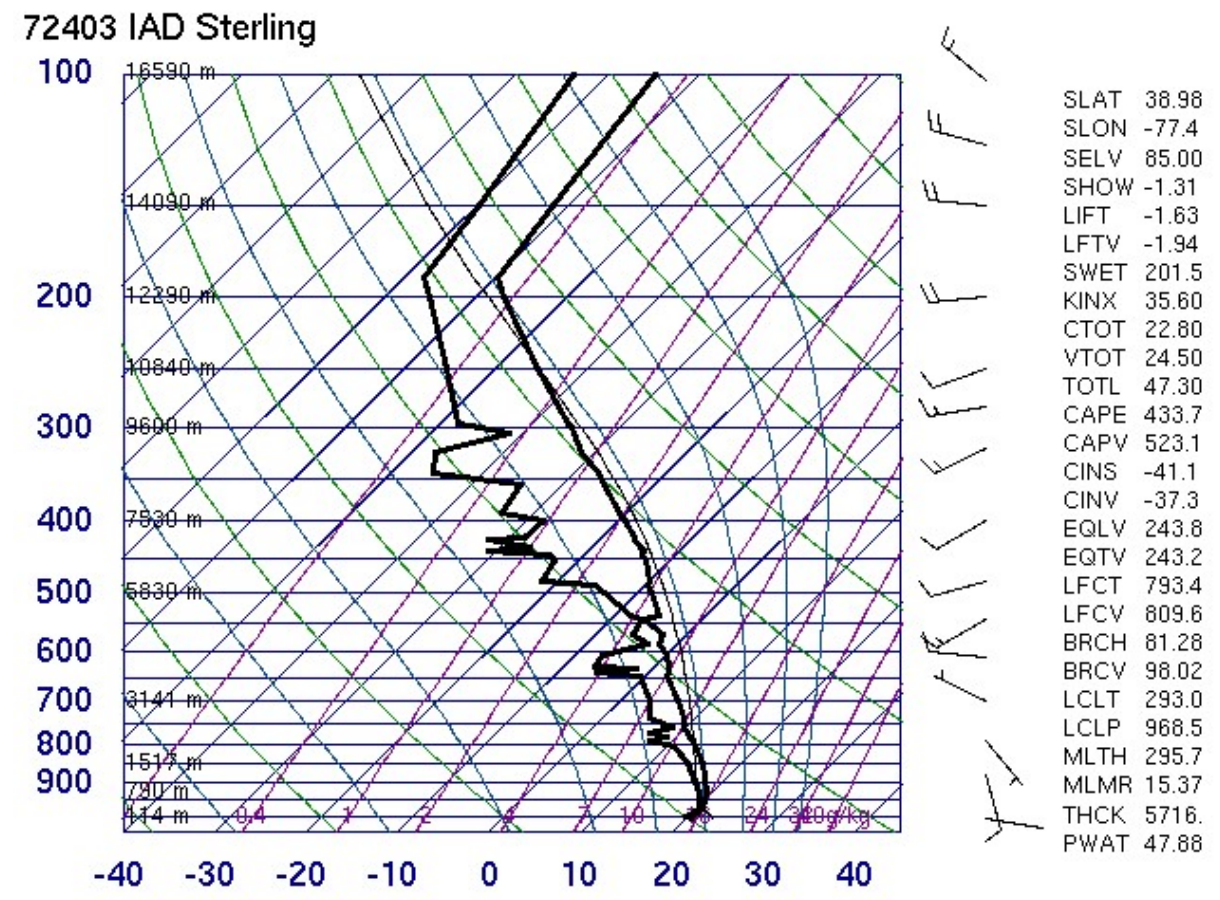

Figure B.2 Sterling, VA, temperature, dewpoint tmeperature, and wind sounding of the Rapidan River basin and southern Virginia storms for 1200 UTC on June 26, 1995. Listed are several stability indices. 


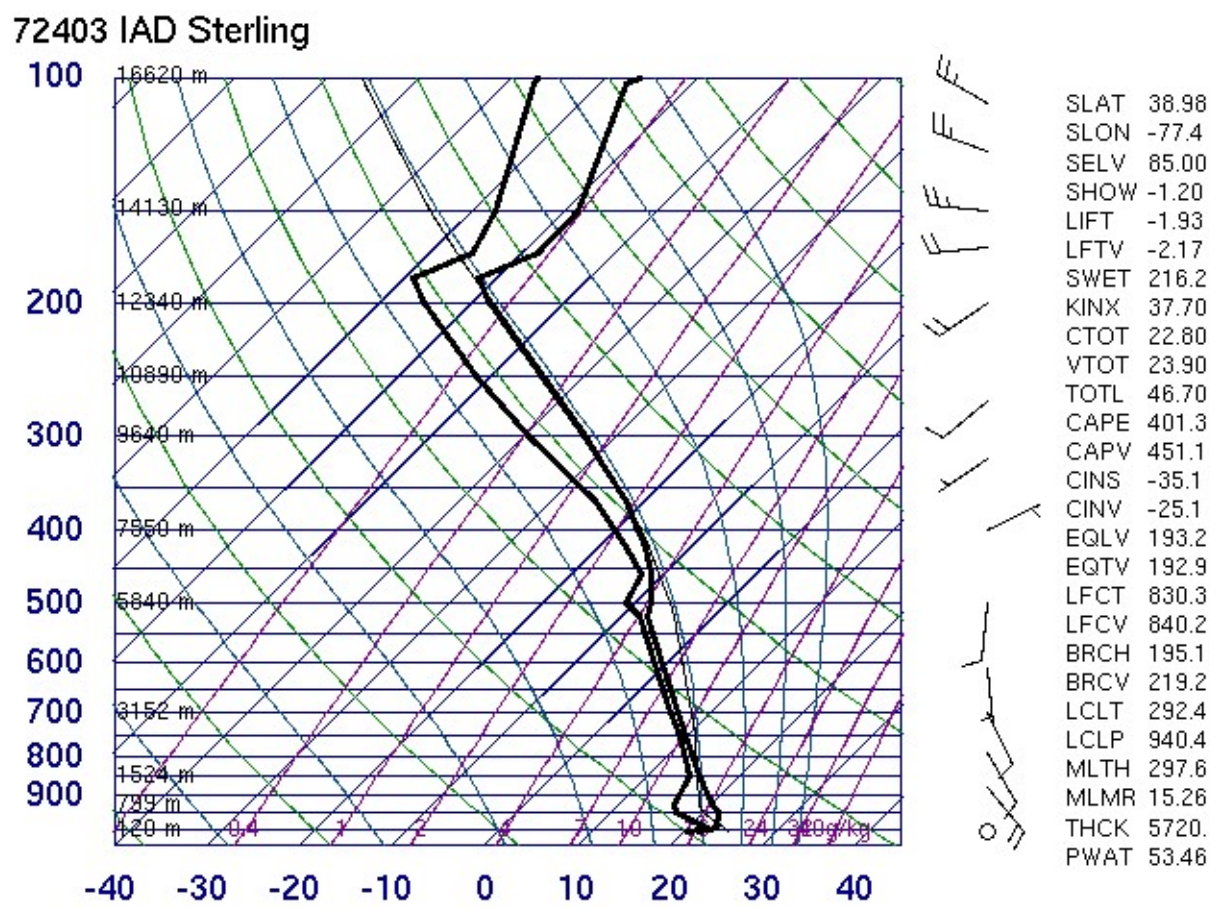

Figure B.3 Sterling, VA, temperature, dewpoint tmeperature, and wind sounding of the Rapidan River basin and southern Virginia storms for 0000 UTC on June 27, 1995. Listed are several stability indices. 


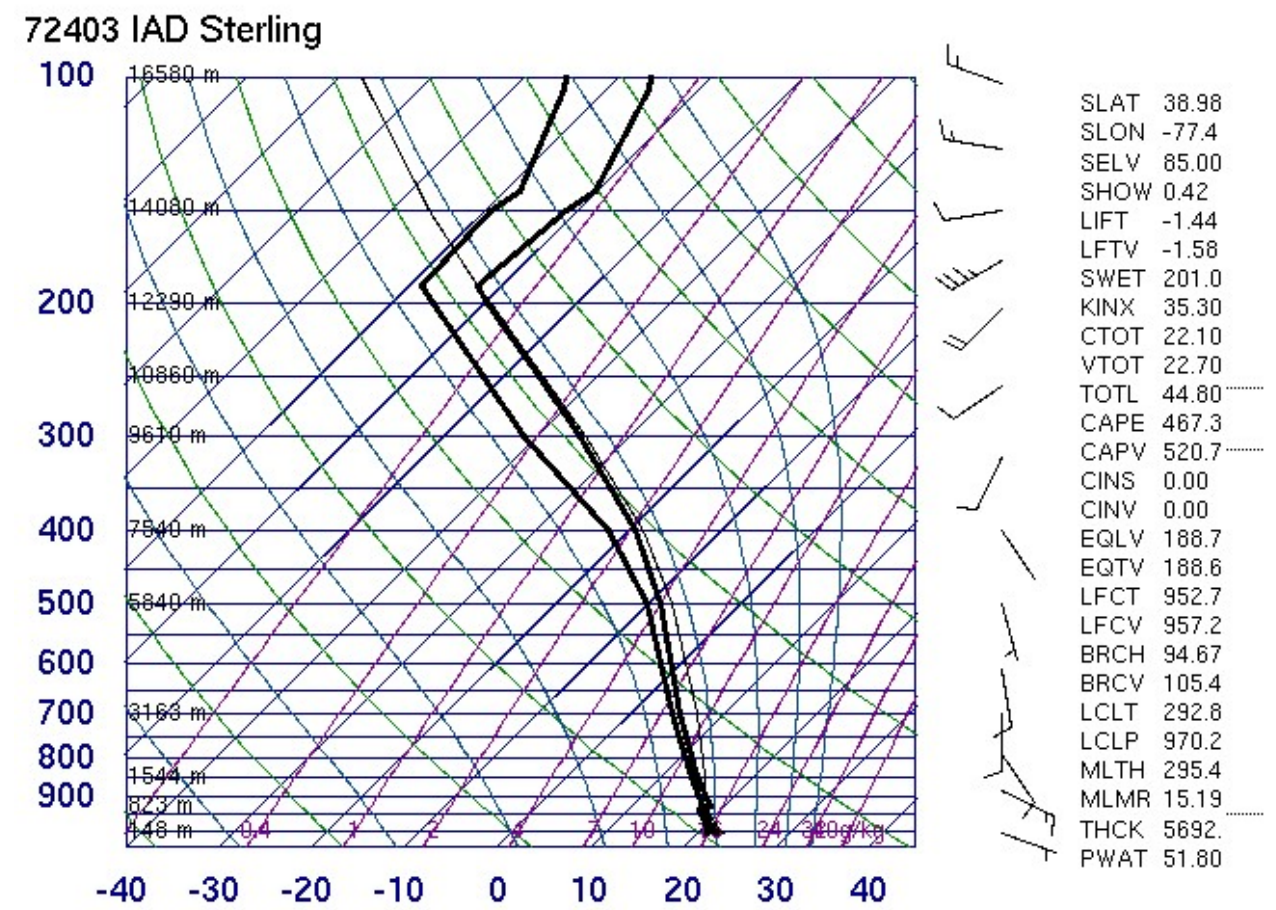

Figure B.4 Sterling, VA, temperature, dewpoint tmeperature, and wind sounding of the Rapidan River basin and southern Virginia storms for 1200 UTC on June 27, 1995. Listed are several stability indices. 


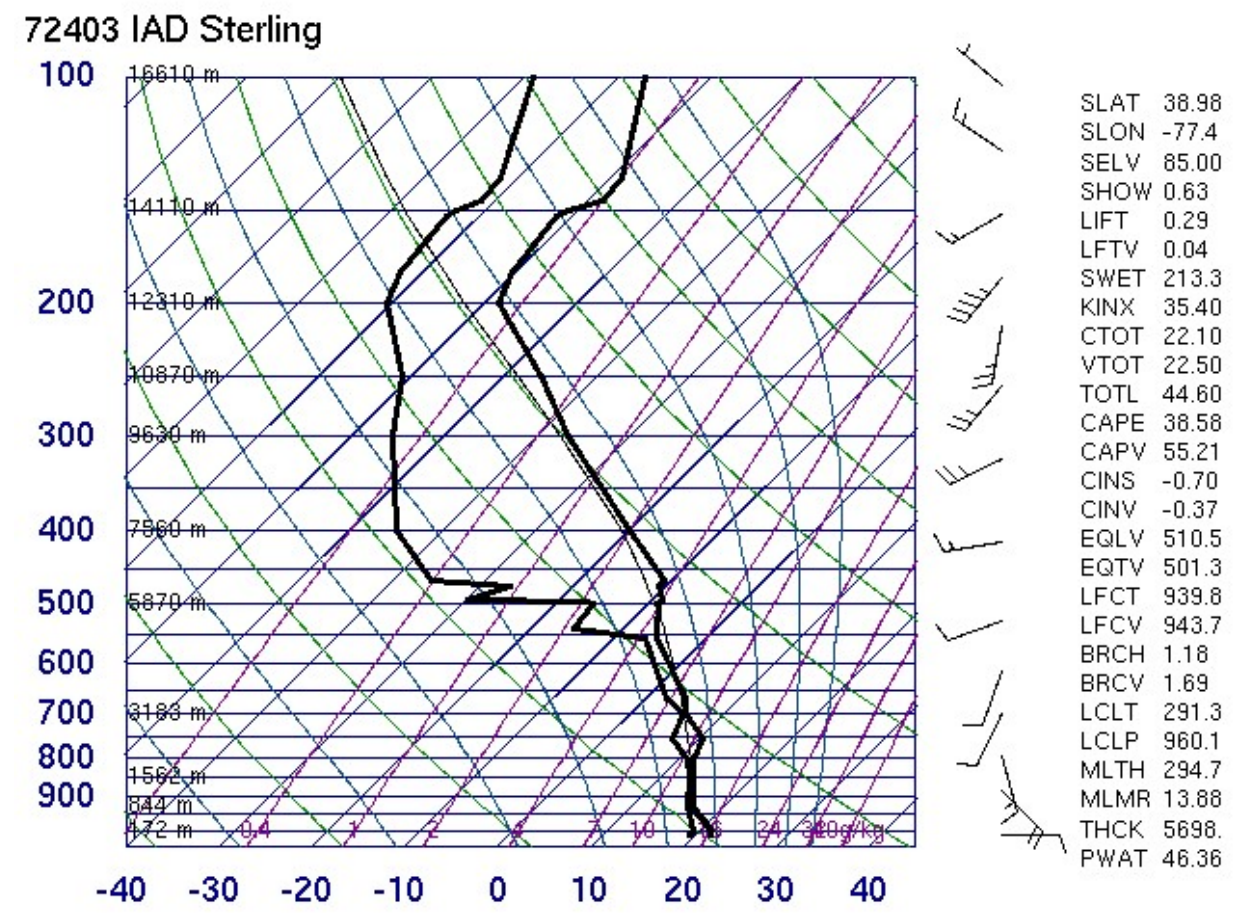

Figure B.5 Sterling, VA, temperature, dewpoint tmeperature, and wind sounding of the Rapidan River basin and southern Virginia storms for 0000 UTC on June 28, 1995. Listed are several stability indices. 


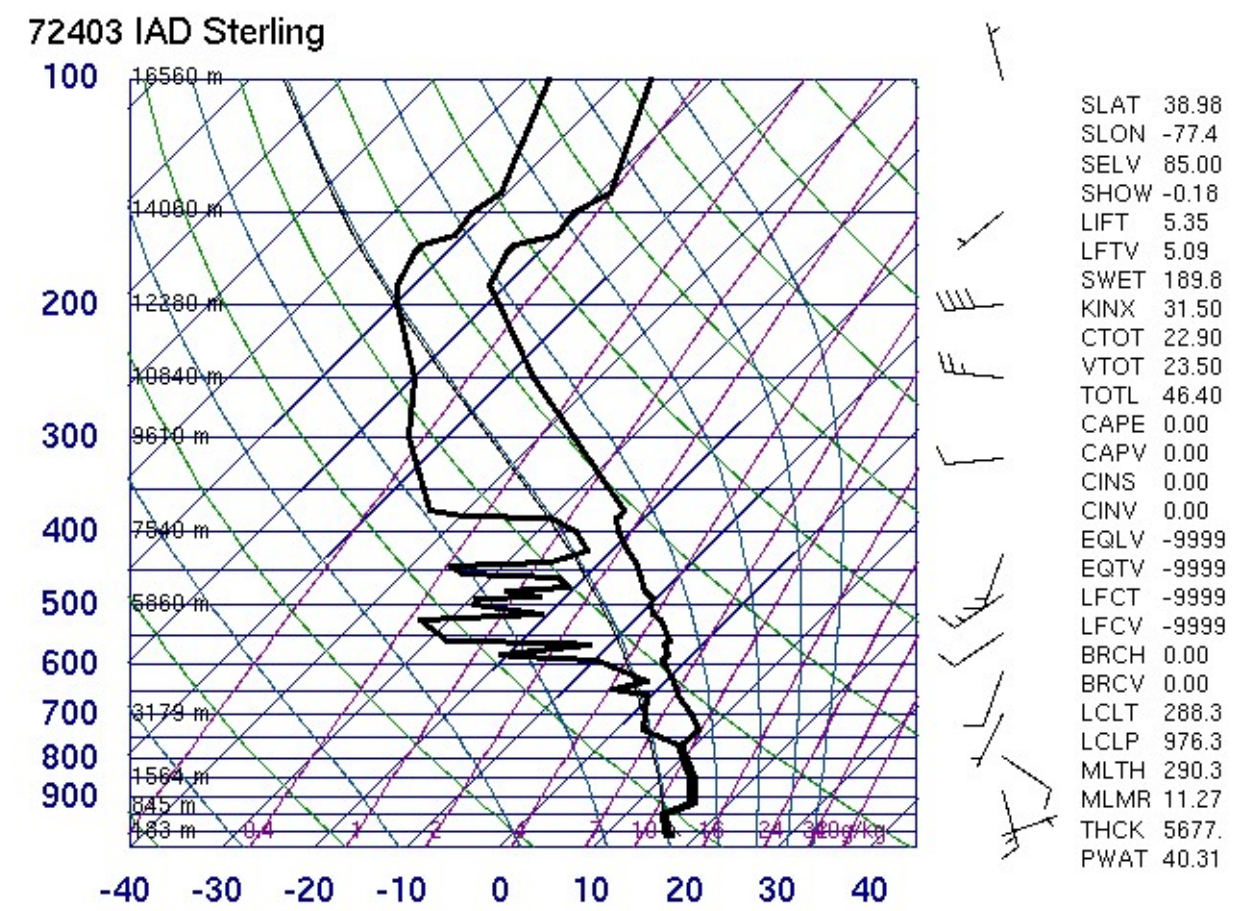

Figure B.6 Sterling, VA, temperature, dewpoint tmeperature, and wind sounding of the Rapidan River basin and southern Virginia storms for 1200 UTC on June 28, 1995. Listed are several stability indices. 
Appendix C

Atmospheric Sounding Plots 2

C.1 Redbank Creek Storm of July 18-19, 1996 


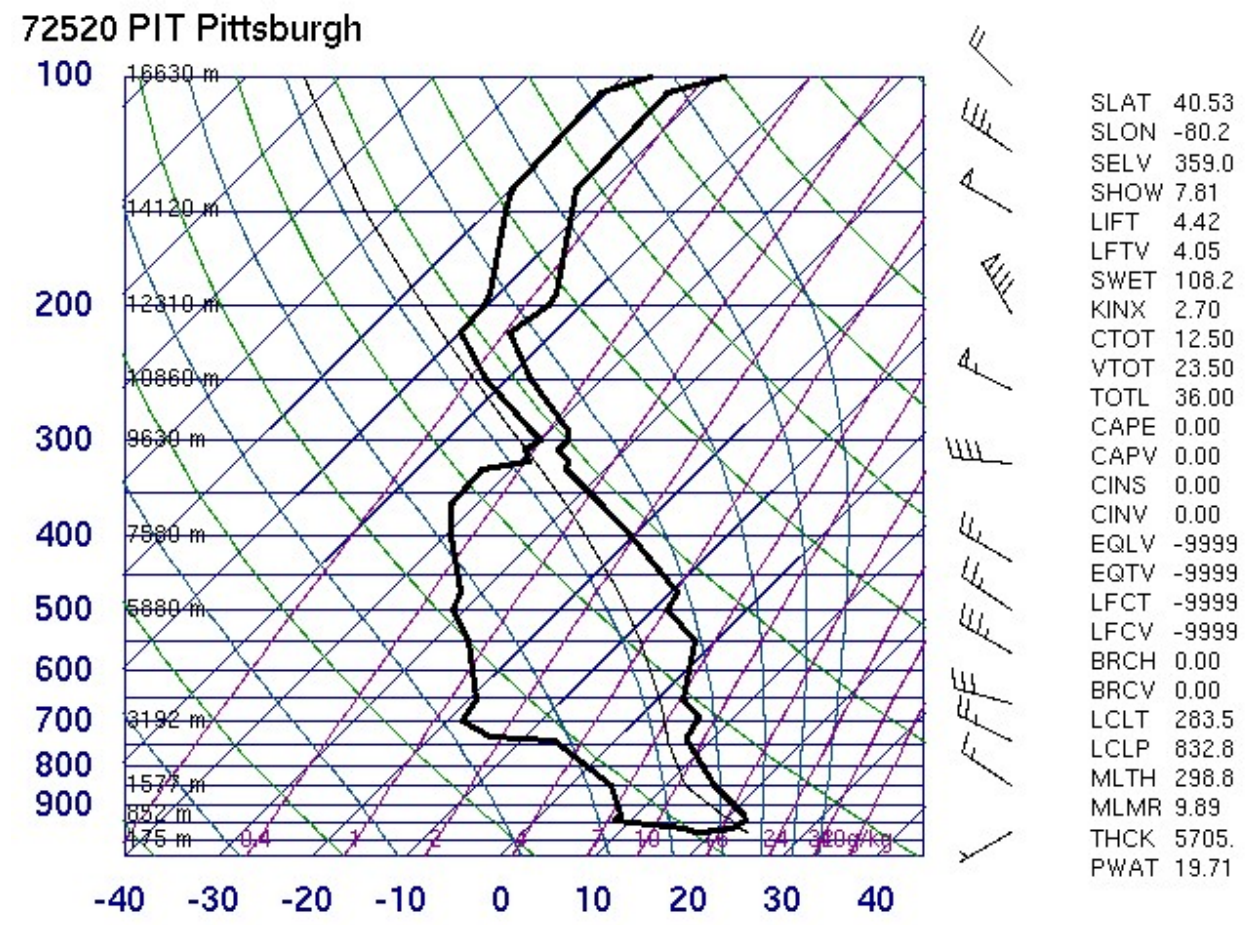

Figure C.1 Pittsburgh, PA, temperature, dewpoint tmeperature, and wind sounding of the Redbank Creek storms for 1200 UTC on July 17, 1996. Listed are several stability indices. 


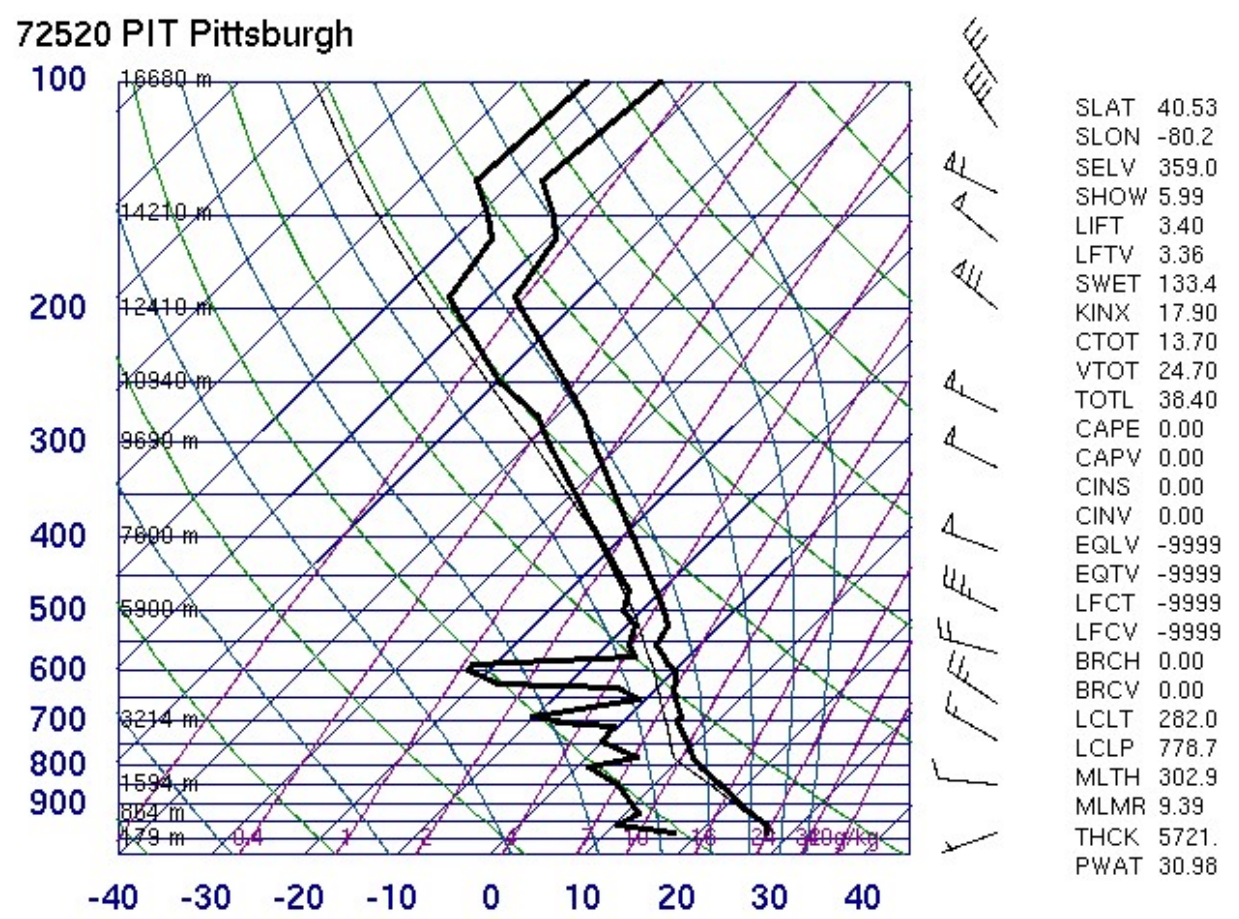

Figure C.2 Pittsburgh, PA, temperature, dewpoint tmeperature, and wind sounding of the Redbank Creek storms for 0000 UTC on July 18, 1996. Listed are several stability indices. 


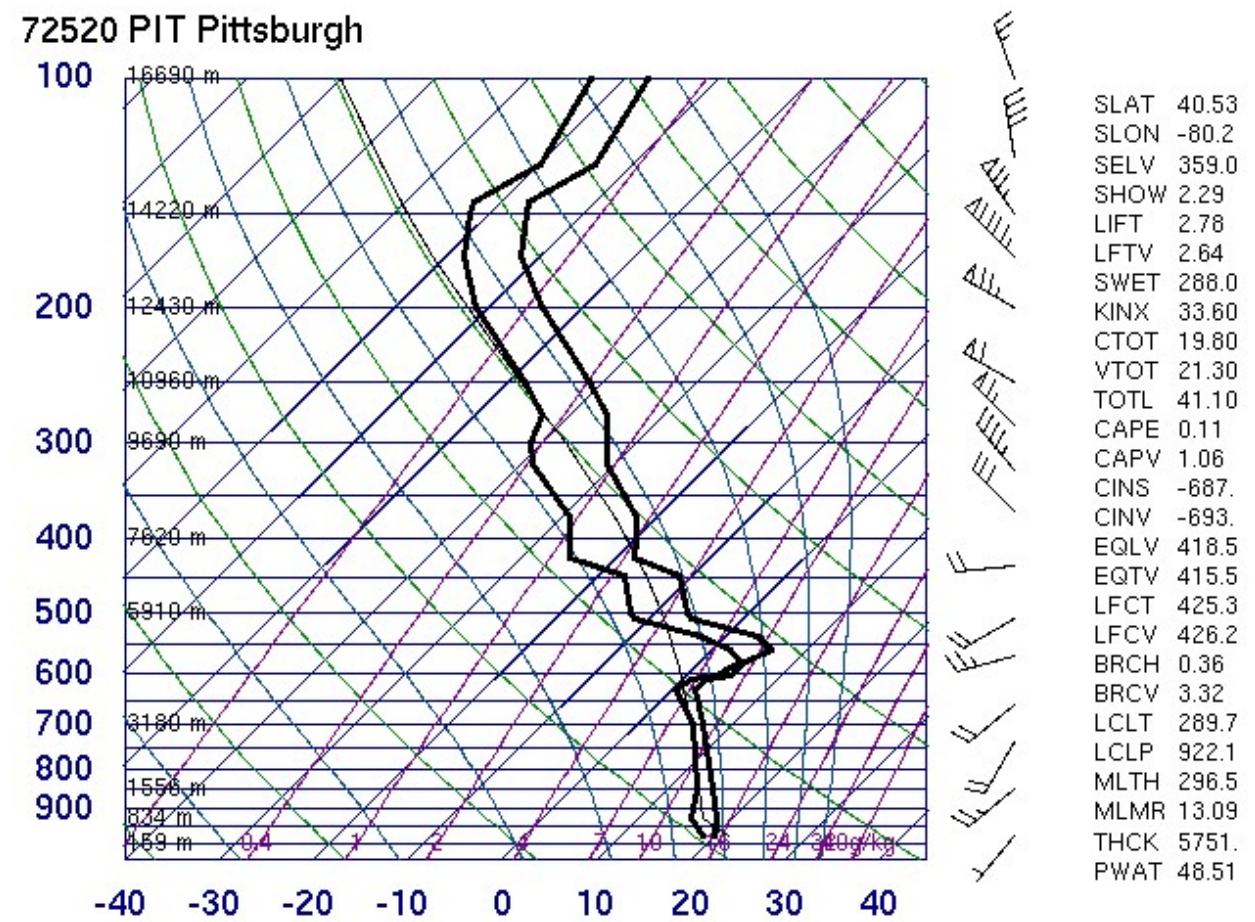

Figure C.3 Pittsburgh, PA, temperature, dewpoint tmeperature, and wind sounding of the Redbank Creek storms for 1200 UTC on July 18, 1996. Listed are several stability indices. 


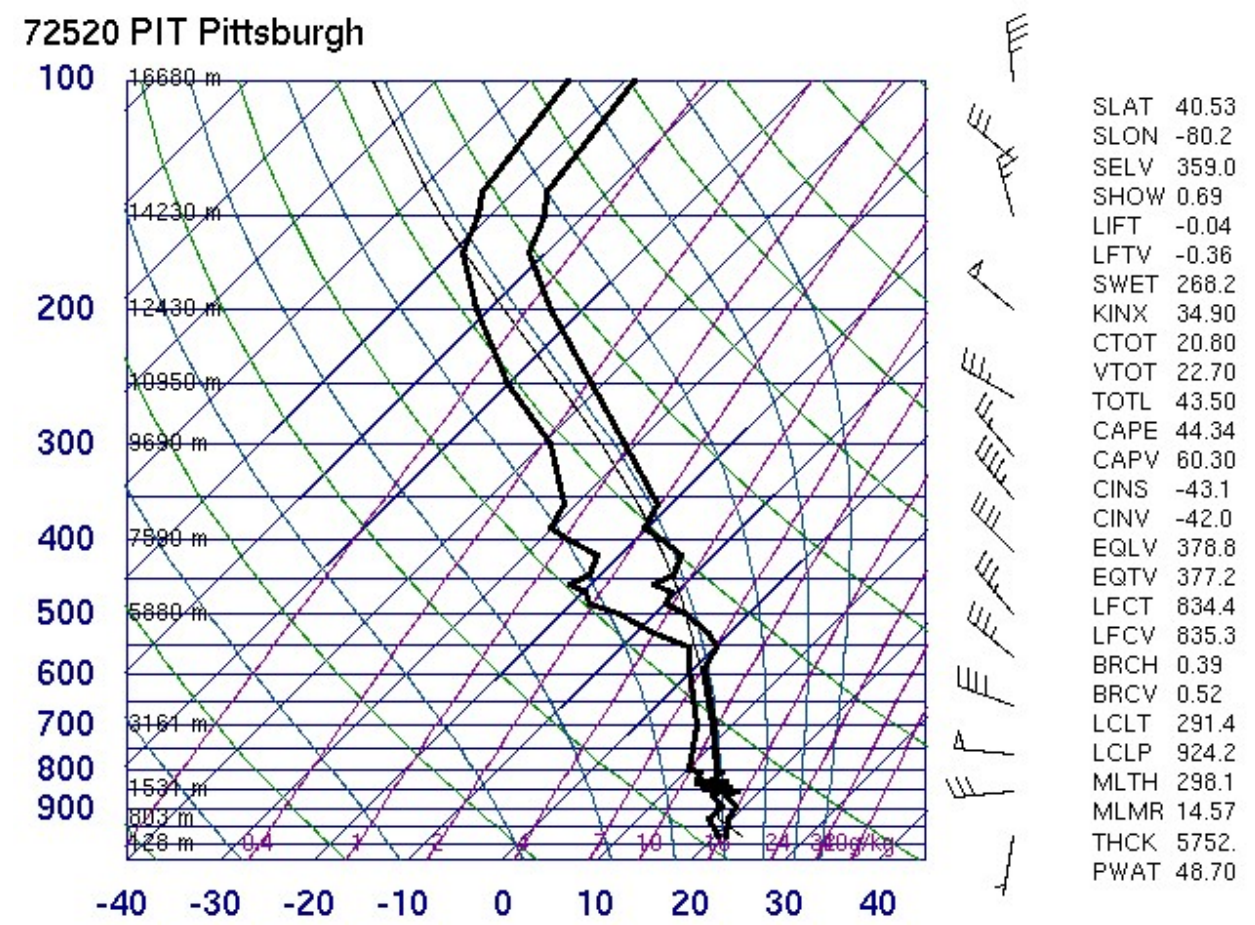

Figure C.4 Pittsburgh, PA, temperature, dewpoint tmeperature, and wind sounding of the Redbank Creek storms for 0000 UTC on July 19, 1996. Listed are several stability indices. 


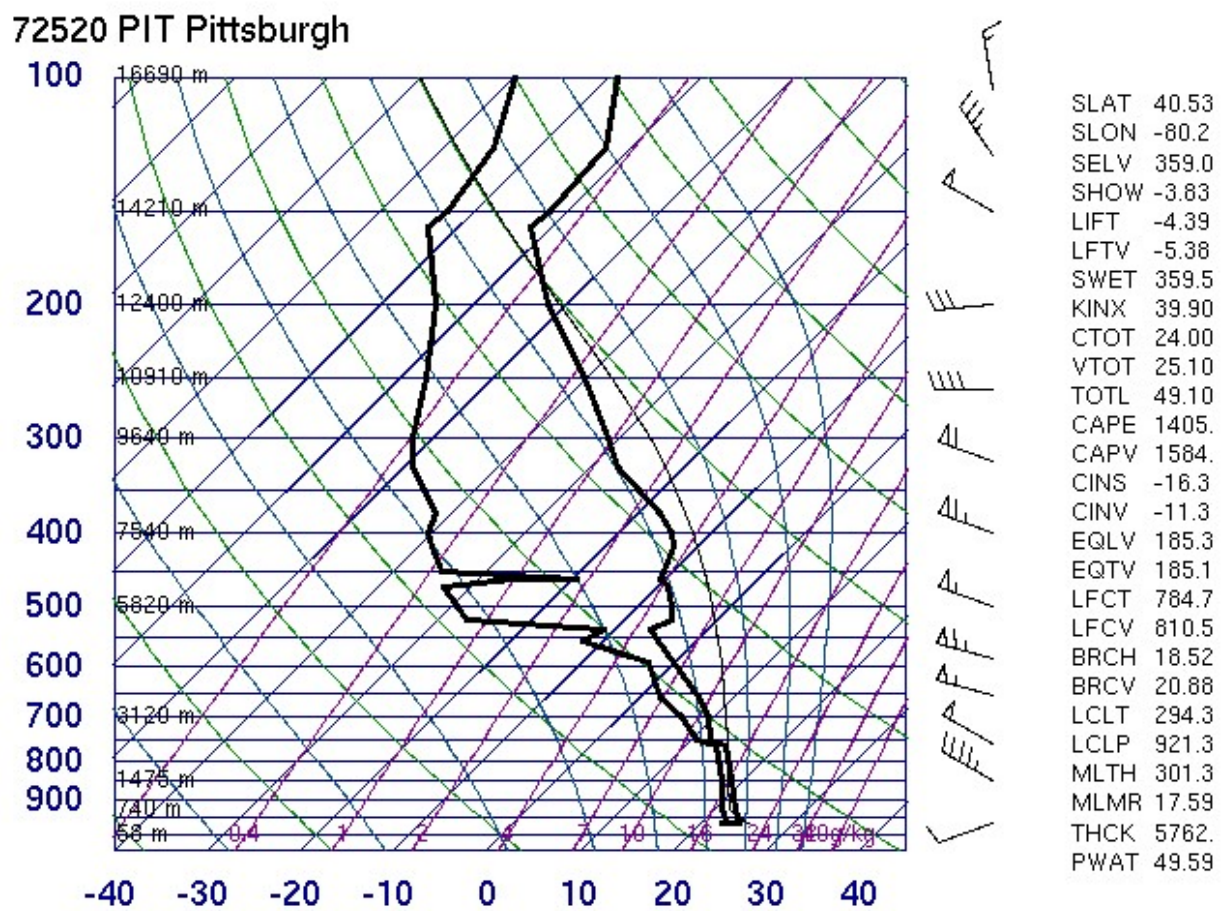

Figure C.5 Pittsburgh, PA, temperature, dewpoint tmeperature, and wind sounding of the Redbank Creek storms for 1200 UTC on July 19, 1996. Listed are several stability indices. 


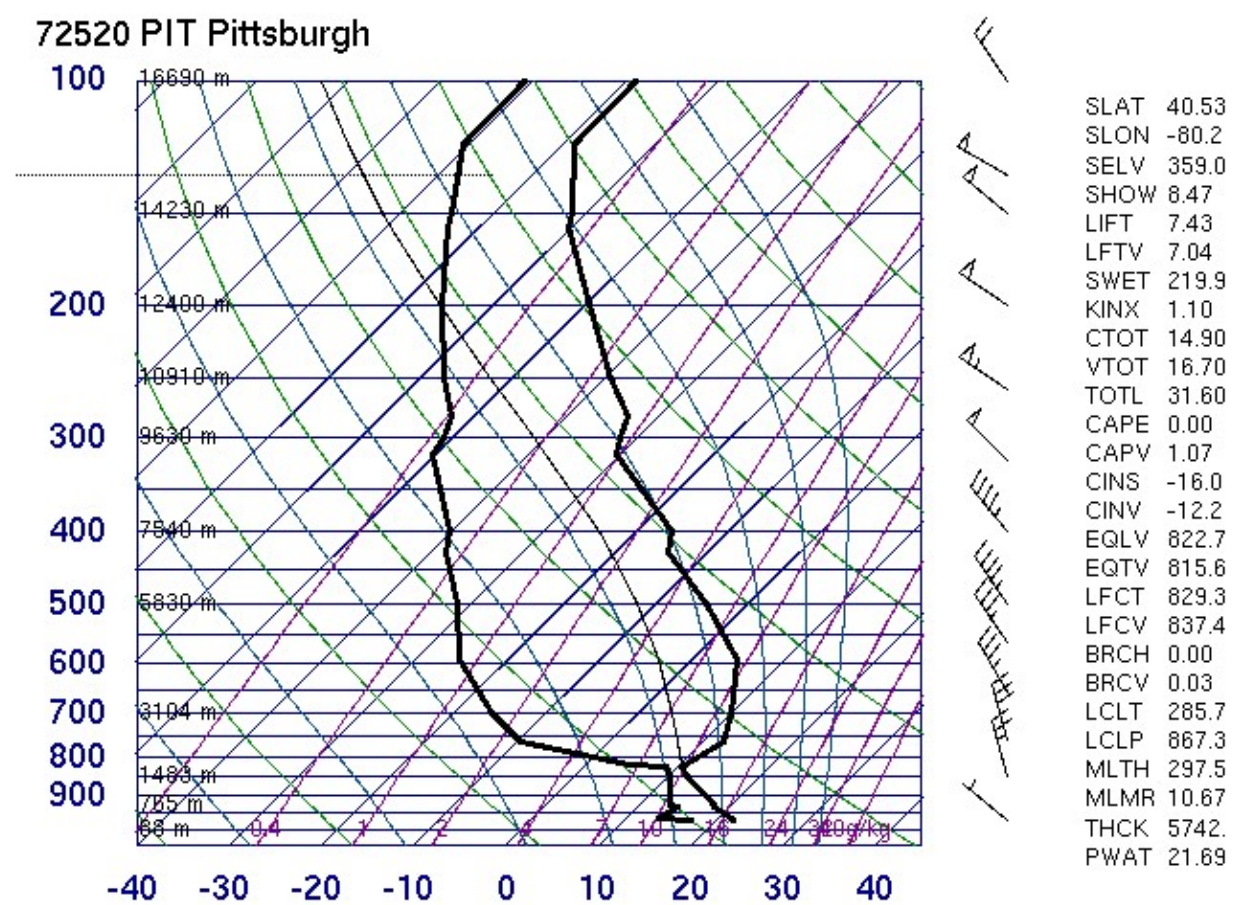

Figure C.6 Pittsburgh, PA, temperature, dewpoint tmeperature, and wind sounding of the Redbank Creek storms for 0000 UTC on July 20, 1996. Listed are several stability indices. 
Appendix D

Atmospheric Sounding Plots 3

D.1 Buffalo Creek Storm of July 12-13, 1996 


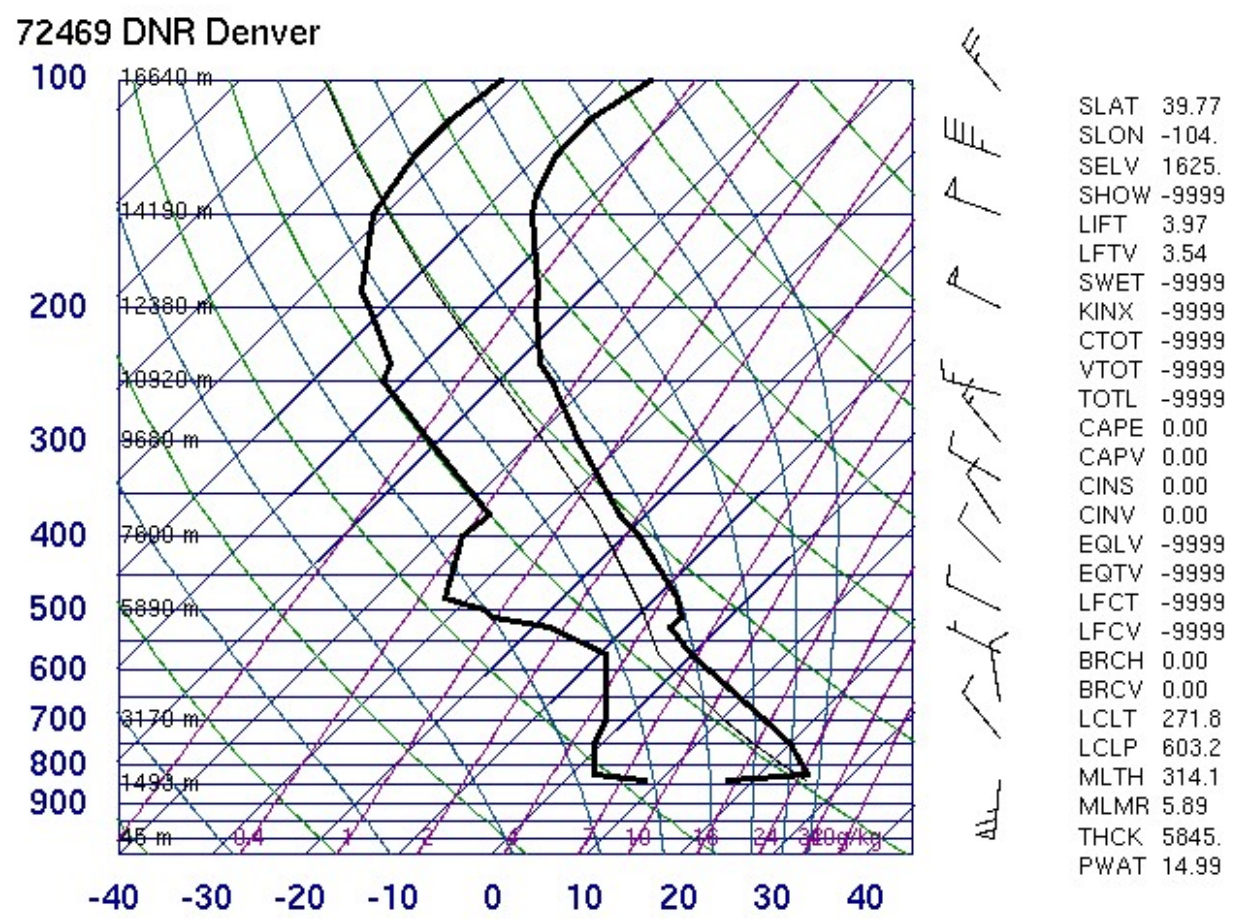

Figure D.1 Denver, CO, temperature, dewpoint tmeperature, and wind sounding of the Buffalo Creek storms for 1200 UTC on July 11, 1996. Listed are several stability indices. 


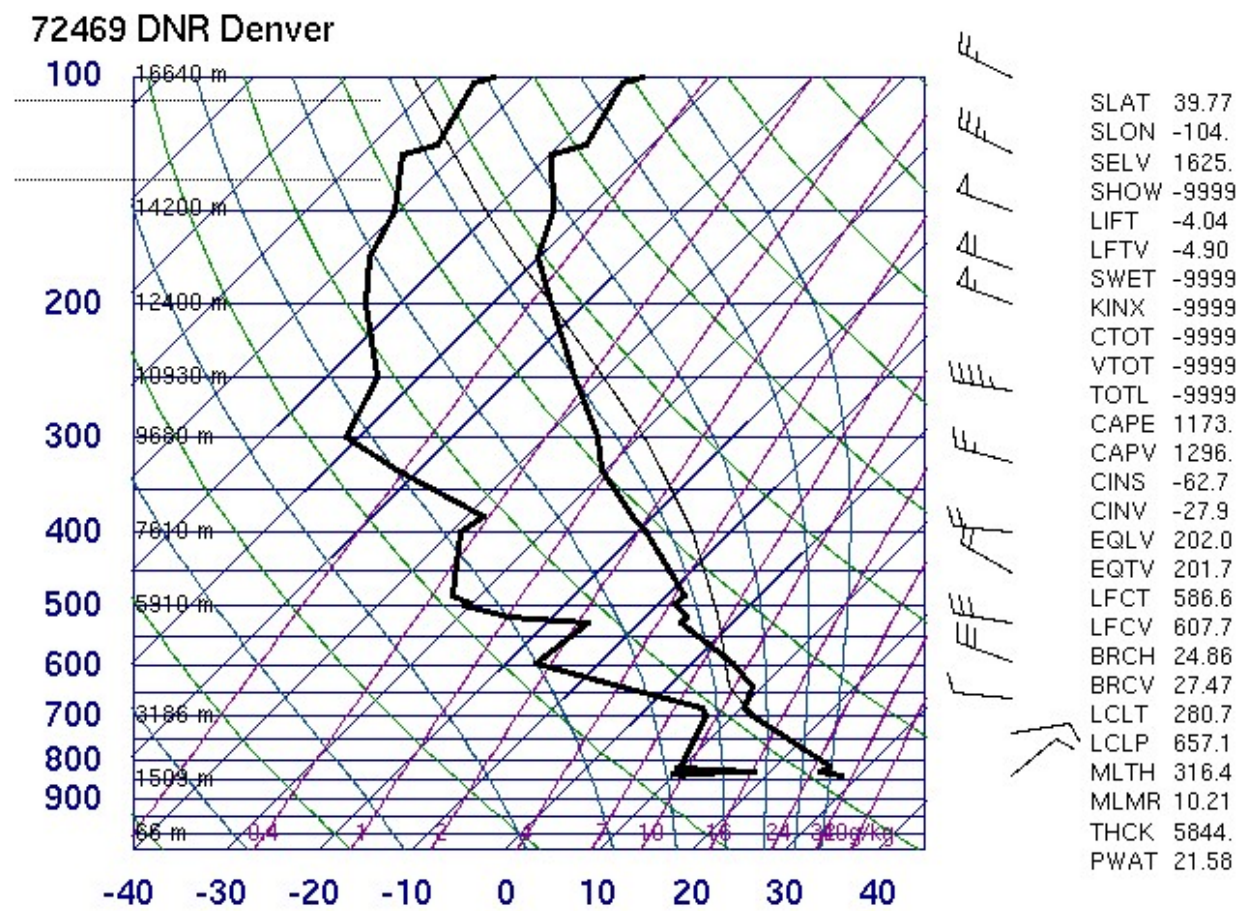

Figure D.2 Denver, CO, temperature, dewpoint tmeperature, and wind sounding of the Buffalo Creek storms for 0000 UTC on July 12, 1996. Listed are several stability indices. 


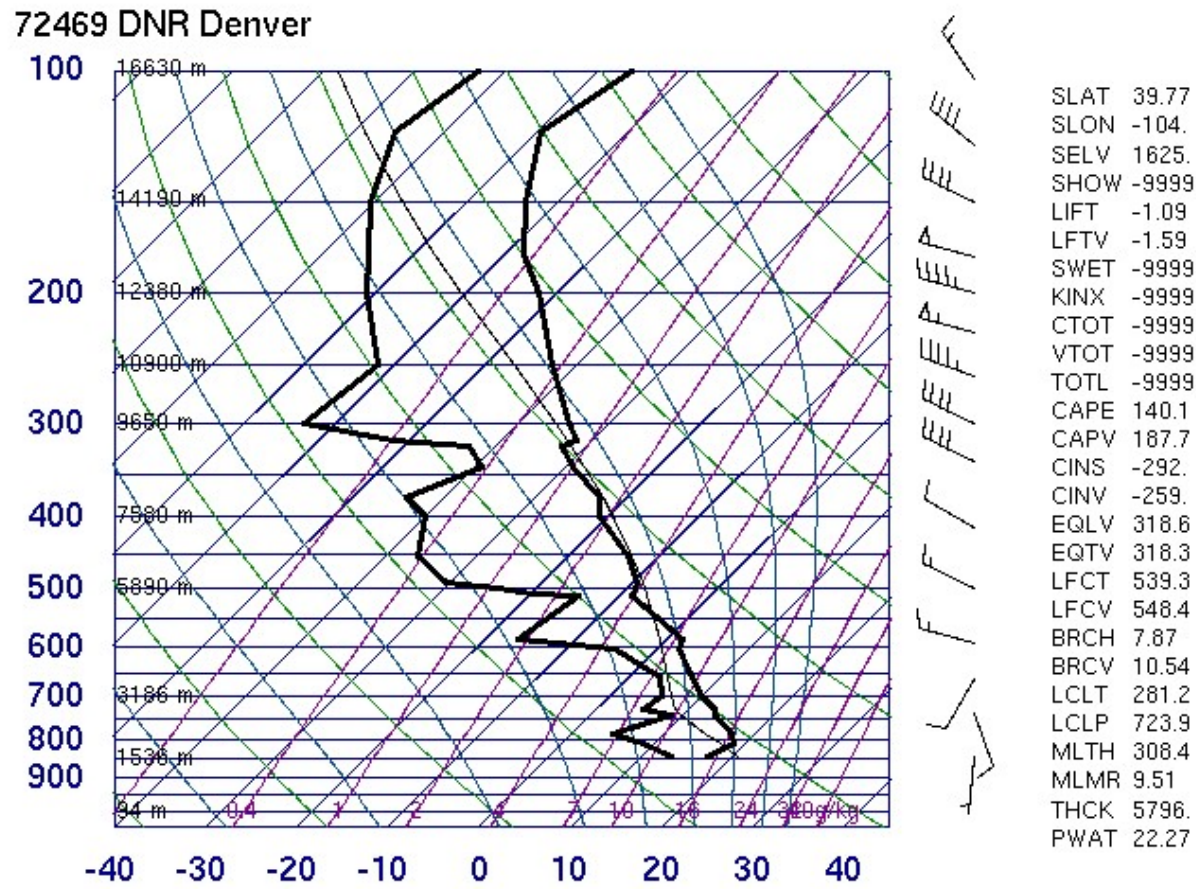

Figure D.3 Denver, CO, temperature, dewpoint tmeperature, and wind sounding of the Buffalo Creek storms for 1200 UTC on July 12, 1996. Listed are several stability indices. 


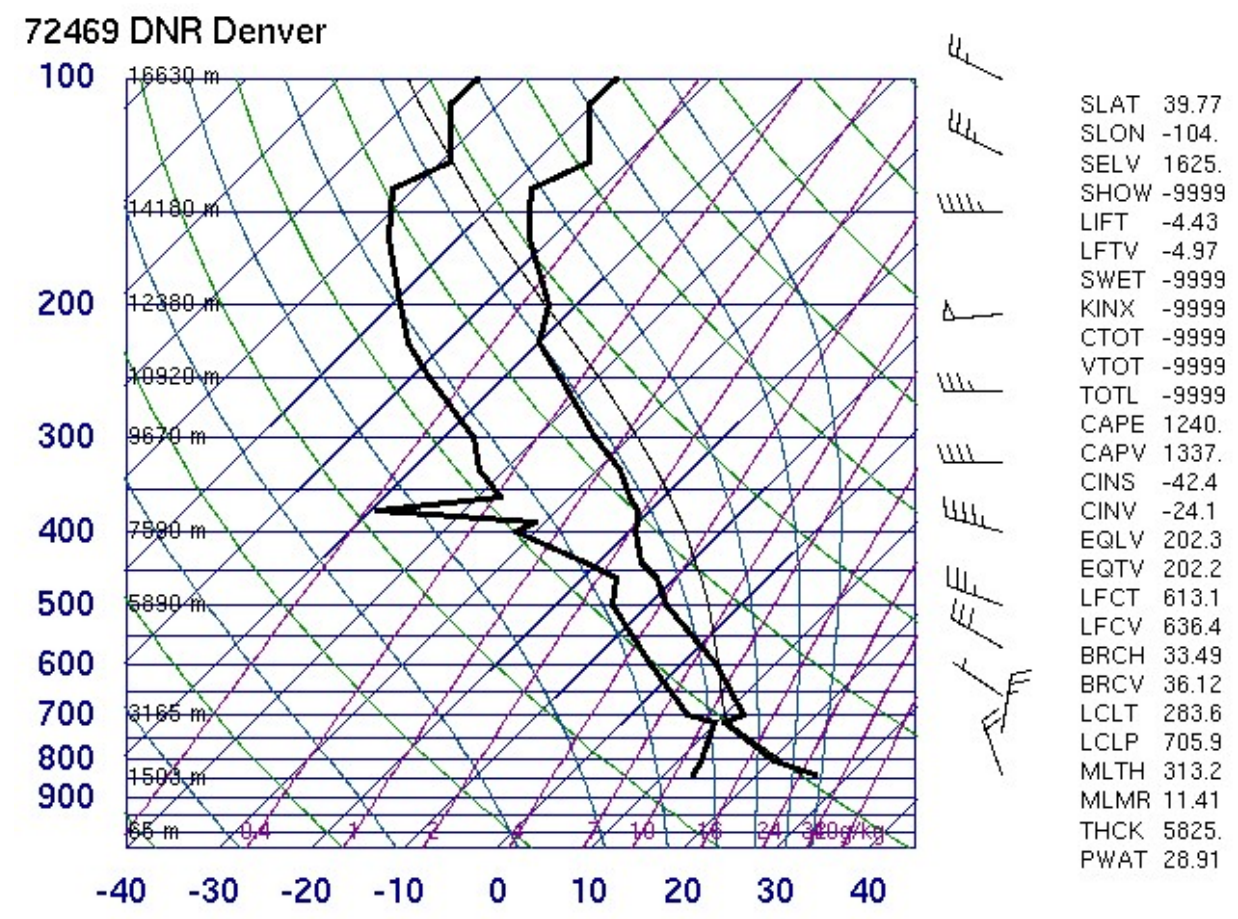

Figure D.4 Denver, CO, temperature, dewpoint tmeperature, and wind sounding of the Buffalo Creek storms for 0000 UTC on July 13, 1996. Listed are several stability indices. 


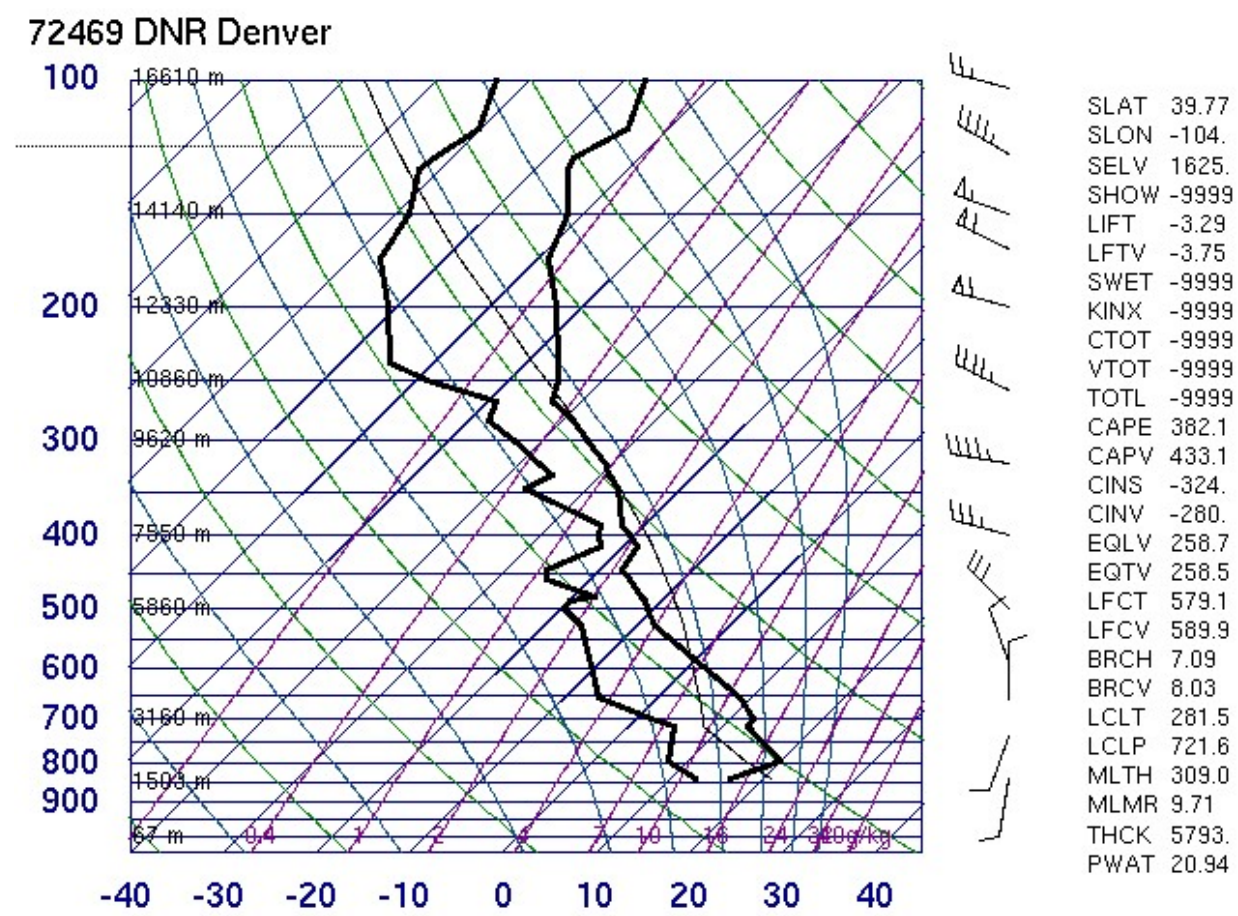

Figure D.5 Denver, CO, temperature, dewpoint tmeperature, and wind sounding of the Buffalo Creek storms for 1200 UTC on July 13, 1996. Listed are several stability indices. 


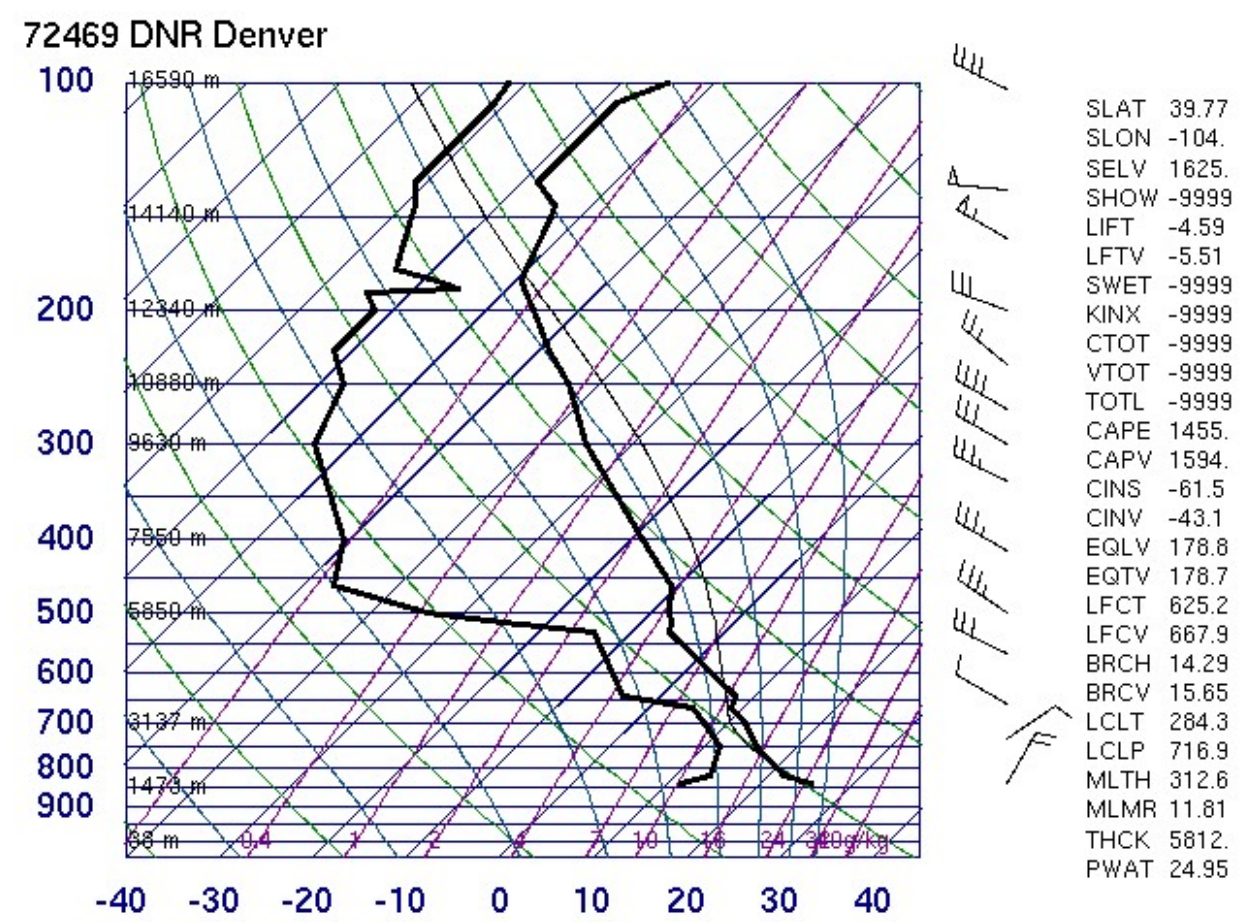

Figure D.6 Denver, CO, temperature, dewpoint tmeperature, and wind sounding of the Buffalo Creek storms for 0000 UTC on July 14, 1996. Listed are several stability indices. 
Appendix E

Atmospheric Sounding Plots 4

E.1 Fort Collins Storm of July 28-29, 1997 


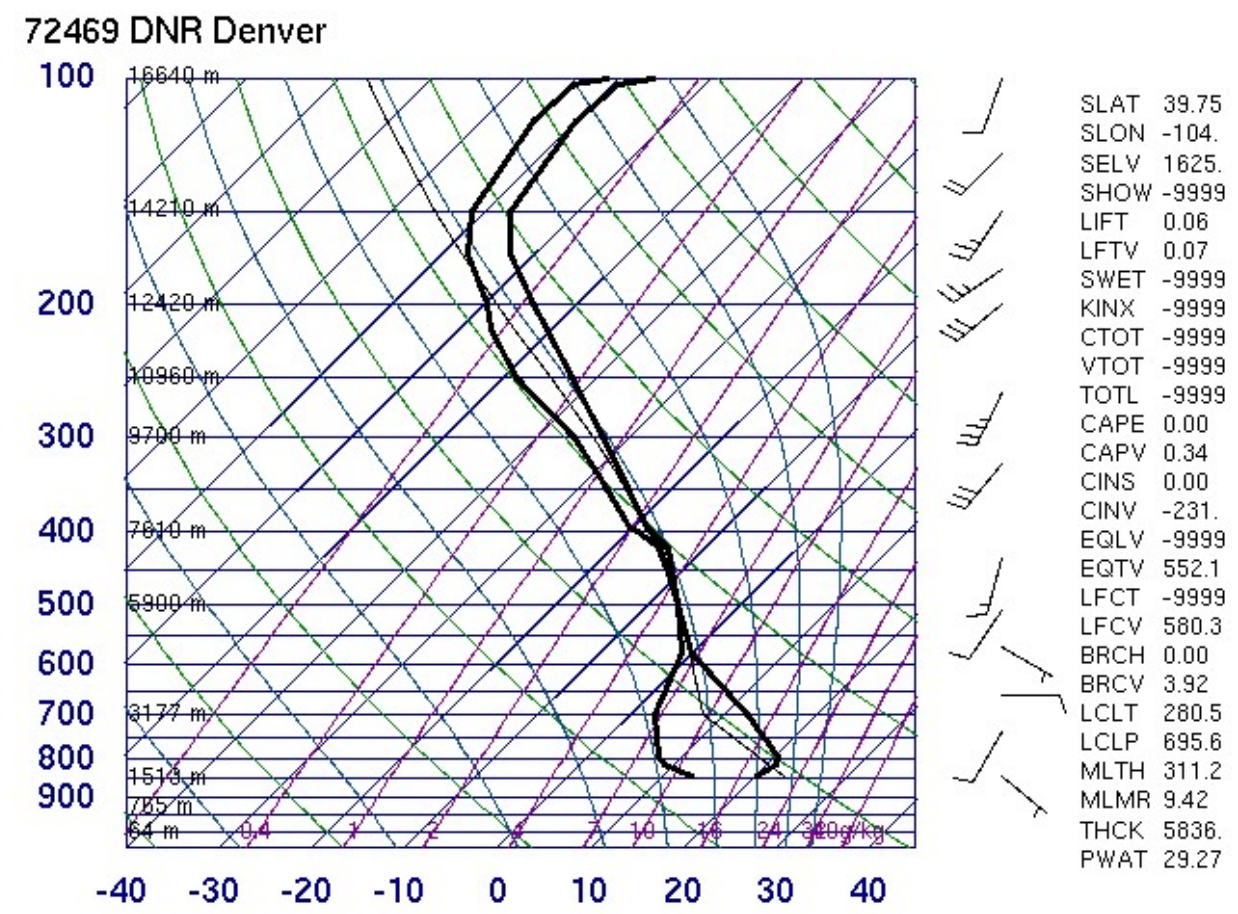

Figure E.1 Denver, CO, temperature, dewpoint tmeperature, and wind sounding of the Fort Collins storms for 1200 UTC on July 27, 1997. Listed are several stability indices. 


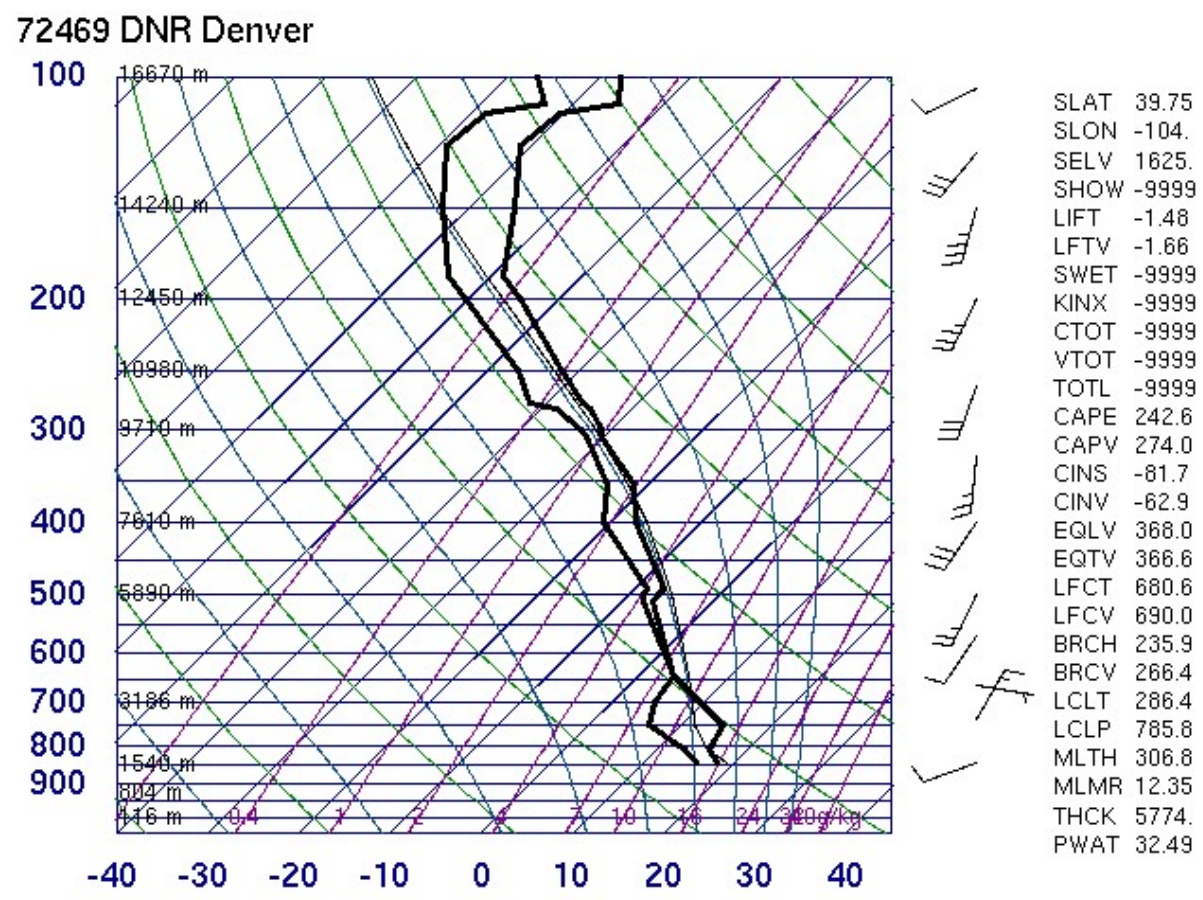

Figure E.2 Denver, CO, temperature, dewpoint tmeperature, and wind sounding of the Fort Collins storms for 0000 UTC on July 28, 1997. Listed are several stability indices. 


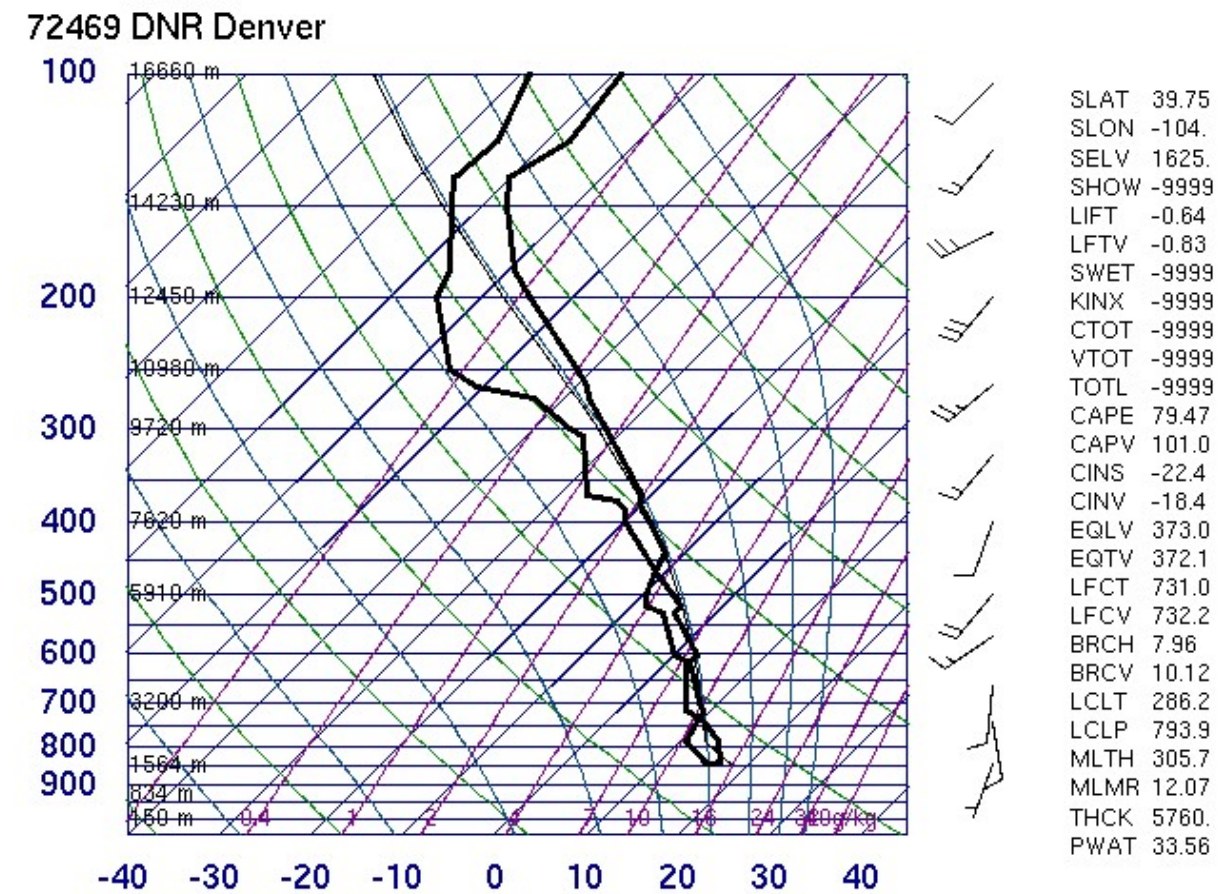

Figure E.3 Denver, CO, temperature, dewpoint tmeperature, and wind sounding of the Fort Collins storms for 1200 UTC on July 28, 1997. Listed are several stability indices. 


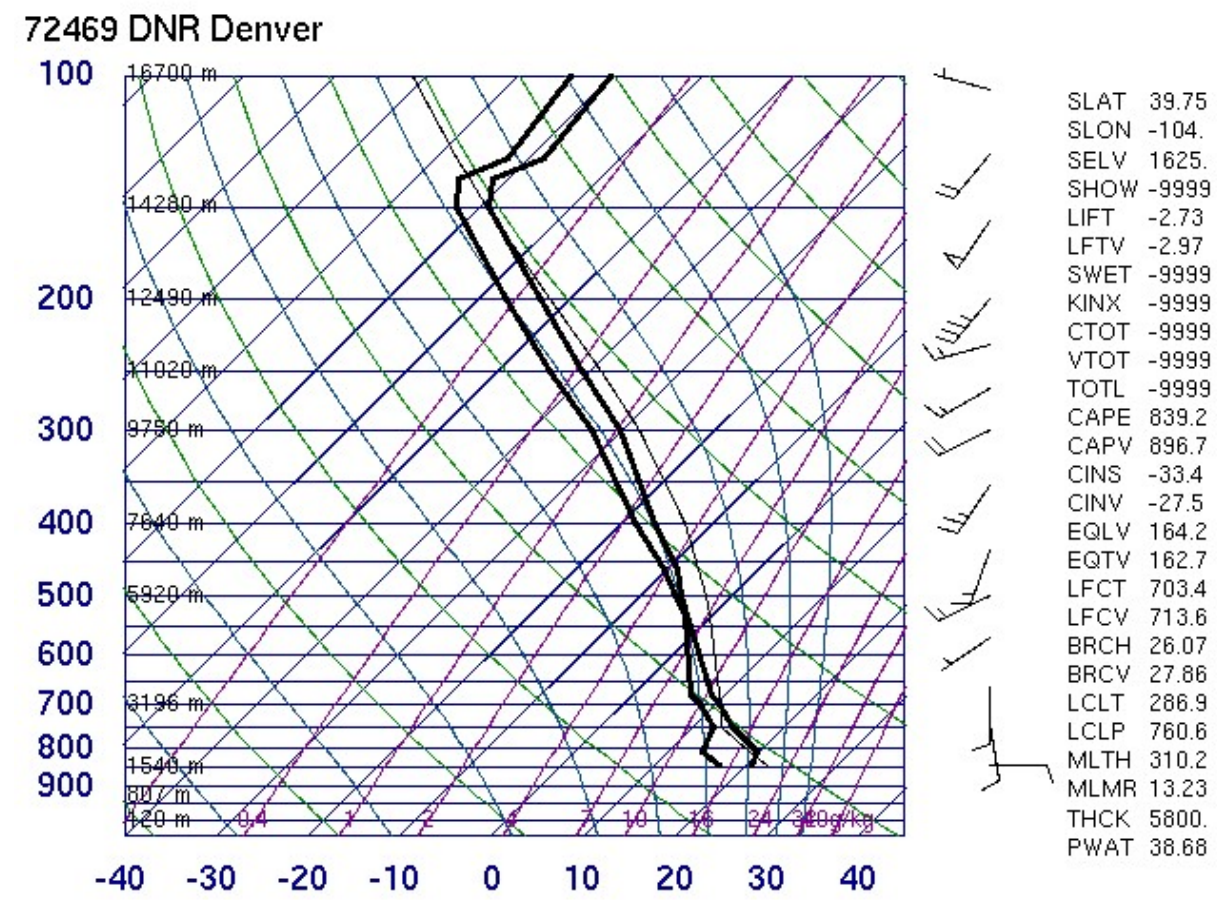

Figure E.4 Denver, CO , temperature, dewpoint tmeperature, and wind sounding of the Fort Collins storms for 0000 UTC on July 29, 1997. Listed are several stability indices. 


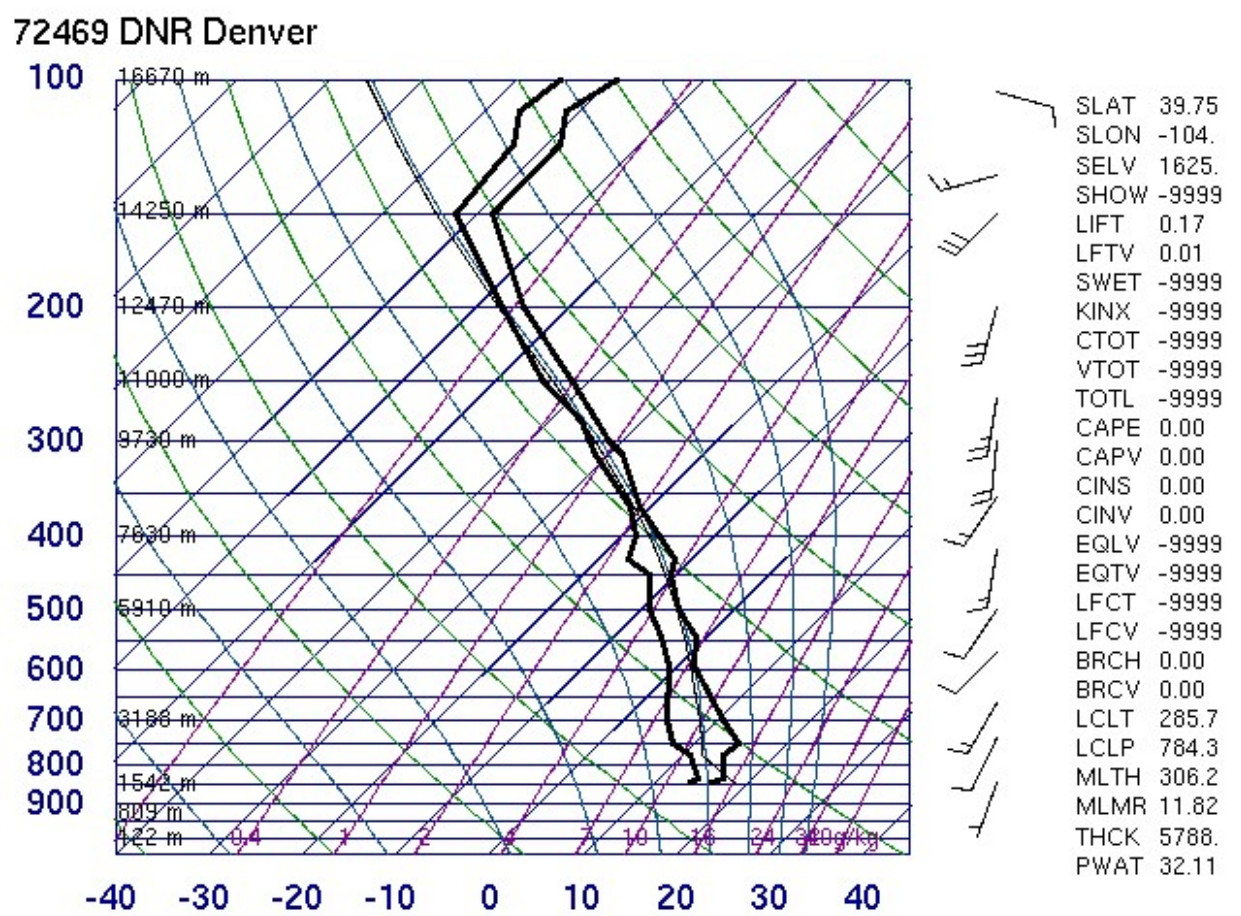

Figure E.5 Denver, CO, temperature, dewpoint tmeperature, and wind sounding of the Fort Collins storms for 1200 UTC on July 29, 1997. Listed are several stability indices. 


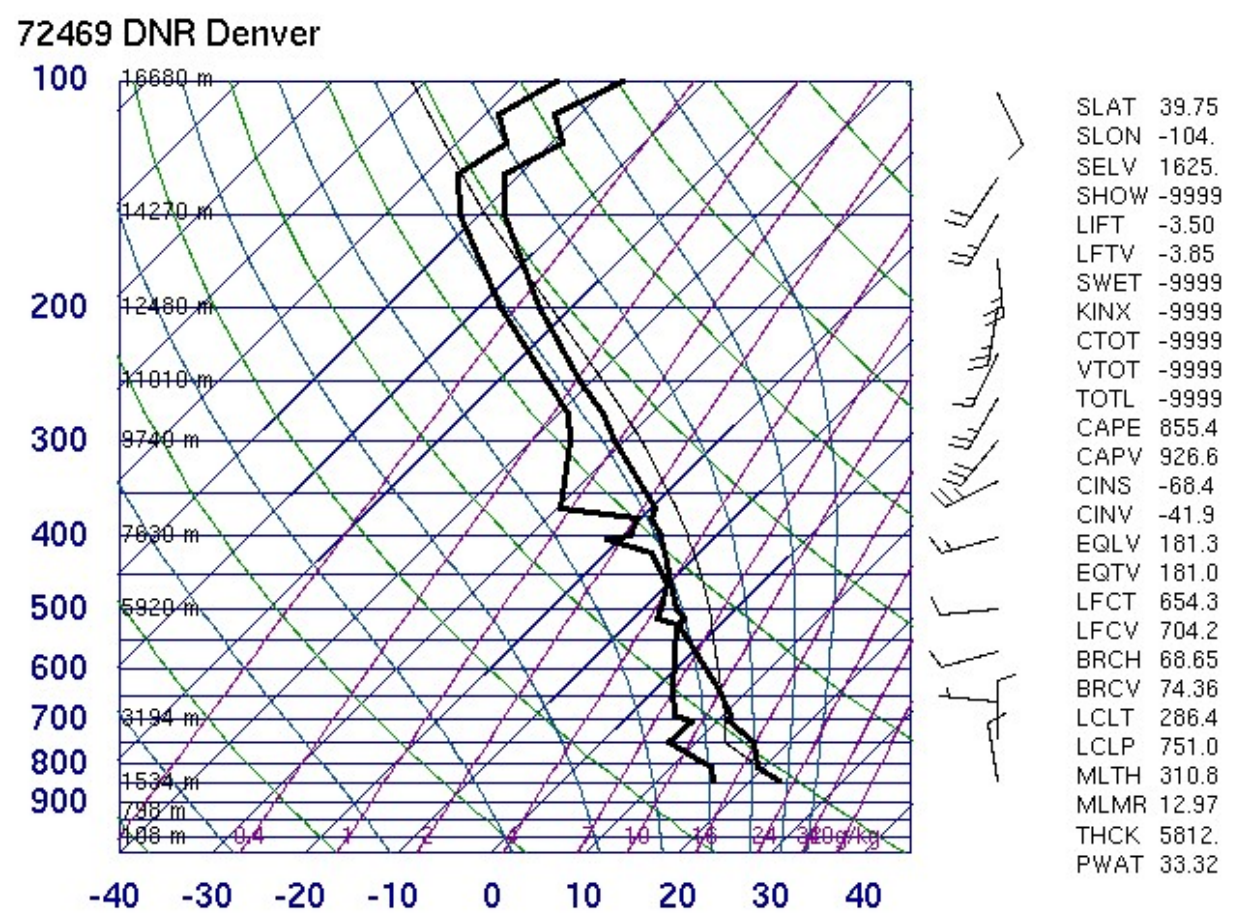

Figure E.6 Denver, CO, temperature, dewpoint tmeperature, and wind sounding of the Fort Collins storms for 0000 UTC on July 30, 1997. Listed are several stability indices. 
Appendix F

Atmospheric Sounding Plots 5

F.1 Loveland Pass Storm of July 28-29, 1999 


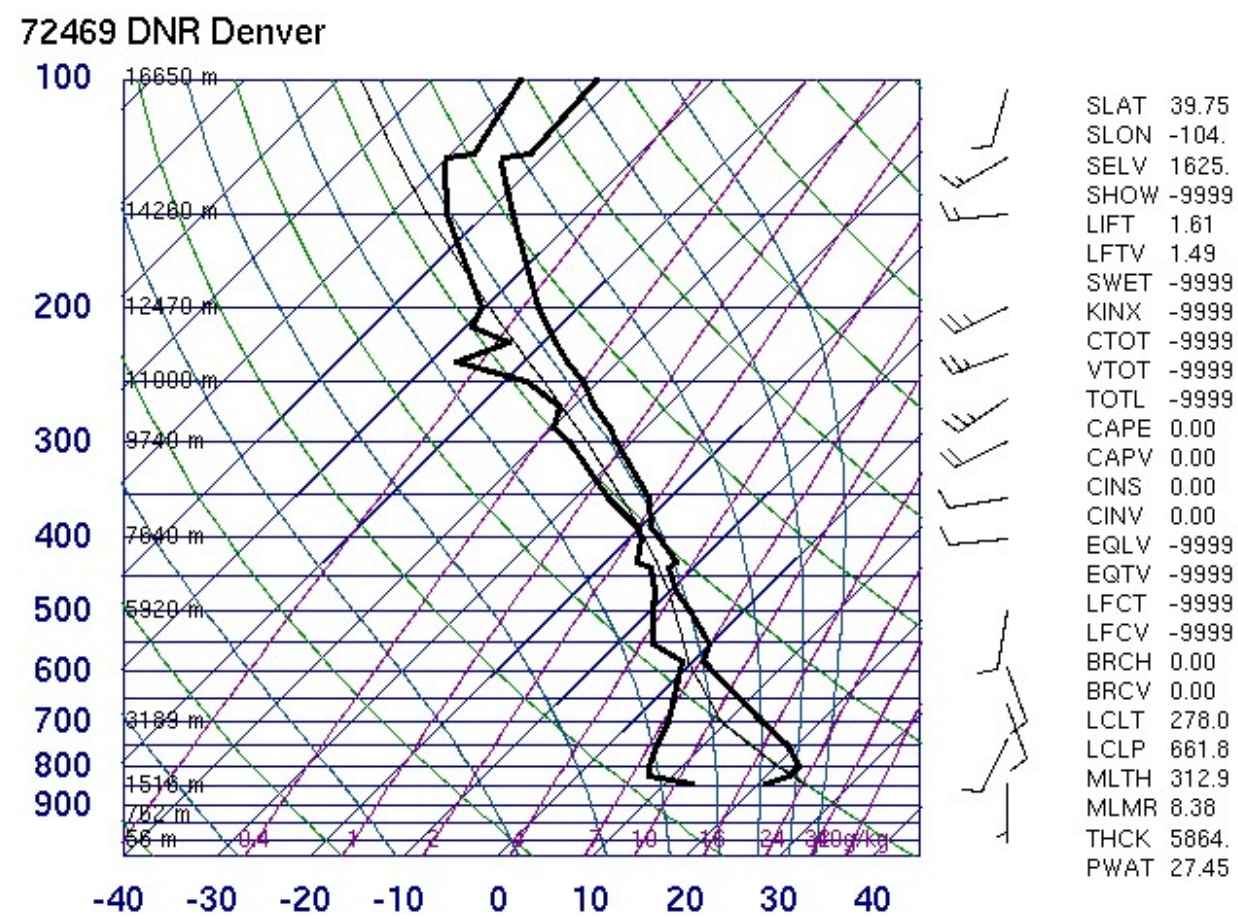

Figure F.1 Denver, CO , temperature, dewpoint tmeperature, and wind sounding of the Loveland Pass storms for 1200 UTC on July 27, 1999. Listed are several stability indices. 


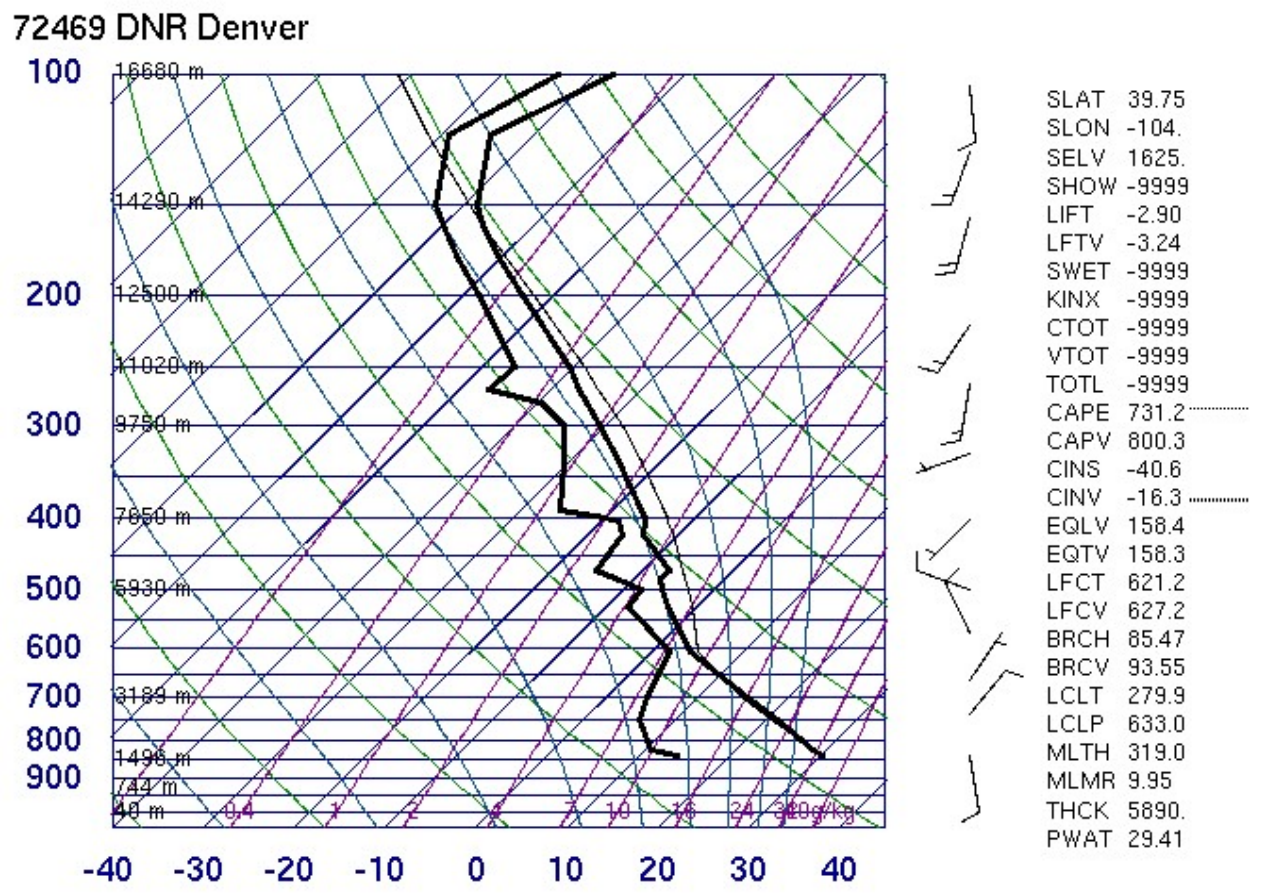

Figure F.2 Denver, CO, temperature, dewpoint tmeperature, and wind sounding of the Loveland Pass storms for 0000 UTC on July 28, 1999. Listed are several stability indices . 


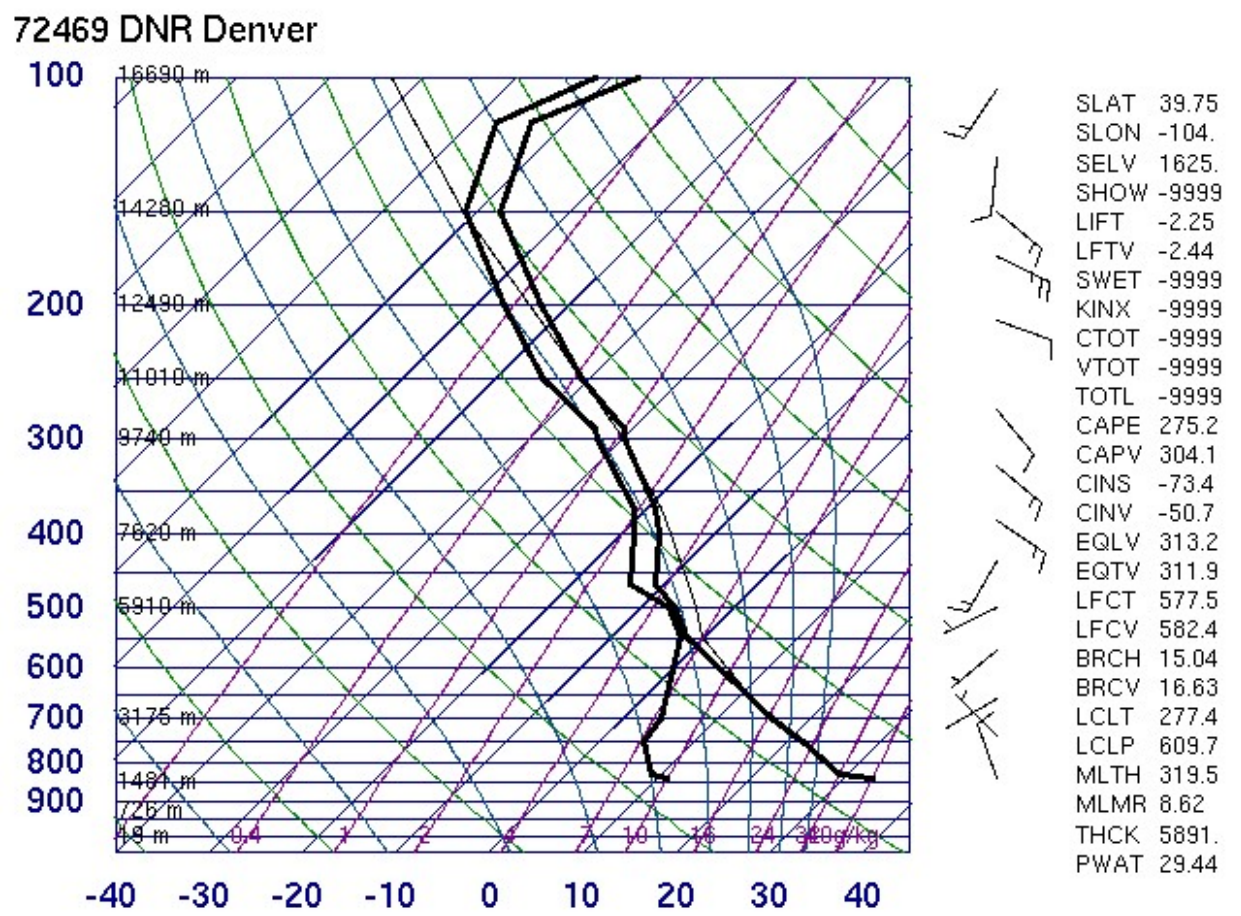

Figure F.3 Denver, CO, temperature, dewpoint tmeperature, and wind sounding of the Loveland Pass storms for 0000 UTC on July 28, 1999. Listed are several stability indices . 


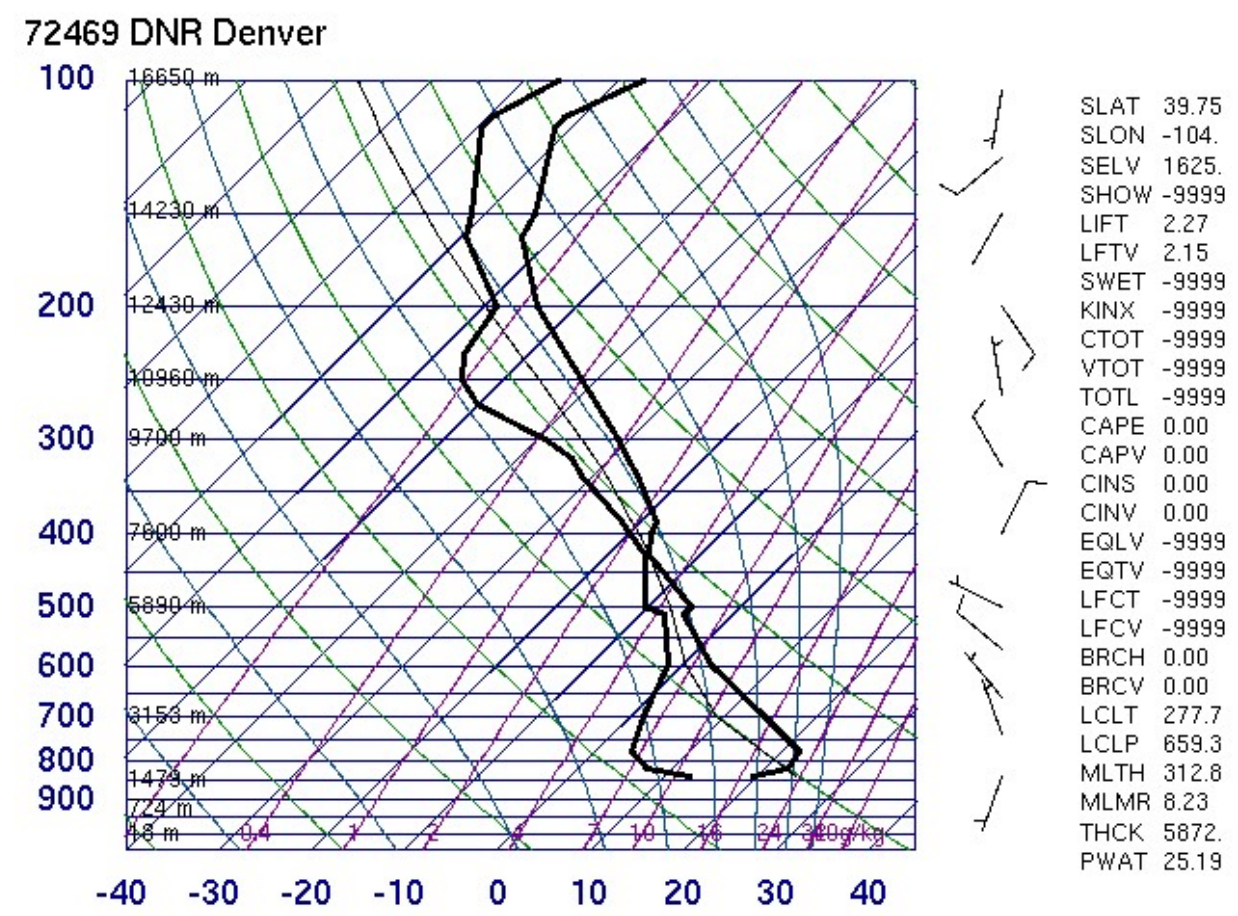

Figure F.4 Denver, CO, temperature, dewpoint tmeperature, and wind sounding of the Loveland Pass storms for 1200 UTC on July 29, 1999. Listed are several stability indices . 


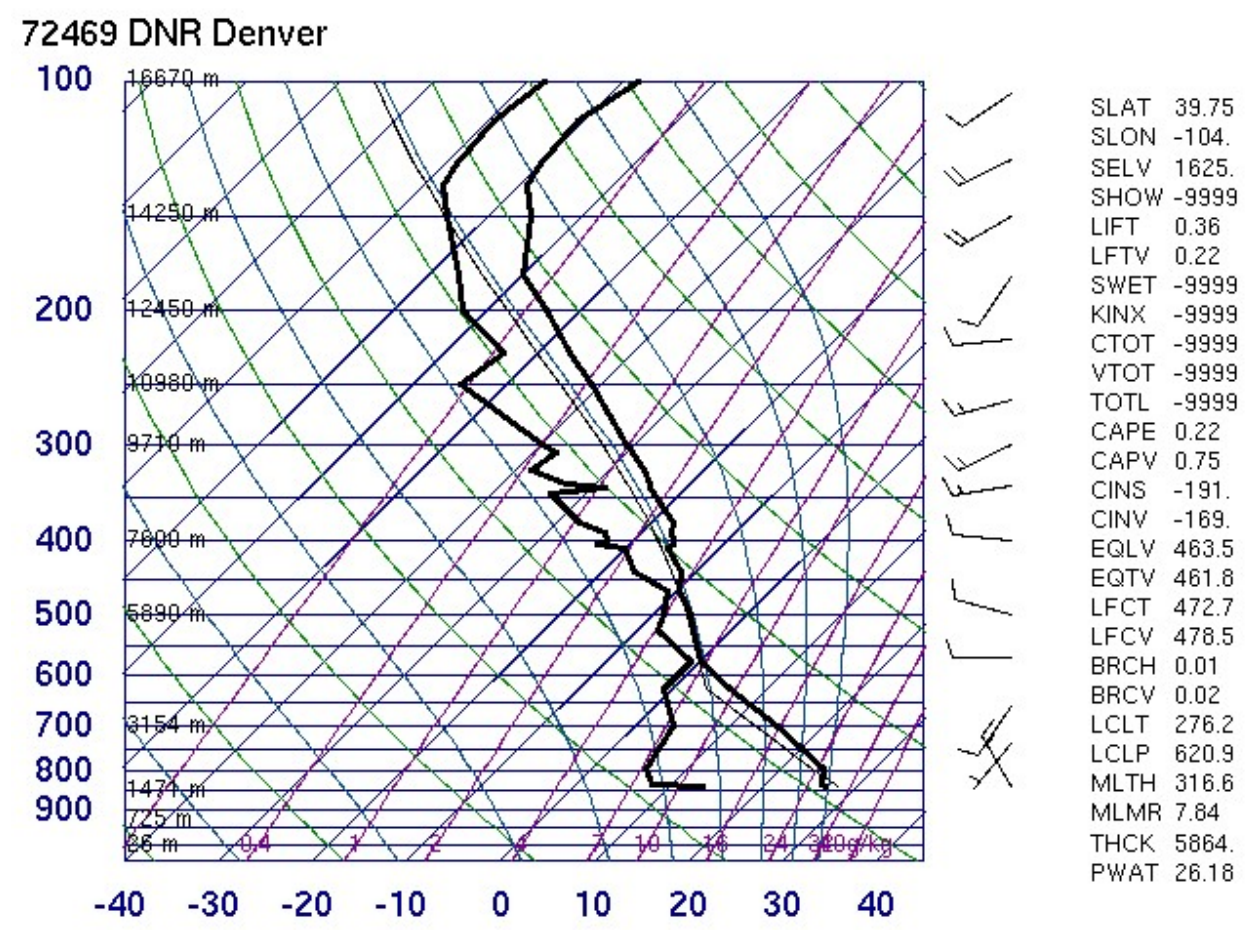

Figure F.5 Denver, CO, temperature, dewpoint tmeperature, and wind sounding of the Loveland Pass storms for 0000 UTC on July 30, 1999. Listed are several stability indices . 